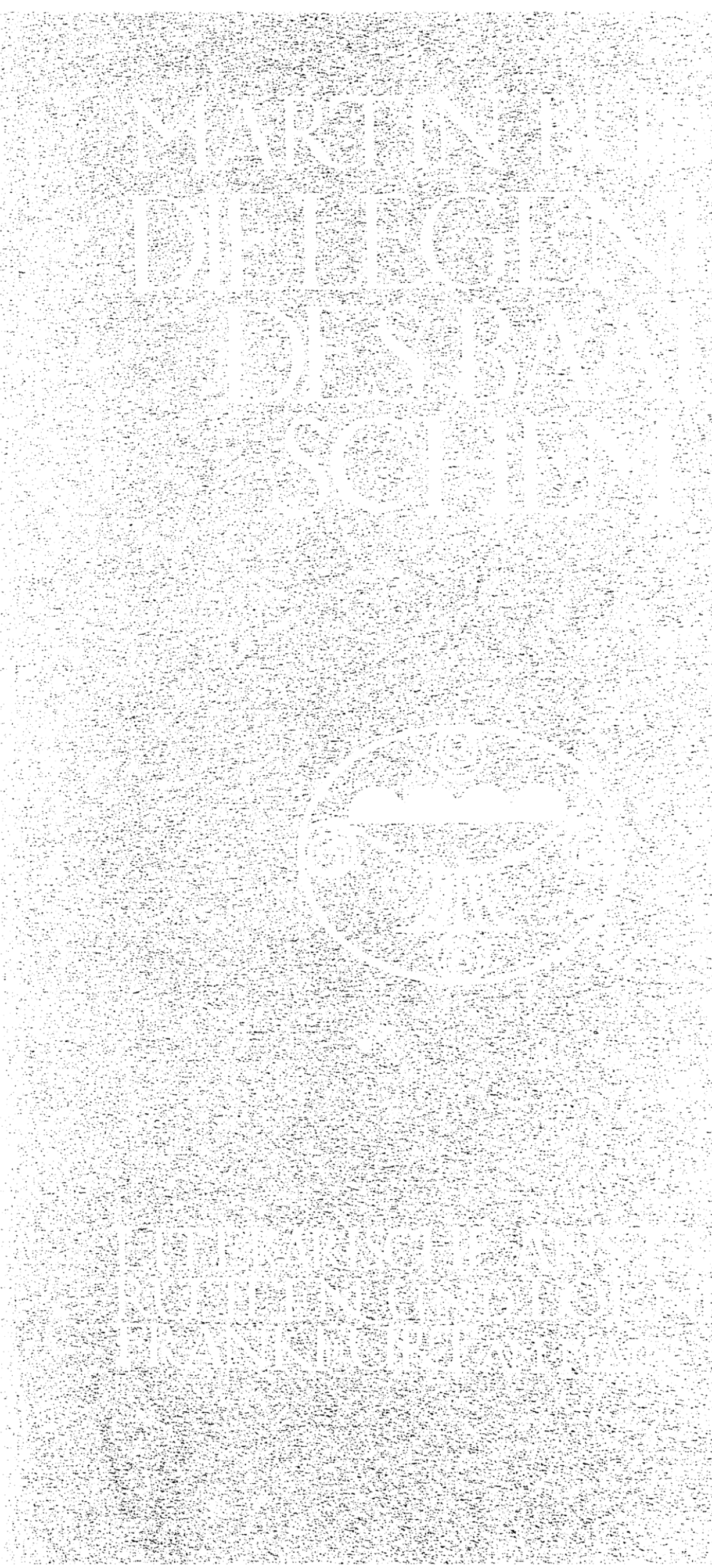


GEDRUCKT IN EINER AUFLAGE VON 2000 EXEMPLAREN IN DER OFFIZIN VON IMBERG \& LEFSON, BERLIN. ES WURDEN AUSSERDEM 25 EXEMPLARE AUF ECHTEM BÜTTENPAPIER HERGESTELLT UND HANDSCHRIFTLICH NUMERIERT, DIE IN GANZPERGAMENT GEBUNDEN ZUM PREISE VON 25 MARK NUR VON DER LITERARISCHEN ANSTALT RÜTTEN \& LOENING IN FRANKFURT AM MAIN DIREKT ZU BEZIEHEN SIND. DRUCKANORD. NUNG, TITEL, INITIALEN UND EINBAND VON E. R. WEISS.

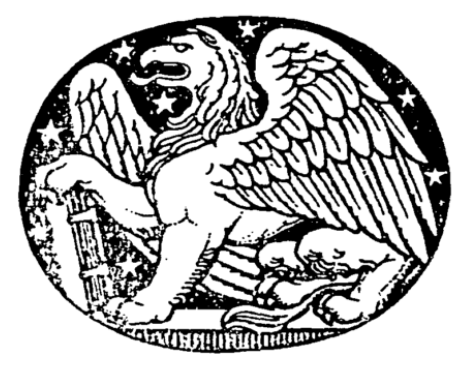




\section{DIE LEGENDE DES BAALSCHEM}



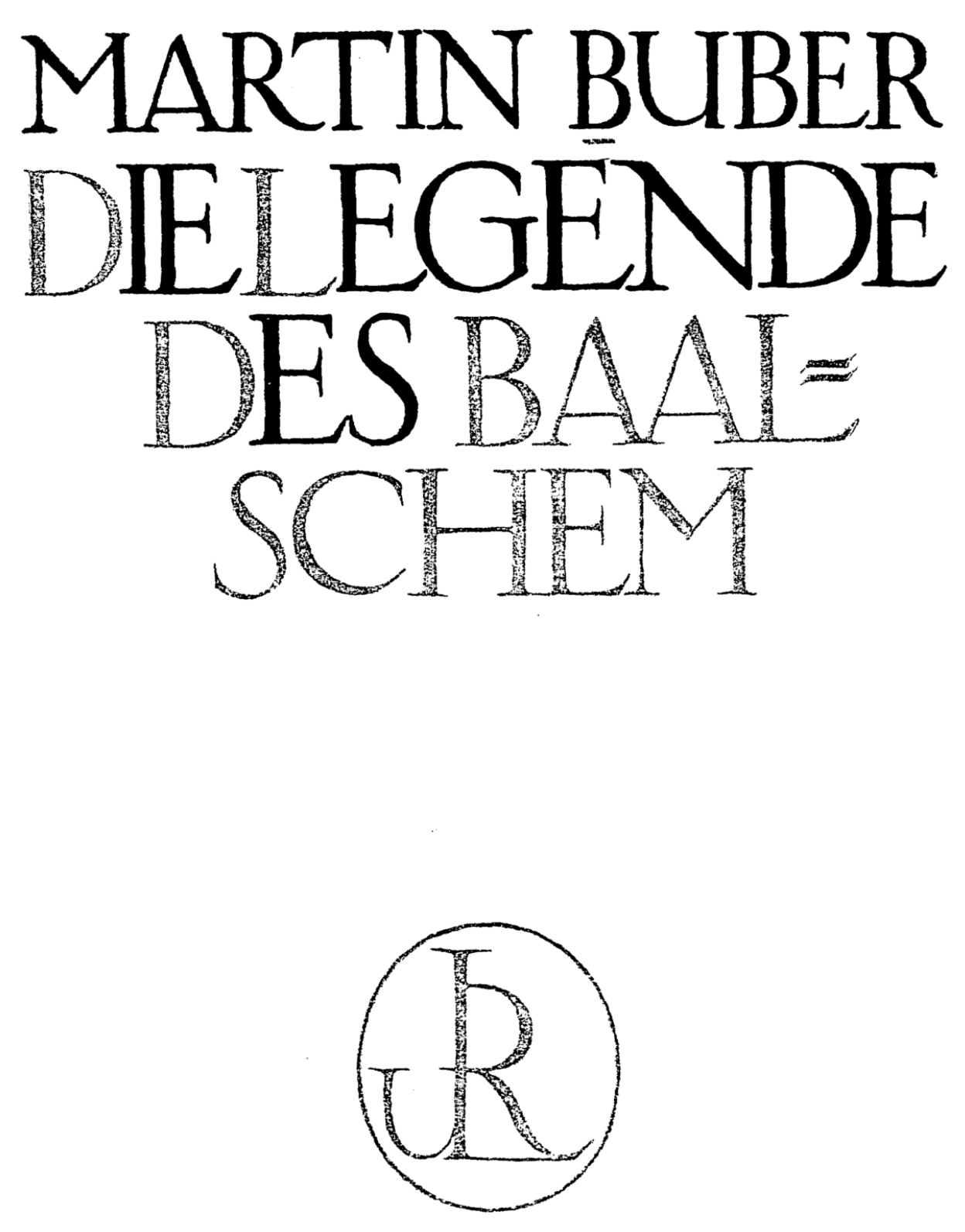

\section{LITERARISCHE ANSTALT/ RUTIIENUNDLOENING FRANKFURT AM MAIN}


Alle Rechte, besonders das der Übersetzung behält sich die Verlagshandlung ausdrücklich vor. Published February 20. 1908. Privilege of copyright in the United States reserved under the act approved March 3, 1905 by the Literarische Anstalt Rütten \& Loening, Frankfort o. M. 


\section{EINFÜHRUNG}

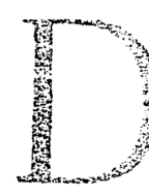

IESES BUCH BESTEHT AUS EINER

Nachricht und einundzwanzig Geschichten.

Die Nachricht sagt das Leben der Chassidim, einer ostjüdischen Sekte, die gegen die Mitte des achtzehnten Jahrhunderts entstand und noch in unseren Tagen entartet fortbesteht. Die Geschichten erzählen das Leben des Stifters dieser Sekte, des Rabbi Israel ben Elieser, der Baal-schem, das ist Meister des wundersamen Gottesnamens, genannt wurde und von etwa 1700 bis 1760, zumeist in Podolien und Wolhynien, lebte.

Aber das Leben, von dem hier Kunde gegeben wird, ist nicht das, das man das wirkliche zu nennen pflegt. Ich berichte nicht die Entwicklung und den Verfall der Sekte, ich beschreibe nicht ihre Gebräuche. Ich will nur das Verhältnis zum Absoluten und zur Welt mitteilen, das diese Menschen dachten, wollten und zu leben versuchten. Ich zähle auch nicht die Daten und Tatsachen auf, deren Zusammenfassung die Biographie des Baalschem zu nennen wäre*. Ich baue sein Leben aus seiner Legende auf, in der der Traum und die Sehnsucht eines Volkes sind.

Die chassidische Legende hatnicht die strenge Macht,

* Ich unterschätze aber eine Arbeit an diesem - zumeist recht dürftig und unsicher überlieferten - Material nicht und freue mich, dass nach dem Vorgang von S. Dubnow nunmehr S. A. Horodezky sie unternommen hat, noch mehr aber darüber, dass M. J. Berdy. czewski, vor allen der Geeignete, die Worte des Baalschem nach ihren Gegenständen geordnet hat. Beide Publikationen stehen (in hebräischer Sprache) bevor. 
in der die Buddhalegende redet, und nicht die innige, die die Sprache der Franziskuslegende ist. Nicht im Schatten uralter Haine und nicht an silbergrünen Olivenhängen erwuchs sie, in engen Gassen und dumpfen Kammern ging sie von ungelenken Lippen zu bange lauschenden Ohren, ein Stammeln gebar sie und ein Stammeln trug sie weiter von Geschlecht zu Geschlecht.

Ich habe sie aus den Volksbüchern, aus Heften und Flugblättern empfangen, zuweilen auch aus lebendigem Munde, aus dem Munde von Leuten, die noch das Stammeln gehört hatten. Ich habe sie empfangen und neu erzählt. Ich habe sie nicht übertragen, wie irgend ein Stück Literatur, ich habe sie nicht bearbeitet, wie irgend einen Fabelstoff, ich habe sie neu erzählt als ein Nachgeborener. Ich trage in mir das Blut und den Geist derer, die sie schufen, und aus Blut und Geist ist sie in mir neu geworden. Ich stehe in der Kette der Erzähler, ein Ring zwischen Ringen, ich sage noch einmal die alte Geschichte, und wenn sie neu klingt, so schlief das Neue in ihr schon damals, als sie zum ersten Mal gesagt wurde.

Mein Erzählen der chassidischen Legende geht ebensowenig wie auf das "wirkliche" Leben darauf, was man die Lokalfarbe zu nennen pflegt. Es ist etwas Zartes und Ehrwürdiges, etwas Heimliches und Geheimnisvolles, etwas Ausgelassenes und Paradiesisches um die Atmosphäre des ,Stübels", in dem der chassidische Rabbi, der "Zaddik“, der „Gerechte“, der Heilige, der Mittler zwischen Gott 
und Mensch, mit weisem und lächelndem Mund das Mysterium und das Märchen austeilt. Aber mein Gegenstand ist nicht die Darstellung dieser Atmosphäre.* Meine Erzählung steht auf der Erde des jüdischen Mythos, und der Himmel des jüdischen Mythos ist über ihr.

Die Juden sind vielleicht das einzige Volk, das nie aufgehört hat, Mythos zu erzeugen. Im Anfang ihrer grossen Urkunde ist das reinste aller mythischen Symbole, der Pluralsingular Elohim, und die stolzeste aller mythischen Sagen, die vom Kampfe Jakobs mit dem Elohim. In jener Urzeit entspringt der Strom mythengebärender Kraft, der - vorläufig - im Chassidismus mündet; von dem die Religion Israels zu allen Zeiten sich gefährdet fühlte, von dem aber in Wahrheit die jüdische Religiosität zu allen Zeiten ihr inneres Leben empfing.

Alle positive Religion ruht auf einer ungeheuren Vereinfachung des in Welt und Seele so vielfältig, so wildverschlungen auf uns Eindringenden: sie ist Bändigung, Vergewaltigung der Daseinsfülle. Aller Mythos hingegen ist Ausdruck der Daseinsfülle, ihr Bild, ihr Zeichen; unablässig trinkt er von den stürzenden Quellen des Lebens. Die persönliche, ungemeinsame und unzugängliche Religiosität der Einzelseele hat ihre Geburt im Mythos, ihren Tod in der Religion. Solange die Seele in dem reichen Boden des Mythos wurzelt, hat die Religion keine

* Es ist sehr Schönes in dieser Art geschrieben worden. Das Schönste sind die chassidischen Geschichten von J. L. Perez (im jüdischen Idiom). 
Macht über sie. Deshalb sieht die Religion im Mythos ihren Erzfeind und bekämpft ihn, wo sie ihn nicht aufzusaugen, ihn sich nicht einzuverleiben vermag. Die Geschichte der jüdischen Religion ist die Geschichte ihres Kampfes gegen den Mythos.

Seltsam und wunderbar ist es zu beobachten, wie in diesem Kampfe die Religion immer wieder den scheinbaren, der Mythos immer wieder den wirklichen Sieg gewinnt. Die Propheten streiten durch das Wort wider die Vielheit der Volkstriebe; aber in ihren Visionen lebt die ekstatische Phantasie der Juden und erwählt sie wider ihr Wissen zu Mythendichtern. Die Essäer wollen das Ziel der Propheten durch eine Vereinfachung der Lebensformen erreichen; und aus ihnen wird der Menschenkreis geboren, der den grossen Nazarener trägt und seine Legende schafft: den grössten aller Triumphe des Mythos. Die Meister des Talmuds gedenken in dem zyklopischen Werke einer Kodifizierung des Religionsgesetzes einen ewigen Damm wider die Leidenschaft des Volkes zu erbauen; und unter ihnen erstehen die Urheber der beiden Mächte, die im Mittelalter die Schützerinnen und Verweserinnen des jüdischen Mythos werden: durch die Geheimlehre die Urheber der Kabbala, durch die Agada die Urheber der Volkssage.

Je weiter das Exil fortschritt, jegrausamer es wurde, desto mehr erschien die Erhaltung der Religion zur Erhaltung des Volkstums notwendig; desto stärker wurde die Position des Gesetzes. Der Mythos musste flüchten. Er flüchtete in die Kabbala und in die 
Volkssage. Die Kabbala hielt sich wohl für dem Gesetz überlegen, für eine höhere Stufe des Erkennens; aber sie war die Domäne Weniger, dem Leben des Volkes unüberbrückbar fern und fremd. Die Sage hingegen lebte wohl im Volke und füllte dessen Dasein mit Farbe und Wohllaut, mit Lichteswellen und heimlicher Melodie; aber sie erachtete sich für ein armseliges Ding, das kaum ein Recht auf Existenz habe, sie hielt sich vergraben im letzten Winkel und wagte nie, dem Gesetz ins Auge zu sehen, geschweige denn eine Macht neben ihm sein zu wollen, sie war stolz und froh, wenn sie da und dort berufen wurde, das Gesetz zu illustrieren.

Und plötzlich wächst unter den polnischen und kleinrussischen Dorfjuden eine Bewegung empor, in der der Mythos sich reinigt und erhebt: der Chassidismus.* In ihm strömen Mystik und Sage zur Einheit zusammen. Die Mystik wird Besitz des Volkes, und zugleich nimmt sie die ganze Erzählerglut der Sage in sich auf. Und in dem dunklen verachteten Osten, unter schlichten unwissenden Dörflern wird dem Kinde der Jahrtausende der Thron bereitet.

Im Chassidismus siegt für eine Weile das unterirdische Judentum über das offizielle, - über das allbekannte, übersichtliche Judentum, dessen $\mathrm{Ge}$ schichte man erzählt und dessen Wesen man in gemeinverständliche Formeln fasst.

* Über die jüdische Mystik und den Chassidismus habe ich einiges Allgemeine in der Einleitung zu den "Geschichten des Rabbi Nachman" gesagt. 
Für eine Weile nur. Es gibt in unseren Tagen noch Hunderttausende von Chassidim; der Chassidismus ist verdorben. Aber die chassidischen Schriften haben uns seine Lehre und seine Legende übergeben.

Die chassidische Lehre ist das Stärkste undEigenste, was die Diaspora geschaffen hat. Sie ist die Verkündigung der Wiedergeburt. Es wird keine Erneuerung des Judentums möglich sein, die nicht ihre Elemente in sich trüge.

Die chassidische Legende ist der Körper der Lehre, ihr Bote, ihr Zeichen auf dem Wege der Welt. Sie ist die letzte Gestalt des jüdischen Mythos, die wir kennen.

Die Legende ist der Mythos der Berufung. Das bedeutet: die ursprüngliche Personalität des Mythosist in ihr gespalten. In dem reinen Mythos gibt es keine Verschiedenheit des Wesens. Er kennt die Vielheit, aber nicht die $Z_{\text {weiheit. Auch der Heros steht }}$ nur auf einer anderen Stufe als der Gott, nicht ihm gegenüber: sie sind nicht das Ich und das Du. Der Heros hat eine Sendung, nicht eine Berufung. Er steigt empor, aber er wandelt sich nicht. Der Gott hat Sonderheit wie er und wie er Grenze. Der Gott des reinen Mythos beruft nicht, er zeugt; er sendet den Gezeugten, den Heros. Der Gott der Legende beruft den Menschensohn: den Propheten, den Heiligen. Zuweilen mag, wo sich Mythos und Legende durchdringen, ein Gott stehen, der zeugt und beruft.

Die Legende ist der Mythos des Ich und Du, des Berufenen und des Berufenden, des Endlichen, der

VI 
ins Unendliche eingeht, und des Unendlichen, der des Endlichen bedarf.

Die Legende des Baalschem ist nicht die Geschichte eines Menschen, sondern die Geschichte einer Berufung. Sie erzählt kein Schicksal, sondern eine Bestimmung. Sie bewegt sich nicht in der Zeitfolge, sondern in den drei Kreisen der Weihung. Ihr Ende ist schon in ihrem Anfang, und ein neuer Anfang in ihrem Ende.

Ravenna

Im Herbst 1907

MARTIN BUBER 


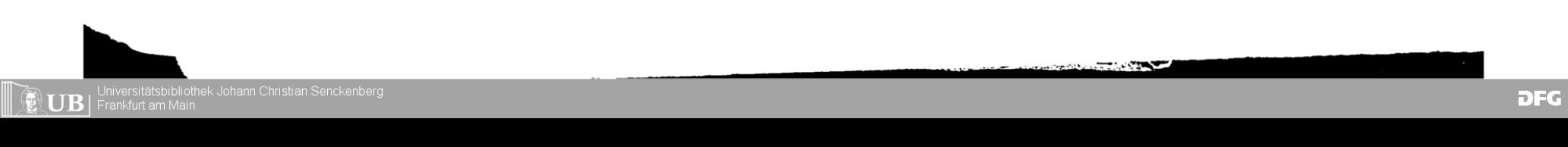



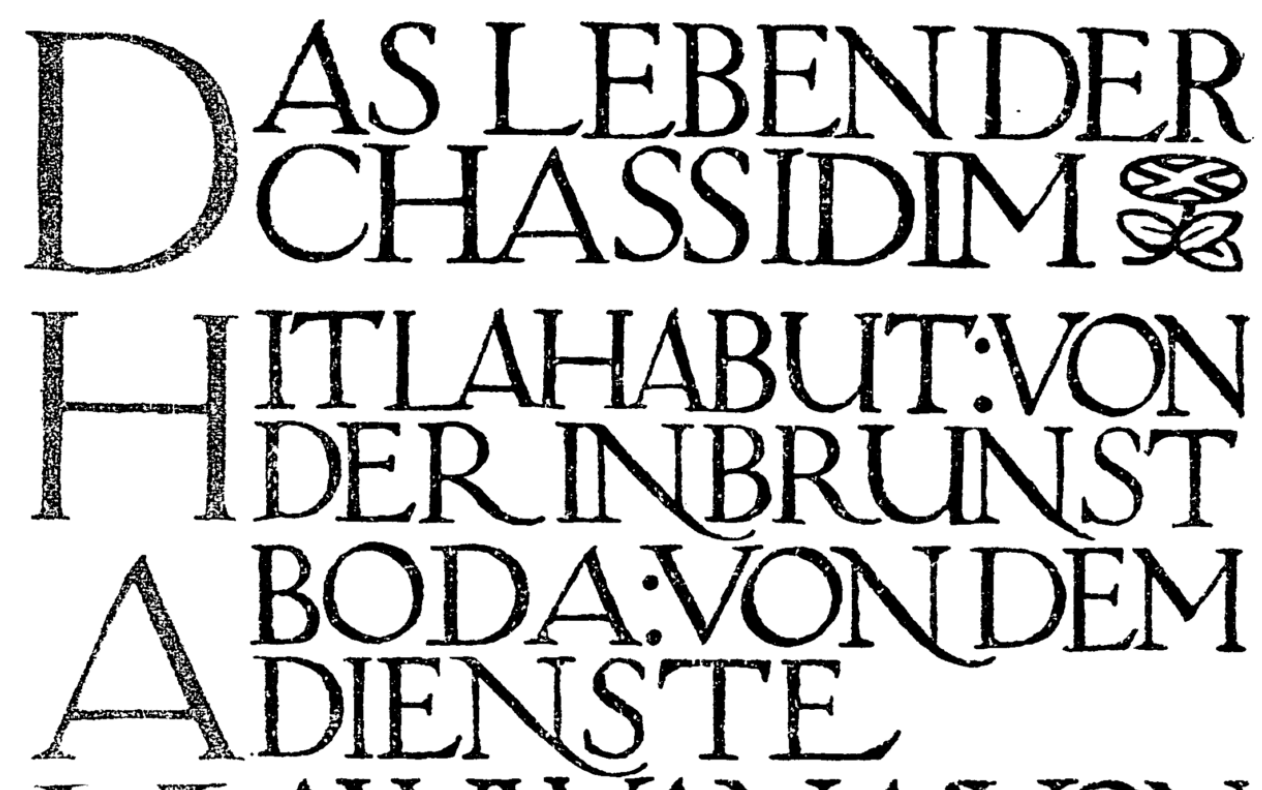

FAWWANA:VON

IDERINTENTION CCHIFLUT:VON $\checkmark$ DERDEMUTT 


\section{HITLAHABUT: VON DER INBRUNST}

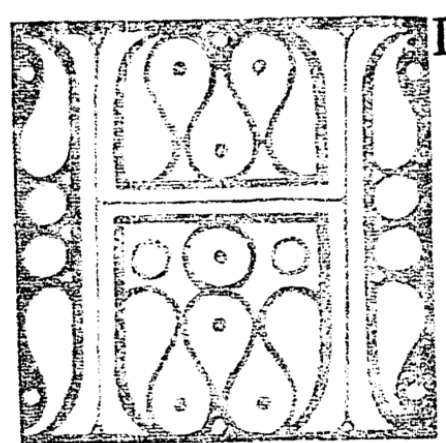

ITLAHABUT IST, DAS BRENnen"; die Inbrunst der Ekstase. Sie ist der Becher der Gnade und der ewige Schlüssel.

Ein feuriges Schwert hütet den Weg zum Baume des Lebens. Es Hitlahabut. Ihr leichter Finger ist ihm übermächtig. Ihr ist die Bahn offen, und alle Schranke versinkt vor ihrem schrankenlosen Schritt. Die Welt ist nicht mehr ihr Ort: sie ist der Ort der Welt.

Hitlahabut erschliesst dem Leben seinen Sinn. Ohne sie hat auch der Himmel keinen Sinn und kein Wesen. „Wenn ein Mensch die ganze Lehre und alle Gebote erfüllt hat, aber die Wonne und das Brennen hat er nicht gehabt: wenn der stirbt und hinübergeht, öffnet man ihm das Paradies, aber weil er in der Welt die Wonne nicht gefühlt hat, fühlt er auch die Wonne des Paradieses nicht."

Allerorten und allezeit kann Hitlahabut erscheinen Jede Stunde ist ihr Schemel und jede Tat ihre Thronlehne. Nichts kann sich ihr entgegenstemmen, nichts sie herabdrücken; nichts kann sich ihrer Macht erwehren, die allen Körper zu seinem Geiste erhebt. Wer in ihr ist, ist in der Heiligkeit. „Er vermag eitle Worte mit seinem Munde zu reden, und die Lehre des Herrn ist in seinem Innern zu dieserStunde; flüsternd $z u$ beten, und sein Herz schreit in seiner Brust; in einer Gemeinschaft von Menschen zu sitzen, 
und er wandelt mit Gott: vermischt mit den Kreaturen und abgeschieden von der Welt." Jedes Ding und jedes Tun wird so geheiligt. „Wenn der Mensch sich an Gott schliesst, kann er seinen Mund reden lassen, was er reden mag, und sein Ohr hören, was es hören mag, und er wird die Dinge binden an ihre obere Wurzel."

Die Gewalt, die so vieles im Menschenleben schwächt und entfärbt, die Wiederholung, ist ohnmächtig vor der Ekstase, die sich gerade an den regelmässigsten, gleichförmigsten Ereignissen wieder und wieder entzündet. Über einen Zaddik geriet Hitlahabut jedesmal, wenn im Vortrage der Schrift die Worte kamen: „Und Gott sprach“. Ein chasssidischer Weiser, der dies seinen Schülern erzählte, fügte hinzu: „Aber auch ich meine: wenn Einer in Wahrheit redet und Einer in Wahrheit empfängt, dann ist es genug an einem Worte, die ganze Welt $z u$ erheben und die ganze Welt zu durchläutern". Ewig neu ist dem Inbrünstigen das Allgewohnte. Ein Zaddik stand im ersten Morgendämmer am Fenster und rief zitternd: „Vor einer kleinen Stunde war noch Nacht, und jetzt ist Tag - Gott bringt den Tag heraufl" Und er war voll der Angst und des Zitterns. Auch sprach er: ,Jeder Geschaffene soll sich vor dem Schöpfer schämen : wäre er vollkommen, wie ihm bestimmt war, dann müsste er erstaunen und erwachen und entbrennen über die Erneuerung der Kreatur zu jeder Zeit und in jedem Augenblick." Aber nicht ein plötzliches Versinken in die Ewigkeit ist Hitlahabut, sondern ein Aufstieg zum 
Unendlichen von Stufe zu Stufe. Gott finden heisst in Weg finden, der ohne Grenze ist. Im Bilde dieses Weges sahen die Chassidim die „kommende Welt", die sie niemals ein Jenseits nannten. Ein Frommer schaute einen toten Meister im Traume. Der erzählte ihm, von der Stunde seines Todes an gehe er an jedem Tage von Welt zu Welt. Und die Welt, die gestern als Himmel über seinen Blicken ausgespannt war, die ist heute die Erde unter seinem Fuss; und der Himmel von heute ist die Erde von morgen. Und jede Welt ist reiner und schöner und tiefer, als die vor ihr war.

Die Engel ruhen in Gott, aber die heiligen Geister schreiten in Gott vor. „Der Engel ist ein Stehender, and der Heilige ist ein Wandelnder. Darob ist der Heilige über dem Engel."

Solch ein Weg ist die Ekstase. Wenn sie ein Ende zu bieten scheint, ein Erreichen, Erlangen, Ergreifen, ist es nur ein endgiltiges Nein, kein endgiltiges Ja: es ist das Ende der Gebundenheit, das Abschütteln der letzten Kette, die Auflösung, die illem Irdischen enthoben ist. „Wenn der Mensch on Kraft zu Kraft wandelt und nur empor und empor, bis er zur Wurzel aller Lehre und alles Gebotes kommt, zu Gottes Ich, der einfachen Einheit und Schrankenlosigkeit, - wenn er da steht, dann sinken alle Flügel der Gebote und Gesetze nieder, und alle sind sie vernichtet. Denn vernichtet ist der Trieb, da er darüber steht."

,Über der Natur und über der Zeit und über dem Denken" - so wird der genannt, der in der 
Inbrunst ist. Er hat alles Leid und alle Schwere abgetan. "Süsse Leiden, ich empfange euch in Liebe", sagt ein sterbender Zaddik, und Rabbi Sussje ruft, da seine Hand sich aus dem Feuer schleicht, in das er sie gelegit hat, verwundert aus: ,Wie grob ist Sussjes Körper geworden, dass er sich vor dem Feuer fürchtet". Der Inbrünstige regiert das Leben, und kein äusseres Geschehen, das in sein Reich eindringt, vermag seine Weihe zu stören. Von einem Zaddik wird erzählt, er habe, als sich das heilige Mahl der Lehre bis zum Morgen hinzog, zu seinen ingern gesprochen: „Wir sind nicht in die Grenzen dts Tages eingeschritten, sondern der Tag ist in unsere Grenzen eingeschritten, und wir brauchen or ihm nicht $z$ u weichen".

In der Ekstase rückt alles Vergangene und alles Zukünftige zur Gegenwart zusammen. Die Zeit verschrumpft, die Linie zwischen den Ewigkeiten versehwindet, einzig der Augenblick lebt, und der Augen- lick ist die Ewigkeit. In seinem unzersplitterten lichte erscheint alles was war und was sein wird, infach und gesammelt. Es ist da, wie ein Herzschlag da ist, und wird offenbar wie er.

Die chassidische Legende weiss gar viel von den Wunderbaren zu erzählen, die sich ihrer früheren Daseinsformen erinnerten, der $Z$ ukunft wie der eigenen Atemzüge gewahr wurden, von einem Ende der Erde zum andern blickten und alle Wandlungen, die sich in den Welten ereigneten, wie etwas verspürten, was ihrem Körper geschah. All dies hat nichts mit dem Gefühl zu tun, in dem Hitlahabut die Welt des 
Raumes und der Zeit überwunden hat. Wohl aber deuten uns etwas davon zwei naive, einander verwandte und einander erğänzende Anekdoten. Von einem Meister wird erzählt, er habe in Stunden der Entrückung auf die Uhr sehen müssen, um sich in iieser Welt zu erhalten; und von einem andern, ar habe, wenn er die Einzeldinge betrachten wollte, sine Brille aufsetzen müssen, um sein geistiges Sehen zu bezwingen; ,denn sonst sah er alle Einzeldinge der Welt als eines".

Aber die höchste Stufe, von der berichtet wird. ist die, auf der der Entrückte der eigenen Inbrunst entgleitet. Als ein Schüler einmal eines Zaddiks "Erkalten" bemerkte und tadeite, wurde er von einem andern belehrt: „Es gibt ein sehr hohes Heiligtum; wenn man dahin kommt, wird man alles Wesens los und kann nicht mehr entbrennen". So vollendet sich die Inbrunst in der eigenen Aufhebung.

Zuweilen äussert sie sich in einem Tun, das sie weiht und mit heiliger Bedeutung füllt. Die reinste Form, die, in der der ganze Körper der erregten Seele dient und jeder ihrer Hebungen und Neigungen das sichtbare Geschwister erschafft, aus tausend Fluten der Bewegung das eine Bild des verzückten Sinnes auftauchen lässt, ist der Tanz. Von dem Tanz eines Zaddiks wird erzählt: ,Sein Fuss war leicht wie eines vierjährigen Kindes. Und alle, die sein heiliges Tanzen sahen, - da war nicht einer, der nicht zu sich heimgekehrt wäre, denn er wirkte im Herzen aller, die es sahen, beides, Weinen und Wonne, in einem." Oder die Seele erfasst 
die Stimme des Menschen und macht sie singen, was sie in den Höhen erfahren hat; und die Stimme weiss nicht, was sie tut. So stand ein Zaddik in den ,furchtbaren Tagen" (Neujahr und Versöhnungstag) im Gebet und sang neue Melodien, „Wunder der Wunder, die er nie gehört hatte und die kein Menschenohr je gehört hatte, und er wusste gar nicht, was er singt und welche Weise er singt, denn er war an die obere Welt gebunden".

Aber das eigentliche Leben des Inbrünstigen ist nicht unter den Menschen. Es wird von einem Meister gesagt, er habe sich wie ein Fremdling geführt, nach den Worten Davids des Königs: Ein Fremder bin ich im Lande. „Wie ein Mann, der aus der Ferne kam, aus der Stadt seiner Geburt. Er sinnt nicht auf Ehre und nicht auf irgend ein Ding zu seinem Wohle, nur darauf sinnt er, heimzukehren zur Stadt seiner Geburt. Nichts kann ihn besitzen, denn er weiss: Das ist Fremdes und ich muss heim." Mancher geht in die Einsamkeit, in ,das Wandeln“. Rabbi Sussje pflegte in Wäldern umherzustreifen und Lobgesänge zu singen, mit so grosser Glut, ,dass man schier von ihm gesagt hat, er sei nicht bei Verstand". Ein anderer war nur in Gassen und Gärten und Hainen zu finden. Als ihn sein Schwiegervater darob ermahnte, antwortete er ihm mit dem Gleichnis der Henne, die Gänseeier ausgebrütet hatte: ,und als sie ihre Kinder auf der Wasserfläche umherschwimmen sah, lief sie bestürzt hin und her, Hilfe zu suchen für die Unglücklichen; und verstand nicht, dass dies jenen all ihr 
Leben war: dahinzustreichen über die Wasserfläche".

Doch gibt es tiefer Abgeschiedene, deren Hitlahabut in ailiedem noch nicht erfüllt ist. Die werden ,unstät und flüchtig". Sie gehen in die "Verbannung", um „das Exil mit der Schechina zu tragen“. Es ist eine Urvorstellung der Kabbala, dass die Schechina, die Glorie oder Herrlichkeit Gottes, verbannt durch die Unendlichkeit irrt, von ihrem "Herrn" getrennt, und dass sie erst in der Stunde der Erlösung sich mit ihm wieder vereinigen wird. So wandern diese Ekstatiker über die Erde, wohnend in den stummen Fernen des Gottes-Exils, Genossen des heiligen Allgeschehens, wissend um das Rauschen im Blute des Weltenherzens. Der dergestalt Abgelöste ist Gottes Freund, ,wie ein Fremdling eines andern Fremdlings Freund ist, ihrer Fremdheit auf Erden wegen". Thm widerfahren Augenblicke, in denen er die Schechina im Menschenbilde schaut, von Angesicht zu Angesicht, wie jener Zaddik sie im Heiligen Lande sah, ,,in der Gestalt einer Frau, die über den Gemahl ihrer Jugend weint und klagt".

Aber nicht bloss in Gesichten aus dem Dunkel und nicht bloss in dem Schweigen der Wanderschaft gibt Gott sich dem um ihn Entbrannten, sondern aus allen Dingen der Erde blickt sein Auge in das suchende, und jedes Wesen ist die Frucht, in der er sich der verlangenden Seele darbietet. Schleierlos ist das Sein in des Heiligen Hand. "Wer eine Frau sehr begehrt und ihre buntfarbnen Gewänder betrachtet, dessen Sinn geht nicht auf das Prunk- 
zeug und die Farben, sondern auf die Herrlichkeit der begehrten Frau, die in sie gehüllt ist. Aberdie andern sehen nur die Gewänder und nichts mehr. So schaut, wer Gott in Wahrheit begehrt und umfängt, in allen Dingen der Welt nur die Kraft und den Stolz des Bildners des Urbeginns, der in den Dingen lebt. Wer aber nicht auf dieser Stufe ist, sieht die Dinge von Gott getrennt."

Dies ist das Erdenleben der Hitlahabut, die sich über alle Grenzen schwingt und sich mit Gott vermählt. Sie ist die Tochter eines Menschenwillens und die Herrin der Heerscharen, das Fünklein eines Wesens, das sterben muss, und die Flamme, die Raum und Zeit verzehrt, das im Aufblühen welkende Gevächs einer Sehnsucht und die Wurzel des Weltenhaumes. Sie erweitert die Seele zum All. Sie verngert das All zum Nichts. Von ihr redet ein hassidischer Meister in Worten des Geheimnisses: Die Schöpfung des Himmels und der Erde ist die intfaltung des Etwas aus dem Nichts, das Hinabsteigen des Oberen in das Untere. Aber die Heiligen. die sich vom Sein ablösen und Gott immerdar anhängen, die sehen und erfassen ihn in Wahrheit, als ¥räre das Nichts wie vor der Schöpfung. Sie wandeln las Etwas ins Nichts zurück. Und dies ist das Wunderbarere: das Untere emporzubringen. Wie as geschrieben steht in der Gemara: „Grösser ist as letzte Wunder als das erste". 
und im Raume.

Hitlahabut ist das mystische Mahl. Aboda ist das mystische Opfer.

Es sind die Pole, zwischen denen das Leben des Heiligen schwingt.

Hitlahabut schweigt, da sie an Gottes Herzen liegt.

Aboda redet: „Was bin ich und was ist mein Leben, dass ich mein Blut und mein Feuer vor dir ¿ararbringen will?"

Alles ist Gott. Und alles dient Gott. Das ist die urgegebene $Z_{\text {weiheit, }}$ zusammengefaltet im Dasein der Welt, entwickelt im Leben des Heiligen. Das Mysterium, von dem man sich entfernt, wenn man von ihm redet, und das in der Wirklichkeit der Gott habenden, Gott suchenden Seele lebendig da ist: bewusst in ihrer Sehnsucht, keimhaft schlummernd in ihrer Ekstase, allsichtbar gegliedert im Rhythmus ihrer Taten.

Hitlahabut ist so fern von Aboda wie Erfüllung von Verlangen. Und doch strömt Hitlahabut aus Aboda wie Gottfinden aus Gottsuchen.

Der Baalschem erzählte: Ein König baute einst einen grossen und herrlichen Palast mit zahllosen Gemächern, aber nur ein Tor war geöffnet. Und als der Bau vollendet war, wurde verkündet, es sollten alle Fürsten erscheinen vor dem Könige, der 
in dem letzten der Gemächer throne. Aber als sie eintraten, sahen sie: da waren Türen offen nach allen Seiten, von denen führten gewundene Gänge in die Fernen, und da waren wieder Türen und wieder Gänge, und kein Ende stand vor dem verwirrten Auge. Da kam der Sohn des Königs und sah: eine Spiegelung war all die Irre, und sah seinen Vater sitzen in der Halle vor seinem Angesicht.

Das Geheimnis der Gnade ist nicht zu deuten. Zwischen Suchen und Finden liegt die Spannung eines Menschenlebens, ja tausendfacher Wiederkehr der bangen wandernden Seele. Und doch ist der Flug des Augenblicks langsamer als die Erfüllung. Denn Gott will gesucht sein, und wie könnte er nicht gefunden sein wollen?

DerEnkel RabbiBaruchs, des Enkels desBaalschem, spielte einst mit einem andern Knaben ,Verstecken". Und er verbarg sich und wartete in seinem Versteck viele $Z$ eit und vermeinte, sein Gefährte suche ihn und könne ihn nicht finden. Aber als er lange gewartet hatte, kam er heraus und sah den andern nicht mehr und merkte, dass er ihn vom Anfang nicht gesucht hatte. Alsdann lief er in die Stube seines Grossvaters mit Weinen und Klagen um den Bösen. Da flossen die Augen Rabbi Baruchs über und er sagte: "So spricht Gott auch".

Wenn der Heilige ewig neues Feuer heranbringt, dass die Glut auf dem Altar seiner Seele nicht verlösche, redet Gott selbst den Opterspruch.

Gott waltet im Menschen, wie er im Chaos waltete zur Zeit der werdenden Welt. „Und wie als die 
Weit sich zu entfalten begann und er sah: wenn es weiter auseinander fliesst, wird es nicht mehr zu seinen Wurzeln heimkehren können, da sprach er: Genug! - so ist es, wenn die Seele des Menschen im Leide zerflutet und das Übel so mächtig wird in ihr, dass sie bald nicht mehr heimkehren könnte, da erweckt sich sein Erbarmen und er spricht: Genug!"

Aber auch der Mensch kann „Genug!" sagen: zu der Vielheit in sich. Wenn er sich sammelt und vereint, nähert er sich der Einheit Gotres, dient er seinem Herrn. Dies ist Aboda.

Von einem Zaddik wurde gesagt: „Bei ihm ist Lehre und Gebet und Essen und Schlafen, alles Eines, ein Dienst, und er kann die Seele zu ihrer Wurzel erheben."

Alles Tun in Eines gebunden, und das unendliche Leben in jeder Tat getragen: dies ist Aboda. „In ile Taten des Menschen, Sprechen und Schauen und Horchen und Gehen und Stehenbleiben und Sichlegen, sei das Schrankenlose eingekleidet."

Aus jeder Tat wird ein Engel geboren, ein guter oder ein böser. Aber aus den halben und wirren Taten, die ohne den Sinn oder ohne die Kraft sind, werden Engel geboren mit verrenkten Gliedern oder ohne Haupt oder ohne Hände oder ohne Füsse.

In allem Tun durchstrahlt von den Wellen der Allsonne und gesammelten Lichtes in allem Tun, dies ist der Dienst. Aber keine Handlung ist zu ihm auserwählt. Gott will, dass man inm auf alle Arten diene. 
„Es gibt zwei Arten von Liebe: die Liebe eines Mannes zu seinem Weibe, der geziemt es im Geheimen zu sein und nicht am Orte der Schauenden, dieweil diese Liebe beschlossen ist nur an einer von den Wesen geschiedenen Stätte; und die Liebe zu den Geschwistern und den Kindern, die keiner Verborgenheit bedarf. Und so gibt es in der Liebe zu Gott zwei Arten: die Liebe durch die Lehre und das Gebet und die Erfüllung des Gebotenen, und ihr geziemt $e s$, in der Stille $z u$ wandeln und nicht im Offenbaren, damit sie nicht zu Ruhm und Stolz verführe; und die Liebe in der Zeit, da man mit den Geschöpfen vermischt ist, redet und hört, gibt und nimmt mit ihnen, und in dem Geheimnisse seines Herzens hangt man an Gott und lässt nicht ab, ihm zuzusinnen. Und dies ist eine höhere Stufe als jene, und von ihr ist gesagt: Wer gäbe dich mir zum Bruder, der an den Brüsten meiner Mutter sog, ich würde dich in der Gasse finden und dich küssen, und nicht dürften sie mich darob verachten."

Dies ist aber nicht so zu verstehen, als sei in dem dergestalt Dienenden eine Spaltung zwischen der irdischen und der himmlischen Tat. Vielmehr ist jede Bewegung des Hingegebenen ein Gefäss der Weihe und der Macht. Von einem Zaddik wird erzählt, er habe alle seine Glieder so geheiligt, dass jeder Schritt seiner Füsse Welten miteinander vermählte. „Der Mensch ist eine Leiter, aufgepflanzt auf der Erde, und ihr Haupt reicht in den Himmel. Und alle seine Gebärden und Geschäfte und Reden ziehen Spuren in der oberen Welt." 
Hier ist der innere Sinn der Aboda angedeutet, der aus der Tiefe der altjüdischen Geheimlehre kommt und jenes Mysterium der Zweiheit von Inbrunst und Dienst, von Haben und Suchen wohl nicht klärt, aber verklärt.

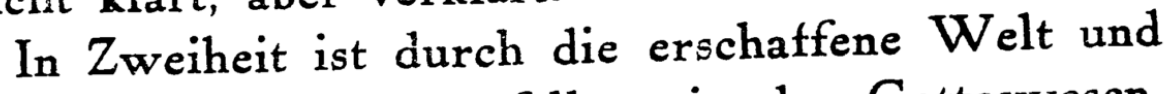
hre Tat der Gott zerfallen: in das Gotteswesen, Elohut, das den Kreaturen entrückt ist, und die Gottesglorie, Schechina, die in den Dingen wohnt, wandernd, irrend, verstreut. Erst die Erlösung wird beide in die Ewigkeit vereinigen. Aber es ist der Besitz des Menschengeistes, durch seinen Dienst die Schechina ihrem Quell nähern, in ihn eintreten lassen zu können. Und in diesem Augenblick der Heimkehr, ehe sie wieder niedersteigen muss in das Sein der Dinge, verstummen die Wirbel, die durch das Leben der Gestirne sausen, erlöschen die Fackeln der grossen Verheerung, entsinkt die Geissel der Hand des Geschickes, hält die Weltenpein inne und lauscht: die Gnade der Gnaden ist erschienen, der Segen träuft nieder auf die Unendlichkeit. Bis die Macht der Verstrickung die Gottesglorie herabzuzerren beginnt und alles wird wie zuvor.

Das ist der Sinn des Dienstes. Nur das Gebet, das um der Schechina willen geschieht, lebt wahrhaft. „Durch seine Not und seinen Mangel kennt er den Mangel der Schechina, zu beten, dass der Mangel der Schechina gefüllt werde und dass durch ihn, den Betenden, die Einung Gottes mit seiner Glorie geschehe". Der Mensch soll wissen, dass sein Leid aus dem Leide der Schechina kommt. Er 
ist "eines von ihren Gliedern", und die Stillung ihres Entbehrens ist allein die echte Stillung des seinen. „Er sinne nicht auf seine Lösung im untern oder im obern Bedürfen, dass er nicht sei wie der die ewige Pflanzung verwüstet, Trennung zu schaffen; sondern alles tue er um des Mangels der Gottesglorie willen, und aus sich selber wird alles gelöst werden, auch sein eigen Leid befriedet aus der Befriedung seiner oberen Wurzel. Denn alles, oben und unten, ist eine Einheit." „Ich bin das Gebet", spricht die Schechina. Ein Zaddik sagte: „Die Menschen meinen, sie beten vor Gott, aber es ist nicht so, denn das Gebet selbst ist Gottheit."

In der Enge des Selbst kann kein Beten gedeihen. „Wer in Leid betet ob der Schwermut, die ihn regiert, und denkt, er bete in der Furcht vor Gott, oder wer in Freude betet ob der Helle seines Gemütes, und denkt, er bete in der Liebe zu Gott, dessen Gebet ist gar nichts. Denn diese Furcht ist nur Schwermut, und diese Liebe ist nur leere Freude."

Es wird erzählt, der Baalschem sei einmal an der Schwelle eines Bethauses stehen geblieben und habe nicht eintreten wollen und habe im Widerwillen gesprochen: „, Da kann ich nicht ein. Ist doch das Haus von Ende zu Ende und über alle Ufer voll des Gebetes." Und da sich die Begleiter verwunderten, weil ihnen schien, es könne kein grösseres Lob geben als dieses, deutete er es ihnen: Wenn die Worte nicht in ihrer Absicht auf das obere Geschehen gerichtet sind, dann können sie nicht aufsteigen, 
sondern lagern sich am Boden Schicht auf Schicht, bis sie das ganze Haus füllen in dickem Wirrsal. Zweierlei vermag die Gebete festzuhalten: wenn sie ohne die Intention gesprochen werden, und wenn die früheren Taten des Betenden sich zwischen ihm und dem Himmel wie eine harte Wolke breiten. Die Hinderung kann nur bezwungen werden, wenn der Mensch in die Sphäre der Inbrunst emporwächst und sich in ihren Gnaden reinigt, oder wenn eine andere Seele, die in der Inbrunst ist, die gefesselten Worte frei macht und mit dem ihren nach oben trägt. So wird von einem Zaddik erzählt, ex sei beim Beten der Gemeinde eine lange Zeit stumm und ohne Bewegung dagestanden und habe dann erst selbst zu beten begonnen, ,gleichwie der Stamm Dan am Ende des Lagers zog und alles Verlorene sammelte"; sein Wort sei ein Gewand gewesen, in dessen Falten hätten sich die niedergehaltenen Gebete geschmiegt und seien emporgetragen worden. Dieser Zaddik pflegte vor dem Beten zu sagen: „Ich binde mich mit ganz Israel, mit denen, die grösser sind als ich, dass durch sie mein Gedanke aufsteige, und mit denen, die kleiner sind als ich, dass sie durch mich gehoben werden."

Aber dies ist das Geheimnis der Gemeinschaft, dass nicht bloss der Niedere des Höheren bedarf, sondern auch der Hohe des Niederen. Hier ruht ein weiterer Unterschied zwischen dem Zustand der Ekstase und dem Zustand des Dienstes. Hitlahabut ist des Einzelnen Weg und Ziel; ein Seil gespannt über dem Abgrund, an zwei schlanke Bäume ge- 
bunden, die der Sturm bewegt; in Einsamkeit und Grauen betritt es der Fuss des Wagenden. Hier gibt es keine Menschengemeinschaft, nicht im $Z_{\text {weifel }}$ und nicht im Besitz. Der Dienst aber ist vielen Seelen in ihrer Vereinigung erschlossen. Er gewährt die letzten Schauer nicht, aber er ist frei von den dunkelsten Ängsten. Er ist nicht ein Seil, sondern eine Brücke. Den auf dem Seile Kommenden umfängt drüben der Arm des Geliebten; den Wanderern der Brücke öffnet sich die Halle des Köniłgs. Die Ekstase will nichts als ihre Vollendung in Gott, sie gibt sich dahin. Im Dienste lebt eine Absicht, eine „Kawwana". Die Wollenden binden sich aneinander zu grösserer Einheit und Macht. Es gibt einen Dienst, den nur die Gemeinde vollbringen kann.

Der Baalschem sagte ein Gleichnis: Menschen standen unter einem sehr hohen Baume. Und einer von den Menschen hatte Augen zu sehen. Und er sah: im Wipfel des Baumes stand ein Vogel, herrlich in wesenhafter Schönheit. Aber die andern sahen den Anblick nicht. Und über jenen Mann fiel ein grosses Bangen, zu dem Vogel zu kommen und ihn zu nehmen; und er konnte nicht von dannen ohne den Vogel. Aber wegen der Höhe des Baumes war es nicht in seinem Vermögen, und auch eine Leiter war nicht zu finden. Doch aus dem grossen und mächtigen Bangen gab er seiner Seele den Rat. Er nahm die Menschen, die umherstanden, und stellte sie aufeinander, jeden auf die Schultern eines Gefährten. Er aber stieg zu oberst, also dass er zum Vogel kam, und nahm ihn. Und die Menschen, 
wiewohl sie dem einen geholfen hatten, wussten nichts von dem Vogel und sahen ihn nicht. Er aber, der von ihm wusste und ihn sah, hätte ohne sie nicht $z u$ ihm kommen können. Würde jedoch der unterste von ihnen seinen Ort verlassen, dann müsste der oben zur Erde niederfallen. „Und der Tempel des Messias wird im Buche Sohar das Vogelnest genannt."

Es ist aber nicht etwa so, als werde nur des Zaddiks Gebet von Gott empfangen und als seinur dieses lieblich in seinen Augen. Kein Beten ist gnadenstärker und dringt in geraderem Fluge durch alle Himmelswelten, als das Beten des Einfältigen, der nichts zu sagen und nur das ungebrochene Müssen seines Herzens Gott darzubringen weiss. Gott nimmt es an, wie ein König das Singen der Nachtigall in der Nacht seines Gartens, das ihm süsser klingt als die $\mathrm{Hul}$ digung der Fürsten im Thronsaal. Die chassidische Legende weiss sich nicht genug der Beispiele für die Gunst, die dem Ungeschiedenen leuchtet, und für die Macht seines Dienstes. Eines seihier mitgeteilt.

Ein Dorfmann, der Jahr für Jahr an den ,furchtbaren Tagen" im Bethaus des Baalschem war, hatte einen Knaben. Der war stumpfen Verstandes und konnte nicht einmal die Gestalt der Buchstaben empfangen, geschweige denn die heiligen Worte erkennen. Und der Vater nahm ihn an den furchtbaren Tagen nicht mit sich in die Stadt, dieweil er nichts wusste. Aber als er dreizehn Jahre war und mündig vor Gottes Gesetzen, nahm ihn der Vater am Versöhnungstag mit, damit er nicht etwa esse 
am Tage der Kasteiung aus Mangel seines Wissens und Verstehens. Und der Knabe hatte ein Pfeifchen, darauf pfiff er immer in der Zeit, da er im Felde sass, die Schafe und Kälber zu weiden. Und er nahm es mit sich in der Tasche seines Kleides, und sein Vater sah es nicht. Und der Knabe sass in den heiligen Stunden im Bethause und wusste nichts $z u$ sagen. Als aber das Mussafgebet angehoben wurde, sprach er zu seinem Vater: „Vater, ich habe mein Pfeifchen bei mir und ich will darauf singen." Da war sein Vater sehr bestürzt und fuhr ihn an und sprach: „Hüte dich und hüte deine Seele, dass du dies nicht tuest." Und er musste es in sich bewahren. Aber als das Mincha-Gebet kam, sprach er wieder: „Vater, erlaube mir doch, mein Pfeifchen zu nehmen." Und als der Vater sein Verlangen sah und dass seine Seele bangte $z \mathrm{u}$ pfeifen, war er zornig und fragte ihn: „An welchem Orte hast du es?" und da er ihm den Ort zeigte, legte er die Hand auf die Tasche und hielt sie fortan darauf, um das Pfeifchen zu hüten. Und das Neilla-Gebet begann, und die Lichter brannten zitternd in den Abend, und die Herzen brannten wie die Lichter, unerschöpft vom langen Harren, und durch das Haus schritten noch einmal müde und aufrecht die achtzehn Segensprüche, und das grosse Bekenntnis kehrte zum letzten Mal wieder und lag vor der Lade des Herrn, die Stirn auf der Diele und die Hände gebreitet, noch einmal, ehe der Abend sich neigt und Gott entscheidet. Da konnte der Knabe seine Inbrunst nicht länger halten und riss mit vieler Kraft das Pfeifchen aus der Tasche 
und liess seine Stimme gar mächtig schallen. Und alle standen erschreckt und verwirrt da. Aber der Baalschem erhob sich über ihnen und sprach: „Das Verhängnis ist durchbrochen und der Zorn zerstreut vom Angesichte der Erde."

So ist jeder Dienst, der aus einer schlichten oder geschlichteten zwiespaltlosen Seele kommt, zureichend und vollkommen. Noch aber ist ein höherer. Denn wer von Aboda zu Hitlahabut aufgestiegen ist und seinen Willen in sie getaucht hat und seine Tat einzig aus ihr empfängt, der hat jeden besonderen Dienst überstiegen. "Jeder Zaddik hat seine besondere Art des Dienstes. Wenn aber die Zaddikim ihre Wurzel betrachten und zum Nichts gelangen, dann können sie Gott auf allen Stufen dienen". So sprach einer von ihnen: "Ich stehe vor Gott wie ein Botenknabe". Denn er war zur Vollendung und zum Nichts gekommen, bis er keine besondere Art mehr hatte, ",sondern er stand bereit für alle Arten, die Gott ihm weisen würde, wie ein Botenknabe dasteht, bereit für alles, was ihm sein Herr befehlen wird."

Wer dergestalt in der Vollendung dient, der hat die urgegebene $Z_{\text {weiheit besiegt }}$ und hat Hitlahabut in das Herz der Aboda eingetan. Er wohnt in den Reichen des Lebens, und doch sind alle Mauern gefallen, alle Grenzsteine ausgerissen, alle Scheidung ist vernichtet. Er ist der Bruder der Geschöpfe und fühlt ihren Blick, als wäre es sein eigener, ihren Schritt, als gingen ihn seine Füsse, ihr Blut, als flösse es in seinem Leibe. Er ist der Sohn Gottes und 
legt bange und sicher seine Seele in die grosse Hand zu all den Himmeln und Erden und ungewussten Welten, und steht auf den Fluten des Meeres, in das alle seine Gedanken und aller Wesen Wanderschaften münden. „Er macht seinen Körper zum Throne des Lebens und das Leben zum Throne des Geistes und den Geist zum Throne der Seele und die Seele zum Throne des Lichtes der Gottesglorie, und das Licht umströmt ihn ringsum, und er sitzt inmitten des Lichtes, und zittert, und frohlockt." 


\section{KAWWANA: VON DER INTENTION}

\section{CaWWANA IST DAS MYSTERIUM DER auf ein $Z_{i e l}$ gerichteten Seele.}

1 Kawwana ist nicht der Wille. Sie sinnt nicht darauf, ein Bild in die Welt der wirklichen Dinge zu versetzen; nicht, einen Traum zum Gegenstande festzumachen, dass er bei der Hand sei, beliebig oft empfunden zu werden in satter Wiederholung. Auch darauf nicht, den Stein der Tat in die Wellen des Geschehens zu werfen, dass sie eineWeile unruhig werden und sich verwundern, um sodann zurückzukehren zu den tiefen Befehlen ihres Lebens; einen Funken zu legen an die Zündschnur, die durch die Reihe der Geschlechter geht, dass eine Flamme hüpfe aus Zeit zu Zeit, bis sie in einer ohne Abschied und Zeichen erlischt. Nicht dies ist Kawwanas Meinen, dass die Pferde an dem grossen Wagen einen Antrieb mehr verspüren, oder dass ein $B a u$ mehr aufgerichtet werde vor dem übervollen Blick der Sterne. Kawwana meint nicht den $Z_{\text {weck, sondern das }} Z_{i e l}$.

Es gibt aber keine Ziele, sondern das Ziel. Nur

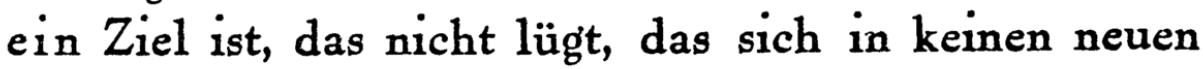
Weg verfängt, in das alle Wege münden, vor dem kein Abweg ewig flüchten kann: die Erlösung.

Kawwana ist ein Strahl der Gottesglorie, der in jedem Menschen wohnt und die Erlösung meint.

Dies aber ist die Erlösung, dass die Schechina aus der Verbannung heimkehre. „Dass alle Schalen von der Gottesglorie weichen und sie sich reinige und sich eine ihrem Eigner in vollkommener Einung." Des 
zum Zeichen erscheint der Messias und macht alle Wesen frei.

Manchem ist sein Leben lang, als müsse es hier und heute geschehen. Denn er hört die Stimmen des Werdens in den Schluchten brausen und fühlt das Keimen der Ewigkeit auf dem Acker der Zeit, wie wenn es in seinem Blute geschähe, und so kann er es nimmer anders denken, als dies und dies sei der erwählte Augenblick. Und immer noch heisser zwingt ihn sein Wähnen, weil immer noch gebieterischer die Stimmen reden und noch heischender das Keimen schwillt.

Von einem Zaddik wird erzählt, dass er also sehr der Erlösung harrte: wenn er auf der Gasse ein Getümmel hörte, sogleich wurde er erregt $z \mathfrak{u}$ fragen, was dies wolle und ob nicht der Bote gekommen sei; und jedesmal, wenn er zum Schlafen ging, befahl er seinem Diener, wenn der Bote käme, solle er ihn im gleichen Augenblick wecken. „Denn also sehr war in seinem Herzen das Kommen des Erlösers eingefasst, wie wenn ein Vater den einzigen Sohn aus dem fremden Lande erwartet und steht auf der Turmwarte mit Sehnsucht der Augen und lugt durch alle Fenster aus, und wenn man die Tür öffnet, eilt er hinaus, um zu sehen, ob sein Sohn nicht gekommen ist."

Andere aber sind des Schreitens kundig in seinem Masse und sehen Ort und Stunde der Bahn und wissen die Ferne des Kommenden. In allem stellt sich ihnen das Unvollendete dar, die Gebrechen der Wesen reden zu ihnen, und der Atem der Winde trägt ihnen Bitterkeit zu. Wie eine unreife Frucht ist die Welt 
vor ihren Augen. In sich sind sie der Glorie teilhaftig - da schauen sie hinaus: Alles liegt im Kampfe.

Als der grosse Zaddik Rabbi Menachem in Jerusalem war, ereignete es sich, dass ein törichter Mann den Ölberg bestieg und in die Schofarposaune stiess. Und keiner hatte ihn gesehen. Und es war ein Gerücht im Volke, dies sei das Schofarblasen, das die Erlösung verkündigt. Als dies an die Ohren des Rabbis kam, öffnete er ein Fenster und sah in die Luft der Welt hinaus. Und sogleich sprach er: „Da ist keine Erneuerung."

Dies aber ist der Weg der Erlösung: dass alle Seelen und Seelenfunken, die der Urseele entsprossen und in der Urtrübung der Weit oder durch die Schuld der Zeiten gesunken und hinausgestreut sind in alle Kreaturen, die Wanderschaft beschliessen und geläutert heimkehren. Die Chassidim reden davon im Gleichnis des Fürsten, der das Mahl erst anheben lässt, wenn der letzte der Gäste eingezogen ist.

Alle Menschen sind die Stätten wandernder Seelen. In vielen Wesen wohnen sie und streben von Gestalt zu Gestalt nach der Vollendung. Die sich aber nicht zu läutern vermögen, werden von der „Welt des Wirrsals" befangen und hausen in Wasserlachen, in Steinen, in Gewächsen, in Tieren, der erlösenden Stunde entgegenharrend.

Doch nicht bloss Seelen sind überall verschlossen: auch Seelenfunken. Dieser ist kein Ding leer. Sie leben in allem, was ist. Jede Form ist ihr Kerker.

Und dies ist der Sinn und die Bestimmung der Kawwara: dass es dem Menschen gegeben ist, die 
Gefallenen zu heben und die Gefangenen zu befreien.

Nicht bloss warten, nicht bloss ausschauen: wirken kann der Mensch an der Erlösung der Welt.

Dies eben ist Kawwana: das Mysterium der Seele, die darauf gerichtet ist, die Welt zu erlösen.

Es wird von Heiligen berichtet, die es im Sturm und in der Gewalt zu vollbringen vermeinten. In dieser Welt; wenn sie von der Gnade der Inbrunst so durchglüht waren, dass ihnen nichts mehr unerreichbar schien, die sie doch Gott umfangen hatten. Oder in der kommenden Welt; ein Zaddik sprach im Sterben: „Die Freunde sind hingegangen und wollten den Messias bringen, und haben es in der Wonne vergessen. Aber ich werde nicht vergessen."

In Wahrheitjedoch kannjeder nurin seinem Bereiche wirken. Jeder hat eine weit in Raum und Zeit ausgespannte Sphäre des Seins, die ihm zugeteilt ist, durch ihn erlöst zu werden. Orte, die von Ungehobenem beschwert und in ihrer Seele gefesselt sind, warten auf den Menschen, der zu ihnen kommen wird mit dem Worte der Freiheit. Wenn ein Chassid an einem Orte nicht beten kann und an einen anderen geht, dann fordert der erste Ort von ihm: „Warum wolltest du nicht auf mir die heiligen Worte sprechen? Und wenn Böses an mir ist, so ist es an dir, mich zu erlösen." Aber auch alle Reisen haben heimliche Bestimmung, die der Reisende nicht ahnt.

Von einigen Zaddikim wird gesagt, sie hätten die helfende Macht über die wandernden Seelen gehabt. In allen Zeiten, sonderlich aber, wenn sie im Gebete standen, seien die Irrfahrer der Ewigkeit bittend vor 
ihnen erschienen und hätten das Heil aus ihren Händen empfangen. Doch auch aus eigenem Trieb hätten sie die Stummen unter den Gebannten im Exil eines müden Leibes oder in Dunkel des Elements zu finden und sie emporzuretten gewusst.

Diese Hilfe ist als ein ungeheures Wagen inmitten von andringenden Gefahren dargestellt, zu dem nur der Heilige sich spannen kann, ohne niedergeworfen zu werden. "Wer eine Seele hat, der mag sich in den Abgrund hinablassen, festgebunden durch seinen Gedanken wie durch ein starkes Seil am oberen Rande, und wird zurückkehren. Aber wer nur Leben hat, oder nur Leben und Geist, der hat die Artung des Gedankens noch nicht, und das Band wird nicht standhalten, und er wird in die Tiefe fallen."

Kann also nur der Begnadete geruhigen Mutes in die Finsternis tauchen, um einer Seele beizustehen, die den Wirbeln der Wanderschaft überliefert ist, so ist auch dem Geringsten nicht versagt, die verlorenen Funken aus ihrem Gewahrsam zu heben und heimzusenden.

Ueberall sind die Funken eingetan. Sie hängen in den Dingen wie in versiegelten Brunnen, sie ducken sich in den Wesen wie in zugemauerten Höhlen, sie atmen Bangigkeit aus und Dunkel ein, sie warten; und die im Raume wohnen, schwirren wie lichttolle Falter um die Bewegungen der Welt umher, schauend, in welche sie einkehren könnten, durch sie gelöst zu werden. Alle harren sie der Freiheit.

„Der Funke in einem Gestein oder Gewächs oder einer andern Kreatur ist wie eine völlige Gestalt, 
die in der Mitte des Dinges wie in einem Block sitzt, dass Hände und Füsse sich nicht strecken können und der Kopf auf den Knien liegt. Und wer den heiligen Funken zu heben vermag, der führt ihn an die Freiheit, und keine Lösung Gefangener ist grösser als diese. Wie wer einen Königssohn aus der Gefangenschaft errettet und zu seinem Vater bringt."

Aber nicht durch Beschwörungsformeln und nicht durch irgend ein vorgeschriebenes sonderbares $T u n$ geschieht die Befreiung. All dies wächst auf dem Grunde der Anderheit, der nicht der Grund der Kawwana ist. Es bedarf keines Sprunges aus dem Gewohnten ins Wunder. „Mit jeder Tat kann der Mensch an der Gestalt der Gottesglorie arbeiten, dass sie aus dem Verborgenen trete." Nicht die Materie der Handlung, nur ihre Weihung entscheidet. Eben dies, was du im Gleichmass der Wiederkehr oder in der Fügung der Ereignisse tust, eben diese aus Übung erworbene oder aus Eingebung gewonnene Antwort des Handelnden auf das vieltältige Begehren der Stunden, eben diese Stetigkeit des lebendigen Stromes wird, in der Weihe vollzogen, zum Erlösen. Wer in Heiligkeit betet und singt, in Heiligkeit isst und redet, in Heiligkeit des gebotenen $T$ auchbades und in Heiligkeit der Geschäfte bedacht ist, durch den werden die gefallenen Funken erhoben und die gefallenen Welten erlöst und erneuert.

Um jeden Menschen ist - in die weite Sphäre seines Wirkens eingebaut - ein natürlicher Bezirk von Dingen gelegt, die vor allem zu befreien er bestimmt ist. Es sind die Wesen und Gegenstände, die 
der Besitz des Einzelnen genannt werden: seine Tiere und seine Wände, sein Garten und sein Anger, sein Gerät und seine Speise. Indem er sie in Heiligkeit hegt und geniesst, macht er ihre Seelen los. „Daher soll der Mensch sich immerdar seiner Geräte und alles seines Besitzes erbarmen."

Aber auch in der Seele selbst erscheinen die der Lösung Bedürftigen. Die meisten sind die Funken, die durch die Schuld dieser Seele in einem ihrer früheren Leben in die Niederung geraten sind. Sie sind die fremden, störenden Gedanken, die oft den Betenden befallen. „Wenn der Mensch im Gebete steht und begehrt, sich an das Ewige zu schliessen, und die fremden Gedanken kommen und fallen: heilige Funken sind es, die gesunken sind und von ihm erhoben und erlöst werden wollen; und die Funken sind ihm zugehörig, der Wurzel seiner Seele verschwistert: seine Kräfte sind es, die er erlösen soll." Er erlöst sie, wenn er jeden trüben Gedanken seiner reinen Quelle wiedergibt, jeden auf Sonderheit sinnenden Trieb in den göttlichen Alltrieb ergiesst, alles Fremde in der Eigenheit untergehen lässt.

Dies ist die Kawwana des Empfangens: dass man die Funken in den umgebenden Dingen und die Funken, die aus dem Unsichtbaren nahen, erlöse. Aber es gibt noch eine andere Kawwana, das ist die Kawwana des Gebens. Sie trägt keine verirrten Seelenstrahlen in hilfreichen Händen; sie bindet Welten aneinander und herrscht in den Geheimnissen, sie schüttet sich in die durstige Ferne, sie schenkt sich der Unendlichkeit. Auch sie bedarf des Wunderbaren nicht. 
Ihre Bahn ist das Schaffen, und das Wort vor aller anderen Gestalt des Schaffens.

Die Sprache war für die jüdische Mystik von je ein seltsamer und schauererweckender Gegenstand. Eine eigentümliche Theorie der Buchstaben als der Weltelemente liegt vor, die von ihren Vermischungen als von dem Innern der Wirklichkeit handelt. Das Wort ist ein Abgrund, durch den der Redende schreitet. „Man soll die Worte sprechen, als seien die Himmel geöffnet in ihnen. Und als wäre es nicht so, dass du das Wort in deinen Mund nimmst, sondern als gingest $d u$ in das Wort ein." Wer des heimlichen Liedes kundig ist, das das Innen ins Aussen trägt, der tiefen, dunklen Weise, die wunderbar die Laute reiht, des heiligen Reigens, der einsame spröde Worte zum Gesang der Fernen verschmilzt, der wird der Gottesmacht voll, ,und es ist, als schüfe er Himmel und Erde und alle Welten von neuem". Er findet sein Reich nicht vor wie der Seelenbefreier, er spannt es aus vom Firmament zu den schweigenden Tiefen. Aber auch er wirkt an der Erlösung. „Denn in jedem Zeichen sind Welten und Seelen und Göttliches, und sie steigen auf und binden sich und vereinigen sich mit einander, und danach vereinigen sich die Zeichen, und es wird das Wort, und die Worte einen sich in Gott in wahrhafter Einung, da ein Mensch seine Seele in sie geworfen hat, und alle Welten einen sich und steigen auf, und die grosse Wonne wird geboren." So bereitet der Wirkende die letzte All-Einung vor.

Und wie uns Aboda in Hitlahabut, das Urprinzip des chassidischen Lebens, mündete, so mündet hier 
Kawwana in Hitlahabut. Denn Schaffen ist Geschaffenwerden: das Göttliche bewegt und bewältigt uns. Und Geschaffenwerden ist Ekstase: nur wer sich in das Nichts des Absoluten einsenkt, empfängt die formende Hand des Geistes. Dies wird im Gleichnis dargestellt. Es ist keinem Ding der Welt gegeben, in sich umgeschaffen $z u$ werden und in neue Gestalt $z \mathfrak{u}$ kommen, es komme denn vordem zum Nichts, das ist zur „Gestalt des Dazwischen“. Kein Wesen kann auf ihr bestehen, sie ist die Kraft vor der Schöpfung und heisst das Chaos. So ist das Vergehen des Eies zum Küchlein und so der Same, der nicht keimt, ehe er in der Erde aufgegangen und verwest ist. „Und dies wirdWeisheit genannt, das heisst: ein Gedanke, der keine Offenbarung hat. Und also ist es, wenn der Mensch will, dass eine neue Schöpfung aus ihm komme, dann muss er mit aller seiner Möglichkeit zur Eigenschaft des Nichts kommen. und dann schafft Gott in ihm eine neue Schöpfung, und er ist wie ein Quell, der nicht versiegt, und wie ein Strom, der nicht aufhört."

So ist zwiefach der Wille der chassidischen Lehre von der Kawwana: dass der Genuss, die Verinnerung des Aussen, in Heiligkeit geschehe; dass das Schaffen, die Veräusserung des Innen, in Heiligkeit geschehe. Durch heiliges Schaffen und heiligen Genuss vollzieht sich die Erlösung der Welt. 


\section{SCHIFLUT: VON DER DEMUT}

\section{OTT TUT NICHT ZWEIMAL DAS 7 gleiche Ding, sagt Rabbi Nachman von Bratzlaw.}

Einzig und einmalig ist das Seiende. Neu und ungewesen taucht es aus der Flut der Wiederkünfte auf, geschehen und unwiederholbar taucht es in sie zurück. Jegliches erscheint zum andern Male, aber jegliches gewandelt. Und die Würfe und Stürze, die über den grossen Weltgebilden walten, und die Feuer und Wasser, die die Gestalt der Erde bauen, und die Mischungen und Entmischungen, die das Leben der Lebendigen kochen, und der Geist des Menschen mit all seinem Versuchen und Vergreifen an der weichen Fülle des Möglichen, sie alle können nicht ein Gleiches schaffen und nicht wiederbringen eines der Dinge, das da besiegelt ist, gewesen zu sein.

Die Einmaligkeit ist eine Ewigkeit des Einzelnen. Denn mit seiner Einzigkeit ist er unverlöschbar in das Herz der Allheit eingegraben und liegt im Schosse des Zeitlosen immerdar als der also und nicht anders Beschaffene.

So ist die Einzigkeit das wesentliche Gut des Menschen, das ihm gegeben ist, es zu entfalten. Und dies eben ist der Sinn der Wiederkehr, dass sich die Einzigkeit in ihr immer mehr reinige und vollkommen werde; und dass in jedem neuen Leben der Wiederkehrende in ungetrübterer und ungestörterer $\mathrm{Un}_{\mathrm{n}-}$ vergleichbarkeit stehe. Denn reine Einzigkeit und reine Vollkommenheit sind eines, und wer so ganz 
und gar einzig geworden ist, dass keine Anderheit mehr Macht über ihn und Ort in ihm hat, der hat die Reise vollbracht und ist erlöst und kehrt in Gott ein. "Jedermann soll wissen und bedenken, dass er in der Welt einzig ist in seiner Beschaffenheit, und kein ihm Gleicher war je im Leben, denn wäre je ein ihm Gleicher gewesen, dann brauchte er nicht zu sein. Aber in Wahrheit ist jeglicher ein neues Ding in der Welt, und er soll seine Eigenschaft vollkommen machen, denn weil sie nicht vollkommen ist, zögert das Kommen des Messias."

Nur aus seiner eigenen Art, aus keiner fremden kann sich der Strebende vollenden. „Wer die Stufe des Gefährten erfasst und seine Stufe fahren lässt, diese und jene wird durch ihn nicht verwirklicht werden. Viele taten wie Rabbi Simeon ben Jochai und es geriet nicht in ihrer Hand, weil sie nicht in dieser Beschaffenheit waren, sondern nur wie er taten, $\mathrm{da}$ sie ihn in dieser Beschaffenheit sahen."

Aber wie der Mensch in einsamer Inbrunst Gott sucht und es doch einen hohen Dienst gibt, den nur die Gemeinde vollziehen kann, und wie der Mensch mit dem Tun seines Alltagis Ungeheures wirkt, aber nicht allein, sondern der Welt und der Dinge bedarf er zu solchem Tun, so bewährt sich die Einzigkeit des Menschen in seinem Leben mit den andern. Denn je einziger einer in Wahrheit ist, desto mehr kann er den andern geben, und desto mehr will er ihnen geben. Und dies eine ist seine Not, dass sein Geben eingeschränkt ist durch den Nehmenden. Denn „der Schenkende ist von Seiten der Gnade und der Emp- 
fangende ist von Seiten des Gerichts. Und so ist es mit jedem Ding. Wie wenn man aus einem grossen Gefäss in einen Becher giesst: das Gefäss schüttet sich in Fülle aus, aber der Becher setzt seiner Gabe die Grenze."

Der Einzige schaut Gott und umschlingt ihn. Der Einzige erlöst die gefallenen Welten. Und doch ist der Einzige kein Ganzes, sondern ein Teil. Und je reiner und vollkommener er ist, desto inniger weiss er es, dass er ein Teil ist, und desto wacher regt sich in ihm die Gemeinschaft der Wesen. Das ist das Mysterium der Demut.

„Der Mensch hat ein Licht über sich, und wenn zwei Menschen einander mit den Seelen begegnen, gesellen sich ihre Lichter zu einander, und aus ihnen geht ein Licht hervor. Und dies wird Zeugung genannt." Allzeugung fühlen wie ein Meer und sich darin wie eine Welle, das ist das Mysterium der Demut.

Nicht das ist Demut, wenn einer ,sich übersehr erniedrigt und vergisst, dass der Mensch durch sein Wort und seine Geberde über alle Welten den überfliessenden Segen herabzubringen vermag". Dies wird unreine Demut genannt. „Das grösste Böse ist, wenn $\mathrm{du}$ vergissest, dass du ein Königssohn bist." In Wahrheit demütig aber ist, wer die andern wie sich fühlt und sich in den andern.

Hochmut heisst: sich gegenüberstellen. Nicht wer sich weiss, nur wer sich mit andern vergleicht, ist der Hochmütige. Kein Mensch kann sich überheben, wenn er auf sich ruht: sind ihm doch alle Himmel 
offen und alle Welten ergeben; der überhebt sich, der sich dem andern gegenüber fühlt, sich höher sieht als das allergeringste der Dinge, der mit Elle und Gewichten schaltet und Urteil spricht.

Ein Zaddik sprach: „Wenn heute Messias kommt und sagt: ,Du bist besser als die andern', dann sage ich ihm: ,Du bist nicht Messias."“

Ohne Werk und Wesen lebt die Seele des Hochmütigen, flattert und müht sich und wird nicht gesegnet. Die Gedanken, die nicht das Gedachte, sondern sich und ihren Glanz meinen, sind Schatten. Die Tat, die nicht auf das Ziel, sondern auf die Geltung sinnt, hat nicht Körper, nur Fläche, nicht Bestand, nur Erscheinung. Wer misst und wägt, wird leer und unwirklich wie Mass und Gewicht. „Wer seiner voll ist, in dem hat Gott keinen Raum."

Von einem Jüngling wird erzählt, der die Abgeschiedenheit auf sich nahm und sich von den Dingen der Welt löste, allein der Lehre und dem Dienste anzuhangen, und sass in der Einsamkeit, fastend von Sabbat zu Sabbat und lernend und betend. Aber in seinem Sinne hatte er über aller Absicht den Stolz seines Tuns, und es strahlte vor seinen Augen, und seine Finger brannten, es auf seine Stirn zu legen wie den Reif des Gesalbten. Und also fiel all sein Werk der ,andern Seite“ anheim, und das Heilige hatte kein Teil daran. Aber immer stärker trieb sich sein Herz auf und fühlte das Sinken nicht, indes die Dämonen mit seinen Taten spielten, und dünkte sich ganz von Gott besessen. $\mathrm{Da}$ kam es einst, dass er sich aus sich hinauslehnte und die Dinge ringsum 
stumm und abgewandt gewahrte, und da ergriff ihn das Erkennen, und er schaute sein Tun, aufgeschichtet zu Füssen eines riesenhaften Götzen, und sich selbst schaute er in schwindelnder Leere, preisgegeben dem Namenlosen. Dies wird erzählt und nicht weiter.

Der Demütige aber hat die ,ziehende Kraft". Alle Zeit, die der Mensch sich über anderen und vor anderen sieht, hat er eine Grenze, „und Gott kann seine Heiligkeit nicht in ihn lassen, da Gott ohne Grenze ist". Aber wenn der Mensch in sich ruht wie im Nichts, ist er durch kein Andres begrenzt und ist grenzenlos und Gott giesst seine Glorie in ihn.

Die Demut, die hier gemeint ist, ist keine gewollte und geübte Tugend. Sie ist nichts als innerliches Sein, Fühlen und Aussagen. Nirgends ist ein $Z_{w}$ ang an ihr, nirgends ein Sichbeugen, Sichbeherrschen, Sichbestimmen. Sie ist zwiespaltbar wie eines Kindes Blick und schlicht wie eines Kindes Rede.

Rabbi Jakob Jizchak von Lublin, der "Seher", hatte einen Widersacher, einen harten und engsüchtigen Gelehrten, der „der eiserne Kopf“ genannt wurde. Derbedrängte ihn unaufhörlich mit Fragen, Einwänden und Vorwürfen. Einmal sagte er zu ihm: „Ihr wisst doch selbst, dass Ihr kein Zaddik seid. Warum führt Ihr andere auf Eure Wege und ziehet sie zu Eurer Gemeinde?" Sprach Rabbi Jakob Jizchak: „Was kann ich tun? Laufen mir zu und werden meines Wortes froh und begehren es gar." Darauf jener: „So gebet es am Sabbat allen insgesamt $z u$ wissen, dass Ihr keiner der Erhabenen seid." Dies zu tun, war der Zaddik erbötig, und am nächsten Sabbat sprach er vor 
den Ohren aller die Worte, die jener ihm befohlen hatte. Da zog in alle Herzen eine tiefe und wundersame Demut ein, und hingen ihm fürder noch eifriger an als bisker. Als er dies dem eisernen Kopf bekannt gab, bedachte sich der und sagte sodann: „Es ist dies der Weg bei euch Chassidim, den Demütigen zu lieben und den Hochmütigen zu meiden. Darum saget ihnen, Ihr seiet der Auserwählten einer, und sie werden sich von Euch kehren." Antwortete der Meister: „Wenn ich auch kein Zaddik bin, so bin ich doch kein Lügner, und wie kann ich wider die Wahrheit reden?"

Der Demütige lebt in jedem Wesen und weiss jedes Wesens Art und Tugend. Weil keiner ihm ,der Andere" ist, weiss er aus dem inneren Grunde, dass keiner des verhüllten Wertes ermangelt; weiss, dass da "kein Mensch ist, der nicht seine Stunde hätte“. Nicht fliessen ihm die Farben der Welt ineinander, sondern jede Seele steht in der Herrlichkeit ihres Eigendaseins vor ihm. „In jedem Menschen ist Köstliches, das in keinem andern ist. Daher soll man jeden ehren nach seinem Verborgenen, das nur er hat und keiner der Gefährten."

Rabbi Wolf von Zbaraz sah an keinem ein Böses und nannte jeden Menschen Zaddik. Als zwei einst miteinander stritten und man Wolf gegen den Schuldigen aufzureden versuchte, antwortete er: „Bei mir sind sie beide gar gleich - und wer kann wagen, sich zwischen zwei Zaddikim zu stellen?"

"Gott schaut nicht auf den bösen Teil," sagte ein anderer, "wie dürfte ich es tun?"

Wer in den Wesen lebt nach dem Mysterium der 
Demut, kann keines verdammen. „Wer über einen Menschen das Urteil spricht, hat es über sich gesprochen." Der Baalschem sagte zu einem Rabbi, der über einen Sündigen eine harte Busse verhängt hatte: „Du hast noch nie den Sinn der Sünde gefühlt und noch nie den Sinn des gebrochenen Herzens."

Wer sich vom Sünder sondert, geht in der Schuld von dannen. Der Heilige aber vermag an der Sünde eines Menschen als an seiner eigenen zu leiden. Sowird uns von Rabbi Sussje, dem seligen Gottesnarren, berichtet. Wenn er ein Vergehen erfuhr, war es ihm, als habe er es getan. So kam er einst in eine Herberge und sah auf dem Angesicht des Wirtes die Sünden vieler Jahre wie ein Netzwerk aus versteckten Furchen. Und eine Weile war er still und unbewegt. Aber als er allein in der Stube war, die man ihm gewiesen hatte, fiel der Schauer des Mitlebens auf ihn, und er warf sich zu Boden und schrie auf: „Sussje, Sussje, du Arger, was hast du getan? Ist doch keine Lüge, die dich nicht verlockt hätte, und kein Frevel, den du nicht ausgeschlürft hättest! Sussje, Törichter, Verwirrter, wohin nun mit dir?" Und nannte die Sünden des Wirtes mit Ort und Zeit als seine eigenen und schluchzte. Der Wirt war dem seltsamen Manne nachgeschlichen und stand vor der Tür und hörte seine Rede. Und erst fasste ihn eine dumpfe Bestürzung, dann aber leuchteten Reue und Gnade in ihm auf, und er erwachte zu Gott.

Mitleben allein ist Gerechtigkeit. Ein Rabbi hiess im weiten Land der Gerechte, denn er sprach jedem das Urteil nach seinem Tun, nicht mehr und nicht 
geringer. Vor den kam einmal ein Weib, in irgend einer Sache seinen Rat zu erfragen. Er aber fuhr sie an: „Eine Buhlerin bist du!" und schüttete sein Wissen um die Heimlichkeiten ihres Lebens in schweren und drohenden Worten über sie aus und hiess sie sich hinwegheben. Da antwortete die Frau und sprach aus der Bedrängnis ihres Herzens: „Der Schöpfer der Welt ist den Bösen langmütig und fordert ihre Schuld nicht in Eile ein und offenbart ihr Geheimnis keiner Kreatur, auf dass sie sich nicht schämen, zu ihm zurückzukehren, und verbirgt ihnen sein Angesicht nicht. Und der Rabbi von Apta sitzt auf seinem Stuhl und kann sich keinen Augenblick lang enthalten, zu offenbaren, was der Schöpfer der Welt bedeckt hat." Seither pflegte der Rabbi zu sagen: „Von je hat mich keiner bezwungen, nur einmal ein Weib."

Mitleben als Erkennen ist Gerechtigkeit. Mitleben als Sein ist Liebe. Denn jenes Gefühl der Nähe und jenes Wollen der Nähe zu Wenigen, das unter den Menschen Liebe heisst, ist nichts als Erinnerung aus einem Himmelsleben: „Die im Paradies beieinander sassen und Nachbarn und Verwandte waren, die sind einander nahe auch in dieser Welt." In Wahrheit aber ist Liebe ein Urweites und Tragendes und ohne alle Wahl und Scheidung hingebreitet $z u$ den Lebendigen. Ein Zaddik sprach: „Wie könnt ihr von mir sagen, ich sei ein Führer des Zeitalters, da ich noch in mir die Liebe zu den Nahen und zu meinem Samen stärker fühle als zu allen Menschensöhnen?" Dass sich dieses Meinen auch auf die Tiere erstreckt, sagen die Erzählungen von Rabbi 
Wolf, der nie ein Pferd anzuschreien vermochte, von Rabbi Mosche Leib, der die vernachlässigter. Kälber auf den Märkten tränkte, von Rabbi Sussje, der keinen Käfig sehen konnte ,und die Unseligkeit der Vögel und ihr Bangen nach dem Fluge in der Luft der Welt, gemäss ihrer Natur, freie Wanderer zu sein", ohne ihn zu öffnen, und die Schläge des Besitzers mit lächelnder Freude wie einen kostbaren Lohn empfing. Aber nicht nur die Wesen, denen der kurze Blick der Menge den Namen der Lebendigen zuspricht, gehören der Liebe des Liebenden zu: „Dir ist kein Ding in der Welt, in dem nicht Leben wäre, und von seinem Leben hat jedes die Gestalt, in der es vor deinen Augen steht. Und siehe, dieses Leben ist das Leben Gottes."

So ist es gemeint: die Liebe $z \mathfrak{u}$ den Lebendigen ist die Liebe zu Gott, und sie ist höher als irgend ein Dienst. Ein Meister fragte einen Schüler: „Du weisst, dass nicht zwei Kräfte zur gleichen Zeit im Menschensinne Fassung haben. Wenn du dich nun am Morgen von deinem Lager hebst und zwei Wege sind vor dir: Liebe $z u$ Gott und Liebe zu denMenschen, welcher ist der erste?" Jener antwortete: ,Ich weiss es nicht." Da sprach der Meister: „Sieh, es stehit geschrieben in dem Gebetbuche, das in den Händen des Volkes ist: ,Ehe du betest, sage das Wort: Und du sollst lieben den Andern wie dich selbst'. Meinst du, das hätten die Ehrwürdigen ohne Absicht befohlen? Wenn einer dir sagt, er trage Liebe zu Gott und trage nicht Liebe zu den Lebendigen, Falsches redet er und Unmögliches gibt er vor zu besitzen." 
Darum ist, wo einer sich von Gott entfernt, die Liebe eines Menschen das einzige Heil. Als ein Vater dem Baalschem klagte: „Mein Sohn ist von Gott gewichen - was soll ich tun?", erwiderte er: "Ihn mehr lieben".

Eines der chassidischen Grundworte ist dieses: mehr lieben. Seine Wurzeln graben sich tief ein und strecken sich weit hin. Der mag die Kategorie: Judentum neu verstehen lernen, der es verstanden hat. Es ist eine grosse Bewegung darin, die sich in unłerirdischer Historie verwirklicht und inniger noch in zeitloser Weisheit und am innigsten wohl in einem Traum, den zu träumen und $z u$ tragen allerorten und allezeit junge Menschen erstehen und sterben.

Eine grosse Bewegung, und doch wieder nur ein verlorener Klang. Es ist ein verlorener Klang, wenn irgendwo - in jener dunkeln, fensterlosen Stube und irgendwann - in jenen Tagen ohne Kraft der Botschaft - die Lippen eines namenlosen, dauerlosen Menschen, des Zaddiks Rabbi Rafael, diese Worte bilden: „Wenn ein Mensch sieht, dass sein Gefährte ihn hasst, soll er ihn mehr lieben. Denn die Gemeinschaft der Lebendigen ist der Wagen der Gottesglorie, und wo ein Riss im Wagen ist, muss man ihn füllen, und wo der Liebe wenig ist, dass die Fügung sich löst, muss man Liebe mehren an seiner Seite, den Mangel zu zwingen."

Dieser Rabbi Rafael rief einst vor einer Fahrt einem Schüler zu, er solle sich zu ihm in denWagen setzen. Darauf jener: ,Ich fürchte, ich könnte es Euch 
eng machen." Und er mit erhobener Stimme: ,So wollen wir einander mehr lieben: dann wird uns weit sein."

Sie sollen hier stehen als Zeugen, das Sinnbild und die Wirklichkeit, verschieden und eines, untrennbar, der Wagen der Schechina und der Wagen der Freunde.

$E_{s}$ ist die Liebe ein Wesen, das in einem Reiche lebt, grösser als das Reich des Einzelnen, und aus einem Wissen redet, tiefer als das Wissen des Einzelnen. Sie ist in Wahrheit $z$ wis chen den Kreaturen, das heisst: sie ist in Gott. Leben durch Leben gedeckt und gebürgt, Leben sich giessend in Leben, so schaut ihr die Seele der Welt. Wessen das eine ermangelt, des wird das andere ihm entgegenschwellen. Wenn eines zu wenig liebt, wird das andere mehr lieben.

Die Dinge helfen einander. Helfen aber ist: selbst in einem gesammelten Willen das Seine aus sich selbst tun. Wie der, der mehr liebt, dem Andern nicht Liebe predigt, sondern selbst liebt und sich also gewissermassen nicht um ihn kümmert, so kümmert sich der Helfende gewissermassen nicht um den Andern, sondern tut das Seine aus sich selbst im Gedanken der Hilfe. Das bedeutet: das Eigentliche, was zwischen den Wesen geschieht, geschieht nicht durch ihren Verkehr, sondern durch eines jeden scheinbar einsames, scheinbar unbekümmertes, scheinbar brückenloses Tun aus sich selbst. Dies wird im Gleichnis gesagt: ,Wenn ein Mensch singt und kann die Stimme nicht erheben, und einer kommt ihm $z$ u helfen und 
hebt an zu singen, dann kann auch jener wieder die Stimme erheben. Und das ist das Geheimnis der Verbindung."

Es gibt aber noch eine andere Hilfe, eine weite und wissende, vom Leid der Welten geboren, von ihrem Blut genährt. Wer der ringenden Ewigkeit hilft, hat jedem Leben geholfen. Auch davon redet ein stilles Gleichnis. Drei Männer sassen einst im Kerker, an einem Orte schwerer Finsternis. Von diesen Männern waren zwei weise, der dritte war ein Tor. Es wurden ihnen aber täglich andere Speisen und anderes Gerät zum Essen gebracht, und das Dunkel und die Not hatten den Narren also verwirrt, dass er nicht mehr wusste, wie er die verschiedenen Geräte gebrauchen solle, die Speisen zum Munde zu bringen, und stumpf und ratlos dasass, ohne zu essen und $z u$ trinken, bis es der eine der beiden Weisen merkte und ihn unterwies. Am nächsten Tage aber wusste er das neue Gerät wieder nicht zu führen, und wieder musste der Gefährte ihm beistehen. Und so ging es seither Tag für Tag. Der andere Weise aber sass und schwieg und achtete keines anderen Dinges als seiner Gedanken. Einmal fragte ihn jener: ,Warum sitzest du für dich und schweigst und hilfst mir nicht, den Toren zu belehren?" Antwortete er: „Du mühst dich stetig aufs neue und kommst zu keiner Grenze, denn morgen wandelt sich das Gerät, und du musst wieder beginnen. Ich aber sitze und sinne, wie ich in die Wand eine Öffnung bohren mag, dass das Licht der Sonne hineinstrahle und er alles sehe." 
Es ist aber all dies nicht etwa so $z u$ verstehen, als gälte das einfache Einanderhelfen nicht im Lichte der Lehre. Vielmehr ist dieses einfache Einanderhelfen keine Aufgabe, sondern das Selbstverständliche und die Wirklichkeit, auf die das Zusammenleben der Chassidim gegründet ist und über der sich die höheren Gestalten der Hilfe aufbauen. Die Hilfe ist keine Tugend, sondern eine Ader des Daseins. Das ist der neue Sinn des alten jüdischen Wortes, das Wohltun rette vom Tode. Nur eines wird geboten und geriordert: dass der Helfende sich nicht auf die Andern besinne, die mithelfen können, auf Gott und die Menschen, und nicht vermeine, eine Teilkraft zu sein, die nur beizutragen habe, sondern dass jeder als Ganzheit antworte und einstehe. So pflegte Rabbi Mosche Leib zu sagen: „Es gibt keine Eigenschaft, die nicht eine Erhebung hätte. Und auch die Gottesleugnung hat eine Erhebung. Denn wenn einer zu dir kommt und von dir Hilfe fordert, sollst du nicht etwas tun und dann ein Frommer sein und $z u$ ihm sagen; ,Habe Vertrauen und wirf deine Not auf Gott', sondern da sollst du handeln, als sei kein anderer, der ihm helfen könnte, nur du allein."

Und noch eines wird geboten und gefordert, und dieses eine ist wieder nichts als ein Ausdruck des Mysteriums der Schiflut: helfen nicht aus Mitleid. das heisst aus einem scharfen, raschen Schmerz, den man bannen will, sondern aus Liebe, das heisst aus Mitleben. Der Mitleidige lebt nicht das Leid des Leidenden mit, er trägt es nicht im Herzen, wie man das 
Leben eines Baumes trägt mit allem Saugen und Treiben und mit dem Traum der Wurzeln und dem Begehren des Stammes und den tausend Fahrten $\operatorname{der} Z_{\text {weige, oder }}$ wie man das Leben eines Tieres trägt, mit allem Gleiten und Strecken und Greifen und allem Glück der Sehnen und Gelenke und der dumpfen Spannung des Gehirnes; er trägt dieses sonderliche Wesen, das Leid des Andern, nicht im Ferzen, sondern er empfängt von dieses Leides äusserlichster Geberde einen scharfen, raschen Schmerz, dem Urohmerz des Leidenden abgrundweit unähnlich, und so wird er bewegt. Es soll wber de lizende mitleben, und nur Hilfe aus Mitleben besterit ror den Augen der Seele. So wird von einem Zaddik erzählt, der, wenn ein Armer sein Mitleid erregte, erst ihn mit aller Notdurft versorgte, dann aber, da er in sich verspürte, dass die Wunde des Mitleids geheilt war, ich mit grosser, ruhevoll hingegebener Liebe in das Leben und Bedürfen des Andern versenkte, es in sich als sein eigenes Leben und Bedürfen fasste und in Wahrheit zu helfen begann.

Lieben heisst: das Bedürfen des Andern als sein eigenestiten und dennoch auch iex eigien Fülle gewahr werden, sie helfend ancumenten. Rabbi Mosche Leib erzählte: ,Ich habe die Liebe von einem Dorfmann gelernt. Der sass mit andern Bauern beisammen, und als sein Herz lebhaft war vom Weine, sprach er zu einem: ,Liebst du mich oder nicht? Und er antwortete ihm: ,Ich liebe dich gar sehr.' Sprach jener: ,Du sagst, ich liebe dich, weisst du denn, was mir fehlt? Liebtest du mich 
in Wahrheit, du würdest es wissen.' Da schwieg der andere und vermochte kein Wort zu sagen. Ich aber verstand: das ist die Liebe zu den Menschen, zu fühlen ihr Bedürfen und zu tragen ihr Leid."

Wer solcherweise miterlebt, der verwirklicht mit seinem Tun die Wahrheit, dass alle Seelen eine sind, denn jede ist ein Funken aus der Seele des Urmenschen, und sie ist ganz in ihnen allen. Und weil er die Einheit der Seelen mit seinem Tun verwirklicht, kann von keiner ihm ein Übel nahen. Denn wenn einer ihm Böses tut, sieht er es, als habe eine närrische Hand die Genossin geschlagen und habe nicht bedacht, dass sie eins sind und dieser Schwerz ihr Schmerz und dass das Herz, das ihn erfährt, eben das ist, das ihr eignes Leben trägt. Wie sollte er darob trauern oder gar zürnen oder gar auf Vergeltung sinnen? ,Wenn ein Mensch sich einmal im Irren einen Schlag versetzt, wird er nun einen Stock nehmen und die Hand schlagen, die ihn geschlagen hat? Es geschah $\mathrm{ja}$ aus mangelndem Wissen, und wie sollte er seinen Schmerz noch mehren wollen?"،

So lebt der Demütige, der der Gerechte und der Liebende und der Helfer ist: vermischt mit allen and allen unberührbar, der Vielheit ergeben und gesammelt in seiner Einzigkeit, vollziehend auf den Felskuppen der Einsamkeit den Bund mit dem Unendlichen und im Tale des quellenden Lebens den Bund mit den Irdischen, blühend aus tiefem Gelübde und allem Willen der Wollenden entzogen. Er weiss, 
dass alles in Gott ist, und grüsst die Boten wie vertraute Freunde. Ihn schreckt nicht das Vorher und Nachher, nicht das Oben und Unten, nicht das Diesseits und Jenseits. Er ist zu Hause und kann nie verstossen werden. Die Erde kann nicht umhin, seine Wiege, und der Himmel kann nicht umhin, sein Spiegel und sein Echo zu sein. 


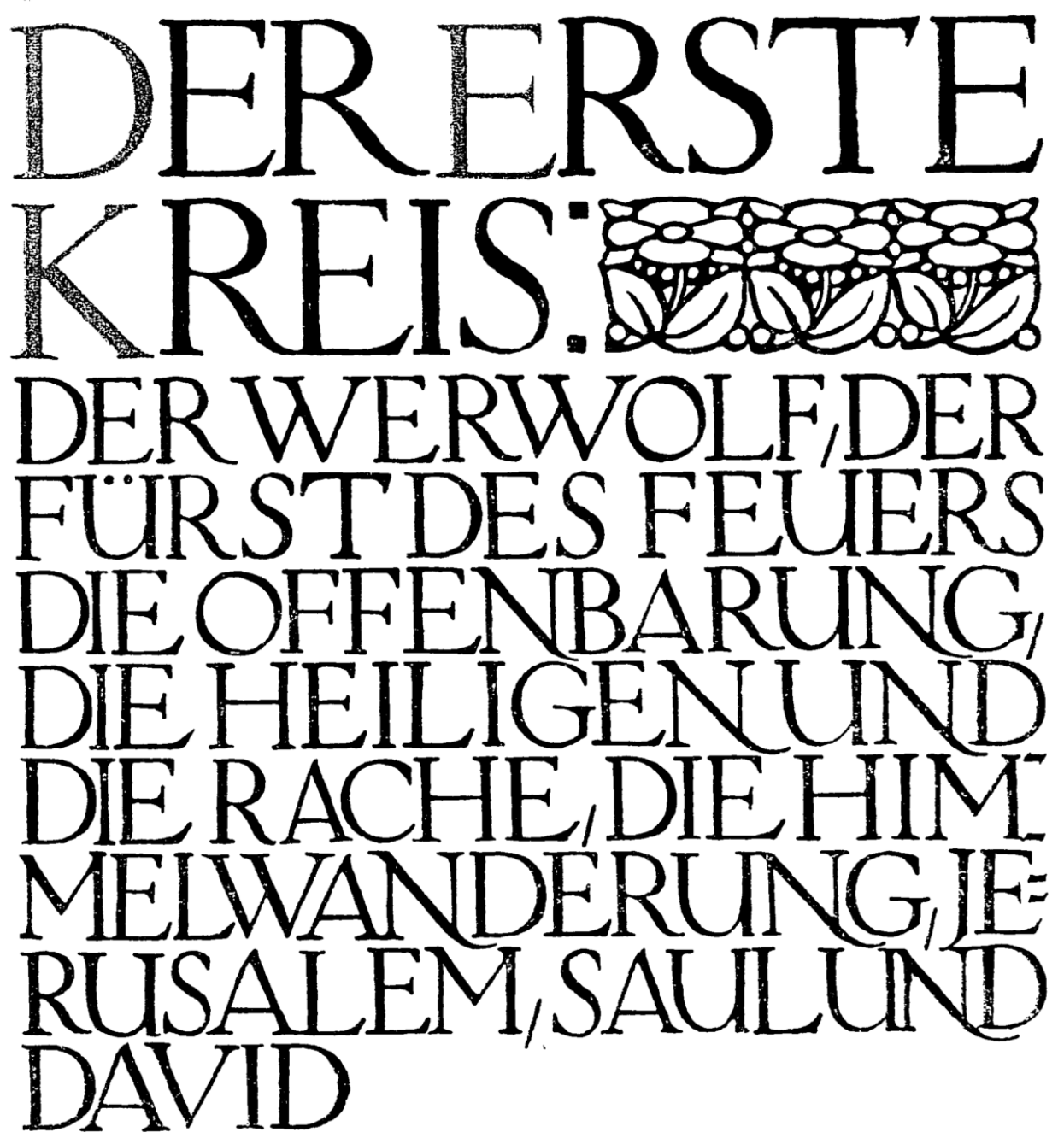




\section{DER WERWOLF}

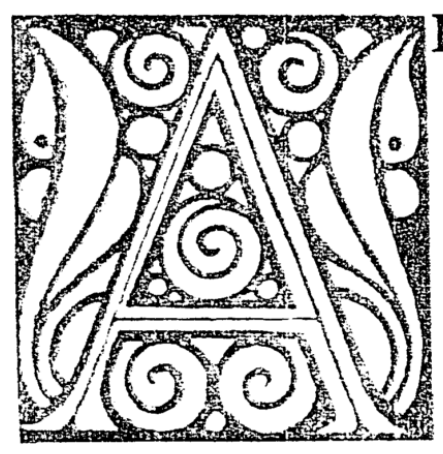

LS RABBI ELIESER, DEN VAter des Kindes Israel, das Sterben überkam, kannte er nicht Wehr noch Staunen, sondern liess dem Tod willig die Seele hin, die in vielen Erdenjahren der Wanderung und des Drangsals müde geworden war und nach dem Feuerquell der Erneuerung verlangte. Aber seine alten Augen, die mit Begier des vollendeten Bildes gewärtig waren, suchten doch noch wieder und wieder das blonde schmale Köpfchen des Knaben; und als ihm die lösende Stunde wie ein Ruf aller Tiefen erschien, hob er ihn noch einmal auf seine Arme und hielt ihn mit inniger Kraft: das selige Licht seiner letzten Wege, das ihm und seinem alternden Weibe so spät noch aufgegangen war. Er sah ihn eindringlich an, als wolle er hinter der hellen Stirn einen Geist aufrufen, der jetzt noch schlief, und sprach: „Mein Kind, er wird dir entgegentreten, der Dunkle, am Anfang, an der Vollbringung, an jeder Wende; im Gesichte des Schattens und im Gesichte des Lebendigen. Er ist die Schale, die du zerbrechen sollst. Er ist der Abgrund, den du überfliegen sollst. Er ist der Rest von dir. Er schliesst deinen Kreis, und du schliessest seinen Kreis. Es werden Zeiten sein, da du wie ein Blitz in seine letzte Verborgenheit niederfahren wirst, und er wird aufgehen vor deinen Gewalten wie eine dünne Wolke; und es werden Zeiten sein, da er dich umringen wird mit Fluten 
weichen Düsters, und du wirst einsam auf deinem Riffe stehen mitten im Meere seiner Nacht. Aber jene Zeiten werden zerreissen, und diese Zeiten werden zerreissen, und du wirst ein Sieger sein in deiner Seele. Und dieses wisse, dass deine Seele ein Erz ist, das keiner zersplittern und nur Gott verschmelzen kann. Darum fürchte den Dunkeln nicht, fürchte nichts und niemals!"

Das Kind las von dem welken Munde die Worte, und es war, als ob ein Unmündiger den grossen, strahlenden Becher leerte, der dem Manne bestimmt ist. Die Worte senkten sich ein und blieben.

Als Rabbi Elieser verschieden war, nahmen die frommen Leute der Gemeinde die Sorge um den Knaben auf sich, um der Liebe willen, mit der sie den Vater geliebt hatten. Und da es an der Zeit war, taten sie ihn in die Schule. Allein es begab sich, dass er der lauten Enge sehr abhold war; immer wieder entwich er und lief in den Wald, wo er sich zwischen Bäumen und Tieren vergnügte und in dem grossen grünen Gehege ohne Scheu vor Nacht und Wetter sich so sicher vertraut bewegte, als wäre es das Haus seiner Geburt. Wenn sie ihn alsdann unter eifrigem Ermahnen zurückbrachten, hielt er wohl einige Tage unter dem einförmigen Sprechgesang des Lehrers still, dann aber lief er wieder davon, entglitt leise wie ein Kätzchen und warf sich in den Wald. Nach einiger Weile erfanden die Männer, die um ihn sorgten, sie hätten des Betreuens genug getan, und ihre Mühen um den Wilden wären ganz und gar vergeblich. So liessen sie $a b$, und er blieb ungeschaut und unge- 
fragt und lebte mit dem stummen Werden der Kreaturen.

Als er zwölf Jahre hatte, verdingte er sich dem Lehrer als Behelfer, die Knaben aus dem Hause zur Schule und wieder heimwärts zu führen. Da sahen die Leute in dem stumpfen Städtchen etwas Wundersames geschehen. Ihre Knaben mit den schattenblassen Wangen und den zagen, altklugen Augen, mit dem müden Schritt, verwandelten sich. Israel führte Tag für Tag einen singenden und jubelnden $\mathrm{Zug}$ durch die Strassen zur Schule und führte ihn auf einem weiten Umweg über Wiese und Wald wieder nach Hause. Die Kinder senkten nicht mehr die kleinen, schweren Köpfe. Blumen und grüne $Z$ weige trugen sie in Händen und regierten die Welt.

$\mathrm{Da}$ entbrannte in ihnen die Andacht. Und so gross war die steigende Flamme, dass sie den trüben Qualm des Elends und der Verwirrung, der wie ein enger Panzer sich um die Erde presst, durchbrach und in die Himmel loderte. Und siehe, oben erglänzte ein ewiger, blühender Widerschein. Und die verlassene Gottesherrlichkeit hielt in der Irrfahrt inne und hob ihr schmerzensreiches Angesicht dem Licht entgegen, das war wie die rosenglühende Dämmerung eines kommenden Reiches.

Der dunkle Geist aber schwoll auf in Hass und Bangen und stieg, nächtig und schwer, stieg bis in die Himmel, und ein rauchfarbnerFlor umdüsterte die schimmernde Ahnung. Er redete mit harter Bewegung von dem, was da unten sich $z u$ ereignen begann, und wie er um sein Werk betrogen würde. 
Er schrie in wütiger Begier, kämpfen wolle er wider den allzufrühen Boten. Sein Schrei drang wie ein doppelt geschärfter Dolch ins Herz der Gottesherrlichkeit, das duldende Haupt sank wieder auf die Brust, und sie hob die leidvolle Hand zur gewährenden Geberde.

$\mathrm{Da}$ ging der Trübe von hinnen und stieg in sich selber hinab. Hier fand er die Bilder aller Wesen in bleicher und gespenstischer Leere : sie lebten nicht, aber sie schoben sich und drängten sich zusammen und gaben sich her und woben die tolle Erscheinung. So griff er nach ihnen, zog eins nach dem andern hervor und prüfte es, die einen mit gleichgültigem, die andern mit gelangweiltem, etliche mit einem zärtlichen und wohlgefälligen Blick. Die band er dann aneinander und mischte und knetete sie und erschuf aus ihnen ein hohles Ungeheuer, umstachelt von allem Entsetzen, mit der Fratze des Lebendigen. Und als ihn das Gebilde angrinste, nahm er sein eigenes Herz, Kern aus dem Kerne der Finsternis, und tat es in die Höhle des Tieres.

Als Israel die singenden Kinder wieder über die Wiesen führte, brach der Werwolf aus dem Walde und fiel in fahler Ungestalt und mit schaumtriefendem Munde unter die Schar. Einige der Knaben flohen in brennender Angst, andere sanken besinnungslos zusammen oder klammerten sich zitternd und stumm an Israel. Zwar entwich das Tier alsbald, aber viele der Kleinen lagen tagelang fiebernd und in wirren Träumen, und allen war das lichte Reich erloschen. Die Eltern bangten und waren bestürzt und ohne 
Rat und hielten die Kinder in den Stuben versperrt.

In Israel aber erwachten die Worte seines Vaters, wie ein Schläfer auf dem Felde erwacht, wenn die Schauer des Abends über ihn gleiten, und er schüttelte das Grauen ab. Und stark im gewonnenen Sinne ging er in die Häuser und sprach den Eltern zu, sie sollten ihm die Knaben wieder lassen, ohne Furcht und Sorge: er wolle sie vor dem Unhold bewahren. Und sein Wort war so hell im Laute und so schwingend im Mute, dass die Leute ihm nicht widerstreben konnten und keinen Willen mehr fühlten als den seinen.

Als er nun wieder mit der jungen Schar hinauszog, sprach er ihr zu, wie er den Grossen zugesprochen hatte, und noch anders, aus der umfangenden Wärme des brüderlichen Lebens, bis die Seelen sich weiteten und erstarkten. Als sie auf die Wiese kamen, hiess er sie stehen bleiben und ging allein weiter. Und wieder brach der Werwolf aus dem Wald, furchtbarer als zuvor, und blutiger Geifer troff ihm aus dem aufgerissenen Rachen. Aber der Knabe Israel ging ihm entgegen. Riesenhaft hob sich das Tier vor seinem Blick, es war ihm, als wüchse es in die Wolken und streckte seine Tatzen über die Fläche der Erde. Aber er ging weiter. Und nun stand er vor dem Leibe des Wesens, nun sah er nichts mehr, alles Bild ging unter, nun war kein Raum mehr zwischen beiden. Aber das Wort war wach in ihm wie der Stoss einer Flamme, und er ging weiter: ging in das Wesen 
hinein. Zuerst fühlte er rings um sich einen feuchten, totkalten Nebel, dann fühlte er nichts mehr, und dann fielen graue, schwere Flocken rings um ihn nieder, und zuletzt zerflossen auch sie und er stand in stiller Luft und ein Herz lag auf seiner Hand, das war dunkel und zitterte. Da griff er danach und umpresste es mit seinen Fingern. Aber als er dies tat, schrie eine dunkle Stimme auf und Tropfen eines dunklen Blutes fielen schwer zur Erde. Da löste er die Finger und sah das Herz an, und er sah es zittern. Und er verstand, dass es nicht aus der $\mathrm{Be}$ drängnis zitterte, sondern es war ein Krampf des Willens und des Verhängnisses von je und für immer. Da kam über Israel das grosse Leid, und er erbarmte sich des dunklen, zitternden Herzens, und es kam ihm, dass er es freigeben musste, gut oder böse, Herz des Satans oder Gottes Herz, um des Leidens willen. So legte er es auf den Boden, und die Erde schlang es ein oder es entschwand.

Für die Knaben aber kam nie mehr die lichte Zeit zurück. Mochten sie auch singen und jubeln, im innern Leben waren sie gebeugt, seit sie das dunkle Herz gesehen hatten. 


\section{DER FÜRST DES FEUERS}

LS RABBI ADAM, DER ZAUBERKUN-
dige, in hohen Jahren stand, fiel auf ihn
die letzte Sorge, wem er seine Schriften nach seinem nahen Tode anheim gebe. Denn in ihnen war der Weg zu jenen unaussprechlichen Gewalten verzeichnet, mit denen er zuweilen in das Triebwerk der Geschicke gegriffen und den Gang der Räder nach seinem Sinne befohlen hatte. Wohl war dem Meister ein Sohn geboren, allein der war nur seines Leibes Erbe und Blüte. Das war dem Rabbi in langen Jahren schmerzliche Erkenntnis geworden, und zwiespältig und bitter dünkte ihm an vielen Tagen seines Willens hohe Kunst, da dieses zu wenden ihr in Ewigkeit verwehrt blieb. $Z_{\mathfrak{u}}$ der Zeit, da sein Leben im hohen Sommer der schwellenden Seelenkraft stand, reckte er allnachts die Fäuste gegen den Himmel und haderte darob mit demUnnennbaren, der auf all sein verwegenes Weltenspiel mit einem Lächeln niedersah wie ein Mann auf eines Knaben kleines, keckes Unterfangen. Dann kamen die Jahre der Müdigkeit, da der Körper schwer und widerspenstig wurde und die Seele einsam $z u$ ihren steilen Wanderungen aufstieg, während der Leib bleiern und lastend der tiefen Schlucht des Schlafes verfiel. Und damals wurde sein Sinn milde, und er blickte um Versöhnung in die ewigen Augen, die über den Welten leuchten. Da hob er sich Nacht um Nacht im Traume und tat die aus Herzblut geborene Frage: „Wem, o Herr, lasse ich die 54 
Quellen meiner Gewissheit und meiner Mächte?" Und oftmals fragte er vergebens, und das Dunkel seines Traumes blieb wortlos. Aber in einer Nacht kam die Antwort und war über ihm: „Du sollst sie senden und zuteilen dem Rabbi Israel, dem Sohne des Elieser, der in der Stadt Ukop weilt."

In den Tagen, die alsbald kamen, fühlte er, wie die Schleier des leiblichen Vergehens ihn sacht umspannen. Er berief den Sohn in die Abgeschiedenheit seiner Kammer und öffnete die Lade, die die geheimnisreichen Blätter barg, darauf jedes Zeichen dem Vorbestimmten ein Schlüssel zu der Burg der Gewalten werden konnte. Indem der Alte zu sprechen begann, erhob sich der ferne Schmerz vergangener Tage noch einmal und drückte ihm die Kehle zu, so dass die Worte nur schwer sich ihr entrissen. Aber wie ein Ding, das dem Scheidenden nimmermehr ziemen will, tat er das Leid ab und gab dem Sohne die Weisung und sprach: „Bringe sie dem Israel, ihm gehören sie zu, denn die Wurzel seiner Seele ist ihnen eingeboren. Achte es für eine hohe Gnade, wenn er bereit sich weist, mit dir zu lernen, und halte dich $z u$ aller Zeit in Demut, dieweil du nur der arme Bote bist, erwählt, dem Helden das Schwert zuzutragen, das schweigsame Geister unter der Erde in vielen Gezeiten ihm geschmiedet und geschliffen haben".

Darnach, als eine kleine Frist dahin war, liess der Alte die Fesseln und Spangen, die Dauer und Ort hiernieden um ihn gelegt hatten, sacht von den dürftigen Gliedern gleiten und entschwand der Welt. Der Sohn, nachdem er des Vaters abgestorbenen Teil 
mit heiligen Ehren der Erde wiederum anheimgegeben hatte, trug in Treuen das letzte Geheiss, bestellte sein irdisches Gut und trat mit den Schriften des Toten die Reise nach Ukop an. Er war allezeit ein willig und fügsam Werkzeug in des Vaters machtreichen Händen gewesen, hatte des eigenen Willens fast ermangelt und seine Seele zum $Z$ ug nach oben derväterlichen überlassen, wie man wohl Nachen an Nachen kettet zur Fahrt den Strom entlang. Nun fristete sein Geist sich führerlosin Bangigkeit dahin, und unter manchem $Z$ agen wandte er es unterwegs im Bedenken, wie er es wohl bestelle, in Ukop jenen Israel zu finden, der seines Vaters Erbe und sein eigner Hort zu werden bestimmt war. Als er sodann die Stadt erreichte, begegneten ihm die Leute, da er sie wissen liess, dass er des Wundertätigen Sohn sei, in vielen Ehren, und er fand es leicht, unter ihnen offenen Auges zu leben, um den Erwählten der Macht zu suchen. Aber wie er sich auch umtat, bot sich keiner seinem forschenden Sinn dar, als der Knabe Israel, der vierzehn Jahre war und im Bethaus kleinen Dienst tat. Denn wiewohl dieser sich in harmloser und einfältiger Art anliess, wo er sich unter den Augen aller wusste, ahnte der Suchende in der Seele des Knaben eine heimliche Gnade, die von diesem Unmündigen in Einfalt gehütet und geborgen wurde. Daher beschloss er im Rate seines Herzens, dem Kinde nahe zu kommen. Dieses Sinnes begab er sich zum Vorsteher der Gemeinde und erbat sich von ihm einen stillen Raum im Bethaus, darin er, dem lauten Tag enthoben, der heiligen Weisheit in Frieden pflegen möchte. Desgleichen 
heischte er, dass man ihm den Knaben Israel zum Diener gewähre, damit er ihm zur Hand sei in all seinem Bedürfen. Der Gemeindevorsteher und die andern waren es wohl zufrieden und ersahen es für den jungen Israel als eine gar reiche Ehre, dem Sohn des Gewaltigen gesellt zu sein.

Der aber gab sich nunmehr das Gebaren, als sei er zutiefst in das Wesen der hohen Bücher versunken und achte alles Ereignis um ihn her nicht mehr und minder als einer Mücke Sonnentanz. Dessen war der Knabe sehr froh und liess nicht von seiner alten $\mathrm{Ge}-$ wohnheit, die also war, dass er allnachts sich zu erheben pflegte, um der Weisheit anzugehören und an die Feuerquellen des Geistes zu dringen, dieweil er des Tages mit kindischem Gehabe jegliches Wähnen täuschte, das sich etwa ob seines schimmernden Antlitzes erheben mochte. Der junge Rabbi aber hatte gleichwohl alsbald sein heimliches Wesen erlauscht und war der Gewissheit gewärtig. Eines Nachts, als der Jüngling erschöpft von der sehnsüchtigen Spannung seines Geistes sich auf sein Lager warf und seinem Alter gemäss einem tiefen Schlaf verfiel, erhob der andre sich, nahm ein Blatt aus den zauberreichen Schriften und legte es auf des Schläfers Brust. Darauf eilte er auf sein eigenes Ruhebett zurück und hielt sich lauschend stille. Nach einer Stunde des schweigsamen Harrens sah er, wie der Knabe erst unruhvoll sich wendete, dann noch schlummerbefangen nach dem Blatte griff, endlich wie von geheimnismächtigen Händen erfasst, sich aus dem Banndes Schlafes aufriss und beim Schein eines kleinen 
Öllichts, das des Nachts in der Kammer glomm, sich in die Schrift versenkte. Und dem Beschauer war, als würde der Raum heller und grösser, indem der Knabe las, und das Kind selbst wurde ihm fremder und heiliger, indem es strahlenden Angesichts seine Seele dem Zaubersinn des Blattes vermählte. Endlich gewahrte der Rabbi, wie ein Seufzer des Knaben Brust erhob und schier zu sprengen schien.

Israel barg das Blatt in seinem Gewande, und wie beladen von einer urgeheimen Last, taumelte er dem Lager aufs neue zu, der unduldsam heischenden Natur zu einem kurzen Schlafe gehorchend. Der Rabbi aber erlahmte seither niemals, seiner zu achten $z u$ allen Stunden, und als in einer zweiten Nacht sich das Geschehen der ersten wiederholt hatte, war er der Wahrheit inne. Nun zögerte er nimmer, rief den Knaben zu sich und eröffnete ihm die Sendung des toten Meisters. „Ich gebe dir ein Ding, das wenige Male im Gange unseres Sternes in vergänglichen Händen lag“, sprach er. „Siehe, nur wenige, die durch seinen Besitz mit ihrem Geist die obern Welten umspannten - und ihre Namen sind unvergessen -, hatten es vor dir zu eigen. Jahrhunderte versank es gleich einem verschwundenen Königsschatz, dann stieg es wiederum auf, mit dem Urstrom der Schauung und der Kraft einen menschlichen Geist zu tränken. Wisse, mein Vater war der letzte jener kurzen Reihe. Jetzt, nach einer Bestimmung, deren Ursprung mir verborgen ist, gehört es dir an, und willst du mir gnädig sein, um dessen willen, dass ich betraut war, dir das Kleinod zu bieten, 
so lass, wenn du über den Schriften verweilst, meine arme Seele die Luft sein, die dein Wort aufsaugt, das sonst ins Wesenlose entflöge." Und Israel antwortete: „Es soll so sein, wie du es sagst. Doch hüte das Schweigen, dass keiner um das Ding wisse, denn du und ich, und lass die äussere Gestalt unseres Lebens nicht anderen Schein gewinnen als bislang." Der Rabbi stimmte ihm bei. Damit aber ihrer Heimlichkeit mehr sichere Hut werde, beschlossen sie, das Bethaus zu lassen, und zogen in ein still entlegenes Häuschen vor der Stadt. Die Juden von Ukop achteten es als eine völlig unvermutete Huld, dass der Sohn des Rabbi Adam den Israel in den Schutz seines Geistes genommen hatte und ihn der Lehre teilhaftig werden liess, und da sie den Knaben nicht anders als des Heiles unbedacht wussten, meinten sie, dieses Glück könne nur so gedeutet werden, dass es um der Verdienste seines Vaters Elieser willen sich also fügen mochte, dass der gelehrte Mann an ihm Wohlgefallen gefunden habe.

Dermassen begab es sich, dass die beiden in eine Einsamkeit sanken, in der die Stimme der Erde zu Tode verstummt war und nichts Lebendes Gestalt gewann. Denn aus den Büchern des Rabbi Adam stieg ein Glanz auf und ein berauschender Atem des Geistes und die Süssigkeit aller Seelenmächte und nahm die Beiden so völlig ein, dass sie alles Leben um sich vergassen und dem Leib nur so viel von Speis und Trank vergönnen mochten, dass er die flüchtige Seele festhalte. 
Es war der junge Israel, der voll lauterer Fröhlichkeit, einem spielenden Kinde gleich, ganz ohne Hinterhalt und zweckbewussten Willen in die Tiefe der Schriften untertauchte und sein Herz in ihnen badete und sie nicht anders aufnahm, als ein Schwamm das Wasser aufsaugt oder ein Stein die Sonnenglut. Also ganz warf er sich ihnen hin und gab des Menschen Gier und Vernunft gänzlichen Urlaub. Der Sohn des Rabbi Adam aber hegte seinen scharfen Verstand und bedurfte eines Dinges, ihn alltäglich daran zu wetzen. Desgleichen war sein Willen ein gefrässig Tierchen und heischte sein Brot und wollte schlingen. Und so gefiel es ihm keineswegs auf die Dauer, ewiglich in der goldenen Luft der Entzückung zu verharren, da die Worte wie springende Strahlen kristallenen Flusses von dem Munde des Knaben kamen. Sondern er begehrte die Dinge zu drehen und im Kopfe zu erwägen, die seltsam genug aus den alten Büchern aufstiegen; und endlich die Macht zu schmecken, die in den Zauberformeln lag. Und in der Entbehrung dieser Dinge, die ihm nottaten und wohlgefielen, zog sich seine Seele zusammen und war eng und beklemmt und schaute ihm kümmerlich und zag aus den trüben Augen. Des ward der junge Israel inne und sagte eines Tages: „Bruder, mein Bruder! Was heischen deine Blicke? Was kannst du missen in diesen Tagen?" Da seufzte der Rabbi aus dem Grunde und gab ihm zurück: „,Knabe, wäre meine Seele also vom $Z_{\text {weifel }}$ und Wägen unversehrt wie die deine, also jung und heil wie ein 
Vogelei, ich würde mich wiegen wie du in dieser Zeiten Wonne. Aber siehe, was dir eingeht wie Honig und deinen Sinn zur Paradiesesruhe stillt, mir nagt und frisst es gleich einer beissenden Lauge an den Wunden. In mir sind viele Gedanken, die ewig kreisend mir niemals Rast vergönnen, in mir gehen $Z_{\text {weifel hin }}$ und wieder, die nimmer stille schweigen. Und in den Reichen ist nur einer, der mir Hilfe geben kann, und so du willst, der du nun des heischenden Wortes mächtig bist, so lass ihn uns rufen, den Fürsten der Thora."

Da erschrak der Knabe Israel bis auf den Grund seiner Seele, und alles empörte sich aus seinem reinen Wesen. „Durchbrich die Demut unseres Harrens nicht," rief er aus. "Noch blendet mich der Schein der Waffen, und noch winkt die Stunde nicht, sie zu brauchen."

$\mathrm{Da}$ versank der Rabbi schweigend und enttäuscht in sich. Sein Aussehn wurde scheel und gelb, also dass Israel sich heftig erbarmte um der edlen Nöte willen, von denen er wähnte, dass sie den Genossen versehrten. So besiegte er die eigene Scheu und hiess den Rabbi sich rüsten, dass sie gemeinsam sich $z \mathfrak{u}$ dem gefahrenreichen Wagnis bereiteten. Um die Kawwana der Seele zu erlangen aber, deren es bedurfte, den Wächter der Thora niederzuzwingen, war es geboten, von Sabbat Abend zu Sabbat Abend nicht Speise noch Trank zu geniessen noch irgend einem Gedanken oder einer irdischen Botschaft Zutritt zu verstatten, vielmehr in völliger Abgeschiedenheit und Reinheit zu verharren, die Seele 
gänzlich gelöst von jeglichen Banden. So rüsteten sie denn das Haus und versperrten Tür und Fenster, dass kein Menschenblick oder Wort sie hemme, ja kein Vogellaut und Sonnenschimmer eindringe. Alsdann tauchten sie in das heilige $\mathrm{Bad}$, alles Unreine von sich abzutun, hernach von Sabbat Abend zu Sabbat Abend lebten sie in Nichtachtung des Verlangens ihrer Leiber nach der Labung durch Speise, und endlich am Eingang der beschliessenden Nacht spannten sie ihre Seelen zur letzten Inbrunst, und Israel rief erhobenen Armes und zuckenden Mundes in der Angst des Vergehens die zwingende Formel in das starre Dunkel hinauf. $\mathrm{Als}$ er aber geendet hatte, stürzte er wie geschlagen zur Erde und schrie: „Wehe, wehe, mein Bruder! Du hast ein Irren in unsere Kawwana fliessen lassen. So ist ob der fehlbelasteten aus dem Munde des $Z$ ürnens ein Verhängnis ausgegangen, und schon fühl ich es die Luft in unserer Kammer zum Ersticken anfüllen. Ich sehe ihn, des Wächters Bruder und Nachbarn, den Fürsten des Feuers, wie er sich erhebt und die dunkelglühenden Schwingen zum Niedersteigen spannt, damit er sehrenden Brand und vernichtende Flamme über uns ergiesse. Wisse, wir sind in Todes Hand gegeben. Wenn unser Lid sich senkt, verfallen wir der feurigen Tiefe. Und es gibt nur eine Rettung: dass wir wachen und streiten ohne Unterlass bis zum Morgen." Sie warfen sich nieder und sammelten starke Worte in ihrer Seele und riefen den Geist zum Sturme auf, also dass das Herz in der Brust ihnen flatterte vor Ungestüm, und 
sie beschworen mutige Bilder vor ihr Auge, auf dass sie dem Träumen nicht verfielen. Eine weiche Glut umlagerte ihr Haus wie Sommermittags Atmen, und aus ihr stiegen süsse Lockungen der Ruhe auf und wurden stärker und sanft bezwingend wie Sommermittags Müdigkeit. Endlich konnte der Rabbj nimmer standhalten und lehnte das Haupt gegen die Mauer. Da umzuckte ihn ein tanzender Blitz, und ein unseliges Fieber riss ihn auf und warf ein Stammeln dunkler Lästerung aus seinem Munde. Und schon streckte er die Arme wider den Knaben, als wollte er ihn verderben, da kam der andere Blitz und fuhr ihm ins Herz, fein und leise, wie wenn's ein Sonnenstrahl wäre, und der Rabbi schlug starr zu Boden.

KAWWANA = Intention: die magische Spannung der auf ein Ziel gerichteten Seele. 


\section{DIE OFFENBARUNG}

M LETZTEN OSTHANG DER KAR.
pathen stand eine dunkle gebeugte Bauern-
schänke. Ihr schmaler Vorgarten mit den roten Beeten atmete der Macht der Berge zu, aber auf der Rückseite blinzelten die schiefen Dachluken zur weiten gelben Ebene hinüber, die im Licht wie in einem nährenden Segen lag.

Das kleine Wirtshaus war recht einsam. An den Markttagen kam wohl einiges Volk des Weges, Landleute und jüdische Händler aus den Bergdörfern, die ein Stündlein verweilten und einander zu glücklichem Kauf oder Verkauf zutranken; sonst aber kehrte nur selten ein Jäger oder ein verirrter Wanderer ein. Wenn ein Gast kam, wurde er von einer schlanken Frau mit braunen und heimlichen Augen in einer stillen Weise begrüsst und zum Sitzen eingeladen. Dann trat die Frau vors Haus, hob die Finger über den Mund und rief mit einer Stimme, die so hell war wie die hellen jungen Stauden vor dem Garten, einen Namen zu den Felsen hinüber: „Israel!"

Im vordersten Felsen, einen Steinwurf weit vom Hause, war ein Raum ausgehauen. Er war wie eine Stube mit vieler Sonne in der Tür und einem schweren Düster im Grunde, und wölbte sich wild und zackig auf, als hätten Träume und die Gewalten einer Seele wieder und wieder zu seiner Decke emporgeschlagen; $n a c h$ den Seiten aber zogen sich gesenkte Gänge in die Finsternis, in eines Menschen 
Höhe und Breite, als träte hier einer in Stunden der Nacht an das Reich der inneren Erde, Zwiesprach zu halten mit namenlosen Dingen. Die Stube war stumm und wehrte den Geräuschen; kam aber der helle Ruf der Frau herüber, dann trug ihn die Luft wie eine treue Dienerin zu dem, dem er galt. Und wo immer er war und ob er dem Dunkel des Grundes nahe lag oder dem Sonnenhimmel, auf den Ruf machte er sich auf, schritt zum Hofe und stand alsbald vor dem Gast, ihn zu bedienen. Dem Gast aber, dem er nahte, griff ein Schauer, wiewohl nicht unhold, ans Herz; und noch die Bauern und Händler, die den Mann von manchem Jahre kannten, erfuhren jedesmal von neuem eine Furcht und ein Ehren ob seines Anblicks. Denn so sanft sein Gruss und seine dienende Geberde war, er erschien ihnen in der Hülle eines strengen Glanzes und war den Bauern wie der Herr der Berge, den Juden aber wie eine ferne, grosse Erinnerung.

Er war dreissig oder mehr: die Jahre flogen zu ihm herbei wie Vögel mit starken Schwingen, und kamen zu ihm und brachten ihm in den Schnäbeln Körner des Geheimnisses, und flogen vorüber. Er sah ihnen nicht nach, er sah den kommenden nicht entgegen. Um ihn war das Warten: die Gipfel sahen auf ihn nieder und warteten, die Quellen blickten wartend zu ihm hinauf; er aber wartete nicht. Von diesen Jahren ist nichts erzählt, als dass er mit seinem Weibe, mit dem er lange im Elend gewandert war, am Osthang des Gebirges wohnte und den Wanderern diente. Aber die Höhle im 
Berge ist noch unzerstört: da kannst du die wilde Wölbung und die gesenkten Gänge lesen.

Doch ein Morgen erschien, da wurde ihm das Auge der Gipfel, das Auge der Quellen offenbar. Er erkannte, dass er in einem Warten stand und durch ein Warten ging. Die Erde seiner Höhle brannte, vom Eingang war die Stille, von den Wänden das Flüstern genommen: die Stimmen riefen ihn. Aus derWölbung donnerte ein Befehl, in den Gängen hallte sein Echo, die Stimmen waren irgendwo in einer Stimme gebunden wie die Strahlen in der Sonne.

Diesem Morgen folgte der Tag, und ihm viele Tage: der Befehl wuchs über dem Haupte des Mannes. Er fühlte die Stunde kommen, er hörte ihren Schritt in der Ferne. Er sah hinter sich wie in ein zertrümmertes Throngemach, er ging in die $T$ at seines Lebens wie in eine Dämmerung ohne Ziel.

Und wieder erschien ein Morgen, da hellte es sich ringsum, und das Wissen kam leise zu ihm, wie ein Kind sich von rückwärts zum Vater schleicht, die Arme um seine Schläfen und die Finger vor seine Augen zu pressen. Da schwieg der Befehl, das Schweigen erglühte, und der Baalschem löste die Stirn aus den umschlingenden Händen und schaute in die Welt.

An diesem Morgen fuhr Rabbi Naftali der Ebene $z u$. Er hatte südlich des Gebirges einen Freund besucht, und ob die Rückfahrt auch schon Tage währte, er war noch voll des Gespräches. In seinem Gedanken 
wiederholten sich Rede und Widerrede, aber reiner und mächtiger, als sie gesprochen worden waren, und fügten sich zueinander und zeugten neues und neues Wort und wuchsen in Geschlechtern der Rede. Und Rabbi Naftali wusste nichts anderes als das Gespräch in ihm. Es schlug in Zeichen durch die Wolken, in der Stimme des Windes waren seine Laute verstreut.

So kam der Wagen zu der kleinen Bauernschänke am letzten Hange. Da zerriss das Wort in Rabbi Naftali. Er erschrak und blickte auf. Da sah er das Haus mit dem hellen Vorgarten, und es kam ihn plötzlich an, er sei müde, ja er müsse wohl müde sein, da das Wort in ihm zerrissen sei. Er stieg vom Wagen und trat in das Haus. Die Frau begrüsste ihn, hiess ihn sich setzen, stand hoch, die Finger überm Mund, und rief $z \mathfrak{u}$ den Felsen hinüber: „Israel!" Und nach einem Augenblick sah Rabbi Naftali den Wirt in langen, festen Schritten herankommen und sich ihm mit einem gütigen Lächeln verneigen. Es war an Stirn und Augen zu sehen, dass der Mann ein Jude war; aber er trug Bauerntracht, den kurzen Schafspelz mit dem dicken bunten Gurt und die erdfarbnen Schaftstiefel, und sein langes lichtbraunes Haar presste kein Käppchen ein. Das verdross den Rabbi, und nicht gar freundlich sagte er ihm seinen Wunsch. Aber der Mann wahrte das Lächeln und die Demut der Haltung und diente dem Rabbi so fein und leise, dass es fast seltsarn schien, wie zart sich der grosse und offenbar starke Mensch bewegte. 
Als Rabbi Naftali eine Weile geruht hatte, rief er: „Israel, bereite mir den Wagen, denn ich will weiter fahren". Der Wirt trat hinaus, um den Befehl zu vollziehen, aber im Gehen wendete er sich halb und sagte lächelnden Angesichts: ,,Sechs Tage führen vom Anfang zum Sabbat - warum solltet Ihr hier nicht noch sechs Tage bleiben und bei mir Sabbat halten?" $\mathrm{Da}$ fuhr ihn der Rabbi an und hiess ihn schweigen, denn leichtfertiges Sagen war ihm widerlich. Und der Mann schwieg und bereitete den Wagen.

Als aber Rabbi Naftali weiter fuhr, war es ihm unmöglich, das Gespräch in seinem Geiste wieder anzuheben, sondern es erschien ihm wie ein zerrissenes Gespinst, das niemand ganz machen kann. Und er verwunderte und betrübte sich. Und da er sich dennoch mühte und nicht ablassen wollte, geschah es, dass sich seinem Auge alle Dinge verwirrten, und ein grosser Wirbel umfing ihn, also dass er im Wirbel dahinfuhr, inmitten verwirrter und durcheinander kreisender Dinge. Es hatte aber Rabbi Naftali bislang niemals die Dinge betrachtet, sondern es war ihm genug, ihre Gegenwart zu kennen und zu ertragen. Und nun zwang ihn der Wirbel, aufzuschauen, und er sah die Dinge der Welt, aber verscheucht von ihren Orten und verloren im Wirrsal. Es war ihm, als breche von unten eine wilde Tiefe herein, Erde und Himmel einzuschlürfen. Und über den Rabbi fiel der Schrecken nieder wie ein Würger, im Herzen des eigenen Sinnes spürte er den Wirbel schwellen, und er erfuhr die Finsternis. In dem 68 
gleichen Augenblick aber sah er einen riesenhaften Mann im Schafspelz und erdfarbenen Schaftstiefeln auf den Wagen zuschreiten. Der Mann ging leichten Fusses durch die Verwirrung und schob die jagenden Kreise der Zerstörung sacht zur Seite, wie ein Schwimmer friedsame Wellen. Dann nahm er die $Z$ ügel und wandte mit einem starken Ruck die Pferde, die sogleich den Weg, den sie gekommen waren, mit verdreifachter Schnelligkeit zurückzulaufen begannen, so dass sie nach kurzer Zeit wieder an der Bauernschänke standen. Dem Rabbi Naftali waren Angst und Qual mitsamt der Verwirrung im $\mathrm{Nu}$ verschwunden, als sei all dies nie gewesen. Er verstand nicht, was ihm widerfuhr, aber keine Frage war in seinem Sinne. Als er vom Wagen stieg und wieder in den Vorgarten trat, in dessen Mitte jetzt der zum Mahle gerüstete Tisch stand, begrüsste ihn wieder die schlanke Frau mit freundlichem und unbewegtem Angesicht, wieder rief sie zu den Felsen hinüber, und wieder stand der bäurische Mann vor ihm und verneigte sich, nicht anders, als wenn er ihn zum erstenmal sähe.

Eine lange Zeit war die Weihe des Unbegreiflichen über der Seele des Rabbis. Als er aber Stunde für Stunde um sich die Dinge in der gewohnten Art und im geordneten Treiben aller Tage sah, und den Wirt damit beschäftigt, die Wanderer zu bedienen und ihre Pferde zu tränken, edleren Gebarens wohl, aber sonst ganz so wie irgend ein kleiner Schankpächter des Landes, begann er den Geschehnissen nachzusinnen. Und wie stets vor diesem Tage, 
so waren ihm nun auch wieder seine Gedanken zu Willen, so dass er bald in sich die Einsicht geformt und gefestigt hatte, hier habe nichts als ein Trug seiner in der scharfen Luft der Berge ermatteten Augen oder seines vom Hin und Her des neugeschaffenen Gesprächs überwältigten Sinnes gewaltet. So beschloss er, über Nacht in der Herberge zu bleiben und alle Müdigkeit auszuschlafen, am Morgen aber weiter zu ziehen.

Als der Rabbi am nächsten Tage wieder auf der Fahrt war, musste er über die gestrige Torheit hell auflachen. Schön und stark geflochten lag der Kranz der Kreaturen um ihn her, jede an ihrem Orte wachsend und gesichert. Er fühlte, er sehe sie nun zum erstenmal in ihrer Wahrheit, und war dessen froh und hatte einen jungen Mut in seinem Schauen und verwunderte sich über sich selber. Wie glückselig war diese Freiheit und Zuversicht der Wesen im Raume! Aber während er dergestalt staunte und sich freute, geschah es, dass er den Blick zum Himmel hob, und er entsetzte sich, und ein Grauen erschlug seine Freude. Denn statt des leichten, vieltönig blauen oder von mannigfaltigem Grau durchzogenen Gewölbes, das ihm von gleichgültiger Gewohnheit des Sehens vertraut war, spannte sich eine erzene Feste hart, schwer, aller Fugen und Lücken bar, über der Erde. Und als er erbebend niederblickte, merkte er, dass keines der Dinge in Freiheit und Zuversicht stand, sondern gefangen und siech wuchsen sie an ihren Plätzen, und die sich regten, schlichen wie in einem weiten, aber dumpfen Käfig 
umher. Und es erschien Rabbi Naftali, auch er selber sei gefangen, in einen ewig unentrinnbaren Kerker gebannt, und er verfiel einer Trauer, aus der ihn nicht sein Gedanke und nicht seine Gewissheit Gottes emporzutrösten vermochte. Aber da er im tiefsten Schachte der Trauer lag, wurde sein Blick wach, und da er aufsah, da war am Firmament das Wandeln eines Mannes. In erdfarbnen Schaftstiefeln ging er am Himmelsrund hin und rührte hier und hier leise an die eherne Decke. Und wo sein Finger sie traf, da lockerte und löste sie sich, und es war wie ein Schmelzen und wie ein Aufgehen. Der Finger schlug Bresche auf Bresche in die Feste, und das leichte Blau strömte herein. Zuletzt zerfloss die ganze starre Wölbung, und das weiche Lichtgewebe breitete sich wieder über dem Gesichtskreis, wie es sich den Menschenaugen an allen Tagen zeigt. Und darunter atmeten alle Kreaturen tief auf, und noch das verschlafene Gewürm schüttelte sich, als würfe es Fesseln ab. Und mit den andern allen atmete Rabbi Naftali auf und atmete die Freiheit ein wie die Luft des Lebens. Er sah zum Himmel empor und suchte den Wundermann, aber der war verschwunden. Da fasste den Rabbi wieder das Geheimnis an, er wandte den Wagen und trieb die Pferde, bis er wieder an der Bauernschänke stand. An der Schwelle trat ihm der, den er suchte, mit dem alten Gruss entgegen, ohne Frage in Wort und Geberde; aber der Gruss dünkte dem Rabbi liebreicher als am Tage zuvor. Darum zwang er alles Bedenken und sprach: „Israel, was ist dies für ein 
Ding mit dir, dass ich dir in seltsamer Weise auf meinen Wegen begegne?" $D_{a}$ hob der andere den Blick und lächelte. Und das Lächeln war nicht nach Menschenart, sondern wie eines Sees, der $z$ wischen Felsen ruht, schmerzliches und nachsichtiges Lächeln aus seinem Grunde herauf, wenn die Abendsonne ihn streichelt und spricht: ,Nun gebe ich dich dir zurück" - aber der See lächelt und antwortet: „Mir?" So lächelte der Mann und antwortete: „Mir?“" Und der Rabbi wollte nicht weichen, sondern weiter fragen: aber da fühlte er, dass sein Mund verschlossen war, denn das Lächeln des andern hatte ihn getroffen. So blieb er schweigsam und der Fragen voll. Von dannen konnte er nicht mehr, und das Bleiben brachte ihm Stunde um Stunde neue Ungewissheit und neuen Seelenstreit. Die Nacht kam und war wie der Tag, nur langsamer, und so, dass jede Unbegreiflichkeit sich in ihr noch vertiefte. Am Morgen erst löste ihm der Schlaf die Seele, und sie empfing einen Traum. Und der Traum, den der Rabbi träumte, war der Anbeginn der Schöpfung. Das Licht schied sich von der Finsternis, und die Feste ward zwischen den Wassern. Und Rabbi Naftali erschien es, als sei das Wirrsal, aus dem geschaffen wurde, seine Seele, und als sei sie die gesichtlose Tiefe, aus der Himmel und Erde hervorsprangen. Und er spürte die knetende Hand des Geistes.

$\mathrm{Als}$ er erwachte und vors Haus trat, war er der Ungewissheit frei. Alles schien ihm einfach und bestimmt, und er umfing die Welt mit den Augen 
wie mit Armen der Seele. Es war ihm, als sehe er die Dinge nicht aus der Ferne seines Leibes, sondern aus ihnen heraus und wie ein Ding sich selber sieht, wenn es vor den Wegen des Lebens erschrickt und sich besinnt und sich in sich anschaut. Und er sprach zu sich: „Ich weiss es nun. Es gibt Zeiten, da der Wirbel über die Welt stürzt und ihre Fügung zerbricht, und Licht und Finsternis sind nicht mehr geschieden, und die Kreaturen haben ihren Ort verloren und schwirren im Raume umher. Und es gibt Zeiten, da der Himmel die Erde gefangen hält, und die Feste, die nur sondern sollte, bannt und bindet die Kreaturen. Aber ist all dies nicht eine Spieglung und ein Spiel der Zeit? Denn nun sehe ich: ein Glück ist über den Dingen und eine Freude. Mitsammen leben die Dinge, ungestört von Wirbel und Bann, und gehen aufrecht durch den Zorn der Gewalten und verharren. Und jedes wirkt das Seine aus seinem Herzen in die Welt, und hat in seiner $T$ at die Freude, und hat aus seinem Werk die Glückseligkeit. Kein Wirbel kann den Kranz des Tuns zerreissen, der die Wesen umschlingt und einigt. Kein Bann kann die Liebe fesseln, die vom Wesen zu seinem Werke geht. Unüberwindlich in ihrem Glück ist die Schöpfung, die selige Welt der schaffenden Dinge." Als der Rabbi also $z u$ sich selber sprach, schloss er die Augen vor Glück, und eine stille Weile ging über die Welt hin. Und die Weile wurde immer stiller, bis die Stille so tief war wie ein Schauer der Seele. Da öffnete der Rabbi die Augen. Und das erste, was 
er sah, war das Zusammensinken eines ungeheuren Schleiers. Dann lag die Welt vor ihm wie ein Abgrund. Und in dem Abgrund war das Aufgehen der Sonnenscheibe wie eine stumme, langsame Qual, und das Wachsen vieler Bäume und Kräuter wie ein ewiges, schmerzensvolles Zucken, und das Laufen und Hüpfen und Fliegen vieler Tiere wie ein sinnloses Jagen und Suchen. Und jede Kreatur litt, dass sie tun musste, was sie tat, und kam nicht los und keuchte in ihrem Leide dahin. Es war aber also: alle Dinge standen in dem Abgrund, und doch war der ganze Abgrund ohne Schranke $z w i s c h e n$ jedem Ding und dem andern, und keines konnte zum andern hinüber, ja keines konnte das andere sehen, denn der Abgrund ohne Schranke war zwischen ihnen.

Und dieser Blick des Rabbi war nicht wie ein Gesicht, das schauend du, wiewohl davon besessen, doch ahrist, es werde jetzt oder später, irgend einmal vor deinem Tode schwinden und nicht mehr da sein. Sondern es war ihm, als sei er all seine Zeit in einem Trug gegangen und sehe nun erst die Wahrheit und das Leben; und als würde ihm, möchte er auch bis zum Zerfall der Welt dauern, niemals ein anderes Bild erscheinen als dieses. Und dieser Blick nahm dem Rabbi mit einem Griff, was er gewonnen hatte in der Stunde davor und in allen Stunden, und sein Herz schwankte, halb gezogen, sich gegen Gott zu erheben, und halb, mit Gott zu leiden.

Aber in dem Augenblick, da Rabbi Naftali dieses geschah, gewahrte er, dass ein Mann im Abgrund 
erschien, der war ihm vertraut von Gestalt und von Angesicht. Und der Mann war hier und überall, und hatte Flügel und vielfältiges Sein und überspannende Gegenwart. Denn sein Mund war an das Ohr der Sonne gelegt und sprach zu ihr, und sein Arm war um den Leib der Bäume geschlungen, und das Getier schmiegte sich an seine Knie und die Vögel an seine Schultern. Siehe, da war der Trost in die Welt gekommen. Denn durch den Helfer waren die Dinge verbunden und sahen und kannten und fassten einander. Und die Sonne litt nicht mehr, denn sie schaute, was sie schuf und wem sie es schuf. Und was wuchs, wusste, wem $z u$ es sich regte, und was lief, wusste, wen es suchte. Und alles war in allem, denn die Dinge erfuhren den Helfer und sahen einander durch sein Auge und berührten einander durch seine Hand. Und da die Dinge zu einander kamen, war kein Abgrund mehr, sondern ein lichter Raum des Schauens und Umfangens, und eine tiefe Welle aus Sinn und $\mathrm{Ziel}$.

*

Diese waren die drei ersten Tage. Und ihnen folgten die drei andern, und an jedem weitete sich Rabbi Naftali der Weg, und er erkannte die Schöpfung. Aber in dem Häuschen am Berghang blieb das Leben, wie es war, und der Wirt blieb der Gleiche im Gang und in der Geberde. So war dem Rabbi seine Welt wie ein Pendelschlag, und ewig wechselten ihm das Wunder der Ferne und das Wunder der Nähe. Er wagte kein Wort mehr, keinen fragenden Blick: er lebte und wartete. 
So kam der Sabbatabend heran. Mit schlichtem und demütigem Wort sprach der Wirt den Gruss an die heilige Braut, und hielt das Mahl in Treuen nach frommer, ungelehrter Männer Art. Naftali sah von einer Weile zur andern zu ihm hin und erwartete, er wusste nicht was für ein Geheimnis und Heil. Aber nichts geschah, und er wartete noch immer, als der Wirt schon den Tisch gesegnet hatte, und wartete noch, als er sich erhob, dem Gast die Hand entgegenstreckte und ihm den Frieden wünschte für diese Nacht und für alle $Z$ ukunft sines Lebens. In der Nacht fand der Rabbi keinen Schlaf. Aller Wille dieser Tage war $z u$ einem grossen Rauschen über seinem Haupte geworden, und es war ihm, als müssten hier und jetzt das Wunder der Ferne und das Wunder der Nähe zusammenfliessen.

Mitten in der Nacht kam der Befehl zu ihm, lautlos, ohne Erscheinung. Er stand auf und ging. Da war er auch schon in der andern Kammer und sah.

Und sah: die Kammer war bis zur Manneshöhe von Flammen erfüllt. Stumpf und dunkel stiegen die Flammen auf, als zehrten sie von einem Schweren, Unbekannten. Kein Geräusch und kein Rauch gesellte sich dem Brande, und jegliches Gerät blieb unversehrt. Mitten im Feuer aber stand der Meister mit erhobener Stirn und geschlossenen Augen.

Und weiter sah der Rabbi: eine Scheidung geschah in dem Feuer, und es gebar ein Licht, und das Licht war wie eine Decke über den Flammen. Und das Licht war zwiefach. Unten war es bläulich und gehörte dem Feuer an, aber das obere Licht 
war weiss und unbewegt, und es breitete sich um das Haupt des Meisters bis an die Wände. Und das bläuliche Licht war der Thron des weissen, und das weisse ruhte auf ihm wie auf einem Throne. Und das bläuliche Licht wandelte unablässig seine Farbe, zuweilen zu Schwarz und zuweilen zu einer roten Woge. Aber das weisse oben wandelte sich nie, es blieb immer weiss. Und das bläuliche Licht war ganz in das Feuer gebettet, und das Fressen des Feuers war sein Fressen. Aber das weisse Licht, das auf ihm ruhte, verzehrte nicht und hatte keine Gemeinschaft mit der Flamme.

Und der Rabbi sah: das Haupt des Meisters stand ganz im weissen Licht. Und die Flammen schlugen am Körper des Meisters empor. Aber welche der Flammen emporkam, wurde zu Licht, und von Weile zu Weile wurde mehr des Lichtes.

Und der Rabbi sah: alles Feuer war zu Licht geworden. Und das blaue Licht begann ins weisse einzudringen, aber jede Welle, die eindrang, wurde selber weiss und wandellos.

Und der Rabbi sah, dass der Meister ganz in weissem Lichte stand. Aber über seinem Haupte ruhte oben ein verborgenes Licht, das war aller Farben und allen Blickes bar und nur im Geheimnis offen dem Schauenden.

Und der Rabbi fiel nieder. Denn er erkannte den Menschen und das Ziel des letzten Tages.

*

Als der Morgen kam, feierten sie den hohen Sabbat mitsammen. 


\section{DIE HEILIGEN UND DIE RACHE}

\section{LS DIE MACHT DES BILBUL ÜBER DIE}

Stadt Pawlicz kam und der Triumph der Lüge einherfuhr, flohen aus allen Orten der Gegend die Juden vor der drohenden Vernichtung in die Weite. Aber einige fromme, alte Männer wollten sich nicht bewegen lassen, von dannen zu ziehen. Sie sprachen zu ihren Seelen: „Wie eine lange eingedämmte Schleuse ist dieses fremde Volk. Es will uns schlagen, um seine Kraft zu schmecken. Aber wie lange sind wir selbst wie eine eingedämmte Schleuse gewesen und konnten Gott nicht dienen nach unserem Sinne! Von Geburt auf war unser Leben ein gestörter und entweihter Gottesdienst. Denn hier ist die Welt eng und dumpf, und wir haben keinen Raum, dem Herrn zu jubeln, und wir atmen eine Luft, die nicht des Herrn ist. Einst war die Miazo das Werk unseres Feldes, und die Kraft unserer Hände lebte in unserem Felde und diente Gott. Aber jetzt kommt die Mazo zu uns aus der Erde der Fremden, die unser Feind ist. Einst war der Esrog die Lust unseres Gartens, und der Herzschlag unserer Freude lebte in unserem Garten und diente Gott, Aber jetzt kommt der Esrog zu uns wie ein Gast aus einem sehr fernen Lande, das wir nicht schauen werden. Und in diesem fernen Lande sind die Wurzeln unseres Gebetes geblieben. Nun sprechen wir dieWorte, aber sie haben keineWurzeln, und wie könnten sie da zu Gott emporwachsen? Es ist uns nicht gegeben, dem Herrn mit unserem Leben 
zu dienen. So wollen wir ihm mit unserem Tode dienen und ausharren zur Heiligung seines Namens." Also sprachen sie und liessen sich in Gewahrsam nehmen und warteten in Freuden, dass sie getötet würden.

Aber einer war nicht mit ihnen geblieben. Das war der Rabbi von Koraczow. In jungen Jahren hatte er ein Buch begonnen, in dem gesagt wurde, wie man Gott dienen könne mit seinem Leben. Er hatte streng und hart gelebt und alle Kraft und alles Verlangen und allen Gedanken in das Buch getan. Wenn er irgend etwas träumte und wollte, nahm er seinen Traum und seinen Willen wie einen Stein in die Hand und legte ihn auf die andern, dass sein Bau zu Gott emporwachse. So fügte sich ein Teil des Buches langsam zum andern. Es war aber alles darin so angeordnet, dass ein Aufstieg waltete von niederen Stufen des Dienstes zu immer höheren. Und so oft er daranging, von einer neuen Stufe zu reden, bereitete sich der Rabbi in grosser Glut der Seele und lebte in Sammlung alle Tage, bis er in seine Kammer ging, um zu schreiben. Da sass er dann und tat sein Werk, und keiner durfte ihn rufen und zu Speise und Trank oder zum Schlafe mahnen, bis er vollendet hatte, von der Stufe zu reden. Und er sprach $z$ u keinem von seinem Buche. Als aber der Bilbul dahergezogen kam, unterredete sich der Rabbi mit seiner Seele, und es war ein tiefes Zwiegespräch durch viele Stunden in der stillen Kammer. Und das Buch, das bis zur höchsten Stufe gediehen war - von dieser aber war noch 
nicht begonnen $z u$ reden -, lag auf dem Tische, und er sah es nicht an. Zuletzt aber kam sein Blick und ruhte auf dem Buche. Und er erhob sich und nahm das Buch und machte sich auf, nach der Wallachei zu fliehen.

Als der Rabbi auf seinem Wege nach Miedzyborz kam, hiess ihn der Baalschem bei ihm bleiben, bis er ihn entlassen würde. Und er blieb beim Baalschem. Und dieser sprach zu ihm: „Die Heiligen werden errettet werden" und wiederholte es Mal für Mal. Aber am Vorabend des Sabbat kam ein Brief zum Rabbi; darin stand, wie sie gepeinigt worden waren mit allen Arten der Todespein, und wie sie in Qualen und grosser Freude dahingegangen waren zur Heiligung des Namens. Als der Baalschem den Brief gelesen hatte, ging er Mincha beten und zitterte, und wer ihn ansah, musste zittern. Und einer sprach zum andern: ,Wenn erst die Stunde kommt, den Sabbat zu empfangen, wird die Freude gewiss zu ihm heimkehren. Denn was immer ihm je widerfuhr, noch nie hat er den Sabbat ohne Freude empfangen." Aber die Stunde kam, und der Baalschem empfing den Sabbat in grossem Zittern und hielt den Becher in einer zitternden Hand. Und sogleich ging er von dannen in die Stube, in der er zu schlafen pflegte, und legte sich auf die Erde, das Gesicht zum Boden und die Arme von sich gestreckt, und lag so eine lange Zeit. Und da das Hausgesind und die Gäste auf ihn warteten, kam sein Weib in die Stube und sprach: „Die Lichter werden schon ausgehen." Er sprach: „Lass die Lichter 
ausgehen und schicke die Gäste heim." So ging sie, er aber lag immer noch auf der Erde.

Aber der Rabbi konnte es nicht länger ertragen, denn sein Herz brannte. Und er ging zu der Stube des Baalschem und lauschte, aber es war sehr still in der Stube. Und er ging an die Tür und sah durch eine Spalte der Tür und schaute in das Dunkel. So stand er und stand bis zur Mitternacht. Da kam ein grosser Lichtschein in die Stube. Und der Baalschem rief: „Gesegnet sei, der da kommt, Rabbi Akiba!" Und jeden der Heiligen grüsste er bei seinem Namen und rief: „Gesegnet sei, der da kommt!" Sodann sprach er zu ihnen: ,Ich verhänge es über euch, dass ihr Rache nehmet an den Widersachern. An dem Senator, der euch foltern liess. An den Knechten, deren Hand bereit war zu eurer Qual. An dem Volke, dessen Mund jauchzte vor eurem Leide." Da tönte durch den Raum ein dunkler Chor und war doch wie Eine Stimme, die sprach: „Wir bitten dich, dass dieses Wort nicht noch einmal von deinen Lippen gehe." Er aber wiederholte: „Ich verhänge es über euch." Und wieder sprachen die Heiligen: "Wir haben unsern Tod gern gelitten!" Aber der Baalschem stand mitten im Lichte wie eine rote Flamme und schrie, und sein Wort war wie das Rauschen gewaltiger Flügel: „Für das Schlagen und Stechen, für das langsame Morden, für die Schändung durch ihre Hände, für den Stoss ihrer Füsse, für das Ducken und Erniedrigen, für das Spotten und Spielen, für die Knechtschaft der Jahrhunderte, für die Not des Schlechtwerdens nehmet 
Rache." $\mathrm{Da}$ war eine Bangigkeit und ein Beben in der Choresstimme, als sie sprach: "Wir bitten dich, dass das Wort des Verhängens nicht zum dritten $\mathrm{Mal}$ von deinen Lippen gehe. Denn du sollst wissen, dass du an diesem Abend den Sabbat der Welten gestört hast. Siehe, es ward ein grosses Gewirr, und wir wussten nicht, was das sei. Und wir stiegen zu höheren Kreisen auf, und auch da war das Gewirr, und wir wussten nicht es zu deuten. Und als wir zu einem gar hohen Kreise kamen, wurde zu uns gesprochen: ,Gehet eilig hinab, machet still die Tränen des Rabbi Israel Baalschem.' So wollen wir es dir denn erzählen. Du sollst wissen: alle Schmerzen, die ein Mensch leidet in seinem Leben, sind ein leichter Tand gegen die Schmerzen, die wir gelitten haben zur Heiligung des Namens, gesegnet sei er. Und der böse Trieb kam über uns und wollte unsern Sinn beugen, und wir stiessen ihn mit beiden Händen hinweg. Aber es gelang ihm, mit einer Fingerspitze einen Gedanken in uns zu berühren, und er machte ein Zeichen an dem Gedanken. Um dieses Dinges willen ward uns bestimmt, für einen Augenblick in das Tal Hinom zu kommen und einen Augenblick lang die Not der Welt zu leiden. Und alle Schmerzen, die wir gelitten hatten, erloschen und waren wie leichter Tand vor diesem Leide. Und als wir in den Garten Eden kamen, sprachen wir: ,Wir wollen Rache nehmen für die Knechtschaft der Jahrhunderte, für die Not des Schlechtwerdens, die dem bösen Trieb Macht gegeben hat, unsere Gedanken zu berühren. Für 
den Raum, in dem wir gewohnt haben, für die Luft, die wir eingeatmet haben, für den gestörten und entweihten Gottesdienst unseres Lebens wollen wir Rache nehmen.' $\mathrm{Da}$ wurde uns geantwortet: ,Wollt ihr Rache nehmen, so müsset ihr in neue Körper eingehen und auf die Erde zurückkehren und noch einmal als Menschen ein Leben zu Ende leben. Wir aber sprachen: ,Wir loben den Herrn, gesegnet sei er, und danken ihm, dass wir bestanden haben zurHeiligung seines Namens, und dass wireinen Augenblick lang das grosse Leid im Tale Hinom gelitten haben. Heute aber, sollen wir auf die Erde zurückkehren, wo wir keinen Raum haben, dem Herrn zu jubeln, und wo wir eine Luft atmen, die nicht des Herrn ist, so kann es fürwahr geschehen, dass wir schlechter werden und die Macht des Bösen erhöht wird. Wir wollen nicht zurückkehren.' Also sprachen wir. Und so bitten wir dich, dass das Wort des Verhängens nicht zum dritten Mal von deinen Lippen gehe." $\mathrm{Da}$ schwieg der Baalschem und sprach kein Wort. Und der Lichtschein schwand aus der Stube, und das Dunkel erfüllte sie. Aber der Baalschem lag auf der Erde wie eine rote Flamme.

Der Rabbi von Koraczow aber hat sein Buch nicht vollendet. Ja, es weiss kein Mensch, was daraus geworden ist.

BILBUL $=$ Verwirrung, Verleumdung, hier Ritualmord-Be. schuldigung. $\mathrm{MAZO}=$ das ungesäuerte Brot, das am Osterfeste zur Erinnerung an den Auszug aus Aegypten gegessen wird. 
ESROG $=$ der $z u$ religiösen $Z$ wecken am Laubhüttenfeste benützte Paradiesapfel. MINCHA $=$ Nachmittagsgebet. TAL HINOM $=$ Hölle.

Rabbi Akiba, der den Zug der Märtyrer führt, ist der grosse Meister des Talmuds, der unter Hadrian den Foltertod erlitt.

Die kleine Stadt Miedzyborz in Podolien war der endgültige Wohnsitz des Baalschem.

Zur Heiligung des Namens (des Gottesnamens) = zum Ruhme Gottes. 


\section{DIE HIMMELWANDERUNG}

\section{TAGE DIENT ER DEN KREATUREN.}

Auf den Winden kommen Boten gefahren, bittende Herolde steigen aus dem Boden auf. Zusammengeflutet aus dem Munde alles Lebendigen, dringt die Stimme des Leidens zu ihm.

Er empfängt den Ruf und teilt die Antwort aus. Unablässig gibt er seine Gabe, den tiefen Trost. Unter der Berührung seiner Finger heilen die Wunden der Welt.

Am Tage dient er den Kreaturen. Aber am Abend löst sich seine Seele. Sie will nicht bei dem trägen Genossen ruhen. Sie streift Ort und Dauer wie zwei Handfesseln weg und enthebt sich den Grenzen. Sie stösst das Land mit dem Fusse ab, sie prüft den Flug, und die Himmel nehmen die Freigelassene auf.

In den Himmeln ist nicht Ort und Dauer, nur Weg und Ewigkeit. Jede Nacht führt die Seele weiter im Wege, tiefer in die Ewigkeit.

Aber eine Nacht kommt, da steht eine Weltenwand vor der Seele auf und deckt ihr Bahn und Blick. Schrankenlos wie der Flug war, ist die Hemmung. Der Weg stirbt. Ein dunkler Finger hat das Licht aller Sterne und die Verheissung aller Himmel ausgelöscht. Über dem toten Weg reckt sich eine dunkle Wand randlos in die Nacht.

Und die Wand hat ein Gesicht, ungeheuer und schattenhaft, doch scheint es der Seele näher als ihr eignes Auge. Und die Seele erkennt es: es ist 
das Angesicht des Lebens, das sie am Abend verlassen hat und in das sie am Morgen zurückkehren will wie in ein wartendes Bett.

Aber jenseits der Wand erwacht ein Laut, eine grosse Stimme in der Finsternis. $E_{s}$ ist, als stünde drüben der tote Weg auf und redete.

Und die Stimme der Verborgenheit spricht:

"Seele, verlangende Seele, Seele der Kraft und des Traumes! Seele, die sich bewahren mag und sich verlieren! Seele, die alles begehrt, beides, Bestand und Unendlichkeit, Wollen und Wissen, Sinne und Geheimnis zugleich!

Hier ist die Grenze. Hier ist der Altar der Welt. Hier geht kein Leben vorbei, es opferte sich denn. Denn der Name dieses Ortes ist: Gottes Wahl. Eine.

Bis hierher gilt Diesundjenes. Hier beginnt das

Seele, die bis hierher gekommen ist, Stille, Mächtige, wähle!

Scheide ab von dem Leibe der Erde, und ich öffne mich dir. Oder wende den Flug. Denn wer mich berührt hat, kehrt nicht wieder."

Und die Stimme versinkt. Und wieder ist nichts vor der Seele als die dunkle, stumme Wand.

Aber die Seele erhebt die Stirn. Einen Augenblick lang steht sie, als horchte sie dem verklungenen Worte nach, dann spricht sie die Antwort:

Ich scheide ab von -

In diesem Augenblick hat sich auf der Erde eine Frau über ein Bett gebeugt, in dem der Körper eines Mannes liegt. Sie schaut, sie tastet über die 
bleiche Schläfe des Liegenden hin. Dann schreit sie auf: „Israel!"

In geradem Fluge hebt sich der Ruf den Himmeln zu. Er ist schneller als die Geister der Sterne, schneller als die Engel des Raumes. Ehe der Augenblick sich schliesst, steht er am Ende des Weges, den die Seele in vielen Nächten vollbracht hat, und legt seine leichte Hand auf ihre Schulter.

Da hält die Seele im Wort inne und blickt hinter sich. Dann spricht sie nicht weiter. Sie legt den Arm um den Nacken des Boten und wendet den Flug.

Diese war die letzte Wanderung des Meisters in den Himmeln. 


\section{JERUSALEM}

S GESCHAH ZU ZEITEN, DASS DEN Baalschem des Nachts Stimmen aus der Tiefe aufriefen und sein $\mathrm{Ohr}$ wurde hell und wach, obgleich der Schlaf auf seinen Sinnen lag. Er unterschied alsdann mit grosser Klarheit, wie von undenklicher Ferne der Laut aus dem Munde vieler uralter Dinge auf der Wanderschaft zu ihm war und ein einiges Getön von ungeheurem Weh sein Lager umgab. Er fühlte, dass ein Wille hier hundert getrennte Stimmen zu einer verflochten hatte. Die Stimmen langten an sein Herz und weckten es auf. Aber sie waren von allzuweit, und das Herz verstand den Sinn ihres Wortes nicht. Es konnte nur die grosse, ferne Not ahnen, die es anrührte, und war von dieser $Z$ eit $z u$ allen Tagen und Nächten im Gleichmass seiner Schläge erschüttert. Aber in einer Nacht waren die Stimmen ganz nah an des Meisters Ohr, zitternd von der Müdigkeit der langen Wanderung. Er erkannte sie und woher sie ihm kamen, und er erkannte Eines, das ihm fremd gewesen war bis zu dieser Stunde. Denn es war das alte Land, das zu ihm sprach aus der nie erlösten Schande des Verfalles. Es war der alte Weinberg, nun zur fahlen Steppe geworden, die die Herden fremder Wandervölker mit verhassten Hufen traten Jahr für Jahr, die begrabenen Mauern unter der Erde, das verschüttete $\mathrm{Erz}_{\mathrm{r} z \text {, das mitdröhnte unter }}$ der Last des unermesslichen Schuttes, der versteinerte Hang, der einmal den leuchtenden Wald getragen 
hatte, und der verdorrte Wasserquell. Sie schrieen aus der letzten Not, die fühlt, dass der Schlaf unversehens in den Tod sich hinüberschleichen will, jetzt und jetzt, von Atemzug zu Atemzug, wenn die Hand nicht kommt, die aus dem Dunkel aufreisst und die Seele befreit, die müde geschlagene Seele des alten Landes.

Und die Stimmen redeten zum Baalschem: „Komm, komm und säume nicht. Du bist der Erwartete, dessen Atem das Gestein von unseren Gräbern heben wird wie der Frühlingswind den Flaum, der aus dem Vogelneste fällt. Dein Wort wird die Kräfte entfesseln. Der Bach wird rinnen, der Wald auferstehen, der Weinstock Früchte tragen, der Fels wird sich kleiden. Komm und lege deine Hand auf uns!"

Von der Nacht war die Seele des Baalschem in sich gewiss, dass er sich auftun müsse und hingehen zum Lande. Und er reckte sich empor und schrie zu Gott: „Gib mir Urlaub, Herr, und Frist. Löse, womit du mich hier gebunden hältst, damit ich hingehe in dein Land, das mich ruft." Aber Gott sprach nächtens zu ihm und antwortete: „Israel, es ist mein Spruch über dir, dass du weilest an deinem Orte und dich nicht auftuest nach meinem Lande."

Da lag der Baalschem viele Nächte in der Qual. Die Stimmen waren vor seinem Ohr und das Wort des Herrn auf seinem Herzen. Und der Jammer der Stimmen fuhr als Sturmwind in den Lüften. und es war eine Bewegung wie von grossem Sterben, wie an dem Tage, da Jerusalem, die Herrliche, fiel. Da siegte die Sehnsucht nach der sterbenden Erde 
über das Wort des Himmels, und da tat sich der Meister auf und wanderte gegen Jerusalem.

*

Es war die erste Nacht, da sie auf ihrer Fahrt unter fremdem Dache sich zur Ruhe legten, der Baalschem und Rabbi Zewi der Schreiber, sein Schüler, der mit ihm war. In jener Nacht kehrten die Stimmen der Heimsuchung wieder an den Ort, von dem sie ausgegangen waren. Und da sie heimkehrten, flog ihnen ein grosses Raunen entgegen, und die alte Erde bebte unter ihrem Gruss, und jegliches begrabene, erstarrte und versagende Ding erhob sich und lauschte.

Und die Stimmen riefen: ,,Stehet auf, ihr Schlafenden, und ihr Verstümmelten, bereitet euch, denn euer Erlöser ist auf dem Wege!"

$\mathrm{Da}$ hob sich der ungeheure Leib der Erde in einem schweren Atemzug, und in dem einen Aufatmen schüttelte sie den uralten Schlaf ab. Und ein jegliches Ding rief mit herzgeborenem Ton den Lebensruf aus, und war ein gewaltiges Rauschen der Freude in der Nacht, und ein Leuchten war und ein geheimes grosses Erheben von Schlucht zu Gipfel, und das versunkene Gut blühte, Schwert und Opferschale, und die erstorbenen Gewässer rauschten, und es kreiste der Saft des Kornes und der Rebe. Und die Sterne über dem alten Lande wuchsen in dieser blauen Nacht der Erwartung.

$*$

Der Baalschem schritt unverdrossen vorwärts, aber seine Helle und Freudigkeit war nicht bei ihm. Er 90 
blieb still und sann in sich, und wenn Rabbi Zewi von dem wunderbaren Ziel ihrer Reise sprach, antwortete der Meister kaum anders, als mit einem verlorenen Seufzer. Denn er trug ein Ding auf seinem Herzen, das lastete sehr und wurde schwerer mit dem Wege. Das war die Gottesstimme, die vor der Sehnsucht hatte verstummen müssen und nun gar stille schwieg, aber immerdar weilte und nicht von dem Herzen wich. Und zuweilen war dem Meister, als sei eines zarten Kindes heimlich verhaltenes Weinen in seiner Brust, und nachts war da manchesmal ganz inwendig ein Klagegetön ohne Wort, so tief und leidensvoll, dass er erwachend in sich horchen und horchen musste. Allein mit jedem Morgen trug er die wachsende Last weiter auf die Wanderschaft. So liess er Stadt und Land hinter sich, Vertrautes und Fremdes. Der Mond hatte schon zu mehreren Malen über ihm gewechselt, als er nach eines Tages Irregehen des Abends an die Küste des Meeres kam, das ihn vom Ziele schied. Doch da war nicht Haus noch Stätte, so weit das Auge sah, kein Segel am Wasser, nur Strand, schimmernd und weit, der Wasserschlag am Sand und eine laue Nacht mit mildem Himmelslicht. Da warfen sie sich beide nieder zur Erde, die noch des vergangenen Tages Glut ausatmete, zu ruhen und den Morgen zu erwarten, der sie zu Schiffernweisen würde.

In der Mitte der Nacht fand der Meister sich mit dem Weggesellen auf hohem Meer in einem kleinen Schiff ohne Ruder, nur ein Segel über sich, flammend rot und gelb. Das Schifflein aber wurde 
von einem ungeheuren Sturm hin und her geworfen, und ringsum war nicht Himmel noch Land zu sehen, nur Wasser in aller Weite, entfesselt und heulend. Der Baalschem suchte um sich, aber da war nichts als des Wassers tötliche Einsamkeit. Er suchte in sich, aber siehe, da war alles von ihm gewichen, alle Weisheit und alle Herrschaft. Da fühlte er eine Verlassenheit, die grösser war als die Meeresnot. Er fand sich leer und bar in seiner Seele wie die hingeworfene Schale einer Frucht ohne Saft und Süsse. Ein grosses Weinen kam über ihn, und sein Beben war stärker als das Rütteln des Sturmes. Dann warf er sich neben den Gefährten hin und wartete auf das Vergehen. Aber indem er lag, ein elend taubes Ding, tat sich ganz sacht eine Stimme auf und hub zu reden an, erst leise und heimlich, doch allgemach schwoll sie an und ward grossmächtig und schlang das Tobendes Meeres wie ein nichtiges Geräusch in ihren Schall. Und der Meister trank den Laut der Gottesstimme. Im Morgenzwielicht erhoben sich der Baalschem und Rabbi Zewi aus dem nassen Sand. Haar, Antlitz und Gewand waren ihnen durchnässt, wie denen, die das Meer ans Ufer spült. Sie sprachen nicht und mieden einer des andern Auge und wandten sich, und ohne Wort und Zeichen schritten sie einig den Weg zurück, den sie am Abend gekommen waren.

Als sie mehrere Stunden gewandert waren - die Sonne stand hoch und trocknete ihnen die feuchten Kleider - , sah der Rabbi von ungefähr den Meister an und gewahrte das alte heilige Leuchten auf seinem geliebten Angesicht.

92 
In der Nacht, da der Baalschem mit der Verlassenheit auf den Wassern und mit der Verlassenheit in seiner Seele kämpfte, lag das Land, das ihn gerufen hatte, in der Erwartung. Die Stimmen der Lebendigbegrabenen redeten aus derErde hervor und fragten die Stimmen in der Luft: ,Was höret ihr?" Da sprachen die Schwestern in der Luft: „Ein Sturm braust, und aufden empörten Wassern streitet, der uns erlösen soll ".

Und eine Zeit verging, dann fragten wieder die Stimmen der Erde: „Naht er dem Lande?" Und die Antwort kam: „Das Wort ist über ihm".

Und wieder schwand eine Zeit, und noch einmal stieg die Frage empor: "Was höret ihr?" Und wie das Rauschen todmatter Flügel klang es zurück: "Wir hören den Schritt des Davonziehenden in der Ferne". Da tat die alte Erde den Mund auf und sprach; „So will ich mich hinlegen zu sterben“. Und sie verhüllte ihr Angesicht und schloss die Augen. Und jegliches Ding kehrte an den Ort seiner Ruhe zurück und bereitete sich zum Tode. Und die Stille dehnte sich über das Land hin, und in der Stille war der Gram, und in dem Gram war das Sterben.

Aber über der Stille ward ein Ruf lebendig, der durchbrach und zerstreute sie. Und der Ruf umfing das Land und redete $z u$ ihm; „Du wirst nicht sterben, meine Freundin. Erde des Herrn, du wirst erwachen und leben. Und du hadre nicht mit dem, den du gerufen hast. Denn er ist geboren als einer, der wiederkehren soll, und die Hand des Herrn ist über seinen Wurzeln, ihn wiederzubringen zu seiner Zeit; ihn wiederzubringen $z u$ deiner Zeit, o meine Freundin." 


\section{SAUL UND DAVID}

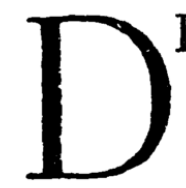

\section{IES WAR, ALS DER BAALSCHEM}

zurückgekehrt war von der vergeblichen Reise und die Männer sich um ihn zu sammeln begannen, das Heil zu nehmen von seiner segnenden Hand und von seinem ratenden Munde. Und diese Ersten wurden geheissen: die Gemeinschaft. Denn sie sassen miteinander an seinem Tische und war ihnen gemein die Luft der Seelen, und doch erschien Jeglichem das allgemeine Wort des Meisters wie eine Heimlichkeit, die seinem Ohre bestimmt war und keinem.

In jener Zeit geschah es zuweilen, dass der Baalschem inmitten des Gespräches in der Rede stockte, erbleichte und dann für eine lange Zeit verstummte und ohne Anteil, das Auge blicklos ins Ungewisse gewendet, unter den Freunden verweilte. Dann pflegten allgemach auch die Getreuen zu erschweigen und in einem bänglichen Warten auszuharren, bis der Sinn des Meisters ihnen heimkehrte. Wenn sich dieses nach einiger Frist erfüllte, erschien der Heilige sehr ermattet, als ob irgend eine verhehlte Kraft am Quell seiner Seele sich genährt und ihn schier zum Versiegen gezwungen hätte. Er fand dann wohl noch ein mildes Zeichen für jeden seiner Gäste, aber alsbald"pflegte er sich zu erheben und in sein Gemach zu gehen, das er sodann für viele Stunden verschloss.

Die Schüler redeten oftmals untereinander von diesem Ereignis, doch fanden sie nimmer, wie sie auch forschten, dem fremden Geschehen die Deutung. 
Da fügte es sich einmal, dass Rabbi Wolf, der Fröhliche, der keiner Angst je Einlass gab und immerdar getrost war ob der Liebe des Meisters, um dieses Dinges willen ihn anging und Widerrede und Aufschluss empfing. So hat es sich begeben, dass wir wissen, wie es sich zugetragen hat. Was aber später geschah, das haben die Lippen des Mannes selber kundgegeben, der an den Wurzeln des Geheimnisses wohnte.

Denn in den Jahren des Baalschem lebte in der Stadt Kossow ein Rabbi, der in seinem dunkeln gewaltsamen Geiste den Erhabenen bekriegte. Dieser Hader aber war uralten Grundes und hatte seinen Keim in den grossen Tagen der Könige. Es wird berichtet und dargetan, dass Jsrael, der Sohn des Elieser, den wir den Baalschem nennen, als ein Erbe und Unterpfand der Zeiten in seinem Blute die Seele trug, die einst David, den König, verlassen hatte, als seine Jugend zerbrach und die Sucht ihn befiel. Dem Rabbi von Kossow aber, dessen Name wie der Name jenes künftigen Schmerzgekrönten, des Urenkels des Baalschem, Nachman war, hatte Sauls, des Traumfürsten, Seele sich einverleibt. Darum geschah es von einer Weile zur andern, dass der Rabbi von einem Ingrimm befallen wurde, der unerbittlich und aller Martern kundig war und nicht in ihm geboren, und den er tagelang in sich hegte und mit dem Leben seiner Adern nährte, bis das Ding in ihm mächtig war und ihn übermannte. Dann riss er sich mit den letzten Kräften auf und entsandte seine rasende Seele, dass sie der Seele des Heiligen sich nahte wie ein ge- 
spenstischer Vogel und ihr in düsteren Lauten ein Raunen zuwarf, sich mit ihm zu messen, und da jene das Tuch übers Haupt schlang und schwieg, sich erhöhte wie ein Drache der Finsternis und in Worten einer ungestümen Schwermut und eines dröhnenden Hohnes die Verborgene herausschrie. So ereignete es sich, dass der Baalschem zuzeiten plötzlich von seiner Seele verlassen wurde, da sie zum Kampfe auszog. Mal um Mal aber, wenn dieBlicke wie Schilder aneinanderklirrten und die Welten sich aus dem Schlafe reckten und erwachten, das glühende Ringen $z u$ schauen, vermochte es keine der beiden Seelen, sich wider die andere $z u$ heben, denn der einen klare Flamme schlug in aufrechtem Erbarmen zu den Himmeln auf, dieweil der anderen schwarzes Feuer zweifelsüchtig und wie von Schrecknissen gescheucht zerflackerte. Es war aber die Macht und das Zehren dieser Stille also gewaltig, dass die Seelen, sobald der Ruf der Leiber oder eine mahnende Stimme aus der ungeschiedenen Tiefe sie traf, zum Letzten erschöpft sich erfanden und wie nach schwerer Fehde heimkehrten.

Nun aber tat der Rabbi von Kossow wohl niemals einem Menschen Erwähnung von diesen Dingen und sprach nie im Lauten Feindseliges wider den Meister; er konnte jedoch die Schatten nicht verjagen, die sein Angesicht überkamen, wenn von allen Zungen das lebendige Zeugnis für jenen erstand. Dies gewahrten die Schüler, die ihm anhingen und ihn liebten, und es war ihnen weh, seine Seele alsdann sich in derPein ergehend zu schauen, auch erregte sich 
wohl der Eifer in ihnen, dass ein anderer sich über ihren Lehrer erheben sollte. So bedrängten sie den Rabbi viele Male mit stacheligen Reden, sein Heimliches zur hellen Glut zu schüren und ihn zum offenen Widerstreit zu bewegen. "Saget uns, o Herr", sprachen sie, "wie geht dieses $z u$, dass alle Leute $z u$ diesem Manne ziehen und so wundersam, mit Verklärung im Ton und wie von einer Gnade Berührte sein Lob ausrufen? Ist es etwa derwegen, dass niemals noch einer kam, gross und geschmeidig genug im Geiste, seine Ränke und Künste zu zerbrechen? Soll er die Ursache werden, dass Euer Ruhm zu allen Zeiten sterbe vor dem seinen? Ewig die Schlinge, die Euren Aufflug hemmt? Ziehet hin, auf dass er sich an Euch messe, sodann werden wir und alle mit der Augen Innerstem die Wahrheit schauen."

Lange verschloss sich der Rabbi, der stolz und ehrlich vor sich selbst und seines Feindes tief bewusst war, diesen Worten. Da aber die Schüler nicht abliessen in ihn $z u$ dringen, gewannen sie allgemach Wirkung und Macht in seiner Seele. Eines Tages rüstete er sich mit den Seinen zur Fahrt, bezwang die Scham und zog nach Miedzyborz zum Baalschem. Als sie in sein Haus traten, kam der Heilige ihnen entgegen, schlank erhoben, doch voller Ehrfurcht, und mit hohen Worten gab er dem Rabbi seinen Gruss. Jener neigte sich und gab den Gruss zurïck, und es war, als ob zwei grosse Helden der alten Zeit einander den Willkomm spendeten. Sie schienen den Genossen urfern und entrückt und wurden selber keines andern Dinges gewahr und 
achtsam denn einander. Die Schüler verbliebeñ scheu im Vorhof, die Beiden aber traten selbander in ein Gemach, und als die Tür hinter ihnen ins Schloss fiel, war es der harrenden Schar, als sei sie durch einen Wall der Zeiten von den Meistern geschieden.

Die standen Aug in Auge, und die alte Liebe stand auf und das alte Leid und der alte Hass. Wie ein Feld lebendiger Halme rauschte die Fülle der verschollenen Jahre. Aber bald war nur noch der Grimm im Rabbi, und er erfand sich vielverschlungene, maschenreiche Reden und führte sie mit schlauem Bedacht gegen den Baalschem, dass der sich in ihnen verfange und ihm erliege; doch sie fielen ohne Kraft und Griff zur Erde. Nachdem das Gespräch eine Weile $z$ wischen den beiden hin und her geglitten war-der Heilige aber ruhte wie ein lächelndes Kind in der friedseligen Gewissheit seines Wesens -, fragte der Rabbi: „Ist dem so, wie sie sagen, Israel, dass du jeglichen Gedanken der Menschensöhne weisst?" Und der Meister antwortete: „Dem ist so." Darauf fragte jener zum Neuen: „So ist es dir bewusst, was meinen Gedanken füllt zu dieser Zeit?" „Du weisst,“ sagte der Baalschem, ,dass die Gedanken der Menschen gemeiniglich nicht zu ruhen pflegen, sondern hin und wieder kreisen wie die Möven über dem Wasser. Binde deinen Gedanken nunmehr an ein Ding, und ich will es dir nennen." Also tat der Rabbi, und der Baalschem sprach: „Der vierfach urgeheime Name Gottes ist es, daran dein Gedanke hängt." Da der Rabbi erkannte, dass 
der Heilige in seinen Geist geblickt hatte, ergriff ihn eine fiebernde Erbitterung, und er rief: „Dieses konntest du ohne Wunder und Erschauen wissen. Muss ich doch den Namen Gottes zu jeder Zeit vor mir tragen, und wenn du heischest, dass all mein Denken ein Ding umschlinge, was bleibt mir als dieses Letzte, Eine? Gering, fürwahr, achte ich deine Kunst."

Der Baalschem aber harrte aus in seiner Milde und sprach: „Hat Gott nicht viele Namen? Ich aber sage dir den einen, unaussprechlichen an." $\mathrm{Da}$ er jedoch sah, wie die Blicke des Rabbis zuckten und sich wehrten, trat er vor ihn hin, und aus seinen Augen brach nun entfesselt der Strom der Liebe. Und er redete also: „Dieses hast du gedacht, Nachman: ,Soll ich ewig gefangen bleiben in den vier Buchstaben? Zwingt mich ewig das tyrannischeWort? Versunken sind die Zeiten und enttauchen wieder, und mich hält in peitschenden Ketten der Geist. Wohin bist du geflogen, letzter der reinen Tage, $\mathrm{da}$ ich durch das Land Benjamin zog mit fröhlichen Schultern, Hauptes länger denn alles Volk? Tag der Sonne, Tag der Freiheit, nie, nie bist du gekehrt. Aber dein Bruder blieb, der dir gefolgt war, blieb bei mir mit dem Ölglas und dem Namen des Herrn. Er umspannt meinen $\mathrm{Hals}$, wenn ich mich lege, er schliesst sich um meine Knöchel, wenn ich vom Lager aufspringe. Er hat mich mit Zorn getränkt und mit Wahnsinn gefüttert. Er führt mein Schwert wider meinen Leib: täglich stürze ich darein und sterbe.' Dieses hast du gedacht, Nachman: ,Soll 
ich ewig gefangen bleiben in den vier Buchstaben? Wie, wenn ich mich losmachte und wieder würde wie dazumal, ehe ich in die Stadt kam, in der der Mann des Herrn war!' Aber ich sage dir, Nachman, mein Freund, du Freund Gottes: willst du losmachen dein Herz von deiner Brust und dein Hirn von deinem Haupte? Sieh: du hast dich erkannt, - bist du noch länger gefangen? Sieh, du hast dich erkannt, - fühlst du nicht deinen Willen in Gottes Willen brennen? Nimm die Last der Zeiten in die Hände, ist sie nicht schon geschwunden? Küsse den Tag, der dich bannte, - bist du nicht schon gelöst? Rege die Seele in Gott wie das Herz sich in deiner Brust regt. Nun kehrt die Zeit der Sonne dir wieder, die Zeit der Freiheit."

Der Rabbi sprach: ,Du hast die Wahrheit geredet, Israel !" Dann neigte er sich und sprach das Wort des Friedens und ging zur Stunde hinweg mit gestillter Seele. 


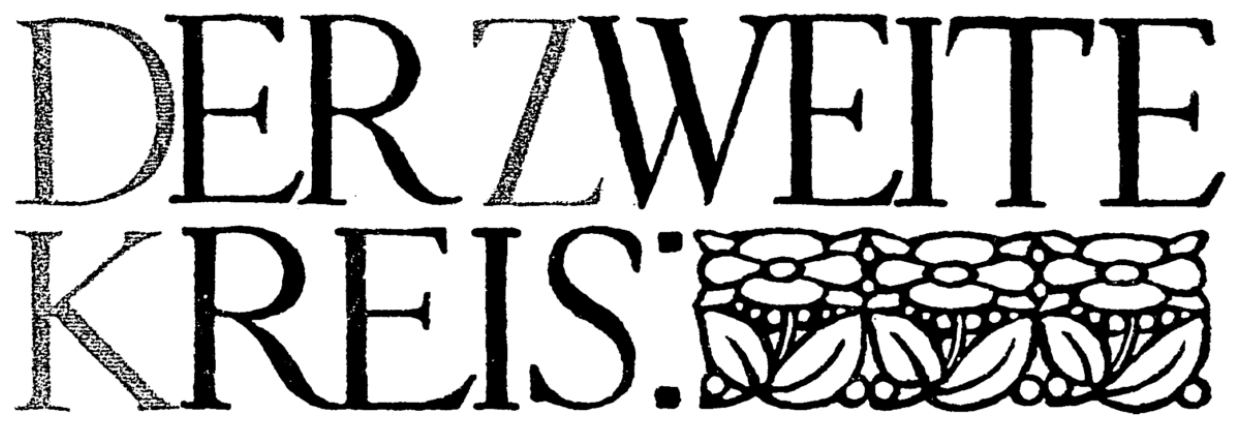

DAS GEBETBUCH DAS GERICHT, DIE SCHICHTE, DIENE DERGESTIEGENESEE LE,DER PSALMEN SAGERDER ZERSTOR TE SABBAT,DERWI DERSACHER

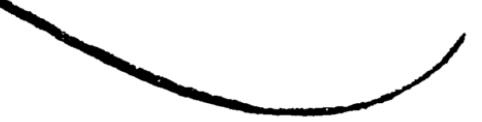




\section{DAS GEBETBUCH}

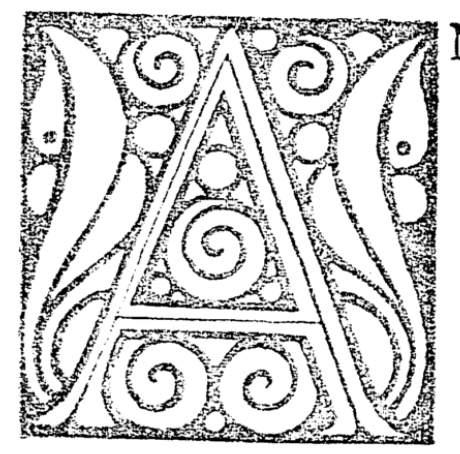

N DEN ZWEIHOHEN FESTEN, welche die furchtbaren Tage genannt werden, das sind die Feier des neuen Jahres und der Versöhnungstag, pf legte der Rabbivon Dynow, wenn er vor die Bundeslade trat, um $z u$ beten, das grosse Gebetbuch des Meisters Lurja zu öffnen und vor sich auf den Ständer hinzulegen. So lag es offen vor ihm alle Zeit seines Betens, aber er blickte nicht hinein und rührte es nicht an, sondern liess es gross und offen daliegen im Angesicht der Lade und vor den Augen der Gemeinde, dass das starke unverblasste Schwarz der Lettern aus dem breiten, gelblichen Grunde weithin schlug, und er stand hochgestreckt in seiner Weihe davor wie der opfernde Hohepriester vor dem Altar. Also geschah es, und aller Augen mussten immer wieder darauf blicken; aber keiner von den Chassidim wagte es, davon zu sprechen. Einmal jedoch stärkten etliche ihr Herz und fragten den Rabbi: „Wenn unser Herr und Lehrer aus dem Buche des Meisters Lurja betet, warum sieht er nicht hinein von Seite zu Seite nach der Ordnung seines Betens, und wenn er nicht daraus betet, warum öffnet er es und warum liegt es vor ihm?" Da sprach der Rabbi zu ihnen: „Ich will euch erzählen, was sich in den Tagen des heiligen Baalschem, sein Andenken sei zum Segen, ereignet hat.

In einem Dorf lebte ein Pächter mit seiner Frau 102 
und seinem kleinen Sohn. Der Gutsherr war dem stillen Manne zugetan und gewährte ihm manche Vergünstigung. Dennoch kamen schlimme Jahre über ihn. Einer schlechten Ernte folgte im nächsten Sommer immer wieder eine schlechtere, und so stieg und schwoll die Not, bis die grauen Wogen über seinem Haupt zusammenschlugen. Er hatte jeder Mühe und jeder Entbehrung standgehalten; dem Elend konnte er nicht ins Auge schauen. Er fühlte sein Leben schwach und schwächer werden, und als sein Herz zuletzt stille stand, war es wie das Ersterben eines Pendelschlags, dessen stetes Leiserwerden man nicht wahrgenommen hat und dessen Aufhören über einen nun wie etwas Plötzliches gerät. Und wie seine Frau mit ihm durch das holde und das arge Schicksal gegangen war, so ging sie auch mit ihm hinaus. Als sein Grab bereitet war, konnte sie sich nicht länger zwingen, sie sah ihren kleinen Sohn an und konnte sich doch nicht zwingen, und so legte sie sich hin und redete sich vor, sie gehe nicht zum Tode, bis sie zu ihm kam.

Der kleine Nachum war drei Jahre alt, als die Eltern starben. Sie waren aus der Ferne gekommen, und man wusste von keinen Verwandten. So nahm ihn der Gutsherr zu sich, dem der Knabe mit dem schmalen, aus den goldroten Locken blütenweiss hervorschimmernden Gesicht gar gut gefiel. Bald gewann er des Kindes zarte, fast traumhafte Art mehr und mehr lieb, und er zog es wie ein eigenes auf. So wuchs der Knabe heran in Licht und Freude und wurde in allem Wissen und in allen Künsten unterwiesen. Von seiner Eltern Art und Glauben wusste 
er nichts. Wohl verschwieg ihm der Gutsherr mit nichten, dass sein Vater und seine Mutter Juden gewesen waren; doch als er ihm davon sprach, fügte er hinzu: „Ich aber habe dich mir genommen, und nun bist du mein Sohn, und all das Meine ist dein". Dies verstand Nachum wohl; das aber, was ihm von seinen Eltern gesagt worden war, das schien ihm jenen $\mathrm{Ge}-$ schichten zugehörig, die ihm die Mädchen von Waldteufeln, Nixen und buntem Elfenvolk erzählten; wunderbar war es ihm nur und unbegreiflich, dass er selbst mit solch einer Geschichte zu schaffen hatte, und er fühlte sich einem fernen Dunkel verbunden, das ein Grauen und eine Sehnsucht zu ihm entsandte, von dem er dergestalt zuzeiten wie von einer leichten, schwermütigen Welle seine Seele umfangen spürte und das ihm doch ewig fremd und ewig rätselvoll blieb.

Eines Tages kam er unversehens in eine abgelegene Kammer des Hauses, in der allerlei Gerümpel übereinandergeschichtet lag, das seine Eltern einst hinterlassen hatten. $\mathrm{Da}$ waren seltsame Dinge, die er nicht kannte. $\mathrm{Da}$ war ein sonderbar gestaltloser weisser Mantel mit langen schwarzen Streifen. Da war ein gesticktes Stirntuch von prächtiger und doch stiller Art. Da war ein mächtiger, vielarmiger Leuchter verblassten Glanzes. Da war ein reich verästelter, in einer Krone zusammenwachsender Gewürzbehälter, um den noch ein letzter, dünner Duftnebel zu flattern schien. Und da war endlich ein grosses schweres Buch, in dunkelbraunen verschlissenen Sammet gebunden, die Ecken silberbeschlagen, mit silbernen Klammern. Das 
waren die Dinge, die seine Eltern nicht hatten aufgeben können, auch vor den Augen des letzten Elends nicht. Und nun stand er und sah darauf, und die Boten des Dunkels waren ihm näher als je. Dann nahm er das Buch und trug es scheu und vorsichtig, beide Arme fest darum gelegt, in sein Zimmer. $\mathrm{Da}$ löste er die Klammern und öffnete es ganz leise, und die breiten schwarzen Lettern starrten ihn an, fremd und doch nicht fremd, sahen ihn an wie eine Schar kleiner Kameraden, blickten $z u$ ihm empor wie ein Reigen lieber feiner Gesellen, wirbelten vor ihm dahin, flogen durcheinander, zerflimmerten, - und siehe, da waren keine Lettern mehr, und das Buch war wie ein dunkler See, daraus schauten ihm zwei Augen entgegen, tränenlos, aber eines ewigen Schmerzes voll. Und Nachum wusste, dass dies das Buch war, aus dem seine Mutter gebetet hatte. Seither hielt er es tagüber verborgen, aber an jedem Abend holte er es aus dem Versteck, und beim Licht der Lampe, und lieber noch beim lebendigen Licht des Mondes sah er auf die fremden Lettern, bis sie sich zum Reigen einten und zum See zusammenflossen, daraus die Augen der Mutter hervortauchten.

So kamen die Tage des Gerichtes heran, die Tage der Gnade, die furchtbaren Tage. Aus allen Dörfern zogen die Juden zur Stadt, um im Rauschen der Volksgemeinde vor Gott zu stehen, um ihre Schuld mit der Schuld der Tausende ihm darzubringen und in seinem Feuer aufgehen zu lassen. Nachum stand vor der Tür des Hauses und sah die Wagen vorübereilen, unzählig viele, sah Männer und Frauen darin in Festgewändern, 
und über allem war die Macht der Bereitschaft. Und ihm war, als seien all die Menschen Boten zu ihm, Boten des Dinkels nicht mehr, Boten der Sonne und des lichten Seelengrundes, und als enteilten sie ihm nur deshalb, weil er sie nicht anriefe. Und er rief einen an und fragte ihn: "Wohin fahret ihr, und was ist dies euch für eine Zeit?" Und jener sprach : „Wir fahren dem Tag der Erneuerung entgegen, dem Tag des Anfangs, da im Buch des Himmels geschrieben wird unsere Tat und unsere Lösung. Und wir fahren, um $z \mathfrak{u}$ Gott $z \mathfrak{u}$ reden in grosser Schar und unsere Stimmen zu binden zu ein e $m$ Gebete." Der Knabe hörte das Wort; aber weit ausgespannt darüber flog ihm ein anderes Wort zu, ein grosses Rufen, das kam aus der Unendlichkeit $z u$ ihm. Und von dieser Stunde an war das Rufen über ihm, brausend im Schweigen wie ein mächtiger Sturmwind, still im Lärm wie die Schwingen eines stillen Vogels. Und das Rufen erhellte das Dunkel, das ihm so lange die Welt umkleidet hatte, und das Grauen ging in der Sehnsucht auf, und die Sehnsucht war wie ein junges grünes Blatt in der Sonne. So wandelten die zehn Tage der Busse hin, und der Vortag des Versöhnungsfestes warda. Und wieder sah der Knabe die Juden aus den Dörfern die Strasse zur Stadt fahren; stumm und regungslos sassen sie da, und ihre Gesichter waren bleicher als vordem. Und wieder fragte Nachum einen von ihnen: „Was führt euch und wohin?" Und jener sprach: „Dies ist der Tag, auf den wir hofften und harrten, der Tag der Versöhnung, da unsere Schuld sich löst im Lichte des Herrn und er seine Kinder aufnimmt 
in die Heimat seiner Gnade." $\mathrm{Da}$ lief der Knabe in seine Stube und nahm das Buch mit den silberbeschlagenen Ecken in die Arme und lief aus dem Haus auf die Strasse und lief, bis er in die Stadt kam. Und in der Stadt lenkte er seinen Schritt zum Bethaus, und er trat ein. Und als er eintrat, war es die Stunde, da das Kolnidre gesprochen ward, das Gebet der Lösung und der heiligen Freiheit. Und er sah die Scharen stehen, in den langen weissen Sterbegewändern, stehen und sich neigen und sich erheben vor Gott. Und er hörte sie aufschreien zu Gott, aufschreien aus allen verdeckten Tiefen zum Licht, aus allen Geheimnissen ihrer Seele zur Wahrheit. Und die Hand des Geistes war auf der Schulter des Knaben, und er stand und neigte sich und erhob sich vor Gott, und er schrie auf zu Gott. Und da er merkte, wie rings um ihn Worte schallten in einer fremden Sprache, und es über ihn kam, dass er nicht beten konnte wie die andern, nahm er das Buch der Mutter und legte es auf den Ständer und rief: „Herr der Welt! Ich weiss nicht was $z \mathrm{u}$ beten, ich weiss nicht was $z u$ sagen - da hast du, Herr der Welt, das ganze Gebetbuch." Und er legte den Kopf auf das offene Buch und weinte und unterredete sich mit Gott.

Es war aber an jenem Tage, dass die Gebete der Gemeinde wie flügellahme Vögel amBoden flatterten und sich nicht emporschwingen konnten. Und das Haus war ihrer voll, schwer die Luft, trüb und verzagend der Sinn der Beter. Da kam das Wort 
des Knaben, das nahm die Gebete aller auf seine Fittiche und trug sie in Gottes Schoss.

Der Baalschem aber sah und erkannte alle diese Dinge, und er sprach das Gebet in hoher Freude. Und als das Fest vorüber war, nahm er den Knaben zu sich und zog ihn heran und lehrte ihn den Sinn des Lebens und alle lautere und gesegnete Weisheit." Also erzählte der Rabbi von Dynow seinen Frommen. Und er sprach: „Auch ich weiss nicht, was ich tur soll, und ich weiss nicht, wie viel, und wie ich die Absicht der heiligen Männer, der ersten Beter, aus deren Mund die Gebete sind, erfüllen kann. Darum nehme ich das Buch des Meisters Lurja, des Ehrwürdigen, und mische es auf, dass es vor mir liege zur Stunde des Gebetes, und gebe es Gott mit allem Willen der darin ist und aller Inbrunst und allem Sinne." 


\section{DAS GERICHT}

\section{CINMAL BEGAB ES SICH - ES WAR}

$\square$ an dem vierten Tag der Woche, sagen sie, und um jene erste Stunde des Abends, da die Sonne uns eben entschwunden ist -, dass der Baalschem sein Haus verliess, eine Reise zu tun. Und keiner Seele, so Schüler nicht als Freund, heisst es, hatte er dazumal von seinem Weg gesprochen, so dass $Z_{\text {iel }}$ und Sinn jener Fahrt für alle die Seinen im Dunkel lagen, selbst für jene, die ihn begleiteten. Und auch dazumal fuhr er in einer knappen Stundenzahl eine grosse Strecke des Weges, wie es ja allen bekannt ist, dass dem Willen des Meisters Ort und Zeit nicht Fessel und Hindernis bedeuteten wie einem unter uns. Um Mitternacht - die Fahrt war dermassen eilig gegangen, dass die, so mit ihm waren, nicht Haus noch Baum am Wege unterschieden, - hielt der Baalschem in einem fremdem Dorf vor dem Haus eines Zollpächters und Herbergvaters an, die Stunden der Nacht, die ihm verblieben waren, dort $z u$ ruhen. Es wies sich, dass der Wirt weder den Baalschem noch einen unter den Seinen kannte, wohl aber begierig war, wie es unter Leuten dieses Gewerbes kein Seltenes ist, zu wissen, wes Standes sein Gast wohl sei und zu welchem Ende er diese Reise unternehme. Indem er dem Meister und den andern einen späten Imbiss bot und ihnen zum Lager aufbreitete, gab sich Rede und Antwort, also dass der Baalschem dem Wirt auf dessen Anfrage zu wissen tat, er sei ein Prediger und habe vernommen, dass am Vorabend 
des kommenden Sabbats ein reicher und grosser Mann in Berlin Hochzeit halte, und zu der Zeit wolle er dort sein, um bei dem Fest seines Amtes zu tun. Als der Gastgeber das gehört hatte, hielt er ein Weilchen still und betreten an sich, ehe er sagte: „Herr, Ihr verhöhnet wohl meine Wissbegier! Kenne ich doch die Stadt Berlin reichlich hundert gute Meilen weit von hier! Wie wollt Ihr die Strecke in der Frist abtun, die Euch bleibt! Ja, wenn Ihr Pferd und Mann nicht schontet und Euch des Nachts nicht Rast gönntet, Ihr würdet etwa vermögen, zum andern Sabbat dort zu sein, nimmermehr aber an diesem." $\mathrm{Da}$ lächelte der Baalschem ein kleines und bot ihm Antwort: „Sei um deswillen unbekümmert, Freund, meiner Pferde bin ich sicher. Sie haben schon manch gutes Stücklein für mich getan."

Der Baalschem legte sich mit den Seinen zur Ruhe nieder, der Wirt aber blieb die ganze Nachtauf seinem Bette wach, denn der fremde Mann und seine Sache dünkten ihm allzu wunderlich. Dazu verstand er, dass etwas an dem Manne war, was ihn nicht glauben lassen mochte, er sei ein Spassvogel oder gar ein Narr. DasVerlangen kam über ihn, das Ende dieses Dinges zu sehen Und als er so um einen schicklichen und ehrbaren Vorwand sann, dem fremden Prediger sein Geleit zu bieten, fiel ihm manches Geschäft ein, das er in Berlin mit einigem Vorteil hätte abtun können. $\mathrm{Da}$ beschloss er, des Morgens mit dem Gaste darüber zu reden. Als der Meister mit seinen Leuten zu guter Zeit sich vom Lager erhoben hatte, trat der Wirt $z u$ ihm und trug ihm seinen Wunsch vor, und der Baalschem war 
es gern zufrieden. Hingegen zeigte er nicht sonderliche Eile wegzukommen, sah sich auf mancherlei Weise geruhig im Hause um, sprach mit den Seinen eine gute Weile ein Gebet und hiess endlich den Wirt noch eine kräftige Mahlzeit bereiten. Die nahmen sie $z u$ sich und verblieben dann noch in mannigfaltigem Gespräch, während der Wirt von innerer Unrast und Neubegier getrieben ab und zu ging und sich nicht Rast noch Deutung über dieses absonderliche Wesen wusste.

Als der Tag wiederum niederging, befahl der Meister, den Wagen zu bereiten und die Pferde anzuspannen. Sie zogen von hinnen, und bald kam die Nacht über sie. Der Baalschem mit den Seinen sass schweigend. Dem Wirt war es bald seltsam und fremd in seinem Sinne, und es dünkte ihn, dieses sei eine Fahrt, derengleichen er niemals noch eine getan. Nichts als das Dunkel war da. Zuweilen war es ihm, als rollten sie tief unter den Wegen der Menschen durch geheimnisreiche Gänge der Erde hin, und dann wieder schien ihm der Weg, den sie nahmen, so entfesselt von Schwere, so leicht und durchsichtig, als schwebten sie über allen Dünsten in den Lüften dahin. Sie begegneten keinem Laut, keinem Menschen, keinem Tier, keinem Ort. Der Wirt vermochte keinem Gedanken Halt zu gebieten, alles in ihm und um ihn schien sich in Flüchtigkeit aufgelöst zu haben.

Plötzlich war es ihm, als würde die Luft um ihn dichter, die erste Helle brach an, er fühlte die Erschütterungen des Wagens auf dem Erdboden wieder unter sich, fernhin bellte ein Hund, ein Hahn 
krähte, eine Hütte lag seitab im Dämmer. Eine Weile fuhren sie so, der Morgen war klar, und als die letzten Dünste in der Sonne aufgingen, sah der Wirt vor sich eine grosse Stadt liegen. Nicht der vierte Teil einer Stunde ging um, da langten sie in Berlin an.

Der Meister wählte eine bescheidene Herberge, die am Ende der Stadt stand, in jener Gegend, wo noch niedere Häuser fast ländlich in ihren Gärtchen lagen. $\mathrm{Da}$ liess er sich in einer Laube vor dem Haus mit seinen Schülern zum Morgenimbiss nieder. Als sie diesen eingenommen hatten, blieben sie im Gebet und in Gesprächen gelassen beisammen. Der fremde Wirt, der die Fahrt mit ihnen getan hatte, dachte der Worte des Predigers, dass er zur Hochzeit eines grossen Mannes nach Berlin reise und dass heute der Tag des Festes sei, und er konnte nicht verstehen, wie der Baalschem so ruhig sich hier verweile, statt sich den Gästen im Hause des Bräutigams zugesellen. Noch tief befangen in dem Geschehnis der Nacht und doch schon gestachelt von der neuen Frage, lief er ab und zu, aber wenn er sich dem Meister näherte und sich anschickte, den Mund aufzutun, hob der Baalschem das helle Angesicht, und der Wirt schaute darin den heiteren Spott, mit dem jener über seine unruhige Seele in grosser Güte lächelte. Da verging ihm der Mut zur Frage, und er nahm Urlaub, sich ein wenig in der fremden Stadt umzutun.

Er war noch nicht eine Stunde unterwegs, als er sah, dass allenthalben die Menschen beisammen- 
standen, einander eine Neuigkeit mitzuteilen und sie $z u$ besprechen. So trat er an einen heran und fragte bescheiden, was da wohl geschehen sei, dass die Leute ihrer Geschäfte vergässen und so in Aufregung umherstünden.

Er bekam den Bescheid, dass im Haus eines reichen Juden, der eben heute habe Hochzeit halten sollen, am Morgen dieBraut plötzlich dahingeschieden sei, nachdem sie noch bis zur Mitternacht mit aller Freudigkeit ihren Staat gerüstet und die Vorbereitungen zum Fest geleitet, den Rest der Nacht aber in friedvollem, gleichmässigem Schlafe verbracht hatte. Auch war siekeineswegs krank oder schwächlich gewesen, sondern als ein schönes und starkes junges Geschöpf allen bekannt. Der Wirt liess sich dasHaus des Bräutigams weisen. Dort eingetreten, fand er die Festgäste in Trübsal und Verwirrung die Tote umstehen, die bleich, aber unentstellt auf ihrem Bette ruhte. Die Ärzte schienen sich noch $\mathrm{mm}$ sie bemüht zu haben und nahmen eben ihren Abschied von dem Herrn des Hauses, indem sie mit etlicher Verlegenheit schonend vermeinten, dass nun doch tot bleiben müsse, wer tot sei. Der Bräutigam stand und schwieg, und sein Antlitz war vom Kummer wie von einem grauen spinnwebenen Schleier umsponnen. Der und jener unter den Gästen trat zu ihm und raunte ihm $z u$, was ihn trösten sollte, aber der Mann blieb stumm, als ob er nicht hörte. Da wagte es auch der Wirt und ging $z u$ ihm und erzählte ihm, auf welche absonderliche Weise er heute Nacht so weiten Weg gekommen sei, mit 
dem fremdem Prediger, der zu seiner, des Bräutigams Hochzeit gewollt habe. Und er meinte, der Wundermann, der diese Fahrt vermochte, verstünde sich wohl auf mehr, was nicht gewöhnlich sei, und riet dem Herrn des Hauses, zu ihm zu gehen und ihm sein Leid zu vertrauen. Da wies es sich, dass der Trauernde ihn vernommen hatte, denn er griff nach seiner Hand und hielt sie fest und begehrte zur Herberge des Baalschem zu gehen. Er trat vor den Meister und sagte ihm alles von der schweren Begebenheit und entbot ihn an das Bett der Toten. Der Baalschem ging unverweilt mit ihm, trat an die entseelte Braut und schaute lange in ihr verschwiegenes Angesicht.

Alle waren still geworden und warteten auf sein Wort. Er aber wandte sich von der Ruhenden und achtete keines und sprach mit unbewegter Stimme zu den Frauen: „Bereitet eilig der Toten das Sterbegewand und tut eure Bräuche gar schnell und ungesäumt.“ Zum Bräutigam sagte er: „Entbiete rasch Männer, dass sie am Orte des Lebens, wo du die Toten deines Hauses zur Ruhe bringst, auch dieser eine Stätte bereiten." $\mathrm{Da}$ sandte der Bräutigam hin und liess ein Grab aufwerfen. Der Meister aber sprach weiter: „Ich gehe mit euch dieser Toten zum Geleite. Ihr aber nehmet die Hochzeitsgewänder und den Schmuck, den sie sich selbst zum heutigen Tage erlesen hat, und bringet ihn zum Grabe." Als alles bestellt war, legten sie die Leiche in einen offenen Schrein und trugen sie hinaus. Der Baalschem ging als erster 
dem Sarge nach, und ihm folgte vieles Volk mit zitternden Herzen und verhaltenem Atem.

Vor dem Grabe befahl der Baalschem, die Tote im unbedeckten Sarge in die Grube zu legen, so dass ihr Angesicht frei gegen Himmel schaute und von allen gesehen werden konnte. Auch hiess er keine Erde auf sie werfen. Z Wei Männern gab er Weisung, neben ihm zu stehen und seines Winkes gewärtig zu sein. Dann trat er zum offenen Grabe, lehnte sich auf seinen Stab und liess seine Augen auf dem Antlitz der Toten ruhen. So stand er unbeweglich, und die ihn ansahen, bemerkten, dass er gleichsam ohne Leben war, als ob die Seele ihm entwichen wäre oder er seinen Geist an einen andern Ort entsandt hätte. Alle umstanden in weitem Kreise das Grab. Der vierte Teil einer Stunde verging, da regte sich sein Gesicht, und er winkte den beiden Männern. Sie traten an das Grab und sahen, dass das Antlitz der Verschiedenen sich mit dem Hauche des Lebens gerötet hatte und dass der Atem aus ihrem Munde kam und ging. Der Baalschem gebot sie aus dem Grab zu heben, und so geschah es, und sie stand aufrecht und blickte um sich. Da trat der Meister zurück und befahl dem Bräutigam, er möge unverzüglich und schweigend die Braut in ihre Schleier kleiden lassen und zum Baldachin führen und des Geschehenen mit keinem Worte gedenken. Der Bräutigam aber bat den Meister, er möge es sein, der die' Ehe segne. So führten sie die Verschleierte ins Haus unter den Baldachin. Als der Baalschem aber die Stimme erhob 
und den Ehesegen über das Paar sprach, riss die Braut sich die Schleier vom Gesichte, sah ihn an und rief: "Dieser ist der Mann, der mich losgesprochen hat." $\mathrm{Da}$ fuhr der Baalschem auf und schrie sie an: „Schweige!" Die Braut verstummte und der Baalschem verliess das Haus.

Später, als alle Hochzeitsgäste beim Mahl sassen und die Schatten der vergangenen Ereignisse zu weichen begannen, hub die Braut selbst an, ihre Geschichte zu erzählen.

Ihr Bräutigam war bereits einmal vermählt gewesen, und als Witwer hatte er sie zur Frau begehrt. Das erste verstorbene Weib aber war ihre Tante gewesen und hatte sie als kleine Waise bei sich aufgenommen und gehegt und neben sich im Hause gross werden lassen. Da geschah es, dass die Frau krank wurde und ihr nimmer zu helfen war, und sie selbst verstand gar wohl, dass ihrer Zeit nun das Ende kam. $\mathrm{Da}$ legte es sich ihr schwer in den Sinn, dass, wenn sie ein Weilchen tot wäre, ihr Mann, der noch jung war, es wohl kaum werde lassen können, eine andere an ihre Stelle zu erheben. Und wie sie nachsann, begriff sie, dass es ihre junge Verwandte sein würde, die so wohl Bescheid wie sie selbst in heilen Tagen in allen Geschäften des grossen Hauses wusste und lieblich anzusehen ihm zu jeder Stunde des Tages vor Augen sein würde. Und weil sie selbst ihren Mann sehr geliebt hatte und bang um die kurze Frist war, die ihr an seiner Seite nur gegönnt gewesen, neidete sie das junge Wesen gar sehr. Und 
als sie ihre letzten Stunden verrinnen fühlte, rief sie die beiden an ihr Bett, die sie so vergehen sahen und sie liebten, und ihre Seelen flossen vor Trauer über. Und da nahm sie ihnen Versprechen und Handschlag $a b$, einander niemals zu nehmen. Den beiden, die um die Sterbende litten, dünkte das nicht schwer, und gern gaben sie es hin.

Dann aber trug man àie Tote hinweg, und ihr Platz war leer, und selbst ihr Schatten war aus den Räumen gewichen, und da waren nur noch die Lebenden und alles war Leben um sie her, und sie sahen sich ins Auge zu jeder Stunde und verstanden bald, dass sie einander dennoch nicht lassen konnten.

$\mathrm{Da}$ brachen sie ihren Eid und gelobten sich einander an.

Aber am Morgen der Hochzeit, als die Luft im Hause voll leichten freudigen Lebens schien und keiner der dunklen Tage dachte, da eine nun Tote hier leidvoll gehaust hatte, kam der Wille der verstorbenen Frau zurück an seine Stätte und heischte sein gebrochenes Recht und begehrte das lebende glückliche Weib zu töten. Als nun, der fremden Kraft zu Gebot, das Leben der Braut sich von ihrem Körper gelöst hatte und der starr und unbewegt lag, rang ihre Seele gewaltig mit der Seele der Toten um den Bräutigam. Als man sie zu Grabe trug aber, kamen ihrer beider Seelen vor die Entscheidung, und es war eine Menschenstimme über ihnen, die das Recht sprach, und sie rangen vor ihr um das Gericht. Und die Stimme sprach das Urteil: „Du Tote, die du keinen Teil mehr an der Erde hast, lass ab von ihr. Denn 
siehe, bei den Lebendigen ist das Recht. Es ist keine Schuld auf diesem Weib und dem Mann, der es begehrt. Sie mussten tun, was sie nicht wollten, um die Not ihrer Seele zu stillen." Und da die Tote nicht nachliess, die Braut zu bedrängen, schrie die Stimme sie an: „Lass ab von ihr! Siehst du nicht, dass sie zur Hochzeit gehen muss? Der Baldachin wartet!" $\mathrm{Da}$ erwachte die Braut zum Leben, liess sich aus dem Grabe tragen und in ihre Schleier kleiden, und noch leise betäubt folgte sie den Frauen zum Baldachin.

"Aber", sprach sie zum Bräutigam und zu den Gästen, da sie ihre Erzählung vollendet hatte, „als der Prediger den Segen über uns sprach, erkannte ich die Stimme, die über mich das Recht gesprochen hatte." 


\section{DIE VERGESSENE GESCHICHTE}

LS DER LEIB DES BAALSCHEM SICH
im immerwährenden Feuer seiner Seele schon
fast aufgezehrt hatte und er daran war, sein Er war auf sein letztes Lager hingestreckt, das ernimmer lassen sollte; den Kopf hatte er, ein weniges erhoben, in die linke Hand gestützt, und sein Antlitz war während der ganzen Zeit, da er sprach, voll den Seinen zugewandt. Es war schon gänzlich bleich und gleichsam entrückt, aber sein Blick ruhte fest und eindringlich auf dem, zu dem er sprach. Er sagte einem jeden aus der Schar, wie er sein künftiges Leben zu führen habe, welchem Geist er es anheimgeben solle, und achtete es nicht gering, den einzelnen Mann zu beraten, welcher Art sein Erwerb sein müsse, auf dass auch der Seele das Ihre beschieden werde. Manchem sagte er voraus, was die Zeit für ihn daherführen und welcher Gestalt sein Teil sein würde, das sie ihm auf ihrem Flug dereinst vor die Füsse fallen liesse.

Unter seinen Schülern aber war einer, der ihm auch diente und stets um ihn blieb. Dessen Name war Rabbi Simeon. Ihn rief der Baalschem zuletzt und sprach $z u$ ihm: „Freund, dir ist es vorgesehen, in der Welt umherzufahren und alle Orte heimzusuchen, wo Juden wohnen. Da wirst du in die Häuser gehen und Geschichten erzählen, von mir reden und mit ehrlichen Worten darstellen, was du all dein Lebtag bei mir gesehen und von mir erfahren hast. 
Und was die Menschen zum Lohn dir in die Hände legen für dein lebendiges Wort, davon soll dein Erwerb sein." Da quoll dem Rabbi Simeon ein Unmut im Herzen auf. Wohl liebte er es, wie nichts sonst auf der Welt, vom Meister zu reden und dessen Worte mit den eigenen Lippen nachzuformen; aber wie mochte es ihm frommen, bettlergleich umherzuziehen, keines Hauses - auch des geringsten nicht Herr zu sein, ein ewiger Wanderer zu Gast am fremden Herde? So brachte er es nicht über sich, zu schweigen, und musste sein Tröpfchen Bitterkeit und Kümmernis in des Herrn Sterben fliessen lassen, und er sagte halblaut: „Was wird der Sinn davon sein, unstetund flüchtig'soll ich werden und derärmstePilgermann hiernieden." Da tröstete ihn der Baalschem und redete ihm zu: „Dein Weg wird ein lichtes Ende haben, Freund, und auch ein irdisches Gut wirst du auf ihm finden."

Wie es dann alsbald geschah, dass der Meister sacht die letzten Fesseln löste und der Geist in das Ewige einging, waren die Schüler in Liebe bedacht, zu erfüllen, was der Wille des Baalschem über sie bestimmt hatte. Rabbi Simeon tat ein Wanderkleid an und zog von dannen und ging von Stadt zu Stadt, allen Juden die Geschichten vom heiligen Baalschem zu vermelden. Er gewann Ehre davon und hatte sein leichtes Auskommen. Und da er noch jung war und mit unbeschwertem Sinn die Augen schweifen lassen konnte, gewann er die schönen Wege sehr lieb, die über die bunte Erde führen, und im Hin- und Wiederziehen fühlte er keine Bangnis mehr. So 
waren zwei Jahre und ein halbes hingegangen, da traf er einen alten Mann, der aus Jerusalem kam, und der tat ihm zu wissen, dass in Italien in einer Stadt, deren Namen er ihm nannte, ein reicher Jude angesessen sei mit grossem Besitz, der in seinem Herzen eine erstaunliche Liebe trage zum heiligen Baalschem. Sein ganzer Sinn sei von ihm erfüllt, und all sein Trachten stehe darauf, vom Meister zu hören. Da meinte RabbiSimeon bei sich, dieser Jude in Italien sei der rechte Mann, die wunderbaren Geschehnisse, von denen er zu sagen wusste, zu vernehmen. Waren doch seine Worte von dern Erhabenen über manchen törichten Sinn dahinund an manchem leichtfertigen $\mathrm{Ohr}$ vorbeigezogen, so dass er wohl Lust spürte, vor einem wahren Lauscher, der ihm das Herz auftäte, zu erzählen.

Er kaufte ein Pferd und rüstete sich zur Reise. Sieben Monate währte es, bis er zur Stadt des reichen Mannes kam, denn er musste an jedem Orte unterwegs so lange verweilen, bis er sich durch sein Erzählen in den Häusern das Geld zur Zehrung für einen neuen Teil seiner Fahrt erworben hatte. Sogleich nach seiner Ankunft in der Stadt ging er in das Haus eines Juden und fragte nach jenem Mann, der so grosse Ehrfurcht für den Baalschem hegen sollte. Da erzählten ihm die Leute, dass der Jude, den er nannte, vor etwa zehn Jahren als ein Fremder in die Stadt gekommen sei. Er habe schon damals unerhörten Reichtum mit sich getragen. Wenige Monate habe er hier geweilt, da sei der Letzte eines grossen, schier königlichen Geschlechres gestorben; sein Palast und all sein umliegendes Gut sei an einen fernen Verwandten in 
Rom gefallen, der alsbald, da er sein angestammtes Haus nicht lassen wollte, den Wunsch aussprach, für all das hier möchte ein Käufer sich finden. Da nun sei der fremde Jude hingegangen und habe in purem Golde den grossen Kaufpreis erlegt. Und alle Juden des Landes seien es über alle Massen zufrieden, dass der fremde Mann so fürstengleich unter ihnen hause; denn es sei ein frommer und gütiger Segensgeist in ihm und über ihm. Auf dem Boden seines Besitzes habe er den Genossen einen herrlichen Tempel errichtet. $\mathrm{Da}$ trage seine Seele, die in einem ewigen niegesehenen Aufschwung zu Gottes Füssen liege, auch die Seelen der Lauen und Weltlichen mit sich nach oben. Am Sabbat sei sein Palast jedem ehrbaren Juden cffen, in weiten Sälen stünden die Sabbattafeln im Kerzenschein, im Linnen- und Silberglanz, und seit dem Fall der heiligen Stadt sei der Tag des Herrn wohl nirgend und nimmer so strahlend und herrlich erlebt worden wie hier. Und bei jeder der drei Mahlzeiten des Sabbats lasse der Reiche je eine Geschichte vom heiligen Baalschem sich und seinen Gästen vortragen, und in Ehren werde jeder aufgenommen, der von dem Gnadenreichen zu sagen wisse. Auch sei der Lohn über alle Weise: am Tage nach dem Feste reiche ihn der grosse Jude selbst in wohlgeprägtem Gold dem Erzähler.

Als Rabbi Simeon solches vernommen hatte, stärkte sich seine Seele in grosser Freude. Er entsandte nach dem Palast und liess da melden, ein Diener und Schüler des Heiligen sei in der Stadt angekommen. Sogleich kam der Haushofmeister, holte ihn ab und. 
führte ihn unter mancher Ehrenbezeugung nach dem Schloss, wo ihm mehrere schöne und bequeme Räume zu seiner Wohnung angewiesen wurden.

Indessen hatte es sich in der Stadt selbst, ja im ganzen umliegenden Land unter den jüdischen Leuten als seltene Kunde verbreitet, dass ein Schüler des Baalschem gekommen sei. Und am Sabbat drängten sich alle, die zu hören begierig waren, in so grosser Menge wie noch nie $z u$ den Tischen des gastlichen Mannes. Als die Gesänge der ersten Sabbatmahlzeit unter den Säulen der Halle feierlich und inniğ erklungen waren, erhob der Hausherr das Antlitz und wandte es dem Rabbi Simeon zu, und der las darin eine tiefe Bitte und eine sehnsüchtige Erwartung. Der Grosse forderte ihn mit leiser und demütiger Stimme auf, wenn er ihn und sein Haus dessen für würdig erachte, von dem hohen Meister zum Trost der Seelen zu reden. Rabbi Simeon richtete sich in seinem Stuble auf, legte die Arme auf die geschnitzte Lehne und öffnete den Mund, um in süssen und ehrfürchtigen Worten das Bild des wundersamen Herrn aus seiner Seele aufsteigen zu lassen. Und er war es gewöhnt, dass die Worte und Gleichnisse aus dem Leben des Baalschem wie von selbst aus seinen Lippen kamen, und dass sein Herz war wie ein volles Salbgefäss, bereit, bei jedem Gedenken an den Meister überzufliessen. Aber wie er nun da sass, gewärtig, dass die Rede sich ihm im Munde gestalten würde, stieg ihm plötzlich von innen eine Eiseskälte auf, das Wort gefror ihm auf den Lippen, er erstarrte und erbleichte; dann stürzte eine siedende Welle über ihn 
hin, er erglühte und errötete, und alles Besinnen wich von ihm. Wie hinter einem glutroten Schleier sah er viele Augen an seinem Munde hängen; er tat die Lippen auf, seinen eigenen Laut zu hören, aber er fühlte, dass er klanglos totgeboren blieb. Es peinigte ihn die stumme Forderung auf all den Gesichtern, die ihm unerbit lich zugewandt blieben; allenthalben sah er Gedanken

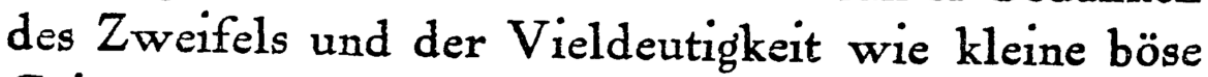
Geisterchen darüber hinschwirren. Da nahm er alle seine Kraft zusammen, um das Bild des toten Meisters vor seine Seele zu stellen, aber es blieb in ewigem Schatten und wollte nicht aufsteigen. Nun gedachte er der Stadt Miedzyborz, ihrer Häuser und Mauern und Gärten und all der kleinen Dinge, die ihm so vertraut waren, aber der Gedanke wandelte sich nicht zum Bilde und sein Herz blieb leer. Und nichts, nicht der kleinste Zufall, nicht die geringste Begebenheit war ihm gegenwärtig. Es war, als ob er, am selben $T$ ag geboren, nichts von der Welt in seinem Sinne trüge. Tief verwirrt und beschämt brach er in Tränen aus und fühlte wie ein Feuermal brennend den Schmerz in seiner Seele, den die Missachtung, die nun offen auf allen Gesichtern stand, ihm zufügte. Sie mochten wohl glauben, er sei ein Betrüger, vom Geist der Lüge tückisch im Stiche gelassen, ein Falscher, der den Baalschem nie von Angesicht erschaut. Und er erlebte, wie die Leute voll Abscheu sich von ihm wandten. Nur der Hausherr sah ihn voll gütigen Verstehens und versonnen an, und er sagte: "Wir warten bis morgen. Vielleicht kommt dir dein Erinnern zurück." 
Rabbi Simeon lag die ganze Nacht in Tränen und wartete, dass das Bild des Baalschem ihn heimsuchen würde. Aber er blieb verlassen, und sein Sinn war verödet. Als er bei der Sabbatmorgenmahlzeit erschien, wandten sich alle von ihm ab oder sahen über ihn hinweg, als ob der Raum, in dem er sich befand, eitel Luft wäre, und er spürte wohl, welch bittere Verachtung aller Herr geworden war. Der Hausherr aber sprach ihn wiederum an: „Vielleicht kannst du uns jetzt eine Geschichte erzählen." Da redete Rabbi Simeon zu ihm und beschwor ihm, dass diese Nacht des Vergessens, in die sein Denken versunken war, kein leer und zufällig Ding sei, sondern sicherlich von einer überirdisch herrschenden Gewalt verhängt aus tiefem Grund und zu sinnvollem Ziel. Der reiche Mann antwortete; ,Lasst uns warten bis zur dritten Mahlzeit." Und Rabbi Simeon wurde auf seinem Angesicht eines stillen, demütigen und ergebenen Lächelns gewahr. Aber er war von Schmerz und Scham allzusehr heimgesucht, als dass er sich dessen in sich bedacht hätte. Auch bei der dritten Mahlzeit kehrte ihm die Erinnerung nicht wieder, und er litt in einem Abgrund der Qualen. Der Sinn der Gäste war gegen ihn ergrimmt, denn sie vermeinten, er habe sie mit falschen Worten verhöhnen wollen oder sein Herz sei noch mit unerforschten Ränken wider sie erfüllt. Sie sagten ihm spitze und beissende Reden und übergossen ihn mit Spott und schimpflichen Worten. Err aber wappnete sich in Liebe und nahm alles mit getreuem und unverzagtem Herzen 
entgegen, denn ganz in sich fühlte er nun, dass alles dies geschehen müsse, um ein wunderbares Ding zu erfüllen. Aber sein irdischer Verstand gab sich nicht zufrieden, wie sehr auch sein hohes Erkennen in sich ruhte. Er quälte sich gar sehr, seine Seele mit einer Erklärung des Geschehens zu stillen. So meinte er zuweilen, dass der Baalschem über ihn erzürnt sei, weil er die Heimat gelassen habe, um in ein ungewisses Land zu ziehen, oder dass er ihn um der Ursache willen, dass sein Sinnengrund nicht genug geläutert und erglüht sei, nicht mehr wert erachte, sein Leben zu erzählen. Und noch viel dergleichen ersann er sich, aber nichts drang so tief in sein Gemüt, dass es seine fragende Begierde erlöscht hätte. So waren seine Nöte ohne Ende, und er versank ins Gebet, ob ihm nicht aus dem Grunde der Andacht sein Heil entgegenschauen möchte.

Am Sabbatausgang sandte sein Gastgeber ein letztes Mal zu ihm und liess ihn fragen, ob er sich nun entsinne. Aber Rabbi Simeon fühlte den hohen Sinn der Dinge nicht mehr, auch nicht die Inbrunst und Sehnsucht, die in der Frage war; er spürte nur noch die Bedrängnis, die man ihm antat, und die verdross ihn sehr, und er sprach; „Es liegt nicht in meiner Macht. Der Himmel ist es, der nicht will. Lasst mich nach Hause zurückkehren!" Da kam der Herr selbst zu ihm und sagte ihm: „Tue mir die Liebe an und verweile noch ein weniges, etwa bis zur Mitte der Woche, vielleicht dass uns von oben noch Erbarmen wird. Und entsinnst du dich auch 
dann nicht, so magst du scheiden und nach Hause zurückkehren." Rabbi Simeon achtete der Worte des Mannes in seinem eigenen Gram nicht allzusehr. Er verstand nur, dass er bleiben sollte, und er willigte darein, weil er dem Herrn, der durch ihn enttäuscht worden war, zu Willen sein mochte.

Die Zeit aber war bald dahin, und nichts hatte sich verändert. Rabbi Simeon nahm unter Tränen der Scham Urlaub. Der reiche Mann entliess ihn mit traurig gesenktem Auge und reichte ihm eine ansehnliche Gabe, die ihn für die weite Reise und die vielen Nöte entschädigen sollte. Auch gab er ihm einen bequemen Reisewagen und Diener mit, dass sie ihn bis an die Grenze des Landes brächten, von wo ab er sich wohl leichter allein mit seinem Pferde behälfe. Der Gast stieg hinab und setzte sich in den Wagen. Alles war bereit, der Kutscher trieb eben die Pferde an, da war es Rabbi Simeon, als führe ihm blitzgleich ein weisser zündender Lichtstrahl durch den Leib. Schmerz und Seligkeit waren in ein Gefühl gemengt. Und als er sich auf sich selbst zu besinnen vermochte, war es eine gewaltige Geschichte von dem heiligen Baalschem, die plötzlich urnahe mit Bildesklarheit ihm vor der Seele stand. Er gab sich eine Weile dem heftigen Entzücken hin, das ihn im Augenblick der Gnade überkommen hatte, dann hiess er den Kutscher den Wagen, der sich bereits einige Strassen von dem Palast entfernt hatte, wenden und kehrte zum Hause zurück, wo er einen Diener zum Herrn entsandte und ihm melden liess, Rabbi Simeon sei zurückgekehrt, da er sich einer 
herrlichen Geschichte von dem heiligen Meister entsonnen habe. Und der Herr empfing ihn - Rabbi Simeon aber, der nichts als seine Geschichte sah und fühlte, entging die zitternde Erwartung in seinen Mienen -, und er sprach: „Ich bitte dich, dass du dich zu mir setzest und mir die Begebenheit vermeldest, deren du dich zu dieser Stunde entsannest." Rabbi Simeon aber erzählte ihm, was folgt:

,Es begab sich einmal um die Zeit des ersten Frühjahrs, just vor den Tagen, in denen die Christen ihr Ostern feiern, dass der heilige Baalschem einen ganzen Sabbat in unsäglicher Betrübnis verbrachte. In tiefer Versunkenheit ging er in seinem Haus umher, bange, als ob seine Seele ihn verlassen hätte und $z u$ irgend einem gefahrreichen, verhängnisschweren Kampfe gezogen wäre, und als erwartete er zitternd und der $Z_{\text {weifel voll ihre Wiederkehr. Nach }}$ der dritten Mahlzeit, die er schweigend eingenommen hatte, hiess er den Wagen bereiten und die Pferde einspannen. Seine Schwermut und sein $Z$ agen hatten wie eine drohend gefärbte Wetterwolke über dem Haus und den Seinen gelagert; es war, als ob alle in einem innern Weinen aufgingen. Bei seinem Gebot, die Ausfahrt zu rüsten, aber zog ein freies Aufatmen erlösend durch den Raum, denn alle wussten, auf diesem Weg ins Land nach Sabbatausgang pf legte sich $z \mathfrak{u}$ schlichten und $z u$ befreien, was vorher an Bösem und Gefahrvollem sich angesammelt und zusammengeballt hatte.

Diesesmal waren es nur drei unter den Seinen, denen er deu Segien gönnte, an der Fahrt teilzuhaben, 128 
und ich war einer unter ihnen. Wir fuhren die ganze Nacht, und wie oft schon, kannte keiner von uns das Ziel der Fahrt. Als das Morgenlicht zögernd aufstieg, kamen wir in einer grossen Stadt an. Die Pferde mässigten ihren rasenden Lauf und hielten plötzlich, wie von einer gewaltigen Hand eingehalten, vor dem Tor eines grossen düsteren Hauses, dessen Seite in einer engen Gasse lag, während der Giebel einem breiten Platz zugekehrt schien. Das Tor aber war verschlossen, die Fenster von den Läden bedeckt, die ganze Gasse lag öde und verschwiegen da. Der Meister hiess mich absteigen und anpochen. Ich tat es und tat es eine geraume Zeit vergeblich, und schliesslich legte ich all mein Begehren nach Rast hinein, und die grauen, verschlossenen Häuser hallten von meinen Schlägen wieder. $D_{a}$ wurde eine kleine Tür, die in einem der riesigen Seitenflügel des Tores eingelassen war, von innen geöffnet. Vor uns stand eine alte Frau mit verstörtem Angesicht, daraus die geröteten Augen uns trübe und verzweifelt anstarrten. Sie betrachtete uns eine Weile, dann schrie sie plötzlich auf uns ein: „Was treibt euch, dass ihr gerade heute hierher kommen musstet! Ja, wisset ihr denn nicht, dass ihr auf dem Wege zur Schlachtbank seid?" Und da ich sie ohne Verständnis anblickte, denn mir schien, es sei uns eine Tolle in den Weg geraten, zog sie uns in den Torweg und sprach: „Nun sehe ich, dass ihr Fremde seid und mit dem Brauch unserer Stadt nicht vertraut. Der ist so: Sie haben seit etlichen Jahren hier einen Christenbischof, einen stolzen, unbeugsamen Mann, 
der den Juden blutfeind ist. Der nun hat geboten, dass sie alle Juden, die sie am Tag vor ihrem Osterfest auf der Strasse finden, greifen und martern, um Rache für ihren Messias zu üben. Deshalb hüten wir uns an diesem $T$ ag und bergen uns zuinnerst in den Häusern. Das wissen sie wohl, und nun wollen sie das Los werfen, wer von unserem Volk der Pein anheimfallen soll. Wehe ihm, er wird vergehen unter ihren Händen! Euch aber," schrie sie und drängte uns zum Wagen, ,euch, die ihr fremd hier seid, wird man nicht schonen! Ihr kennet nicht die Leute dieser Stadt, reissende Tiere sind sie, wenn ihr Blut entzündet wird! Eilet, eilet, suchet den nächsten Ort zu gewinnen und wartet dort das Ende dieses Unglückstages ab, ehe ihr hierherkommet, eure Geschäfte zu tun!" So schrie die Alte und goss ihren Schmerz über uns aus und hob die Hände und ballte sie gegen oben. Uns dreien, die wir den Meister geleitet hatten, wurde es dunkel im Herzen. Der Baalschem aber hatte ihrer keine Acht, schob sie beiseite, trat ein, hiess uns das Tor öffnen und Wagen und Pferde in den Ställen und unseren Bedarf, den wir mit uns führten, im Hause bergen. Er aber stand und schaute ruhig auf alles, was nach seinem Wort geschah. Dann hiess er uns Tor und Tür wieder schliessen, und wir standen in demgrossen dunklen Flur. DerMeister winkte uns und ging voran, die Treppe aus geschnitztem Holz um einige Stufen ersteigend. Er öffnete eine Tür, und wir traten in einen grossen, stattlichen Raum, der um ein weniges über die ebene Erde erhöht war. Ich stand eine Weile, ehe 
meine Augen das Zimmer übersahen, denn obwohl draussen inzwischen der helle Morgen heraufgestiegen war, lag das Gemach im Dunkel. Man hatte die Fensterläden geschlossen und überdies die schweren Vorhänge zusammengezogen. Nach einiger Umschau wurde ich gewahr, dass der Raum viele Menschen barg. Sie hatten sich lautlos, wie vor Schmerz und Angst der Besinnung ledig, in den Ecken und Winkeln versteckt. Es mochte wohl der ganze Hausstand hier versammelt sein. Indessen war uns die Alte vom Hausflur hereingefolgt, weinte und widerstritt in heftigen Worten dem Baalschem, dass er eingedrungen sei und am Ende damit gar das Unglück über ihr Haus herbeiziehe. Er antwortete ihr aber nicht, sondern durchmass die Stube mit grossen Schritten und hielt bei einem der Fenster, das von einem halbrunden Ausbau ins Freie ging. Er streckte gelassen die Hand aus und schob die Vorhänge zurück, hierauf öffnete er die Fenster und die hölzernen Läden dahinter und stand nun mit seiner ganzen Gestalt gegen den offenen Rahmen. Die Morgenhelle und eine klare Luft strömten herein. Die Alte wagte nicht mehr laut zu reden, aber sie bedrängte den Meister mit verzweiflungsvollen Geberden, dass er wieder schliessen und sich zurückziehen möge. $\mathrm{Da}$ er aber gar nicht auf sie sah, sank sie endlich schweigend neben den andern zu Boden.

Das geöffnete Fenster aber, das uns nun den freien Blick gewährte, ging nicht in die enge Gasse, durch die wir angekommen waren, sondern auf jenengrossen 
Platz, dem die Giebelseite des Hauses angehörte. Inmitten sah ich eine Kirche aus weissem, edlem Gestein, die zwei schlanke, spitze Türme gegen oben sandte. Gerade unserem Fenster gegenüber, an der Aussenseite des Gemäuers, war eine Kanzel angebracht, wunderbar anzuschauen, wie ein geöffneter Blütenkelch. Sie war herrlich geziert mit erhabenem Bildwerk und goldenem Wandschmuck. Etwa dreissig steinerne Stufen führten zu ihrer Höhe. Als der Meister aufgetan hatte, waren noch wenige Menschen dagewesen, aber sie mehrten sich von einer Minute zur andern, sammelten sich und umstanden jetzt schon in gewaltiger Menge die Kanzel. Und alsdann dröhnten die Stimmen vieler Glocken über uns hin und machten die Luft in dem Zimmer erbeben. Draussen unter den Menschen wurde eine Bewegung bemerkbar, ein Schieben und Drängen, und dann wurde in der dunklen Menge eine breite lichte Strasse, und es erschien im prächtigen Aufzug mit Fahnen, Lichtern und Räucherwolken unter seinem silbernen Baldachin der Bischof. Nun war alles still geworden und wartete, der Bischof aber in seinem gleissenden brokatnen Gewand stieg die Stufen zurKanzel hinan. Dortversank er anscheinend in ein stilles Beten, sich zur Predigt zu bereiten, und die ganze Menge kniete lautlos.

Der Meister aber stand unentwegt in dem offenen Fenster und sah hinaus. Plötzlich sprach er mit heller Stimme in eben dieses lautlose Schweigen hinein: „Simeon, gehe hinaus und sage dem Bischof: Israel, der Sohn Eliesers, ist hier und lässt dich 
rufen." Als die Leute, die mit uns im Zimmer waren, diese Worte hörten, kam eine wilde Angst über sie und liess sie selbst die Furcht vergessen, die sie vorher getrieben hatte, sich in den Ecken $z u$ bergen. Sie fuhren insgesamt auf und umringten den Baalschem und schrien auf ihn ein. Ein alter Mann sagte ihm, bebend vor Zorn: „Wer bist du denn, Verruchter, der du einen jüdischen Mann zu dieser Stunde dem Henker in die Hände lieferst!" Und sie verfluchten ihn aus der Bitterkeit ihrer gefolterten Seelen. Er aber stand, als rührten ihre Worte ihm nicht an Ohr und Verständnis, sah mich bedeutsam an und sprach: „Geh, Simeon, geh schnell und fürchte dich nicht!" Und ich, der ich einen Gedanken lang gestanden und wider die Furcht in meinem Herzen gestritten hatte, erkannte nun meinen Herrn wie zuvor und ging ohne Zagen durch die Menge zur Kanzel, und keiner hat auch nur ein Wort gesprochen oder einen Finger an mein Gewand getan. Und ich schritt die Hälfte der Stufen hinan, bis ich innehielt und den Bischof in hebräischer Sprache anredete: „Der Baalschem ist hier in jenem Hause. Er lässt dich rufen, dass du zu ihm kommen mögest." Da gab mir der Bischof in der gleichen Sprache Erwiderung: „Ich weiss von seiner Gegenwart. Sage deinem Herrn, dass ich sogleich nach der Predigt bei ihm erscheinen werde." Und ich wandte mich und ging durch die Menge über den Platz und trat in das Haus. Die Leute aber, bei denen wir weilten, hatten in der Beängstigung ihrer Sinne sich an die ver- 
schlossenen Fenster geschlichen, um durch die Spalten auf den Platz zu blicken und zu sehen, was mit mir sich begeben würde. Und sie sahen, dass ich heil durch die Menge zur Kanzel kam, mit dem Bischof $Z$ wiesprache hielt, wie mir geheissen ward, und ungefährdet wieder heimkehrte. Da fassten sie, dass es etwas Grosses um unseren Meister sein müsse, der dem Geist der Blutgier gebot, und als ich in das Zimmer trat, gewahrte ich sie meinen Herrn umringen und ihm Abbitte tun. Aber so wie er früher nichts um ihr Schelten gegeben hatte, so achtete er jetzt ihres Lobes nicht. Er hörte unbeirrt nur auf meine Botschaft, als seien er und ich allein im Hause. Als er mich vernommen hatte, lächelte er ein weniges und sprach zu mir: „Kehre um, geh noch einmal zur Kanzel und sage dem Bischof: ,Sei kein Narr und komme sogleich, denn es ruft und lädt dich der Mann Israel, der Sohn des Elieser'" Ich tat nach seinem Geheiss und schritt wieder zur Kanzel. Als ich auf den Platz trat, hatte der Bischof eben begonnen, zu predigen. Ich stieg hinan und zog ihn ein wenig an seinen Mantel, dass er meiner gewahr werde. $\mathrm{Da}$ hielt er inne und sah mich an, und ich wiederholte die Worte des Baalschem. Ich bemerkte, dass sein Angesicht sich bei meiner Rede verfärbte; dann wandte er sich zum Volk und sprach: „Habet für eine kleine Weile Geduld. Ich werde zurückkehren." Er folgte mir über den Platz durch die Menge in seinen gold- und blumengestickten Gewändern, die hohe goldene Mütze auf 
dem Haupt, und also trat er in das Haus und trat vor meinen Meister, den heiligen Baalschem.

Sie gingen beide in ein besonderes Zimmer, verschlossen die Tür hinter sich und verharrten so an die zwei Stunden. Dann trat der Baalschem allein heraus. Er war hoch aufgerichtet, und in seinen Augen leuchtete die Herrlichkeit Gottes. Er befahl uns, eilig Wagen und Pferde zu rüsten, und ohne Besinnen und Umschau fuhren wir von dannen.

Ich weiss nicht, was zwischen dem Bischof und unserem Meister sich ereignet hat; auch den Namen der Stadt weiss ich bis heute nicht, denn der Baalschem hat ihn uns damals und später nicht kund getan. Ich weiss nur, dass es ein Grosses war, das der Heilige gewirkt hatte, als er aus jener verschlossenen Stube trat, denn der Geist des Herrn leuchtete gewaltig von seiner Stirne, und er war anzusehen wie ein Cherub aus den Heerscharen. Nach seinem Tod habe ich versäumt, Nachfrage nach jener Begebenheit zu halten, denn ich hatte sie alsbald nach unserer Rückkehr völlig aus den Gedanken verloren, und heute erst, eben als ich dieses Haus verlassen hatte, entsann ich mich ihrer wieder."

Als Rabbi Simeon schwieg, stand der reiche Mann auf, sank wortlos in die Knie, streckte die Hände gegen oben, und Tränen stürzten aus seinen Augen nieder. Endlich rang sich ein Strom glühender Dankesworte von seinen Lippen, und er pries Gott mit unendlichem Lobe. Dann sprach er zu Rabbi Simeon: „Mein Freund, gesegnet sei dein Kommen, 
und gesegnet ein jedes deiner Worte. Ich weiss, dass die lautere Wahrheit aus deinem Munde kam. Ich will dir kundtun, was von der Begebenheit dir dunkel blieb. Wisse, dass ich jener Bischof bin, den du gerufen hast. Und wisse, dass ich dich erkannt habe, sowie du mein Haus betratest.

Ich war einst ein Jude, erfüllt mit der wahren, wunderbaren Weisheit, und eine geheiligte Seele war mein eigen. $\mathrm{Da}$ gewann der Geist der bösen Mächte Gewalt über mich und beherrschte mich völlig, also dass ich vom Glauben abfiel. Und da meine Seele stark und fruchtbar blieb und voll des Feuers war, gewann ich bald hohes Ansehen unter den Gläubigen meines neuen Bekenntnisses. Ich nahm die Weihen ihrer Kirche, stieg immer höher in ihren Würden, und bald beherrschte ich als Bischof alle Seelen des Landes.

Gross aber war mein Hass gegen mein einstiges Volk, und immer höher schwoll er an jedem neuen Tage. Denn wisse: in den Nächten, wenn meine Seele wehrlos war und vom bösen Geiste allen Gewalten preisgegeben, kam die Scham des Abtrünnigen zu mir und erwürgte mir alle Ruhe. Tag's aber, wenn ich gewappnet war mit dem Schilde des Versuchers, nahm ich Rache für die Unrast meiner Nächte, und da schürte ich das böse Feuer und nährte alle Tücken in den Seelen meiner Gemeinde gegen die Kinder des Volkes, das ich verleugnet hatte. Ich hiess sie grausame Racheostern feiern und vergiftete den Juden alle Tage des Jahres mit bitterer Angst. 
Nun aber war es so, dass meine jüdischen Ahnen ein glaubensstolzes und ehrenhaftes Geschlecht darstellten, das ein grosses Verdienst vor dem Herrn aufwies, und manch einer von ihnen hatte mit dem Blute seines Herzens den hohen Bund besiegelt. Meine Missetat hatte den Frieden ihrer Ewigkeit gestört; im Schmerze versammelten sie sich und suchten den heiligen Baalschem heim und baten ihn, dass er sich meiner verfallenen Seele erbarme und $z u$ meiner Lösung wirke. Da kam der Geist des Heiligen in nächtlichen Träumen zu mir und rang mit dem bösen Geiste, der mich besass. Sie waren beide gewaltige Kämpfer, und ich wurde $z$ wischen ihnen hin- und hergerissen wie ein armseliges Blatt im feurigen Sturm. An jenem Sabbat der Juden aber, der dem christlichen Osterfest voranging, war der Geist des Heiligen Tag und Nacht mir zur Seite, und schon hatte er meinen Willen gewonnen, und in der Nacht beschloss ich, am Morgen zu fliehen, alles zu lassen und $z \mathfrak{u}$ dem Volk meiner Kindheit wiederzukehren.

Aber mit dem Tage stieg der Zweifel in mir auf, und als die Glocken nach mir riefen und die Menge wartend die Kirche umgab, die Diener mir die goldenen Gewänder auf die Schultern legten. da vermochte ich nicht, all dem Glanz auf Erden, all der Macht über den Menschensinn zu entsagen, und ich schritt hinan zur Kanzel. Da entsandte dich der Heilige, mich zu rufen. Ich aber wollte vorerst meine Predigt sprechen, denn an meinen eigenen Worten, am entzündeten Gemüt derer, die mich 
umringten, gedachte ich meinen Willen zu stärken, um dann vor dem Meister in meinem Trotz bestehen zu können. Du riefst zum zweiten, und siehe, da verliess mich aller Widerstand, und ich folgte, wie ein Kind in der Dämmerung dem Ruf der Mutter nachgeht.

Ich kam zum Meister, und er rang um meine Seele und gewann sie. Er wies mir den Weg, wie ich mich von meiner Schuld erlösen könne, und ich wurde zum Büsser von dieser Stunde an. Vor dem König und vor allem Volke bekannte ich mein Verfehlen; dann zog ich aus dem Land. Ich kam hierher und verbrachte meine Jahre in der Läuterung meiner Seele und erwartete den göttlichen Losspruch. Denn wisse, der Baalschem hat mir verkündet: ,Wenn einst einer zu dir kommt aus fernem Land und dir deine Geschichte erzählt, deute es als das Zeichen der Befreiung aus den Ketten deiner Taten.' Und als du kamst und alles Geschehene deinem Gedanken entrückt war, da verstand ich, dass dies um meinetwillen sei, weil ich das Meine noch nicht vollbracht habe. Und ich versenkte mich aufs neue in die Tiefen der Hingabe. Nun aber, da du dich entsannest, weiss ich, dass mir geholfen ist.

Du aber, mein Freund, wirst nun eine Stätte haben und nimmer flüchtig sein auf Erden; denn alles, was mein ist, will ich mit dir teilen, aus dessen Munde mir das Wort der Lösung kam.“ 


\section{DIE NIEDERGESTIEGENE SEELE}

S WAR UNTER DEN VIELEN KINDER-

losen Ehefrauen, die mit Bitten und $\mathrm{Be}$ drängen um das Wunder zum Baalschem kamen, ein Weib, das regelmässig in bestimmten, kurzen Zeitfristen wiederkehrte, um zu seinen Füssen zu weinen und ihm den Mangel ihres Lebens still ans Herz zu fesseln. Von ihr kam kein lautes Heischen, kein gewaltsam überfliessendes Schluchzen und Begehren. Sie erschien und verschwand ohne viele Worte, doch mit einer stummen, stählernen Zähigkeit und einem hartnäckigen Brand in den Augen. Als der Baalschem sie zum erstenmal unter seinen Besuchern gesehen hatte, war sie ein lieblich jugendfrisches Geschöpf gewesen. In den Jahren aber, da sie in ihrer eindringlich schweigsamen Art oftmals wiedergekehrt war, wurde ihr Antlitz vergilbt und ihre Gestalt so hager, als sei alles hinweggebleicht und hinweggezehrt vom grossen Wunsch und von den vielen Wanderwegen, denn die Stadt, wo sie vermählt und behaust war, lag weit vom Wohnort des Meisters.

Das war dem Heiligen wohl bekannt und griff ihm innig ans Herz. Als sie einstmals wieder das schmale, stille Haupt vor ihm beugte, die dunklen Augen von lautlos rieselnden Tränen benässt, flehend mit dieser einzigen, ehrfürchtigen Geberde, legte er ihr seine Hand auf den Scheitel und hielt eine lange Weile nachsinnend inne. Sein Auge sah weithin, wie das Auge eines, der aus einer dahin- 
gegangenen Ferne eine lange Reihe vergangener Bilder aufweckt. Dann atmete er tief auf, schaute auf sie nieder und sagte mild: „Geh heim, Weib, du wirst in Jahresfrist den Sohn gebären, auf den deine Seele hofft!" Das Weib ging also hinweg. Und sieben Jahresläufe wurde sie nimmer vom Meister ersehn. Darnach fand er sie eines Tages wieder mit einem herrlichen Knaben an der Hand unter der Schar derer, die ihn zum Fürsprech ihrer Seelen erkoren. „Meister,“ sprach sie, ,sieh hier das Kind, das mir nach deinem Worte geboren wurde. Dir bringe ich es dar, denn wisse, ich zittre um sein Wesen, das nicht aus meinem geboren scheint, wie sein Leib aus meinem Leibe. Und ich bin bange, dass sein Anblick und Besitz mein und meines Mannes geringen Sinn zur Hoffahrt verführen möchte." Der Baalschem sah auf das Kind, und es war ihm, als hätte er niemals etwas so Anmutiges und Stolzes ersehen wie dieses kleine Geschöpf in seinem dürftigen Gewändchen. Auch das zarte Wesen schaute auf, aber keineswegs nach Kinderart, scheu oder zutraulich, vielmehr ernst und schwer senkte es seine Augen in die des Meisters ein. Es war wie ein Fragen darin oder ein schwermütiges Suchen. Der Baalschem hob das Kind hoch auf seine Arme und fragte das Weib: „Wie kann dein Herz es verwinden, ihn von dir zu lassen, um den du all die Jahre deiner Jugend mit Gott gerungen hast?" $\mathrm{Da}$ antwortete das Weib: „Herr, als der Knabe zum erstenmal seine Augen auftat und mich ansah, mit fremden 
Blicken wie von weither, da zog mein armes Herz sich zusammen in Staunen und Scheu, als ob er nicht meines Blutes wäre. Mit seinem fernen Auge hat er alsdann, als er grösser wurde, über unser kleines Haus hinweggesehn und über all unser Tun und ist mit uns gewesen gleich als ein Gast und nicht als unser einer. $O b$ er auch still und gut war und mir wenig Nöte mit seines Leibes Bedürfen antat, Meister, es ist ein ewiges Zuwarten und Aufhorchen in seinem kleinen Gesicht und ein ganz seltsames Wesen über ihm. Da sank uns gar bald der Mut, dieses Kind zu leiten und aufzuziehn, denn uns dünkt, wer ihm Führer sein will, der muss weiter sehen, als wir beiden armen Leute. Darum biete ich ihn dir!"

Der Baalschem nickte schweigend und entliess die Frau, den Knaben aber nahm er unter sein Hausgesind auf. Und er gewährte ihm, heranzuwachsen, seinem Herzen allzeit nahe, und speiste seine Seele mit dem grossen, heiligen Feuer des eigenen Wesens. Er liebte ihn mit einer blühenden, reichen Liebe, wie man eines einzig teuren Freundes Kind hält. Der Knabe aber hing seinem Pfleger mit einer Treue an, die so brennend als ehrfürchtig war, und kannte kein seligeres Genügen, als mit dem Heiligen die Luft eines Raumes zu atmen und still geduldet jedes Wort seiner Rede aufzusaugen. Und derart war das Kind im Stand der hohen Gnade, dass es allen Staunen schuf, die ihn sahen, und in allerHerzen Gefallen gewann. Es waren viele unter den Reichen, die ihn gern ihrem Haus 
zur Ehre gewonnen hätten und willens waren, ihn einer Tochter $z u$ vermählen. Und es schickte sich, dass sie dem Meister davon redeten. Der aber gab ihnen nur geringes Gehör und wehrte sie so leichthin lächelnd $a b$, wie man ein gänzlich Unmögliches abstreift. So gedieh in allen die Meinung, es sei dies darum, dass keine der Verbindungen ihm genug des Glanzes für den Pflegesohn verheisse. So gebot ihnen die Ehrfurcht vor dem Meister, ihren Wunsch $\mathrm{zu}$ vergessen.

$\mathrm{Da}$ geschah es eines Tages, dass der Baalschem einen Vertrauten $z u$ sich beschied und ihn in eine entfernte Stadt gehen und alldort einen Mann aufsuchen hiess, dessen Namen er ihm zu wissen tat. Diesem hiess er ihn ein Schreiben reichen, dass er in seine Hände legte. Der Bote ging wie ihm befohlen war und kam nach zweier Wochen Wanderschaft in den genannten Ort und forschte in den Häusern der Frommen nach dem Manne. Allein, es zeigte sich, dass keine Seele den Namen kannte. So ging Tag um Tag hin, und nichts wurde dem Suchenden kund, so dass sein Mut schon sank und Beschämung ihn befiel, als er eines Abends einem ältlichen, gebückten und armseligen Juden begegnete, der einen Korb frischer Gartenfrüchte feilbot. $\mathrm{Da}$ er ihn von ungefähr nach seinem Namen fragte, wies es sich, dass er es sein musste, dem das Schreiben des Baalschem bestimmt war. $\mathrm{Da}$ der Bote dies erkannt hatte, reichte er ihm den Brief, obgleich es ihm gar sonderbar erschien, was der Heilige diesem geringen und töricht aussehenden 
Manne so wichtiges mitzuteilen haben möchte. Allein alsbald zeigte sich, dass der Händler des Lesens keineswegs kundig war, und so eröffnete der Bote den Brief und las ihn ihm vor. Da war geschrieben, dass der Meister für seinen Pflegesohn des armen Mannes drittgeborene Tochter zum Weibe heische - es war ihr Name und Alter genannt und ferner, dass er willens sei, die Aussteuer und Hochzeit aus seinem Gute zu besorgen. Auch wolle er dem Vater fürder Beistand tun, falls es ihm an irgend einem Dinge mangle. „Bist du also zufrieden?" fragte der Bote den Alten. "Ach, Herr", sagte der und lachte über sein ganzes vergrämtes $\mathrm{Ge}$ sicht, ,wie sollt ich es wohl zustande bringen, da unzufrieden zu sein? Hab ich nicht das Haus voller Töchter, die barfuss gehen und sich um den raren Bissen untereinander balgen? Und gar dies Kind, das der Erhabene seinem Knaben zum Weibe begehrt? Sie ist viel zu vornehm für meine Armut, geht und tut ihr Tagewerk, als ob sie im Traume wandle, und setzt ihre Rede, dass ich alter Einfältiger kaum weiss, was sie da sagt!"

Des nächsten Tages brachen sie auf, zum Baalschem zu ziehen, der Bote und der alte Jude mit seinem Kind. Als sie im Haus des Meisters angelangt waren, gab er dem Vertrauten reichen Dank und Lohn, den Vater mit seiner Tochter aber nahm er liebreich auf und tat ihnen viel Güte an, dass sie in Freude und Heiterkeit aurerstanden wie die Pflanzen am Morgenlicht. Alsbald bereitete sich das Haus zur Hochzeit. Das Segensgeleit aber 
sprach der Baalschem selbst über die jungen Leute. Als das Mahl seinem Ende zuging und alle, die um die blanken Tafeln sassen, freudigen und feierlichen Herzens waren, begann der Heilige, fast wie achtlos, nur zum Nächsten gewendet, und erzählte mit leiser Stimme eine Geschichte. An seinen Mienen jedoch und am Ernste seiner wunderbaren Augen erriet ein Jeder, dass dieses Ding, von $\operatorname{dem}$ er zu reden anhub, aus der Urquelle seines Wissens kam und an den Sinn dieses heiligen Tages rührte. So wurden sie aufhorchend stumm und unterliessen jegliche Hantierung, das Antlitz und das Wesen dem Meister zugewandt. Das Brautpaar aber fasste sich an den Händen und lauschte, wie in die eigene Seele hinein horchend, vom Geheimnis umfangen.

Die Geschichte lautete also:

Es herrschte einst ein weitgebietender König in einem fernen Lande, der war sehr traurig durch viele Jahre, denn sein Gemahl hatte ihm kein Kind geboren.

Und da er nach seinem Hingang all seine hohe Macht und das Reich nicht seines eigenen Blutes Sprossen lassen konnte, starb ihm im Herzen der letzte Freudenfunke und der Anblick seiner Throngüter und seines Landes edle Friedensblüte machten ihn nimmer froh. Also sprach er von dieses Schattens nächtiger Düsterkeit über seinem einst strahlenden Leben mit einem grossen Magier jener Tage. Der hörte ihm wägend zu, lächelte böse und vielsagend und redete alsdann: „Mein Herr, es liegt ein jegliches Ding daran, dass wir die 
Oberen zwingen mit heftigem Ansturm der wünschenden Seele und mit nimmermattem Ringen, unserem Begehren nachzugeben. Es mag aber sein, dass du ermüdet bist ob deiner Schwermut. So harre ein kleines, ich will dir Helfer schaffen im Rufen und im Streit. Folge nur meinem Rat ohne Besinnen und lasse noch heute im Lande wissen, dass du es verhängest über das Volk der Juden, das unter deinem eingeborenen Volke haust, es möge solange verurteilt sein, seines Glaubens und seiner Sitten $z u$ vergessen und ihrer nimmer zu pflegen bei Todesnot, bis der Himmel dir den Sohn und Erben deiner glorreichen Herrschaft gewährt."

Obzwar der König mit nichten begriff, wie es in der Meinung des Magiers um das bestellt war, was er dartat, und wie all dies mit einem Erben seines Blutes, den er also gewinnen sollte, zusammenhing, willigte er gleichwohl in den Vorschlag und liess die Kunde verbreiten rings in allen seinen Landen. Da erschrak ein jeglich jüdisches Herz in seiner schmerzlichsten Tiefe, und Scheu und Kummer krochen in die Seelen. Weil die Juden aber ihrem Glauben ergeben waren, liessen sie nicht von ihm, sondern dienten ihm wohl unter Zagen, aber in gleicher Treue wie ehedem, in dunklen Nächten und heimlichen Verliessen, in stählern gehüteter geheimnisvoller Gemeinschaft. Und so kam es, dass die Seelen, die des Tages in den Krallen jenes bitterbösen Tieres, das da Angst heisst, stumm und verschlossen waren, des nächtens, wenn ihnen niemand ihren Gott wehrte, auf- 
stöhnten in hellem und loderndem Wehe, und wie Sturmwind gewaltig stiegen ihre vereinten Bitten auf, der Herr möge dem König das Kind senden, das sie aus knechtischer Schande und Bitterkeit befreie. Und so schaurig war ihr Schrei und so inbrünstig ihre Ausdauer, dass die Himmel von der Unruhe und dem Andrang erregt wurden und die heiligen Seelen, die unentwegt in der Freude Gottes bestehen, wieder irdisches Leid mitzufühlen begannen und mit erzitterten in dem grossen Jammerruf. Aber der Sinn des Allerhöchsten blieb also ruhevoll, als teile nicht der leiseste Seufzer einer Kreatur die seligen Lüfte. $\mathrm{Da}$ wurde eine der verklärten Seelen so gar wunderbar vom Gefühl des süssesten und brennendsten Mitleidens ergriffen, dass sie die Scham beiseite tat und herrlich glühend vor dem Thron des Ewigen erschien und bat: „Du, dessen Namen ich nicht nenne, lasse mich wiederkehren zur Erde, von der du mich erlöst hast, auf dass ich, dem König zum Sohn geboren, durch meine Einkehr in die Menschheit das Judenvolk freimache, das in seinem Jammer meine Seligkeit mit Weh verdunkelt." Und der Herr gewährte es.

Dem König wurde der Sohn geboren, nach dem sein Sinn verlangte. Allein in der völligen $\mathrm{Be}$ glückung vergass der König die Juden und unterliess es, ihre Not nach seinem Wort zu beenden, und es war keiner im Land, der ihr Fürsprech beim Herrscher geworden wäre.

Das Kind aber war über alle Massen schön von Angesicht und liebreizend in seiner Seele und von 
frühen Jahren an dem sinnenden Ernst und der Weisheit hold. Es wies sich späterhin, als es zum Jüngling wurde, dass an seinem lauterklaren Geist die Lehren seiner Erzieher erbleichen mussten wie trügerisches Metall, und so kam der König in eine wahrhafte Not, wen er seinem Sohn zum Führer bestelle. Just in jenen Tagen jedoch war rings im Land viel des Aufhebens um einen alten Fremdling, der vor kurzem erst nach der Königsstadt gekommen und von dessen Herkunft wohl viel des Vermutens aber keine sichere Kunde war. Obzwar der greise Mann keinen suchte und den Markt und die Gassen mied, erzählte man sich doch vieles von seinem unerhörten Wissen und einer seltenen Macht seiner stolzen und gütigen Seele, die ihn da und dort, wo die Not es heischte, zum Berater und Helfer werden liessen. Auch sprach man viel von den eigentümlichen Gewohnheiten seines Lebens, die ganz und gar von jenen abweichen sollten, deren man in jenem Land und zu jenen Tagen pflegte. Das Ende all dieser Betrachtungen war, dass das Volk wähnte, er sei höheren Gewalten verbunden oder gar verschwistert, und grosse Ehrfurcht vor ihm gewann.

Auch dem König wurde davon geredet, und es kam soweit, dass dieser in dem geheimnisreichen Mann den rechten Lehrer für seinen einzigen Sohn erblickte und ihn vor sich rufen liess und von ihm verlangte, dass er bei ihm wohne und den Königssohn erziehe. Der weise Mann war willens, das Begehren des Königs zu erfüllen, wenn ihm ein Bedingen, das er stellte, erfüllt würde. ,Wisse,“ sprach er, ,dass 
im Kreislauf eines jeglichen Tages für mich Stunden kommen, da meine Secle meinen Leib verwaist und zum Firmament aufsteigt, einem ewigen Geheiss Folge zu leisten. In dieser Zeit ist mein Leib todesgleich und meine Sinne sind verschlossen, wer meiner gewahr wird, scheidet mein Wesen für immer und fällt mit mir dem Tod anheim. Darum willst $d u$, dass $i c h$ in deinem Hause wohne, gebiete, dass $z u$ jenen Stunden, in denen ich mein Gemach verschlossen halte, keiner bei mir eindringe, mit Gewalt nicht, noch mit List!" Das gelobte der König mit seiner Rechten und gab es allem Hausgesind wie seinem eigenen Sohn zu wissen, dass nach seinem Willen der Wunsch des Weisen zu achten sei bei eines jeden eigenem Leben.

Der Königssohn gewann eine starke Liebe zu dem Alten und war ihm mehr zugetan denn seinem eigenen Vater. Nur dass der Lehrer ihm zu Zeiten gebot, ihn zu verlassen, tat ihm bittern Schmerz, und nach Art der Jugend setzte er dem Manne zu, mit Schmeicheln und Bitten, er möge ihn in jenen geheimen Augenblicken um sich dulden, ohne dass ihm jemals Gewähr ward. Da verbarg er sich eines Tages in einem Winkel des Gemachs, hinter einer Tür, die auf einen Söller führte, und harrte mit pochenden Pulsen. Als der Meister den Raum verriegelt hatte und nach einer Weile alles still wurde, trat er heraus und fand seinen Lehrer an einem Tisch sitzend über einem alten Buch, bekleidet mit dem Gebetmantel und mit den Gebetriemen gekrönt. Der Alte aber sah ihm voll 
Kummer und Schrecken schweigend ins Angesicht. Da wurde dem Jüngling recht wehe und er sprach: "Ich habe Euch mit nichten betrüben wollen, der ich Euch im Grunde meiner Seele getreu bin. Doch nun würdigt mich Eures Vertrauens und saget mir, welcher Art dies seltsame Gebaren ist, das ich an Euch bemerke." $\mathrm{Da}$ erzählte der Alte, dass er, von Geburt und Abstammung ein Jude, durch das Gebot des Königs seines Glaubens verwiesen also zur Heimlichkeit verurteilt sei. Der Jüngling wurde begierig, etwas von den Gesetzen und vom Wesen dieses Glaubens zu erfahren. Der Lehrer tat ihm den Willen, da er ihm im Gemüte hold war. Alsbald gewann der Königssohn eine Neigung zu den heiligen Schriften, und der Lehrer unterwies ihn nun $T$ ag für $T a g$ in grossem Eifer und Geheimnis. Das alte wundermächtige und heldenhaf te Leben, das aus den ehrwürdigen Zeichen aufstieg und in dem jungen Geist lebendig wurde, überkam den Knaben, und er fühlte, dass er alles dieses fürder nimmer in Verborgenheit gewinnen, sondern offen bekennen und erwählen müsse. Das sprach er seinem Lehrer aus. Der aber riet ihm, er möge, wenn dem also sei, Stand und Ehren und allen Glanz der Zukunft dahinwerfen und in der Stille nächtens mit ihm fliehen in ein fernes Land, wo sie unbekümmertund unangefochten derLehre leben wollten. So war es der Jüngling zufrieden, und sie gingen hinweg, eilends, mit Schweigen und unter grosser Vorsicht, dass keiner ihres Weges gewahr wurde. Also kamen sie in ein Land, da das Judenvolk 
in Frieden seines Glaubens pflegte. Hier lebten sie mehrere Jahre in Abgeschiedenheit. Der Jüngling wurde unter der Leitung des Meisters und durch der eigenen Sehnsucht brennende Bestrebung ein Grosser in der Erkenntnis und ein Begnadeter der Mysterien. Darnach fügte es sich, dass ein heiliger Zaddik aus uraltem, erhabenem Geschlecht in jene Stadt kam, wo die Juden ihn in hohen Ehren empfingen Auch der Königssohn und sein Lehrer eilten herbei, den Heiligen zu grüssen. Dabei begab es sich, dass der Jüngling durch seine edle Führung und die grosse Lauterkeit, die von ihm ausging, das Wohlgefallen des Zaddiks so sehr gewann, dass er ihm seine einzige Tochter zur Ehe bot. Als der Königssohn die Hochzeit beging, sprach er zu dem jungen Weibe: „Ich habe eine Bitte an dich, Teure, an diesem Tag: es ereignet sich zuweilen, dass in den Augenblicken der Erhebung mein Leib wie leblos darnieder liegt und einem Toten gleich sieht. Dann mögest du mit nichten dich dem Schmerz hingeben, noch Zeugen herbeirufen, dass sie mich etwa beleben, sondern gleichmütig und in Frieden die Zeit erwarten, da meine Seele freiwillig in den Bezirk des körperlichen Lebens zurückkehrt."

Das Weib, das so holden als tapferen Gemütes war, versprach dies wohl $z$ achten und tat es auch hinfürder, sowie die Umstände es geboten. Sie war dem Manne eine sanftmütige und glückliche Gesellin und die beiden weilten all ihre $Z_{e i t}$ in liebreicher Gemeinschaft. Da ereignete es sich einstmals, dass der Gatte in eine ungewöhnlich tiefe Verzückung verfiel, 
in der sein Leib wahrlich totengleich verblieb. Die junge Frau ertrug den Anblick anfangs gefassten Mutes, alsdann aber, als die übliche Spanne Zeit verstrichen war, überkam sie eine betäubende Angst, sie wollte Menschen herbeirufen, entsann sich aber des Verbotes und sank alsdann still an der Seite des Leblosen in verzweifeltem Harren nieder. Nach langen Stunden zeigten sich an dem Körper des Entrückten die ersten Spuren der wiederkehrenden Belebung. Er richtete sich auf und kam langsam zur völligen Besinnung. Die Frau wollte ihn freudig grüssen, allein er erwiderte still und wehmütig ihre fröhlichen Worte, und es war ihr, als ob sein Blick mit einem zagenden, zarten Mitleiden auf ihr ruhe. Auch blieb er den ganzen $\mathrm{Tag}$ in sich gekehrt und versonnen. Des Abends fragte ihn die Frau mit liebevollem Drängen, was ihm das Herz belaste, er möge ihr nichts verschweigen. $\mathrm{Da}$ antwortete er ihr; "Wisse, Geliebte, dass mir heute, als ich in den ewigen Höhen weilte, eine bittere Kunde geworden ist. Um meiner Geburt willen und um der ersten Jahre meines Lebens, die ich in Gepränge und eitler Weltlichkeit am Königshofe gehalten wurde, ist mir ein höherer Aufstieg der Seeleverwehrt, es sei denn, dass ich den Tod ergreife und dannwiedergeboren werdevon einem armen, reinen und demütigen Weibe. Darum bitte ich dich, mein Liebling und mein Gemahl, dass du eines Sinnes mit mir seist, und mir, der voll Sehnsucht ist, gewährest dahinzugehen ohne Verzug." Es sprach die Frau in leuchtender Liebe: "Ich bin es zufrieden, wenn du mich mit dir sterben 
lässt und wenn ich mit deiner Seele wiederum zur Erde kehre und alsdann in deinem verjüngten Leben aufs neue dir als Weib vereint werde."

Sie legten sich zum Todesschlaf selbander und gingen im gleichen Atemzug vereint dahin. Und es verging hier unten ein Mass der Zeit, indessen ihre Seelen ins Dunkel tauchten, da man die Zeit nimmer misst. Und dann kehrten sie wieder. Der Mann wurde von einer Demutsreichen in der Stille der Armut geboren, und das Weib sah in eines Dürftigen Hütte wieder ins irdische Licht. Und siehe, ihre Kindheit und die Jahre ihrer Jugend waren ein langes, ungewusstes Suchen nach dem Unbekannten, das ihnen im Grunde des Herzens schlief. Sie sahen über das Leben und ihre Nächsten hinaus mit fremden, irrenden Augen dem Gemahl ihrer Seele entgegen und waren nur zaghaft, weil sie, seit sie aus den Fluten des Vergessens aufgestiegen waren, nicht mehr wussten, was sie erwarteten. Und ihr, Freunde, ihr alle sollt wissen, dass sie sich gefunden haben und sich begegnet sind auf dem neu bestrahiten Wege ihrer Jugend, und dass sie hier Bräutigam und Braut mild vereint unter euch sitzen."

$\mathrm{Da}$ war ein grosses Bewegen in aller Herzen, als der Baalschem schwieg, und über aller Stirnen lag ein Glanz wie vom Begreifen aller Wandelgänge der Ewigkeit. 


\section{DER PSALMENSAGER}

\section{TN EINER STADT UNFERN DER STADT}

des Baalschem lebte ein reicher Mann, der zu 1 den stillen seltenen Zeiten seiner Einkehr in sich selber dem Dienste Gottes gar hold war, gemeinhin aber dem bunten Treiben und einer herzhaften Geselligkeit hingegeben die Güter seiner Seele brachliegen liess. Er hatte wohl of t von dem Heiligen gehört und wusste, dass alle Frommen ihn heimsuchten, doch mied er ihn von jeher, sei es, dass er eine Scheu vor ihm trug, sei es, dass er von jeglichem Tag mit irgend einer Last weltlichen Glückes beladen keinen Drang nach dem hellen Frieden des Meisters verspürte. Der Baalschem aber wusste um ihn und um sein Leben, wie um das aller Kreatur, und liebte ihn auf eine heimliche Weise aus der Ferne. Denn der sorglose Mann war im Grunde seines lärmenden Wesens von einer triebhaften grossen Güte, die, bisweilen vom Begehren nach der Lustbarkeit überwuchert, vom jäh aufwallenden Zorn verdunkelt, doch immer wieder kräftig hervorbrach und vielen Armen und Bedrängten ein bescheidenes Genügen im Schatten seines breiten, reichlichen Daseins gewährte.

Als er einmal wiederum in sich schaute, fand er, dass er etwas für die Ehre Gottes tun müsse, und beschloss gesammelt und voll Demut, eine Thora schreiben zu lassen. Als die Stille aus seinem Herzen verflogen war, blieb wohl der Wille zurück, allein die Demut hatte ihn verlassen, und er begann die 
Ausrührung auf seine Art mit vielem Prunk und Glanz. Ein berühmter und sehr kunstreicher Thoraschreiber wurde berufen. Dann liess der Reiche selbst die auserlesensten Tiere schlachten, verteilte ihr Fleisch unter die Armen, liess die Häute zu Pergament verarbeiten und auf sie die heiligen Bücher schreiben. Das Werk währte eine lange Zeit und war vollendet die Rede und das Staunen der Stadt. Der Besitzer hatte ihm eine kostbare Lade und eine Hülle aus edlem Stoff mit Zieraten aus Metall und Steinen bereiten lassen. Als alles fertig dastand, gab er der Stadt ein Fest. Nicht die Armen und nicht die Missgünstigen schloss er aus, sondern nahm alle in sein Haus auf zum Mahle, denn er wollte, dass sein stolzer Gottesdienst ein Freudenfeuer in allen Seelen entzünde.

Es währte schon drei Tage, dass sein Haus sich $z u$ jeder Stunde aufs neue mit Menschen füllte, die sich an die langen Tische setzten und assen und tranken, und seine Diener hatten all die Nächte sich des Schlafes erwehren müssen. Unter ihnen war einer, ein schlichter und redlicher Mann, der Psalmensager zubenannt, weil die heiligen Gesänge nicht aus seinem Munde wichen; er gesellte sie aller Arbeit, die er tat, und sagte sie auf eine schöne und seltsame Weise, nicht wie ein Buch der Schrift, sondern wie die Klage eines Menschen, der leidet und Gottes $\mathrm{Ohr}$ an seinem Munde fühlt. Der Reiche kam oft leise herbei und hörte ihm zu, und sein Herz sang mit dem Singenden. Es war ihm, als töne in dem Lied des Mannes die Stille, 
die ihn selber so selten heimsuchte, und wie um ihr zu gehorchen, ehrte er ihn und hielt ihn niemals zu harter Arbeit. In den Tagen des Festes aber hatte der Psalmensager gleich den andern Knechten unablässig bei Tische aufwarten und den Gästen dienen müssen. Doch hatte ihn der Hausvater den Besuchern zugeteilt, die er vor allen wert hielt und in seiner eigenen Stube bewirtete. $\mathrm{Da}$ begab es sich am Abend des dritten Tages, dass die Gäste das Handwasser zum Segen der Waschung vor der Mahlzeit begehrten; sie riefen den Diener, und es wies sich, dass er nirgends $z u$ finden war. Da ging der Herr selbst im Hause umher, ihn zu suchen, und fand ihn nach einiger Weile in einer der Bodenkammern in seinen Kleidern auf einem Bette schlummernd. Er rief ihn an, aber der andere war tief im Schlaf befangen und gab nicht Rede und Antwort. Da stieg dem Herrn der Grimm auf, er riss den Liegenden an den Schultern hoch und schrie ihm zu: "Geh zum schwarzen Jahr, du Psalmensager !" Der Diener sah dem reichen Mann mit starren Augen ins Gesicht. Dann sprach er: „Herr, Ihr wähnet schlecht, wenn Ihr glaubet, es sei da keiner, dem armen Psalmensager sein Recht zu schaffen." Der Herr aber achtete seiner Worte gering und begab sich wieder zu seinen Gästen.

$\mathrm{Als}$ er ein geringes später vom Saal auf den Flur des Hauses ging, um etwa Neuangekommene zu begrüssen, trat eben ein fremder Mann zum Tor herein, nach der Art eines Dieners im Ge- 
wande, der sprach ihn an und sagte: „Herr, mein Gebieter hat ein Ding mit Euch zu bereden, das ist von Wichtigkeit und mag keinen Aufschub leiden. Darum bittet er Euch, da ihn einiges abhält zu Euch zu kommen, Ihr möget die kleine Mühe nicht scheuen, in den Wagen zu steigen, der vor Eurer Tür steht. Der Weg ist kurz und die Pferde schnell, Eurer Zeit wird geringe Einbusse geschehen."

Der reiche Mann wunderte sich ob des fremden Dieners und ob der sonderbaren Sache, aber etwas lähmte sein Bedenken, verbot ihm die Frage und drängte ihn vorwärts. Im leichten Hausgewand stieg er in den Wagen, und das Gefährt bewegte sich eilends von hinnen. Der Mond schob sich gelb und wächsern den Himmel herauf, gross und noch nie erlebt. Nach einer Weile, die dem Mann nicht kurz noch lang schien, bemerkte er, dass der Hufschlag der Pferde verstummt war und der Wagen dennoch weiter raste. Es war kein Weg mehr, und rechts und links war nimmer, keine Luft um ihn, und nichts, dessen sein Erkennen sich hätte bemächtigen dürfen. In ihm war alles in ein Staunen gelöst, ohne Erwartung oder Angst. Er fühlte, er hatte den Schritt hinüber getan, und was gegolten hatte, galt nun nicht mehr.

Da hielt der Wagen an. Er folgte einem Zwang, der so unfassbar als bestimmt war, und stieg aus. Im selben Augenblick gewahrte er, hinter sich blickend, dass der Wagen, dessen Tritt sein Fuss noch vor einer Sekunde berührt hatte, verschwunden 
war. Er stand in einem hochstämmigen Wald, dessen Bäume wie ragende Säulen aufschossen, schlank und glatt; die Kronen aber sah er nicht, weil sie $z u$ hoch sich wölben mochten und weil ein milchweisser Nebel zwischen den Stämmen war, der ihm die Sicht benahm. Unter seinen Füssen war klirrender Frost. Ihn fror mit schneidendem Schmerz an allen Gliedern. Das zwang ihn vorwärts, schwieg auch sonst sein Wille und all sein Wesen, dem zumute war wie einem Kind, das diesen Augenblick in eine gar fremde Welt geboren wurde. Er ging und ging und es schien ihm, als ob in dem milchigen Dunst, der statt einer Luft war, Gesichter auftauchten, ein Wallen und Bewegen von Gestalten, nicht dichter als dieser Nebel selbst und völlig in ihn verschmolzen. Er wanderte durch all dies hindurch, und sein Gehen war ohne Mass und Vergleich wie vordem seine Fahrt, bis vor ihm in der Weite ein Licht aufstand, das, den Dunst durchstrahlend, ihn nach einem Ziele lockte. Dieses wies sich als ein Haus, verschleiert vom Nebel, und die Lichtquelle war die Tür, die offen stand und jene klare Helle ausströmen liess.

Er ging heran, und da er auf der Schwelle stand, klärte sich der Nebel zu einer krystallenen Luft, die unbeweglich stand. Er trat in eine Stube, deren Decke aus starken Balken war und ganz altersbraun, aber Wand und Boden waren frisch und strahlend weiss. Die Stube war von einer süssheimlichen Wärme erfüllt. Sieben hohe Lichter brannten fest- 
lich in einem Ständer auf dem mächtigen Tisch und flammten starken Duft aus ihrer Leuchte. An den Wänden standen Stühle mit aufstrebenden Lehnen, alte dunkle Stühle, aber umfangend und gebieterisch fast wie Throne. Sonst gewahrte der Eingetretene nichts, als einen ungeheuren grünen schimmernden Ofen, der eine Ecke des Raumes füllte. Bang und wie traumbefangen trat er näher, wagte nicht Tisch noch Stuhl zu berühren, sondern barg sich hinter dem Ofen, zu warten, wer allda käme. $\mathrm{Da}$ sass er, und die gläserne Luft sang seltsam in seinen Ohren.

Alsdann traten Drei in die Stube, je einer in kurzer Frist nach dem andern, und waren uralte Männer, gebeugt und dennoch so hoch, dass ihr Haupt an die Balken der Decke zu rühren schien. Haar und Bart wallten eisgrau und es war, als habe die Zeit sich in ihren Wellen verflochten. Hinter dem Schatten der weissen Wimpern barg das Auge Sonne und Blitz. Das Gewand der Drei war schlicht, Leinen und Fell, allein ihr Wesen war von solcher Art, dass der Mann hinter dem Ofen zur Stunde wusste, es habe der Vater- und Königsname vor diesen nimmer zu Recht bestanden. Sie grüssten einander mit grossem sanftem Grüssen mit der Erzväter Namen und liessen sich in die Stühle nieder und ruhten stumm wie nach langer Wanderung. Indes sie sassen, trat ein Vierter ein, der war nicht so alt und nicht so gross, doch mit des Herrschers Gewand und Geberden angetan. Er neigte sich, wie ein Enkel sich ehrfürchtig dem 
Ahnen neigt, und sie grüssten ihn mit Davids, des Königs, Namen. Und er erhob seine Stimme, und es war, als ob die Luft vor ihrem Grimm erbebte, und die Lichter schienen einen Augenblick lang zu versprühen, als er sagte: „Einen Rechtsstreit, o Väter, habe ich wider den Mann, der hinter dem Ofen sitzt!" Dem Verborgenen rissen die Worte die Brust auf, als dränge ein Schwert in sie, und seines eigenen Herzens Schläge empörten sich wider ihn: über ihm stand nichts mehr denn das Grauen. Die Väter aber hoben die Häupter zu lauschen. $\mathrm{Da}$, so fühlte der Mann, tat sich zwischen Geschehen und Geschehen ein Abgrund auf, und ein ungeheures $\mathrm{Rad}$ stand irgendwo stille.

Der König sprach: „Der sich hier verborgen hält, hat der Unbill eines Atemzuges wegen mit der Verwünschung seines Mundes über einen wehrlosen Knecht die letzten Greuel geschleudert. Und dieweil der Knecht mein Diener war vor allen und auf seinem Munde mein Lied nicht erstarb, bin ich aufgestanden $z u$ seiner Hut und heische hier sein Recht, und dass der es beugte des Todes sei um seines Frevels willen."

Dem Reichen in seinem Versteck war, als ob sein Blutkreis allbereits stocke über dem Königswort: und grösser als alle erdgeborene Angst war seine Angst und Not. Er hob das Auge, dass es ihm den letzten Blick gönne, da sah er jenseits des Tisches einen Mann stehen und erkannte ihn als einen, dem er im Leben zuweilen von ferne begegnet war und den sie den Wundertäter und den Meister des 
Namens genannt hatten. Der Mann aber stand dem König aufs Haar gegenüber und trug das Haupt hoch und in seinen Augen war ein Blitzen wie von blauem Stahl. Und er fing des Königs letztes Wort auf, da es noch die Luft schnitt, und erhob seine Stimme wider ihn und sprach, indes die Väter mit stummem Haupteswenden gross und vertraut $z u$ ihm herüberschauten: „Bruder David, kommst von den Himmeln, und ist mir doch, als sässest noch auf deinem Throne zu Jerusalem! Willst ein Böses mit Böserem tilgen, willst eir geringes Weh mit unleidlichem Weh stillen, willst ohnmächtige Rache reinigen mit zündender Rache?" $\mathrm{Da}$ antwortete ihm der König, und sein Wort flog wie ein Felsblock, geschnellt von Gipfel zu Gipfel: „Du spotte mir nicht, Bruder! Ich bin nicht um Rache gierig, es ist um Strafe und Gerechtigkeit? Oder ist dies deine Meinung, dass der getreue Knecht getreten werde und sein Peiniger stolz und straflos verharre?"

Aber die Stimme des Baalschem stand auf und war gewachsen im Schweigen wie eines Erzengels Stimme, die die Ewigkeit geschmiedet hat im Funkeln der Elemente. Und er sprach also: „Bruder und König, siehe, es ist ein Fremdling bei mir zu Gast, und hat des jungen Hirten weiss-rotes Angesicht und blanke Augen, und lasten gleichwohl Binde und Reif auf seiner Stirn, die ohne Schatten ist - -

König, eines Königs Seele ist mit mir. Sie kam zu mir, als ich durch des Weibes Leib dieses neue Mal zum Leben wiederkehrte. Und in Stunden 
der Nacht, wisse, redet sie, geschmiegt an meines Ohres Wurzel, und ist ganz scheu und ist mir ganz vertraut. Und redet aus Urtiefen, aus Schmerzensabgrund: ,Ich habe bei ihm gestanden, als er zum Treuen sprach:, Geh hinab zu deinem Hause', und habe vernommen, als er am andern Tag zu ihm sprach: ,Warum bist du nicht gangen $z u$ deinem Hause?' und war mit ihm am Tag, der nach diesem kam, da er den Brief schrieb: ,Stellet ihn vor den Streit, da er am härtesten ist, und wendet euch hinter ihm $a b$, dass er erschlagen werde und sterbe!' $\mathrm{Zu}$ der Stunde habe ich mich von ihm gehoben mit Blut und Schmerzen, und bin wund von der Stunde an [".

Da hob David die Stirn unter dem Reif, und Stirn und Krone glänzten, und er sprach, und ein tiefer Strom lief unter seiner Stimme hin: „Ich bin in des Ungeheuers Rachen zutiefst getaucht und bin ans Licht gestiegen, und meines Mantels Saum war schwarz und klebte von geronnenem Blut, und ich habe mein Lied mit mir heraufgetragen. Denn mein Lied ist mir geboren aus Sünde und Befleckung, und ist aufgestiegen, und war Friede zwischen Ihm und mir."

Nach diesen Worten des Königis geschah es, dass das Schweigen vom Boden aufstand und $z$ wischen die beiden trat. $\mathrm{Da}$ stand es ragend zwischen beiden und sah $z u$ ihnen nieder. Und unter seinem Blick wandelte sich das Antlitz des Baalschem. Geheimnisse und Klarheiten glitten darüber und es war zu schauen, wie wenn das Firmament seine 
Landschaft mählich entschleiert und hinter den Wolken öffnet sich der krystallene Plan. Alsdann redete der Baalschem, und auch seine Stimme war gewandelt: „Dein Lied ist die diamantene Brücke, die hinaufführt aus dem Kessel der Verworfenheit an Gottes Herz. Und wenn es im Ohr des Sündigsten erklingt, ist es eine goldene Kette und bindet ihn an Gottes Hand. Und wenn es in einer Nacht aus der Brust des Unholds aufstöhnt, ist es ein Engel und trägt ihn über die Sphären und bettet ihn in Gottes Schoss. Als dein Lied mich an der Hand nahm, vergass ich die Gerechtigkeit, und als es mir zulächelte, entschwand mir alles Gegenüber."

$\mathrm{Da}$ beugte der König sein Haupt vor dem Meister, und aus dem Zeitlosen rauschte eine grosse $\mathrm{Be}$ wegung empor, wie wenn ein Geheimnis sich erfüllt und untergeht.

Dem Mann hinter dem Ofen fuhr ein weisser Strahl über die Augen. Er stand in seinem Haus und hielt die Klinke seiner Stubentür. $\mathrm{Da}$ waren die Gäste und wuschen ihre Hände vor der Abendmahlzeit. 


\section{DER ZERSTÖRTE SABBAT}

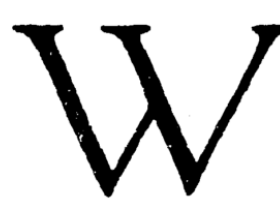

IE IN JEDER WOCHE FUHR DER Baalschem damals bei Sabbatausgang aus der Stadt, und mit ihm waren die drei seiner Schüler, die die drei Davide genannt wurden, nämlich Rabbi David von Nikolajew, Rabbi David Pirkes und Rabbi David Leikes, und der Diener Aleksa, der die Pferde lenkte. Und gemeiniglich war es so, dass der Meister Richtung und Schnelligkeit der Fahrt ohne alle Rede mit seinem Willen bestimmte, und der Diener Aleksa mochte seinen Rücken den Pferden zuwenden, sie brachten den Wagen zur gewünschten Zeit an die gewünschte Stelle. Diesmal aber fühlte der Baalschem, wie sein Wille ohnmächtig war dem starken Zug der Tiere gegenüber, und er sah, wie sie den Wagen einem unbekannten $Z$ iel zuführten und keinen Befehl des erschrockenen Kutschers annahmen. Da wollte er umkehren und rief es laut und fasste selbst die Zügel, aber er hatte keine Macht über die Pferde, und sie liefen, dem Geheiss seiner Hand entgegen, in scharfem Trabe weiter, wohin der unsichtbare $Z_{\text {wang }}$ sie trieb. So kamen sie in eine Wildnis und zogen den Wagen hinein, bis ringsum kein Pfad und kein Ausblick war, und irrten nun in knappem, gleichmässigem Schritt in der Wildnis umher. Dies währte drei Tage, und der Baalschem trug es wie ein Verhängnis, gegen das keine Menschenseele zu murren wagen kann, aber die Schüler sassen betäubt und elend da, und 
der Diener Aleksa gebärdete sich wie toll, als ob er nie noch mit seinem Herrn Wundersames und Furchtbares erfahren hätte. Nach den drei Tagen aber kam ein neuer Trieb in die Pferde, und sie rannten aus der Wildnis in einen darangrenzenden Wald und zerrten den Wagen in das tiefste Dickicht hinein. Da blieben sie stehen und wieherten behaglich, als wären sie in den Stall zurückgekehrt und hätten das schönste Futter vor sich. Die im Wagen aber konnten nicht mehr scheiden zwischen Tag und Nacht. Sie nährten sich kümmerlich von den geringen Vorräten, die sie mitgenommen hatten, und kein Schlaf kam über sie, so überstark hielt die Bangigkeit ihre Herzen umfangen. So vergingen Stunden und wieder Stunden. Aber eine kam, da erkannte der Baalschem an der siebenfachen Traurigkeit, die in seine Sinne drang, dass der Vortag des Sabbats herangebrochen war, und er wusste nicht, wie er mit seinen Schülern den hohen Tag empfangen und ehren könnte. Da drang die Traurigkeit von seinen Sinnen in seine innere Einsicht, und er fühlte, wie ein schwellendes Wasser über all seine Weisheit hinströmte und sie verschlang. In der tiefen Not sass er da und schaute vor sich hin und spürte eine trostlose Ermüdung sich über alle seine Glieder hinziehen und verfiel endlich in einen schweren, stumpfen Schlaf. Da kam eine Hoffnung in die Seele der Schüler, denn sie wussten die Heiligkeit, die um den Schlummer ihres Meisters allezeit webte, und wie ihm, was im Wachen düster und verworren er. 
schien, im Traum sich klärte, und wie da aus aller Trübe die reine Gestalt der Wahrheit sich in strahlender Erscheinung hob; denn der Mund der Dinge suchte das $\mathrm{Ohr}$ des Meisters, wenn er mit geschlossenen Aussensinnen lag und sein Geist sich dem inneren Worte eröffnete. Aber der Baalschem erwachte in einer dumpfen und ruhelosen Weise, und die Starrheit, die auf ihm lag, war fast zur Lähmung gewachsen. Dies war der Augenblick, da die Verzweiflung aus dem Wasser oder aus der Mauer oder aus den Wolken hervorkriecht und den Menschen ansieht. Schon züngelte sie heran, schon suchte ihr roter Blick den, der der Herr der Geheimnisse gewesen war und nun vom letzten Wissen verlassen sass; da reckte er sich auf und hob den Arm und deutete mit zitterndem Finger in die Ferne. Siehe, da war ein Licht in der Ferne, ein kleines, schwankendes Licht hinter tiefem Gestrüpp. So liessen sie den Wagen und gingen mühevoll dem Lichte $z u$, und allgemach erleuchtete sich ihnen das Angesicht der Erde, und die ewige Sonne stand über ihren Häuptern, und sie sprachen : „Gesegnet sei der Herr, und gesegnet sei sein Name!" Im Lichte aber sahen sie in der Ferne ein kleines Haus, das lag wie ein matter grauer Fleck mitten in dem dunkeln Grün des Waldes. Sie gingen auf das Haus zu. Vor der Tür stand ein riesenhafter, stiernackiger Mann, gekleidet nach der Art jener Leichtfertigen, die die gute Sitte der Väter verachten, mit rotgelbem, struppigem Haar und ungeschlachten, baren Füssen: auch waren die Schaufäden des' Gesetzes an seinem Ge- 
wande nicht zu sehen. Er stemmte die Fäuste in die Seiten, sah die Herankommenden hohnvoll an und schwieg. Sie verneigten sich vor ihm und fragten: "Ist es gewährt, dass wir den heiligen Sabbat in Eurem Hause feiern?" Da schrie er sie mit greller Stimme an: "Ich will euch nicht und leide es nicht, dass ihr über meine Schwelle tretet. Kenne ich euch nicht? Euer Gesicht redet von euch. Chassidim seid ihr, tragt eure Frömmigkeit zu Markt und predigt auf den Gassen. Geht, mein Nacken ist Erz gegen eure nichtigen Worte. Ich hasse euch, euch alle hasse ich von gestern und ehegestern und von je her. Mein Vater hat euch gehasst und mein Grossvater, meinem ganzen Hause seid ihr verhasst. Darum geht eilend von hinnen, denn ich will euer Gesicht nicht mehr sehen." Sie aber trugen seine Worte in Schweigen und fragten nur: "So wollet uns sagen, ob es in der Nähe andere Wohnstätten gibt, dahin wir uns wenden könnten, um den heiligen Sabbat zu feiern." Da lachte der Mann hoch auf und rief in grimmigem Lachen: "Wieviel Zeit ihr gebraucht habt, um hierherzukommen, so viel Zeit und mehr braucht ihr, bis ihr an einen anderen Menschenort kommet." Als er dies gesagt hatte und in der gleichen Weise weiter und weiter lachte, als könne er nimmer aufhören, wollte ihnen der neue Mut, der zu ihnen gekommen war, schier wieder entschwinden. AberRabbi David Pirkes, der jüngste der Davide, der sonst nie ein Wort sagte, sondern in der Schar der Schüler schweigsam und versonnen $z u$ sitzen pflegte, trat hervor und sprach zu dem Mann, gar leise und friedfertig: „Es 
mag sein, dass dieses und jenes in deinem Sinne wider uns redet. Aber ist es wahrhaft so, dass du in deinem Willen trägst, uns in die Wildnis hinauszustossen? Sieh, der Sabbat ist dein und unser Heiligtum, und wenn wir uns in ihm ergehen, müssen wir irgendwo und irgendwann auch deinen Schritten begegnen. Willst du den Sabbat der Zukunft verderben? Sieh, der Herr ist dein und unser Gott, und wenn du deinem Rasen gebietest und erschweigst und deine Seele zurückrufst im Schweigen, wirst du es verspüren, wie in diesem Augenblick er dich anschaut aus dem Herzen der Welt." Da war der Mann still und sah von einem zum andern, ohne zu sprechen. Aber Rabbi David von Nikolajew, der älteste der Davide, der sich wohlbewandert glaubte in dem Treiben des Menschengemütes und auf den Wegen der heimlichen Menschenabsicht, sprach: „Bedenke auch, dass wir kein Geschenk begehren. Vielmehr wollen wir dir zahlen, wieviel du auch fordern magst, und sei es das Zehnfache dessen, was allerorten üblich ist." Der Mann jedoch sah mit verächtlichem Lächeln über ihn hinweg und wandte sich zu dem Jüngsten und sagte in einem brummigen und unwirschen Ton: „So sei es. Aber glaubet nicht, dass ihr mir in mein Haus euren Sabbat bringen dürfet. Hier herrscht mein Brauch und mein Gesetz allein. Daher merket auf, was ich über euch verfüge. Fürs erste weiss ich wohl, ihr bringt viel Zeit damit zu, euch zum Gebet $z u$ bereiten, und achtet nicht, wie weit es im Tag sei, und wartet, dass die Gnade euch erfasse. Aber hier gilt das Dasitzen und Ausschauen nicht, ich bete 
$a b$, was zu beten ist, und dann gehe ich ans Essen, denn ich bedarf vieler Speise und muss oft und schnell meinem Hunger Genüge tun. Fürs zweite kenne ich eure Art, zu beten, wie ihr schreit und tobt und einer lauter als der andere zu Gott reden will. Aber hier ist kein Raum für den Lärm eurer Verzückungen, und ich werde mich und meine Leute von euch nicht belästigen lassen. Fürs dritte liebt ihr es, an dem Mahl zu mäkeln und wie rechte Narren des langen $z u$ erwägen, ob dies und jenes für euch Chassidim rein sei; das soll euch hier nicht beifallen." Solch Verkennen und Entstellen der heiligen Sitten und das Verbot, dass sie nicht geübt werden sollten, war dem Baalschem und den Seinen eine harte Schickung, aber sie hatten keinen Weg vor sich als diesen, und so stimmten sie $z u$ und versprachen, sich in alles $z u$ fügen. $\mathrm{Da}$ hiess er sie eintreten. Sie kamen in eine enge und kahle Stube. Als sie sich eine Weile auf den Boden ausgestreckt und von der schwersten Müdigkeit befreit hatten, fragte der Baalschem, ob in der Nähe sich ein Bach oder ein W $W$ asserbehälter befinde, wo sie ein Tauchbad nehmen könnten zu Ehren des Sabbats. Da geriet jener von neuem in Wut und schrie: „Habe ich es mir doch gleich gedacht, dass ihr ein elendes Diebsgesindel seid! Ihr wollt nur herumspähen, wo ich mein Gut verwahre. Wahrlich, ich nehme eure Siebensachen und werfe sie hinaus und euch dazu!" Da mussten sie lange flehen und Versöhnung erbitten, bis er sich wieder geneigt zeigte, sie zu behalten.

Der Baalschem und die Seinen sassen nun da und 
sahen dem Mann zu, der in der Stube aus- und einging, und verwunderten sich über ihn, denn sie hatten noch nie einen Menschen gesehen, der so plump und roh und unsauber war wie dieser. Auch in der Stube waren Boden und Wände besudelt, und weder Tisch noch Bank standen da, sondern vier Pfähle waren in die Diele eingerammt, und darauf lag ein unbehobeltes Brett. Bald bemerkten sie, dass dies der einzige Wohnraum war, denn wohl gab es andere Stuben im Haus, aber sie waren alle verschlossen, und die Türen waren grau vor Staub und mit Spinngeweb bezogen, als ob sie nie geöffnet würden. Auch war nirgends ein lebendiger Hausgenosse zu sehen, nicht einmal eine Katze oder ein Vogel. Der Abend war nah, und noch erblickten sie nirgends weder Geräte noch Speisen zu Ehren des Sabbats. Der riesige Mann ging müssig umher, schnitt zuweilen eine Schnitte von einer ungeheuren Wassermelone $a b$, die in einer Ecke lag, und steckte sie in den Mund. Dann ging er wieder einher und summte vor sich hin nach Art der Bauern. Die Gefährten befiel ein Schrecken, er könnte gar des Sabbats nicht achten und ihm die Weihe versagen, der alle Juden in der Welt mit heiligem Eifer dienen. Da nahm er aber ein Stück grober, ungebleichter Leinwand und breitete es auf seinem elenden Tische aus. Darauf legte er einen kleinen Haufen Lehm, bohrte mit dem Finger ein Loch hinein und tat darein eine armselige Wachskerze. Nun begann er die süssen und holden Worte, mit denen seit Urzeiten Woche für Woche in allen Ländern der Erde der Sabbat als die Braut unserer 
Seele empfangen wird, in eitler Eile herzusagen, wie die Toren tun, die die Laute schlingen und den Sinn des Wortes ersticken. In einem Augenblick hatte er das Gebet vollendet, und die Gäste mussten desgleichen tun, von ihrem Versprechen gebunden. Wie sehr sie auch sein Wesen und sein Wille peinigte, konnten sie doch in der Heiligkeit des Abends keinen Hass wider ihn hegen und riefen ihm zu: „Gut Sabbat!“ Er aber schnaubte sie zur Antwort an: „Ein böses Jahr komme über euch!" Und als sie den Sang anstimmen wollten: „Friede sei mit euch!“, fuhr er auf sie los und machte sie schweigen. Dann schickte er sich an, den Segen über den Wein zu sprechen. Sie baten ihn, er möge ihnen Wein geben, damit sie selbst den Segen tun könnten, aber er weigerte ihn und rief: "Wenn ihn alle segnen wollten, würde das Licht bald dahin sein. Lasst nur mich es für euch tun." Und so nahm er den Becher zwischen zwei Finger und murmelte die Worte vor sich hin. Sodann tat er den Mund weit auf und goss den Wein hinein, dass nur ein paar Tropfen auf dem Grunde des Bechers blieben. Die reichte er ihnen und sagte: „Da, ihr Saufbolde, aber trinket nicht zuviel, dass ihr euch nicht berauschet." Nun legte er ein hartes, schimmeliges Brot aus schwarzem Mehl und Roggenkleie auf den Tisch und brach für jeden ein Stück ab. Und als einer von den Schülern nach dem Laib greifen wollte, um sich ein $z$ weites Scheibchen abzuschneiden, stiess ihn der Hausherr zurück und sprach zu den Gästen: „Waget es nicht, mit euren eklen Händen an mein Brot zu rühren." Hierauf 
setzte er ihnen eine Schüssel mit dünnem Linsenbrei vor und legte vor jeden einen grossen Löffel und hiess sie hineingreifen und essen, denn Teller und dergleichen Feinheiten mehr gebe es hier nicht. Dabei neigte er sich über die Schüssel und schöpfte sich einen Löffel voll Brei und ass mit gieriger Hast, dass ihm die Brühe aus den Mundwinkeln in die Schüssel zurückfloss und die Gefährten es nicht mehr über sich vermochten, eine Hand nach der Speise auszustrecken. Nach dem Mahl wollten sie die Sabbatlieder singen, aber auch das verbot er ihnen, sagte schnell und allen Brauch vernachlässigend das Tischgebet herunter und erhob sich, um den Gästen auf dem Boden ein unwürdiges Lager zu bereiten.

In der ersten Morgenfrühe erwachten sie und hörten ihren Gastwirt umhergehen und das Morgenlied, das mit den Worten anhebt „Die Seele alles Lebendigen“, nach einer bäurischen Tanzweise absingen. Damit begann ihr Tag, und er wurde noch bitterer und leidvoller, als der Abend gewesen war. Den Baalschem hatte alle Kraft des inneren Blickes verlassen, und die heilige Weisheit war von ihm gewichen, und so sass er und schlug die Hände ineinander und konnte nichts denken als dieses: „Was ist dies, und warum ist dies, das mir Gott hier getan hat?" Endlich brach die Nacht heran, und der Schlaf kam sanft und gütig über ihn. Als er sich am Morgen erhob, fühlte er eine neue Kraft in sich keimen und betete mit Macht, denn er reiste nie von einem Orte ab, ohne mit Gott geredet zu haben, und sodann befahl er dem Diener Aleksa, die Pferde, die in den 
Stall gebracht worden waren, vor den Wagen zu spannen. Aber der Diener kehrte sogleich zurück und berichtete, die Haustür sei geschlossen. Da ging der Meister zum Hausherrn und bat ihn, die Tür zu öffnen, und sprach: „Nimm unseren Dank für alle Freundschaft, die du uns erzeigt hast, und wolle uns nun den Weg weisen, darauf wir am schnellsten nach unserer Heimat zurückkehren können." Jener aber gab zur Antwort: „Mit nichten, sondern ihr werdet noch meine Gäste bleiben." Und er liess sich nicht erbitten und hielt sie gleichsam gefangen in seinem Hause bis zum vierten Tag.

Am Morgen des vierten Tages aber kam er zu ihnen und sprach: „Heute werde ich die Tür öffnen." Und während er dies sagte, sah er sie in einer seltsamen Weise an und ging. $\mathrm{Da}$ kam ein Grauen über sie, denn sie verstanden sein Gebaren nicht, und so schlich sich ihnen in den Sinn, ob er sie nicht ermorden wolle. Während sie aber solcher Furcht nachsannen, öffnete sich die Tür zu einem der verschlossenen $Z$ immer, und eine schöne und edel gekleidete Frau trat hervor, die neigte sich vor dem Meister und sprach; „Rabbi, ich erbitte von Euch, Ihr möget mit euren Schülern bei mir den heiligen Sabbat feiern.“ Der Baalschem antwortete ihr: „Du nennst mich Rabbi. Wie konntest du da zulassen, dass mein Sabbat dergestalt zerstört wurde?" $\mathrm{Da}$ fragte die Frau: „Rabbi, erkennet Ihr mich nicht?" Er sprach: „Nein, ich erkenne dich nicht.“ Sie sprach: "Als ich fast noch ein Kind war, diente ich in Eurem Haus. Ich war eine Waise, und kein 
Mensch lebte mir in der Welt. Über meinen Händen aber waltete ein Ungeschick, also dass ich manches kostbare Gefäss, das ich trug, zu Boden fallen und zerschellen liess. Darob ermahnte mich Eure Frau gar häufig. Da wurde einmal der Sabbattisch bereitet, und Eure Frau wollte die Schüsseln auftragen. Ich aber mochte weisen, dass ich gewandter worden war, und bat sie, die Sabbatschüssel in meine Hände zu geben. Kaum aber hielt ich sie, kam ein Zittern in meine Finger, und ich liess die Schüssel fallen. Da erzürnte sich Eure Frau über mich und gab mir einen leichten Streich ins Gesicht. Ihr aber sasset unfern und sahet es und liesset es schweigend geschehen. $\mathrm{Da}$ schrie eine Stimme in den Himmeln laut auf, und das Urteil ward über Euch gesprochen, dass Ihr um Eures Schweigens willen verlieren solltet, was Euch in der kommenden Welt bestimmt war. Mir aber geschah später die Gnade, dass ich von diesem Mann, der ein heimlicher Zaddik ist und seine Heiligkeit in seinem Tun verbirgt, zur Frau genommen wurde. Er war es, der mir eröffnete, was über Euch verhängt worden war. $\mathrm{Da}$ begannen wir $z \mathfrak{u}$ Gott $z \mathfrak{u}$ beten, dass das Urteil gewandelt werde, und unsere Bitte wurde uns gewährt, und es ward milder und immer milder, bis man aussprach, dass Euch ein Sabbat zerstört werden müsse, denn der Sabbat ist die Quelle der kommenden Welt. Und uns wurde es aufgegeben, Euch solches anzutun. Aber nur, wenn wir es ganz und gar vollendeten, so ward uns gesagt, würde unsere Tat das Verhängnis vernichten. So haben wir es denn 
getan im Wehe unserer Herzen. Und nun ist Euer Teil zu Häupten des obersten Paradieses." In diesem Augenblick kehrte die Weisheit zum Meister zurück, und das innere Sehen lebte in ihm auf, und er sah in die Tiefe der Geschicke und sah sein Heil und sah den heiligen und heimlichen Mann in seiner Wahrheit vor sich stehen. So gingen sie mitsammen in die geschmückten Räume und verblieben miteinander diesen und die nächsten Tage und feierten den Sabbat in hoher Freude. 


\section{DER WIDERSACHER}

CINER DER EIFRIGSTEN UNTER DENEN, die sich wider den Baalschem erhoben, war Rabbi Jakob Josef von Szarygrod. Keinem wohl strömte der kämpfende Wille aus so tiefen und verborgenen Quellen zu. Denn die ketzerischen Dinge, die ihn erschauern und ergrimmen machten, lagen wie Ahnung und Keimschicht in seiner eigenen Seele, ganz unten, unter dem Bereich des Wortes, ja tiefer als dẹ Raum, in dem sich der Gedanke gebiert.

Drei Bräuche der Neuerer aber waren es vor allen, denen der Rabbi feind war: die Freude ihrer Feste, die den Zaun des heiligen Gesetzes niederbrach und hoch aufwallte im Tanz und im trunkenen Lied: die Seltsamkeit ihres Dienstes, da die Gemeinde nur lose die Betenden umschlang und in Wahrheit jeder für sich und auf seine Weise, oft auch mit wilder und entfesselter Geberde zu Gott redete; mehr als alles aber die leise, von Geheimnis schwingende Predigt des Meisters nach der dritten Sabbatmahlzeit in der Dämmerung. Oft hatte der Rabbi von dieser Predigt gehört. Sie war nicht, wie die Sitte gebot, aus Deutungen der Schrift aufgebaut, auf denen sich kunstvoll Deutungen der Deutungen türmen. Sie sprach von den Dingen der Seele, als ob man von diesen Dingen reden dürfte. Manchesmal waren es gar gewöhnliche Geschichten, wie das gemeine Volk sie sich in den Trinkstuben erzählt; aber sie wurden langsam und feierlich gesagt wie die Worte des Mysteriums der Keduscha, und die Leute lauschten ihnen, als setzten 
sie die Offenbarung am Sinai fort. So oft auch dem Rabbi davon berichtet wurde, immer wieder überkam ihn der Zorn wie zum erstenmal. Geschichten am Sabbat! Was für einen Sinn können Geschichten haben? Und noch zorniger hiess er in sich die Stimme schweigen, die tief unten erwacht war und es $z u$ wissen vorgab. Und er mahnte seine Seele an den wahren Weg zur Vollendung, durch die Abkehr vom Lebendigen, durch Zucht und Herbheit, durch Fasten und Schweigen. *

Einstmals machte sich der Baalschem am Abend auf und fuhr nach Szarygrod. Er war ohne Gefährten und unterredete sich mit der Sommernacht wie mit einer Freundin. Als sie Abschied nahm und der Tag noch zögernd aufstieg, kam der Wagen des Meisters in die kleine Stadt. $\mathrm{Da}$ lagen die Häuser mit geschlossenen Fensterläden im Zwielicht wie freudlos Schlummernde mit schweren geschlossenen Lidern. Den Baalschem kam das Erbarmen an mit ihnen allen, die hinter diesen Fenstern ihren dumpfen Frühschlaf hielten. Er ging mit steten Schritten unter der wachsenden Tageshelle auf und nieder, bis über eine Weile ein Gesell des Weges kam; der trieb einige Tiere vor sich her, die er tagüber vor der Stadt auf der Weide hatte. $\mathrm{Zu}$ dem begann der Meister wie von ungefähr zu reden und kam, indes der Mensch anfangs ein wenig einfältig und scheu ihm Antwort bot, allmählich ins Erzählen einer Geschichte. Wie er so redete, kam ein anderer herzu, alsbald ein dritter, dann aber immer mehr und mehr, meist Knechte und arme Leute, die 
den Tag früh beginnen. Sie alle standen und lauschten begierig und riefen gar noch andere aus den Häusern herbei. Wie die Stunde vorrückte, kamen die Mägde mit den Wasserkrügen auf dem Weg zum Brunnen und hielten inne, die Kinder kamen aus den Stuben gesprungen, und die Hausväter selber liessen ihr Geschäft und ihren Gang, dem fremden Mann zuzuhören. Es war aber seine Erzählung so seltsam lieblich verknotet, dass, wann immer einer ankam, es ihn wie ein Anfang dünkte und jeder, des früheren unbegierig, ganz auf das Kommende gerichtet war und ihm entgegenharrte wie der Erfüllung seiner liebsten Hoffnungen. So hatten sie alle die eine grosse $\mathrm{Ge}$ schichte, und darin jeder seine eigene kleine und allerwichtigste, und die kleinen kreuzten einander und verhakten sich, als müssten sie sich tief verwirren, aber im Nuwaren sie wiedergelöst und geordnet und liefen fein säuberlich neben einander hin; war aber eine abgelaufen, dann liess sie eine neue Verheissung zurïck, die alsbald eine Genossin zu erfüllen sich anschickte.

Um ein geringes stand das ganze Städtchen auf dem Marktplatz, und alle lauschten, und jeder hatte vergessen, was ihm sonst um diese Stunde zu tun obliegen mochte. Die Handwerker hatten ihre Geräte in der Hand und die Frauen ihre Kochlöffel. Ganz vorn aber stand mit einem grossen Schlüsselbund der Tempeldiener, der just auf dem Weg zum Bethause gewesen war, es zu öffnen. Ueber ihn war die Erzählung mit solcher Gewalt geraten, dass er sich bis dicht vor den Meister durchgedrängt hatte und nun stand und lauschte mit $\mathrm{Ohr}$ und Herz und dem ganzen 
Leibe, seines Amtes so wenig eingedenk, als wäre es nur ein verschollener Traum.

Es war aber die Erzählung des Baalschem nicht wie eure Erzählungen, Kinder der Zeit, die krumm wie ein kleines Menschenschicksal oder rund wie ein kleiner Menschengedanke sind. Sondern der farbige Zauber des Meeres war darin und der weisse Zauber der Sterne und der unbegreiflichste von allen, das zarte Wunder der unendlichen Luft. Und doch war es keine Mär der Ferne, was die Erzählung sagte, sondern jedem erwachte unter der Berührung ihres Wortes die heimliche Melodie, die verschüttete, zersprengte, totgewähnte, und jeder empfing die Botschaft seines verlorenen, vergessenen Lebens, dass es noch da und ihm offen und nach ihm bange war. $\mathrm{Zu}$ jedem sprach sie, zu ihm allein, kein anderer war, alle waren er, er war die Erzählung.

$\mathrm{Da}$ hob der Meister den Blick und sah lächelnd ins Weite, sah durch Häuser und Mauern, wie vor der Tür des Bethauses der Rabbi stand, der um diese Stunde sein Gebet zu verrichten kam; und da war das Haus geschlossen, und der Diener fehlte, und da war keiner von den allen, die Tag um Tag zu dieser Zeit versammelt waren und ihn erwarteten. Der Baalschem sah in den Geist des Rabbis und sah den Grimm und die Bitterkeit in ihm wachsen und wie er seinen Unwillen band und sich zur Geduld bezwang. $\mathrm{Da}$ beschloss der Meister, den Diener aus der Erzählung zu lösen, und augenblicklich kam es über den Mann wie ein Erwachen, und ohne sich zu besinnen lief er, so schnell er konnte, nach dem 
Bethaus. Als er an der Tür ankam, fand er den Rabbi, der mit gefalteter Stirn, die Augen zu Boden gesenkt, die Worte des Unmuts zurückdrängte und nur mit einer barschen Bewegung zu eiligem Öffnen drängte. Der Diener aber, noch erfüllt und umgeben von der Erzählung, ward weder der eigenen Verfehlung noch des Ärgers seines Herrn gewahr, sondern begann von dem fremden Mann zu melden, der auf dem Platz stehe und Geschichten sage, alles Volk um ihn geschart. Er beschrieb die Gestalt und das Ansehen des Fremden, und da wusste der Rabbi, wer gekommen war und mit ihm um die Seelen stritt, und ein zorniges und wehes Funkeln kam in seine Augen. Wortlos schob er den Diener beiseite, trat in das Haus und begann zu beten.

$*$

Nach einer Zeit geschah es, dass ein Mann von den Frommen des Baalschem und aus seiner Stadt seine Tochter einem geliebten Schüler des Rabbis von Szarygrod verlobte. Die Hochzeit sollte in der Stadt des Baalschem vollzogen werden.

Rabbi Jakob Josef hegte einen schweren Kummer ob dieses Verlöbnisses. Als er davon erfuhr, war es ihm wie die Kunde, sein Sohn sei unter schlimme Gesellen geraten. Wohl erwies sich, als der Schüler selbst vor ihm erschien und ihm alles berichtete, die Liebe stärker als der Zorn, und er musste ihn segnen. Aber als er ihn bat, zu seinem hohen Feste nach Miedzyborz zu kommen, weigerte er es ihm und erklärte, nie und nimmer könne er die Stätte des Ketzers betreten. Der Schüler jedoch lag ihm mit inständigen 
Bitten an Tag für Tag, bis dem Rabbi einmal das Wort entfuhr: „Wie soll ich mit dir ziehen - wird doch dich und deine Freunde der erste Gang in Miedzyborz zu dem unheiligen Mann führen, der das Volk Israel verdirbt!" $D a$ versprach der Jüngling, um einen günstigen Spruch seines Lehrers zu gewinnen, er wolle das Angesicht des Baalschem nicht schauen, und unter dieser Bedingung willigte der Rabbi ein, mit ihm zu fahren.

Als sie aber unterwegs waren und unfern des Reiseziels in einer Herberge weilten, merkte er, wie der Schüler" sich mit seinen Freunden heimlich unterredete, und er erkannte, dass sie darüber sprachen, wie sie es anstellen möchten, ohne das Wissen des Rabbis in das Haus des Baalschem zu kommen. Da trat er auf sie zu und sagte zum Bräutigam: „Ich habe Unrecht daran getan, dir ein Bedingen aufzulegen, das du nicht zu erfüllen vermagst. $D a$ es mir aber nicht ansteht, allein die Heimfahrt anzutreten, werde ich hier verbleiben, bis ihr von der Hochzeit heimfahret, und sodann mit euch nach meiner Stadt zurückkehren." Der Schüler versuchte stammelnd erneute Bitte und Versprechung, aber der Rabbi hörte ihm nicht zu, sondern wandte sich zum Wirt und ersuchte ihn, ihm ein Zimmer zu weisen, in dem er ungestört seinen Studien obliegen könnte.

Eine Weile danach sass er in einer stillen Stube und hatte die Bücher aufgeschlagen vor sich liegen. Aber als er sich darüber beugte und beginnen wollte $z u$ lesen, sah er, dass die Lettern, statt wie immer in ihrem schönen Gefüge willig dazustehen, - jede 
freudig erwartend, dass er an sie käme, stolz befriedigt, wenn er sie gelesen hatte, - sich in einem tollen Tanze einherschwangen und die Gliedmassen in die Luft warfen, ja ein dickes rundes Ding überkugelte sich in einem fort, ohne zu ermüden. Der Rabbi schloss die Augen, öffnete sie wieder, und als das Unwesen nicht aufhören wollte, schlug er mit heftiger Hand aufdas Buch. Dawarim Augenblick alles still und wohlgesittet, jedes sass an seinem Platz, als hätte es sich nie von dannen gerührt, und ein paar obenstehende Lettern hatten sogar schon das Lächeln der freudigen Erwartung bereit. Als aber der Rabbi nun anheben wollte zu lesen, drang ihm aus dem Buch ein aus hundert dünnen Stimmen gemischter Lärm entgegen. Das waren die Wörter, die miteinander stritten. Aber es waren nicht etwa zwei Lager von Kämpfern, sondern jedes Wort widersprach allen andern, und jedes versicherte, es sei von Lügnern und Heuchlern umringt, die es lediglich darauf abgesehen hätten, ihm seinen eingeborenen Sinn $z \mathfrak{u}$ rauben und $z \mathfrak{u}$ erschlagen, aus tückischem Neid, weil sie selbst keinen Sinn und keine Seele hätten. Und als der Rabbi auch diesen Krieg beschwichtigt hatte, standen die Sätze auf und erklärten, sie wollten nicht länger einem unbekannten $Z_{\text {weck }}$ dienen, der über allen schwebt, sondern aus sich selber und für sich selber leben.

Der Rabbi sah auf das Buch und lächelte. Dann schlug er es zu und lächelte wieder. Hatte er doch ein Buch in sich, ein grosses und überreiches, das keiner ihm verwirren konnte. Aber als er den 
ersten Gedanken aufrufen wollte, brach sein Lächeln ab. Denn kein Gedanke stieg auf, nur ein dumpfes Vergessen lagerte wie über einer verlassenen Gräberstätte. Da erschrak der Rabbi, und das erste Erschrecken seines Lebens kam über ihn wie eine Todesnot. Dann aber verstand er, dass ihm befohlen war, nach Miedzyborz zu gehen. Und alsbald lebten die Gedanken in ihm auf, so sturzhaft, dass er fast zum zweitenmal erschrak.

Es kam ihm nicht in den Sinn, einen Wagen zu mieten, er trat hinaus auf die Strasse und ging. Als er nach Miedzyborz kam, trug es ihn weiter, ohne dass er seine Augen oder seinen Willen befragte, bis vor ein grosses, abgesondert stehendes Haus, aus dem das Licht vieler Kerzen und das Gespräch vieler Stimmen ihm entgegendrangen. Er verstand, dass es das Haus des Baalschem war, und wollte weitergehen, als es urplötzlich stille ward. Dann erschien es ihm, das Licht werde dreifach heller, und aus dem Schweigen begann eine Stimme $z u$ reden, die tönte so wunderbar, dass er näher treten und lauschen musste. Und er hörte, was die Stimme sprach.

,Ich will euch eine Geschichte erzählen.

Es war einmal ein Rabbi, ein weiser und strenger Mann. Der sass in der Nacht des neunten $\mathrm{Ab}$ in seiner Kammer und trauerte über den Tempel und über Jerusalem. Und anders als in allen Jahren in dieser Nacht war diesmal seine Trauer. Denn in den anderen Jahren war es ihm gewesen, als wäre er hingestellt in die Zerstörung der Stadt 
und schaute mit seinen Augen den Brand und das Verderben. Aber in dieser Nacht war es ihm, er sei eine eherne Säule am Hause des Herrn, und er fühlte die Hand der Chaldäer auf sich, die ihn zerbrach, und wieder war es ihm, er sei das Erz einer zerbrochenen Säule, das gen Babel geführt wird. Und das Klagelied kam auf seinen Mund, aber nicht wie dessen, der sieht und trauert, sondern wie das Stöhnen der zerbrochenen Säule. Und nicht wie einer, der kommt und geht, sondern wie ein Ding, das in der Herrlichkeit gelebt hat und nun zerschlagen und in die letzte Schmach geschleppt wird, rief er zu Jerusalem: Stehe auf, schreie in der Nacht, am Anfang der Wachen schütte dein Herz aus vor dem Herrn wie Wasser! Und da ward es ihm, er sei Jerusalem die Stadt, und der Brand und das Verderben gingen über ihn hin, und die tausendfache Verwüstung geschah an seinen Gliedern. $\mathrm{Da}$ brach der Schrei aus ihm und schüttelte ihn wie ein Sterbendes und warf ihn auf das Lager. Und da er also lag, war sein Leib so bar des Lebens, wie der Leib eines, der im Vergehen liegt. Die Nachtstunden strichen hin und kamen auf ihn, der ohne Empfindung war, wie wenn die Zeit $z u$ Sand würde und auf ihn niederrieselte, ihn $z u$ begraben. Um die Mitternacht aber fühlte er ein Bewegen in der Luft, und ein Hauch glitt an seine Stirn wie lebendiger Atem. Er öffnete die Augen und gewahrte über sich gebeugt die Gestalt eines Knaben und erkannte das Angesicht seines Lieblingsschülers, die weichen Züge, die nun von einem 
Schrecken entstellt waren. Der Knabe berührte seine Hand und sprach, und seine Stimme schwankte: „Rabbi, Ihr laget wie einer, dessen Seele schon flüchtig ist, ihn zu verlassen. Ihr müsset Euch ein wenig Speise gewähren, um Euer Leben zu stärken." Der Rabbi wandte das Haupt und flüsterte, und seine Zähne schlugen wider einander: „Kind, was redest du? Ist doch heute der neunte $A b$, ein Tag der Trauer und des grossen Fastens!" Aber der Knabe umschlang seine Hand fester mit seinen beiden warmen Händen und bat: „Rabbi, denket, dass es verboten ist, sich mit Willen dem Tod anheimzugeben!" Und er ging und kehrte wieder und trug, sie mit den Armen umfassend, eine grosse Schüssel voll herrlicher Früchte und kniete vor dem Rabbi nieder und sah ihn bittend an und neigte bittend den Kopf. Und der Rabbi, vom buntfreudigen Anblick und Wohlgeruch belebt, richtete sich auf und sprach den Segen über die Frucht des Baumes, wie einer, der sich anschickt $z u$ essen. Aber als das letzte Wort seinem Mund entwichen war, ergriff ihn ein jähes Entsetzen über sein Tun. Er hob die Hand gegen den Schüler und schrie ihn an: ,Hebe dich hinweg, Geist der Verführung, der du vertraute Gestalt borgst, mich zu betören!" Der Knabe erzitterte unter den Worten seines Lehrers und wich bangend aus dem Hause.

Der Rabbi aber fiel in einen tiefen Kummer wie in einen Abgrund. Vor ihm erschienen die Jahre seines Lebens mit all ihrem Opfer und Bann, mit ihren Kriegen und Triumphen, mit der hohen Macht 184 
über sich selber, die wuchs und stieg von Jahr zu Jahr. Und dann erschien vor ihm ein kleiner mattäugiger Wunsch, der schleppte sich wie ein kranker Zwerg zu den Jahren hin und wischte sie mit seinem Finger weg, dass nichts mehr von ihnen da war. Und der Kummer des Rabbis wurde immer tiefer, bis die Trauer dieses Tages und das Leid um Jerusalem in dem Kummer versanken, und der Kummer schlang sie ein und breitete sich und herrschte über die Seele mit Geissel und Feuerbrand. Und in dem Rabbi war nichts mehr von der Stunde, da er eine Säule gewesen war im Hause des Herrn und da er die Stadt gewesen war unter der Hand des Unheils, sondern er war dieser Mensch, hier liegend auf einem Lager in der Nacht, dieser Mensch, der gesammelt und gesammelt hatte, mit strenger und nicht ermüdender Hand, und dem nun ein kranker $Z_{\text {werg }}$ alles raubte, mit dem Ruck eines dürren Fingers in der Finsternis. Über sich und ringsum fühlte er die Nacht, stehend und unwandelbar, die Nacht und den Abgrund.

Aber die Nacht stand nicht, sondern zog über ihm hin mit dem Wallen ihrer Haare und dem Wehen ihrer Schleier. Und ehe sie entwich, legte sie ihre Hand auf seine Augen und gab ihm den Schlaf. Aber irgendwoher fiel ein Samen in den Schlaf, und der Traum keimte und wuchs und kündete.

Der Traum führte ihn unter den offenen Mittagshimmel, der durch die Baumkronen eines grossen Fruchtgartens auf ihn herabschaute. Er ging durch die schmalen vielverschlungenen Wege des Gartens, 
gestreift vom hohen Gras und den niederhangenden früchteschweren $Z_{\text {weigen. }}$ So kam er an das Ende des Gartens und sah über die niedrige Mauer hinaus, und was er sah, waren die Gässchen der Stadt, in der er hauste. Ihm aber war in seinem Traum wohl bewusst, dass ein Garten solcher Art in seinem Wohnort nicht stünde, und wunderlich furchtsam und zweifelnd wandte er den Fuss und ging in den Garten zurück und suchte nach einem, der ihm Rede stehen könnte. Als er der Mitte des Gartens sich näherte, wo alle Wege sich kreuzend zusammenliefen, sah er einen Mann in Gärtnertracht stehen; der war tief zur Erde gebeugt, hob aber nun die Stirn ihm entgegen und blickte ihn funkelnd an. Der Rabbi fragte ihn: „Was für ein Garten ist dies, und sage mir, wessen ist er?" Der Mann redete hart und kurz: „Er gehört dem Rabbi dieser Stadt." Der gab verwundert zurück: „Ich bin der Rabbi dieser Stadt und bin arm und kenne keinen Besitz. Woher käme mir dieser Garten?" Da sprach der Mann wieder, und Blitze erwachten auf dem Grund seiner Augen, und ein Donner spielte in seiner Stimme: „Aus Wunsches Pein, aus Schuld und Scham, aus einem eitlen Segensspruch hat dir die Hölle diesen Garten geboren." Er stampfte mit dem Fusse auf, da spaltete sich die Erde bis zum feurigen Kern, und der Rabbi sah die Wurzeln der Bäume verschilungen in die Urtiefe sich senken und dort vereint sich aus der Flamme nähren.

$\mathrm{Da}$ erwachte er, und der Schauer des Traumes hielt ihn bis zum Abend, da der Trauertag endete. 
$Z \mathrm{u}$ der Frist reckte sich der Rabbi auf und schüttelte alles von seiner Seele ab, ging in seine Stube und verschloss die Tür. Er nahm die Bücher der Psalmen in die Hand und stand und sprach die Psalmen mit gewaltigem Ton. Das erste Buch hatte er gesprochen, da ward fern in der Nacht draussen ein Laut, der redete: „Genug, die Früchte sind schon abgefallen!" Aber der Rabbi erhob das Haupt und die Stimme und sprach das zweite Buch. Und da er geendet hatte, tat sich wieder der Laut auf, und er klang näher und deutlicher: „Genug, das Laub ist schon verwelkt!" Doch der Rabbi erneute seine Kraft und betete das dritte Buch. Nun war die Stimme ganz nah, und von ihrem Hauch klirrten die Fenster, und sie redete: „Genug, schon sind die $Z_{\text {weige }}$ verdorrt!" Der Rabbi spannte alles Vermögen seiner Seele und las das vierte Buch. Da wankte der Boden seines Hauses, und die Stimme erscholl, als würde sie unter seinen Füssen aus der Erde geboren: ,Genug, schon sind die Äste abgestorben!" Der Rabbi fühlte, wie das Ermatten sich an ihn heranschlich, aber sein Blick zuckte nicht, und er riss die letzte Macht hervor, und das letzte Buch erstand von seinem Munde und stieg hoch und wirbelnd wie Opferrauch. Als er schwieg, sprang die verschlossene Tür des Gemaches weit auf, und in ihr stand ein düsterer Bote, gebeugt und keuchend, wie gehetzt von einem langen, wilden Lauf, und seine Stimme war wie verflackernd im Luftzug: ,Genug, genug, du hast uns besiegt, schon sind die Stämme 
abgehauen!" Und die Gestalt zerging mit ihrem letzten Ton.

So hat es sich dazumal ereignet. Die Tage, die Monde und Jahre sind darüberhingegangen. Aberdie Wurzeln des Gartens sind in der Erde geblieben, und der Rabbi wacht in vielen Nächten, sinnend, wie er sie ausrotten möchte. Allein er kann es nimmer ersinnen."

So erzählte die Stimme drinnen im hellen Saal. Rabbi Jakob Josef stand im Schatten, die Stirn an die Mauer gepresst, und die Worte fielen auf sein Herz wie Tropfen eines flüssigen Brandes. Als die Rede drinnen verstummte, seufzte er auf und stürzte durch die Tür in den Saal und $z u$ den Füssen des Baalschem und rief: „,Meister, lehre mich, was ich tun soll, die Wurzeln auszurotten!"

Der Baalschem sprach: „Wisse, nicht aus dem Wunsche ist dir der Garten geboren worden, sondern aus des Wunsches Kummer und Pein, da du dich befleckt wähntest und um dich littest und den Gram auf dein Haupt streutest wie Asche. $\mathrm{Da}$ hast du dem leichten Bilde deines Wunsches Bestand und Dauer gegeben und hast seine Wurzeln eingesenkt in das Reich der Körper, da es zuvor ein Schatten war. Aber als ich dies erzählt habe, ist der Körper zum Wort geworden und zum schwebenden Atem und leichter, als das leichte Bild deines Wunsches gewesen war. Und da ich ein Froher zu Frohen redete, ist die Freude hingegangen und hat die Wurzeln ausgerissen."

Rabbi Jakob Josef aber ist darnach der geworden, den sie den grossen Jünger nannten. 


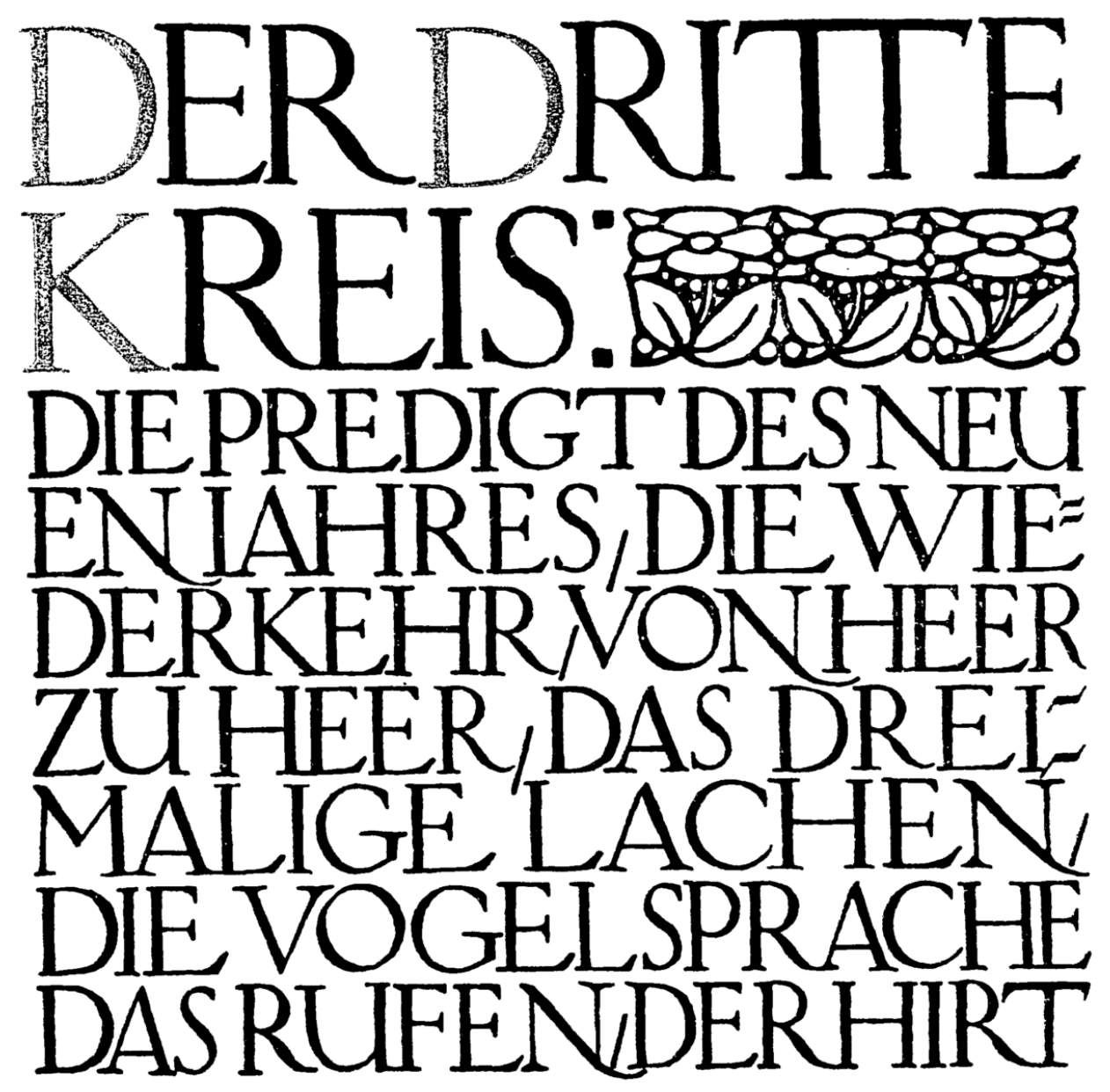




\section{DIE PREDIGT DES NEUEN JAHRES}

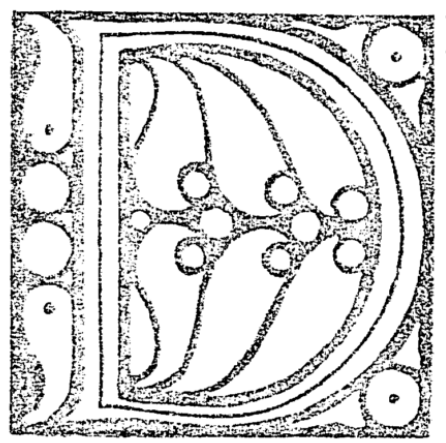

IEERSTESONNEDES JAHRES stand in der Mittagshöhe und die Luft war voll des Schofarklanges. Man hörte ihn auf allen Wegen, ja es gab der Schüler welche, die ihn $z u$ sehen vermeinten, als hätte das Tönen Kreise eines fremden, glühenden Lichtes in das Grau des Frühherbsttages gezogen.

In dem Hause des Baalschem sassen die Schüler um den uralten langen Tisch, der heute fester als je die Füsse gegen den Boden zu stemmen schien, um sich wider die Zeit zu behaupten. Die einen blickten hinaus in die Lichtkreise, die andern sahen an den geschwärzten Wänden hinauf, als müssten sie im nächsten Augenblick zur Seite weichen und das Reich des Geheimnisses erschliessen.

Der Nachsegen des Mittagmahles war beendet, und der Baalschem begann, die Predigt des neuen Jahres zu sprechen. Die Schüler konnten in sein Angesicht nicht schauen, aber wenn sie die Augen schlossen, kam Wort für Wort vor sie mit einem Angesicht, blitzend das eine, abgrundsdunkel das andere, ein drittes rein und still wie die Liebe Gottes zur Welt. Mit geschlossenen Augen sassen sie da, die jungen und die alten, und lauschten, und schauten.

Und der Baalschem sprach. Es ist zu sagen, dass die Stimme des Baalschem gemeiniglich war wie ein leichtes Schlagen von $\mathrm{Erz}$ an $\mathrm{Erz}$, und nur im tiefen 
Gebet mischte es sich zuweilen darein wie der Schrei der Lerchenkehle. Aber am Tag des neuen Jahres war seine Stimme neu und gewandelt. Es war der Schofar, der in ihr atmete und Menschenlaut war. Der Weckruf des Tekia kam und rüttelte an den Toren der Seele. Das wogende Schewarim umpfing die Losgemachte wie das Beben der Sehnsucht. Der hohe Jubel der Terua trug sie zur Erlösung empor.

Und das Wort, über das der Baalschem sprach, war das Wort des neuen Jahres: Stosse in den grossen Schofar zu unserer Befreiung!

"Stosse in den grossen Schofar", so rief er zum Herrn, „wenn der Kreis des Jahres sich rundeś und die Seelen aller Dinge in die Finsternis tauchen zu neuer Geburt. Siehe, deine Kinder sind morsch geworden vom Anhauch der Stürme. Siehe, der Brand der Wüste hat ihr Mark versehrt. Nun da der Kreis deines Jahres sich schliesst und das Dunkel der Wende seine Fluten entsendet, stosse in den grossen Schofar, o Herr, zur neuen Geburt!

Deine Pein hat unsere Hände gemartert, bis sie schwach wurden vor dem Leben. Deine Wanderschaft hat unsere Füsse gejagt, bis sie auf festem Boden wankten. Du hast den Wurm in unsere Herzen geschickt, und sie sind zernagt wie krankes Laub. Dein Bote hat seine Hand auf unsere Stirnen gelegt, und unsere Gedanken starren im Eise. Stosse in den grossen Schofar, o Herr, zu unserer Befreiung!

Der Engel des Herrn erfasste mich in der Nacht und tührte mich hinaus, und ich stand im Leeren, und die Nacht lag auf meinen Schultern wie eine grosse 
Last, und die Nacht wälzte sich von unten an meine Sohlen heran. Und der Engel sprach: „Schaue!“, und die Finsternis wich, und ich stand leicht in heller Leere, und ich sah. $\mathrm{Da}$ war ein Kreis zwischen zwei Abgründen, ein schmaler runder Grat. Und im Bezirke des Kreises schloss sich ein roter Abgrund wie ein See von Blut, und ausser des Bezirkes des Kreises dehnte sich ein schwarzer Abgrund wie ein Meer von Nacht. Und ich sah, siehe da ging ein Mensch auf dem Grate wie ein Blinder, mit wankenden Füssen, und seine beiden schwachen Hände rührten an die Abgründe zur Rechten und zur Linken, und seine Brust war aus Glas, und ich sah sein Herz flattern wie krankes Laub im Winde, und auf seiner Stirn war das Zeichen des Eises. Und der Mensch ging weiter und weiter den Weg des Grates, ohne rechts und links zu sehen, und schon war er dem Ende des Kreises nahe, das sein Anfang ist. Und ich wollte ihm rufen, aber mein Sehen lähmte meine Zunge. Und der Mensch blickte plötzlich auf, und sah rechts und links, und er strauchelte, und aus den Abgründen stiegen Arme auf, ihn zu fangen. $\mathrm{Da}$ berührte der Engel meine Lippen, und meine Zunge war frei, und ich rief und schrie zu jenem: „Erhebe deine Flügel und fliege!" Und siehe, da erhob der Mensch seine Flügel, und keine Schwäche und keine Starrheit war mehr an ihm, und der Grat verschwand unter seinen Füssen, und den Abgrund des Blutes verschlangen Gottes Wasserquellen, und der Abgrund der Nacht verging in Gottes Lichte, und die Stadt des Herrn lag da, offen allerwärts. 
Sehet, ein Kreis ist unser Jahr. Wir gehen auf schmalem, rundem Grat zwischen zwei Abgründen und sehen die Abgründe nicht. Sind wir aber an das Ende des Grates gekommen, das sein Anfang ist, da tällt die Angst und das $Z$ ittern über uns wie der Sturm des Herrn, und der Blitz des Herrn fährt über die Abgründe hin, und wir sehen sie, und wir schwanken. Aber der Schofar tönt über uns und fasst unsere Seelen und trägt sie, und jeder Schofarton trägt viele Seelen auf seinen Flügeln. Und die Schofarim schwingen sich zu den Himmeln auf. Und die Himmel lauschen, und die Angst und das Zittern kommt über sie wie der Sturm des Herrn, und der Weltenschofar erschallt. Und der Weltenschofar trägt auf seinen Flügeln die Seele, die aus unseren Seelen geboren wurde und die Seele des Messias ist. Und er schwingt sich auf $z \mathfrak{u}$ dem Reiche des Geheimnisses, und er schlägt mit seinen Flügeln an die Pforte, und die Pforte tut sich weit auf, und siehe, da ist nicht Pforte mehr noch Mauer, sondern die Stadt des Herrn liegt da, offen allerwärts.

Stosse in den grossen Schofar, o Herr, zur Geburt der Seele!"

Die Stimme des Baalschem war wie der Schofar, bis er schwieg. Dann erhob er sich und ging in seine Kammer und schloss sich ein. Und mit ihm erhoben sich die Schüler und traten hinaus. Wie Träumende gingen sie durch die Gassen, blicklos und bang. Sie hatten ein kleines Haus ausserhalb der Stadt, wo sie sich $z \mathfrak{u}$ versammeln und miteinander die ewigen Dinge 
zu betrachten pflegten. Dahin gingen sie nun, und die Flügel der Stimme waren über ihnen.

Aber im Haus des Baalschem lebte dazumal ein Knabe, Josef mit Namen, und alle nannten ihn Jossele. Als der Meister in seine Kammer gegangen war und die Gefährten alle zu ihrem Hause ausserhalb der Stadt, blieb er allein zurück an dem langen Tische, denn er war zu jung, um von jenen nach dem Ort ihrer Betrachtung mitgenommen zu werden. So sass er zwischen den geschwärzten Wänden und fühlte die Flügel der Stimme an seinen Schultern. Und wie die ersten Schatten des Spätnachmittages ihr goldbraunes Zucken über die weisse Decke des Tisches warfen, legte Jossele den Kopf in die Hände, denn ihm war Angst um der Flügel der Stimme willen, die er an seinen Schultern fühlte. Und die dicht aneinander und vor die Augen gepressten Finger schufen ihm ein Dunkel, aber in dem Dunkel erwachte ein rotblaues Licht, das sang zu ihm wie die Stimme, um deren willen ihm Angst war. Und es geriet über Jossele mit einer stürzenden Gewalt, wie lang verhaltene Tränen urplötzlich hervorschiessen: Jetzt und jetzt wird Meschiach kommen. Und die Stube weitete sich, und die Wände verschwanden, und vor ihm war ein rotblaues Licht, das strahlte rings hinaus mit Strahlen einer nächtigen Sonne. Und Jossele lief auf das Licht zu. Aber da war die Türe, wie ein stechender, weckender Schmerz. Der Knabe stand einen Augenblick lang sehend auf einem schmalen Grat zwischen zwei Abgründen, und der Blitz des Herrn fuhr vor ihm hin, und er 
schauderte und schwankte. Da aber erfasste ihn die Gewalt mit Fängen der Cherubim, und die Stimme brauste, und das Licht war in sein Herz gefallen und brannte. Und Jossele öffnete die Türe und lief hinaus, und er lief durch die Gassen der Stadt, und lief in stürzender Eile, bis er zum Hause der Schüler kam. Da standen seine Sohlen, und seine Kehle spannte sich, und er rief: „Meschiach!" Aber da war kein Laut rings um ihn, nur seine Stimme tönte und verklang sehr langsam und lebte vor ihm und war wie die Stimme, deren Flügel er an seinen Schultern fühlte. Da zwang er seine Augen, aufzusehen, und mühte sich, bis er sah. Da sassen die Gefährten alle vor der Schwelle des Hauses in langer bogenrunder Reihe, und eines jeden Mund war fest verschlossen, und eines jeden Blick lag in der Ferne, und kein Glied regte sich. Und Jossele hörte seine Stimme rufen: "Jetzt und jetzt wird Meschiach kommen" und hörte die Stimme verklingen mitten in starrendem Schweigen. Da flog die Seele des Knaben auf den Flügeln der Stimme auf und flog zu einem der Schüler hin und legte sich an seine Brust, und Jossele sprach: „Nachum, weisst du noch, wie du gefastet hast von einem Sabbat zum andern, um Meschiach zu rufen? Weisst du noch, wie ich $z u$ dir kam, als du am Boden lagst am letzten Tag und mit der Stirn an die Diele schlugst, wie wir dann zusammen geweint und geb etet haben? Sieh, Meschiach kommt!" Aber jener schwieg. Und die Seele wandte sich und flog zum zweiten hin und schmiegte sich an seine Schläfe, und Jossele sprach: „Elimelech, 
ich sah dich einmal über ein Feuer geneigt, dass deine Locken an die Flammen sprangen, und deine Lippen flüsterten : Meschiach. Ich sah dich einmal den Arm emporheben und die Hand gen Himmel schütteln, und deine Lippen flüsterten: Meschiach. Elimelech, er kommt!" Aber jener schwieg. Und abermals wandte sich die Seele und flog auf den dritten zu und glitt über seine Hand, und Jossele sprach: „Jehuda, ich habe dich damals gehört, als du den Zauber tatest über den Wassern und den dunklen Spruch sprachest in das Wehen des Windes. Der Zauber ist mit den Wassern verronnen, und der Spruch ist im Winde verweht. Aber jetzt Jehuda, horch, jetzt kommt er, hörst du ihn kommen? Jehuda, lass uns ihm entgegengehen." Aber jener schwieg. Und Jossele sah die Gefährten an und schaute mit seiner Seele auf sie, und da sah er, sie hörten seine Worte nicht, und er sah sie lauschen, einem fernen Schritt. $\mathrm{Da}$ sassen sie in langer, bogenrunder Reihe und horchten auf einen fernen Schritt und blickten in die Ferne. Alsdann kam die Einsamkeit über Jossele und legte ihre kalte, harte Hand auf seinen Nacken, und die Krallen der Hand gruben sich in sein Fleisch, und die Hand lag auf seinem Nacken wie ein riesenhaftes, lebendiges, sich einkrallendes Siegel. Und Jossele sah, wie das rotblaue Licht seinem Herzen entstieg und vor seinen Augen verflimmerte. Und Jossele fühlte, wie die Flügel an seinen Schultern verschrumpften und wie sie abfielen. Und Jossele wollte sprechen, aber seine Kehle trug keine Stimme. Und Jossele wollte hinweg, aber er konnte den Fuss nicht heben. Und 
Jossele setzte sich zu den andern und blickte in die Ferne und horchte auf einen fernen Schritt.

So sassen sie beisammen, bis die Sterne kamen. $\mathrm{Da}$ wich es von ihnen, und sie kehrten in die Stadt zurück. Und Jossele stand in seiner Stube wie ein Blinder, mit wankenden Füssen, und seine beiden schwachen Hände rührten an die Abgründe zur Rechten und zur Linken, und sein Herz flatterte wie krankes Laub im Winde, und auf seiner Stirn war das Zeichen des Eises.

SCHOFAR = die Posaune, die am Tage des Neuen Jahres geblasen wird. TEKIA, SCHEWARIM. TERUA $=\mathrm{N}_{\text {amen }}$ der angeordneten Schofarklänge. MESCHIACH $=$ Messias. 


\section{DIE WIEDERKEHR}

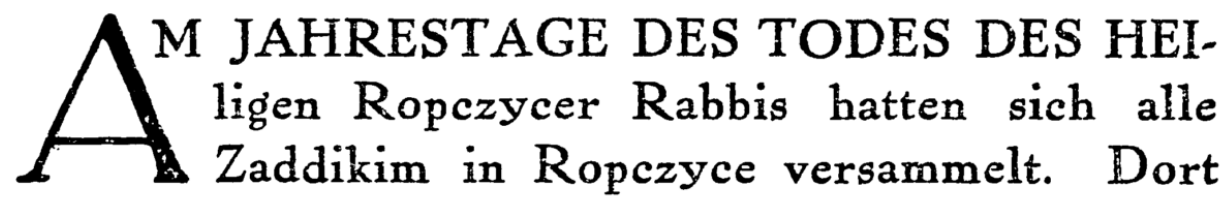

sassen sie in einem Saal und harrten in Wehmut und Schweigen, ob die Seele des Verstorbenen die Schatten seines erhabenen Wesens über ihre in Trauer verdunkelten Herzen ausgiessen würde, als die Tür aufflog und ein grelläugiges Weib hereintürzte, das stöhnen $d$ aus unbeschwichtigten Schmerzen sich auf die Erde warf und schrie: ,Seid mir gnädig, ihr heiligen Meister, und höret, was für ein grausames Unglück über mich dahergefahren ist! $D_{a}$ habe ich vorige Woche einem Juden achthundert Silbergulden eingehändigt, damit er auf die Dörfer fahre, Flachs einzuhandeln. Und den Gewinn, der uns ganz sicher war, darein wollten wir uns teilen, in halb und halb. Vergehen mir da etliche Tage, ich höre nichts von ihm, und mir wird ganz gequält und unruhig um das Herz. Just heute am frühen Morgen kommt mir einer ins Haus, der hier in der Gegend heimisch ist, und ich hör von ihm, der Jud ist gestorben eines jähen Todes und hat man nicht Geld noch Kaufbriefe bei ihm gefunden. Nun frag ich und heisch ich, wo ist mein Geld geblieben? Rabbanim, schaffet mir einen rechten Rat! Ihr sitzet hier beisammen, wie die Erzengel des Herrn im Licht, über euren Häuptern steht der Himmel als eine offene Pforte, eurem Wollen ist die Macht dort einzudringen, was Zaddikim verhängen, macht der Herr zu Geschehen!“ 
Da griff der Jammer des Weibes etlichen der Zaddikim an die Seele, so dass sie sprachen: ,Werde still, Weib, wir wollen dazu tun, dass dein Geld gefunden werde!"

Jetzt aber ist der Zaddik Rabbi Schalom von Kaminka aufgestanden und hat gerufen: „Hört ihr alle, und auch du, Weib! Hier kann kein Versprechen bestehen und Frucht tragen. Das Geld bleibt verloren für alle Zeit. Wer es suchen wollte, müsste in die Kette des Geschehens greifen, die über das Rad aller Zeiten läuft. Vermagst du mir zu sagen, Weib, in welchem Körper deine Seele gehaust und was sie in ihm gewirkt hat, ehe sie auf dem Weg der Wanderung in diesen kam? Es wird sich begeben haben, dass du in einem verblichenen Leben eine unerfüllte Schuld mit von hinnen genommen hast, und dieser Jude wurde nur geboren, um deine Schuld $z u$ erfüllen, und da er es getan hat, war sein Tun in diesem Leibe vollbracht und er ist hingegangen.

Du aber sei froh und danke, dass der Mangel deiner Seele hinweggetilgt ist!"

Und als er dies gesagt hatte, wandte Rabbi Schalom sich zu den Zaddikim und redete: ,Meine Lehrer und Meister, so es euch getällt, höret auf mich, ich will euch eine Geschichte sagen vom heiligen Baalschem, dessen unendliches Verdienst uns stärke.

In Rischa hat in den Tagen des grossen Heiligen ein vornehmer Jude gelebt, ein reicher Mann, gelehrt und wohlbewandert in den Schriften. Ob er gleich den Chassidim nicht zugezählt werden durfte, achtete er doch den Baalschem als einen Wunderbaren und 
Begnadeten, vernahm mit Begierde die Reden, die umgingen über die erstaunlichen Zeichen, die der grosse Meister gewirkt hatte, und gewann so endlich das Verlangen, ihn von Gestalt, Angesicht und Rede kennen zu lernen. $D a$ liess er eines Tages seinen Reisewagen rüsten, hiess den Kutscher und den Diener aufsitzen und fuhr stattlich und prächtig angetan wie ein Adliger nach Miedzyborz, dem Wohnorte des Baalschem.

Dort betrat er dessen Haus und war recht bedacht, den Heiligen seine Gelehrsamkeit spüren zu lassen, denn so hoffte er es zu erlangen, dass der Meister ihn wert erachte, mit ihm über die Auslegung der Schrift oder über die Geheimnisse der Kabbala zu reden. Dergleichen aber liess der Baalschem gar füglich abseits liegen und sprach einfach und beschaulich von allerlei Weltdingen, wobei den reichen Juden dünkte, dass der Zaddik ihm durch das Gespräch keine gewaltige Ehre erwiese. Dennoch wollte er ansehnlich und würdig Urlaub nehmen, und so legte er, bevor er seinen Abschied bot, ein Päckchen Rubel still vor sich auf den Tisch. Der Baalschem sah es, und für einen Augenblick kam ein feines, strahlendes Lächeln in seine Augen, und es war, als ob er über die Stube und den Gast, ja über alles Land weit hinaus auf ein fernes $\mathrm{Ge}$ schehnis schaue.

Wie es nun der Brauch ist bei den Juden, dass sie den Zaddik heimsuchen und von ihm heischen, dass er mit der Gewalt seines Gebetes den Himmel bezwinge, ihren Wünschen Gnade und Ertüllung zu 
gewähren, dafür ihm aber eine Gabe reichen, damit er, der um ihretwillen stets mit dem Geist über der Erde schwebt, sein und seines Hauses täglich Bedürfen auf ihr bestreiten könne, so gab der Baalschem sich jetzt den Anschein, er vermeine, auch hier sei es um solch ein Lösegeld zu tun, und sprach: ,Nun, Freund, müsst Ihr mir aber auch sagen, was Euch fehlt und wofür ich den Mittler machen muss?' Darauf sprach der Reiche, und er legte in seine Worte eine gar stolze Zufriedenheit: ,Mir mangelt - der Name Gottes sei gesegnet - nichts! Mein Haus hat seinen Wohlstand, die Kinder sind mir aufgewachsen zur Freude meiner Seele, meine Töchter haben mir angesehene Eidame zugebracht, Enkelkinder werden mirim Hause gross. . . Nein, Meister, nichts fehlt mir!'

Nun, meinte der Baalschem, solch ein Lösegeld sei ein rares Ding und nicht übel anzunehmen. Ihm sei es noch nie widerfahren, dass ein Jude vor ihn getreten sei und ihm ein Opfer gereicht habe, ohne ihm zugleich das Herz zu zerreissen und die bittere Lauge seiner Leiden wie eine ätzende Flut darüber auszugiessen. Der eine bot ihm den Anblick einer qualvollen Wunde, für die er Heilung suchte, ein anderer weinte, dass sein unfruchtbares Weib ihm Kinder gebären möge, dem dritten drohte das $\mathrm{Ge}$ tängnis und er wollte ihm entrinnen. Hier aber war einer gekommen, der gab, und begehrte nichts.

,Weshalb bist du denn zu mir gekommen?' fragte er.

'Nur sehen wollte ich Euch,' gab der Mann zurück, ,denn Eure Wunder leben im Volke, und man nennet Euch einen göttlichen Mann. Ich aber habe 
zu meiner Seele gesprochen: ,Ich will hingehen und ihn von Angesicht und Stimme kennen!'

Darauf der Baalschem: ,Nun, Freund, ist dem so, dass $\mathrm{du}$ den weiten Weg getan hast, allein um vor mir zu stehen mit Aug und Ohr, so sieh mich auch gut an und hör mir zu - ich will dir eine Geschichte erzählen und hingeben zur Spende auf deinen Weg. Aber, Freund, gut hör mir zu, und alle Kraft der Seele leg in dein Lauschen! Meine Geschichte ist so geschehen:

Es haben einmal in einer Stadt zwei reiche Juden gewohnt, Nachbarsleute, die hatten ein jeder einen Sohn. Die Jungen waren bei gleichen Jahren, begnadete Seelchen und beide von fruchtbarem Verstand. Sie ersannen ihre Spiele füreinander und lernten zusammen und liebten einander mit einer tiefen, unbeirrbaren Liebe, dass einer gleichsam des andern Leben war. Aber wie lange ist Judenkindern die Jugend gegönnt? Werden sie nicht gleichsam zu früh aus dem Schlummer gerissen, der die Kraft des Tages bergen sollte? So die beiden. Sie wurden dreizehn, vierzehn Jahre alt, dann vermählte man sie. Der eine zog viele Meilen weit gegen Mittag, der andere noch weiter nach der anderen Seite fort.

Nun aber, Freund, hör mir gut zu. Die beiden jungen Leute waren bloss in ihrer Liebe zueinander heimisch, die Welt war ihnen noch fremd, und so schrieben sie sich allwöchentlich lange Briefe und darin war ihr Leben.

Allmählich jedoch haftete ihr Blick an dem, was sie zunächst umgab und anging, und das zog ihre Ge202 
danken an sich und sog sich fest in ihrem Geiste; aber jeden Monat schrieben sie einander und verschwiegen sich mit nichten, was ihnen begegnet war. Dann aber schloss die Welt sie in ihre Arme und presste ihren Seelen den freien Atem aus, und sie hatten Scham, einander in Briefen zu gestehen, dass ihrem Herzen die Stille mangelte, daraus das lebendige Wort der Liebe kommt, und waren sich zutiefst zu teuer, einander die hohlen Schalen leerer Worte zu bieten, und so schwiegen sie endlich gar, und nur das Gerücht aus fremdem Mund spann zwischen ihnen feine Fäden hin und wieder, und sie hörten voneinander, dass beide in Wohlstand hausten und gross und gesegnet in ihrer Welt waren.

Nach vielen Jahren aber fügte es sich, dass einer von ihnen alles dessen verlustig ging, was ihn reich, frob und sicher gemacht hatte, ja, dass er so arm wurde, dass kein ehrbares Gewand sein eigen war.

Wie er nun dastand und wider das Elend stritt, dachte er des Jugendfreundes und sprach zu sich: $\mathrm{Er}$, der mir einst die ganze Welt und viel schöner war, als sie selbst es später sein mochte, er wird mich wiederbeleben aus dieser Not, die mich starr und lahm macht, wenn ich nur zu ihm kommen werde. Und er ging unter den Leuten umher und erborgte sich das Reisegeld unter vielen Demütigungen und Leiden und fuhr in die Stadt, in der der Freund hauste, und suchte ihn heim. Dort wurde er in glückseliger Herzenswärme empfangen, das ganze Haus einte sich zum Feste. Als sie beim Mahle sassen, Seite an Seite, fragte der Freund: ,Du Seele 
meiner Kindheit, sage mir, wie ergeht es dir in der Welt?' Sprach der andere: ,Viel mag ich nicht reden, wisse nur, selbst die Kleider, in denen ich gehe, sind nicht mein!" Und wie er redete, fielen ihm die Schmerzenstränen aus den Augen und sickerten in das feine Linnen, das den Speisetisch festlich deckte. $\mathrm{Da}_{\mathrm{a}}$ hat der Gefährte nimmer gefragt, und das Mahl ist weitergegangen mit Scherz, Gesang und Spiel.

Als es zu Ende war und Freund bei Freund in der Stille sass, rief der Hausherr seinen Schreiber und hiess ihn eine Aufstellung seines ganzen Vermögens machen, und als das geschehen war, alles zu zwei gleichen Hälften teilen und die eine seinem Herzbruder übergeben.

Der vor Tagen noch Arme fuhr reichgesegnet heim, traf alsbald Arbeit und Gelingen vereint, und in einigen Jahren stand sein Haus reicher und sicherer $\mathrm{da}$, als es je vordem gewesen war. In der nämlichen $Z$ eit aber fügte es sich, dass im Hause des andern Freundes das Unglück Gast wurde und sich als ein hartnäckiger Geselle erwies, der nimmer von hinnen wich, wie der Mann auch alle Gewalten antrieb, es zu verjagen. Erst mit ihm zugleich zog es aus dem Hause. Da aber war die Dürftigkeit übergross geworden, und zu alledem traf er kein Herz auf seinem bitteren Wege, das ihm geraten und ihm geholfen hätte.

Wie er nun in einer armseligen Stube sass und die Not wie eine grosse, dürstende Spinne in ihr grauses Gespinst ihn einwob, und er fühlte es 
atemlos immer enger und dichter werden, da fiel ihm der Freund seiner Kindheit ein, und vor seinem Namen riss das Gewebe, und er fühlte, wie sein Geist beschwingt und frei sich aus der Tiefe hob, bereit, den Kampf mit den feindseligen und unreinen Elementen der Welt aufs neue zu beginnen. Er schrieb sogleich an den Genossen, von dem er vernommen hatte, dass sein Wohlstand weit über seinen ehemaligen Besitz hinausgewachsen war, dass er $z u$ ihm zu kommen gedächte in grosser Bedrängnis, um aus seiner geliebten Hand ohne Scham sich die Hilfe $z u$ erbitten. Und er liess ihn wissen, an welchem Tag und zu welcher Stunde er die Stadt $z u$ verlassen gedachte, um den Weg zu ihm zu nehmen. Dann, zur rechten Zeit, schon völlig wohlgemut, machte er sich zu Fuss auf den weiten Weg. Der grossen Müdigkeit, die ihn schliesslich befiel, achtete er kaum, denn hinter jeder Biegung der Strasse, in jeder fernen Staubwolke hoffte er das Gefährt des Freundes zu erblicken, der ihm entgegenfahren würde, denn er wusste ja den Tag seiner Wanderung. Er näherte sich schon der Stadt, - noch immer allein, zu Tode erschöpft.

,Vielleicht ist mein Freund auf einem andern Wege mir entgegengefahren, - es gibt wohl deren mehrere, die von seiner zu meiner Stadt führen!' dachte der Wanderer. ,Er wird, da er mich nicht angetroffen hat, umgekehrt sein, und ich werde ihn in seinem Hause finden!'

$\mathrm{Da}$ er die Häuser und Gärten der Stadt in einem Schimmer von Weiss und Grün vor sich 
sah, schwand ihm die Schwere aus den Gliedern, und er schritt rascher aus. Unschwer vermochte er den Weg zu seines Freundes Haus zu erfragen, es lag stattlich und ernsthaft in einer reichen Strasse. Er trat ein und fand den Saal, in den er trat, angefüllt mit wuchtigen, wertstrotzenden Geräten, aber von Menschen leer. 'Seltsam,' dachte er, , dass mein Freund auch hier mich nicht erwartet. Sollte mein Brief verloren, sollte der Bote trügerisch gewesen sein?' Er liess sich nieder und wartete.

Indessen sass sein Freund oben im letzten Stockwerk des hohen Hauses in seinem Gemach zwischen Büchern und Rechnungstafeln.

Er hatte den Kopf in seine Hände vergraben. Seit Tagen stritt seine Seele einen ungeheuren Kampf. Als er den Brief seines Jugendfreundes erhalten hatte, stand jene Stunde vor ihm, da der andere all sein $\mathrm{Hab}$ und Gut mit ihm geteilt hatte, um der Liebe aus den Kindertagen willen, da ihre Seelen Geschwister gewesen waren. Und er verstand, dass nun an ihm die Reihe war, ein Gleiches zu tun. Nun aber hatte sein Wesen, einst rein und gütig den Händen des Ewigen entsprungen als eine klare, singende Quelle, sich in jenen Zeiten, da er aus plötzlicher Armut rasch wieder zu unvermutetem Reichtum gelangt war, getrübt. In ihm war zuerst die Angst vor einem erneuten Verarmen gewesen, später eine übertriebene Liebe zum $\mathrm{Be}$ sitz, die sich $z u$ einem kalten Geiz steigerte. Darüber war er von innen leer geworden. Und nun bäumte es sich in ihm auf vor dem Gedanken, 
sich auch nur von einem kleinen Teil des Seinen zu trennen.

Er beschloss endlich, jede Gabe zu verweigern. Da er aber bedachte, dass beim Anblick des Freundes alle Härte in ihm schmelzen könnte, dass seine Seele auftauen würde, wenn sie aus dem Blütengarten ihrer Jugend das Silberläuten vernähme, überkam ihn eine würgende Angst. Er rief seine Diener und befahl, dass sie den Mann aus dem Haus zu weisen hätten, und er legte ihnen schreckliche Worte, scharfe und seelenlose, in den Mund.

Als nun einer aus der Schar der Knechte eintrat, der Wartende seinen Namen nannte und den Herrn begehrte, tat der Diener nach seinem Befehl und wies ihn fort, wie es ihm geboten war.

Der arme Gefährte ging von hinnen aus der Stadt an einen Ort, wo er mit seiner Seele allein war. Da weinte er sich gut aus vor Gott und sprach: ,Herr, der Freund, der mein einziger Hort auf Erden war, meiner Seele Bruder, dem ich von meinem Gut einst so viel gegönnt habe wie mir selber, er hat mich nicht vor sein Angesicht gelassen.' In seinem bitteren Weinen, in der Auflösung seiner Seele, erschöpft am Leibe von der weiten Reise ohne Rast und Labung ist der Arme gestorben in jener Stunde.

Wenige Tage später ist auch der Reiche dahingegangen.

Zusammen haben sie vor dem hohen Richter der Welt gestanden. Dem Armen hatten Leid und Güte ein Sein im hohen Lichte errungen, der Reiche aber 
sollte versinken in Verwirrung und Trostlosigkeit in den Raum, wo Eis wie Feuer brennt und die harten Herzen ihren Ort haben.

Als sein Gefährte den Richtspruch vernommen hatte, schrie er unter Tränen: ,Herr, selbst die Helle, die von dir ausgeht, kann den dunklen Kummer nicht erleuchten, den ich alle Ewigkeit fühlen werde, wenn dieser in das Reich der Qualen versinken soll, der meine ganze Welt war, als ich, ein Kind, mit ihm zu deinen Füssen spielte.'

Es redete die hohe Stimme der Himmel und sprach zu ihm: ,Dein und sein Richter sollst du sein. Was begehrst du für euch beide?' $\mathrm{Da}$ antwortete jener: ,Gewähre uns, o Herr, noch einmal auf die Welt niederzusteigen, lass unsere Seelen mit einem neuen Körper, mit einer reinen Hülle der irdischen Wirklichkeit geboren werden. Noch einmal lass ihn selbst über den Weg seiner Seele entscheiden. Ihn lass in Reichtum, mich in Armut geboren werden. In Bettlergestalt will ich bei ihm erscheinen und zurückerlangen, was er mir schuldet und verweigert hat in jenem vergangenen Leben. Ist sein Sinn aber karg wie einst, glühende Tränen wie flüssiges Silber will ich über sein Herz giessen, Worte, die wie Flügel die Luft um ihn bewegen sollen, will ich ersinnen, auf den Knien will ich mit seiner starren Seele ringen, um das Gut von ihm zu erreichen, sei es Heller um Heller!'

$\mathrm{Da}$ beschied die hohe Stimme den beiden eine neue Wiederkehr.

Der harte Mann lebte in reichem Hause ein 
üppiges Leben, der a: 'ore kam unter dürftige Leute in einem fernen Lande, ein Armer in Wahrheit.

Nun, o Freund,' mahnte der Baalschem, ,spanne deine Seele an und höre mir gut zu!

Was vor diesem Leben, auf der Wanderung der Geister mit ihnen beiden sich ereignet hatte, das wussten sie nimmer. Es geschah, dass der Arme in der Not seines Lebens auf die Wanderschaft zog, um zu betteln, und so ist er in die Stadt gekommen, wo der andere in seinem schönen Hause unter Reichtum und gutem Leben in die irdische Seligkeit eingebettet war. An dem Tag, da der Arme jenen Ort betrat, war sein Elend undEntbehren so hoch gestiegen, wie einschwellendes Wasser, das seinen höchsten Stand erreicht hat. Er irrte durch die Strassen und kam zum Haus des reichen Mannes. Hier hielt er ein und hob die Hand, mit dem Klopfer die Tür zu berühren. In dem Augenblick kam ein Mensch des Weges, erblickte den Bettler an der Pforte und rief ihm $z u$ : ,Hier pochst du vergebens, aus dem Haus ist noch keiner getröstet weggegangen!' $\mathrm{Da}$ wusste er, dass man ihm die Gabe weigern würde, und seine Hand fiel herab, aber etwas in seinem Herzen sagte ihm, dass er hier und nirgend anders das Almosen empfangen müsse, wenn seinem Leben sollte geholfen werden. So pochte er und trat vor den Herrn des Hauses und bat um eine geringe Spende, damit er seinen wühlenden Hunger stillen könne. ,Reicht Ihr mir nichts, so sterbe ich!" sagte er. 'Ihr haltet mein Leben in eueren Händen!' Der 
Hausherr verzerrte sein finsteres Gesicht zu einem Lachen und höhnte: ,Spar deine Zeit und red nicht lang! Jedes Kind auf der Strasse weiss, ich gebe kein Almosen. Um dich brech ich nicht mit meinem Brauch!'

$\mathrm{Da}$ fühlte der Arme eine seltsam zwingende Kraft in sich aufsteigen, es war ihm, als bäte er um mehr als um sein Leben. Fremde, gewaltige Worte stiegen aus seinem Munde, er fand eindringliche Geberden und rang mit aller Anstrengung um das verschlossene Herz.

Als der Reiche eine so grosse Gewalt auf sich einstürmen fühlte, erfasste ihn die Wut, er schlug auf den Bettler los, und er, der sein letztes Leben in seine Bitten gesammelt hatte, sank unter dem Schlage tot darnieder.

Nun, Freund,' sagte derBaalschem, ,hast du mich zu Endegehört. Fehlt dir wirklich noch immer garnichts?'

$\mathrm{Da}$ brach der Jude in Tränen vor dem Meister in die Knie: ,Rabbi, der Böse bin ich. Du hast den Schleier der Zeiten aufgetan, meine Augen haben über die Kette des Geschehens hingeschaut! Was soll ich tun, dass ich die Seele, die verdorben ist, mir behüte und reinige?'

Es antwortete der Baalschem: ,Geh und sieh in jedem Armen auf dem Wege ein Kind des Bettlers, den du erschlagen hast, gib von deinem Gut und von deiner Hilfe soviel du vermagst, lass deine Seele die Gabe mit Liebe überströmen!"“

Dies hat Rabbi Schalom von Kaminka den Zaddikim erzählt, die zum Jahrestag in Ropczyce versammelt waren. 


\section{VON HEER ZU HEER}

\section{TN DEN TAGEN DES BAALSCHEM LEBTEN}

zwei Freunde. Beide standen in jener Zeit der 1 reichsten Jugend, da noch die letzte Morgenröte hold und unbestimmt am Himmel glüht: die wilden Träume der Dämmerung zittern noch nach, bald naht Sonne, die strenge Herrin, und ihr Reich der Gestalten wird sichtbar, aber jetzt leuchtet die schwere und selige Stunde, und Traum und Tag erblassen vor der morgenroten Frage um den Sinn des Lebens.

Oft sassen die Freunde beisammen, an einen Baum oder an die kahle Wand ihres Stübchens gelehnt, und redeten von dem Sinn des Lebens. Dem einen war die Welt erschlossen durch das Wort des Baalschem. In jedem Ding empfing er eine Botschaft und mit jeder Tat sandte er eine Antwort. Er warf sich auf das junge Feld hin und sog die Gnade aus der Ackererde, er grüsste den Wind und das Wasser und die schönen vorüberlaufenden Tiere, und sein Gruss war ein Gebet. So war ihm der Sinn des Lebens in Gott eingewurzelt. Sein Gefährte aber ereiferte sich gegen ihn darob und meinte, all dies sei eine Sünde wider den Geist der Wahrheit. Denn viele Flächen habe jedes Ding und viele Formen jedes Wesen, und wer seine Seele zur Sklavin eines Glaubens erniedrige, der sehe von allem nur eine Fläche noch und eine Form, arm und behaglich werde sein Weg, und tot sei in ihm das Suchen nach Wahrheit, der Sinn des Lebens. Darauf antwortete jener leisen Mundes, in der Welt der Verklärung gebe es keine Flächen und 
Formen, sondern jedes Ding stehe da in seiner Reinheit. So stritten die beiden Freunde oft miteinander, und jeder fühlte im Sprechen die Tore seiner Seele aufspringen und sah angstvoll und verzückt in ein Land, von dem das Wort nichts zu sagen wusste.

Da geschah es, dass eine schwere Krankheit den einen der Jünglinge, der dem Baalschem ergeben war, befiel. Und an der starren Kraft der Schmerzen erkannte er, dass sie die Boten einer Gewalt waren, die sein Erdenleben zum Ende führen wollte. Daher stemmte er sich nicht wider sie, sondern legte iseinen Wunsch in den des mächtigen Elements, das seinen Leib mit brennenden Armen umschlungen hielt. Mochte er aber noch so willig das Kommen des Blitzes erwarten, der zwischen den beiden Welten aufzuckt, dennoch stand ein Grauen auf dem Wege von seiner Gegenwart, die so leidvoll aber so unsagbar wirklich war, zu alle dem, das sich ereignen sollte im Abgrund der Ewigkeit. Und so liess er dem Baalschem kundtun, dass er sich zum Sterben rüste, und als der Meister an seinem Bette stand, sprach er: „Rabbi, wie und womit soll ich ziehen? Sieh, ein Grauen steht vor mir und stört meinen Frieden." Der Baalschem nahm die Hand des Kranken in seine Hände und redete $z u$ ihm: „Kind, besinne dich : bist du nicht allezeit von Heer zu Heer gegangen und von Tor zu Tor? So sollst du auch fürder gehen in den Gärten der Ewigkeit." Und er hob den Finger über die Stirn des Kranken und berührte sie und redete zu ihm: „Dieweil noch die Stunde der letzten Morgen- 
röte über dir ist, die schwere und selige Stunde, und dieweil du wahrhaft in ihr gelebt und ihr Glück nicht gescheut hast, will ich deinen Weg leicht machen und will mein Zeichen auf deine Stirn schreiben, auf dass niemand deinen Schritt schrecke und deine Bahn hemme. So gehe hin, Kind, wenn dich der Tod beruft, und trage meinen Segen vor dir und deine Wahrheit." Und neigte sich über ihn und legte Stirn an Stirn und segnete ihn.

Aber als der Meister gegangen war, schlich sich der andere Jüngling ins $\mathrm{Zimmer}$ und kniete vor dem Bette nieder. Und er küsste die Hand des Kranken und sprach: „Mein Liebling, sie wollen dich nehmen, und ich weiss, du wehrst dich nicht. Und besinne dich, wie wir damals mit einander redeten, in den Birken am Sommerabend, und zuletzt sagtest du nur: Ja, es ist, und ich sagte: Nein, es ist nicht. Und nun ist mir sehr bange, und du gehst fort von mir, gehst willig fort mit diesen deinen Augen. Mein Liebling, die Birken sind in deinen Augen und der Sommerabend. Und alles sagt: Ja, es ist. Und sieh, ich fühle, dass es ist, ich selbst sage es ja, und weiss es auch, denn sonst wäre kein Sinn in allem, und du gehst fort von mir, und wohin gehst du?" Und er schluchzte über der Hand des Freundes und küsste sie wieder und wieder. Der Sterbende aber sprach: "Lieber, ich gehe den Weg weiter. Und sieh, wenn ich unterwegs bin, dann will ich dein gedenken und unserer Liebe und wie wir unsere Seelen tauschten am Abend. So will ich dann kommen zu dir, dir zu künden von meinem Wege. Darum gib mir deine 
Hand. Sieh, ich umschliesse sie mit meiner und schlinge meine Finger in deine, so stark ich kann, und dies ist mein Versprechen an dich, dass ich kommen werde.“ $\mathrm{Da}$ schrie der andere auf und rief: „Du sollst nicht gehen, ich halte dich, du sollst nicht gehen!" Aber der Sterbende sprach in seinem Frieden: „Nicht doch, und kannst auch nichts wider den Herrn. Jedoch meine Hand sollst du halten, bis das Atmen in ihr aufhört, und dies wird bald sein, und mein Versprechen an dich ist mein Gruss an die Erde, die so schönen Wind und so schönes Wasser und so schöne vorüberlaufende Tiere trägt, mein Gruss, dass ich wiederkommen will, sie und dich zu schauen." Das war sein Scheiden.

Und als er aufstieg, öffneten sich die Pforten des Firmaments vor dem Zeichen auf seiner Stirn, und weit tat sich ihm auf das Reich der kommenden Welt. Und er wandelte von Tor zu Tor und von Heiligtum zu Heiligtum und erfuhr das Unerfahrbare und empfing den Sinn des Lebens. Die Zeit schwieg, und der Raum war nicht da, nur der Weg des Werdens ohne Ort uud Ablauf, nur das Blühen in der Luft der lebendigen Stille.

Aber plötzlich war sein Schritt gehemmt, und die Zeit schwatzte um seine Ohren, und der Raum stiess ihn ringsum mit kantigen Fäusten. Da stand er inmitten von wortlosen Gewalten und konnte nicht weiter. Und er rief ihnen zu und wies ihnen das Zeichen auf seiner Stirn. War ein Starren in den Gewalten und wie ein Lachen und fast wie ein Kopfschütteln, und er verstand, dass seine Stirn 
kein Zeichen mehr trug. So stand er und war ein Mensch, und die Verzweiflung des Menschen glitt heran und fasste seine Finger wie zum Tanz. Da riss er sich los und wandte sich, und da sah er einen alten Mann vor sich stehen, der sprach zu ihm und fragte: „Warum stehst du hier?" Antwortete er: „Ich kann nicht weiter." Sprach der Alte: „Nicht gut ist das Ding. Denn verweilst du dich hier und gehst nicht weiter und weiter, dann kannst du das Leben des Geistes verlieren und bleibst an diesem Ort wie ein stummer Stein. Denn alles Leben der kommenden Welt ist zu schreiten von Heer zu Heer, nach oben und oben, bis in den Ungrund der Ewigkeit." Fragte ihn der Jüngling: "Und was vermag ich zu tun?" Sprach wieder der Alte: ,Ich will in das Heiligtum gehen und hören, $z u$ erfahren, was dies ist und warum dies ist." Er ging und kehrte zurück und sprach: „Du hast deinem Freunde versprochen, $z \mathfrak{u}$ ihm $z u$ kommen und ihm von deinem Wege zu künden, und hast es vergessen und nicht getan. Darob ist das Zeichen von deiner Stirn gewischt nnd ist dir verwehrt, in dieses Heiligtum zu kommen, welches das Heiligtum der Wahrheit ist." $\mathrm{Da}$ schaute der Jüngling die Erde und seinen Freund, und er trauerte ob seines Vergessens. Und nach einer Weile fragte er: „Was soll ich tun, um das Ding zu lösen?" Antwortete der Alte: ,Geh hin zu deinem Freunde und erscheine ihm im Traume der Nacht und künde ihm, was er zu wissen begehrt." Dies sprach er und ging von dannen. 
Der Jüngling aber stieg zur Erde nieder und trat in den Traum seines Freundes ein. Er strich dem Schlafenden über die Stirn und flüsterte in sein Ohr: „Lieber, ich bin gekommen, um dir von meinem Wege zu künden. Du aber zürne mir nicht, dass ich gesäumt habe. Denn wie kann man eines Menschen, und auch des liebsten, gedenken mitten im Schauer der Gotteswirbel, die alle Grenzen übertluten?" Jener aber warf sich im Schlafe empor und drückte die Hand an die Augen und stiess die Worte seines Unmuts aus schier ineinander gepressten Zähnen hervor: ,Geh von mir, du Bild und du Lüge, und ich will mich nicht länger von dir narren lassen. Gewartet habe ich und gewartet, und der Verheissene kam nicht. Und nun ist ob des Wartens mein Sinn verdorben, dass ich Nacht für Nacht getrogen werde und den Verheissenen $z u$ sehen vermeine. Und dann ist alles dunkel und zerfliesst in die Schatten. Aber nun will ich mich nicht länger narren lassen und befehle dir, zerfliesse sogleich und auf mein Wort, denn es soll mich nicht befallen dein Schwinden wie ein Schlag aus leerer Nacht. Und komm nicht wieder, hör dies und komm nicht wieder!" $D a$ erzitterte der Jüngling und beugte sich über den $\mathrm{Ge}$ fährten uud schmiegte sich zitternd an ihn und sprach ihm zu: ,Wahrlich, kein Trug, sondern dein Freund bin ich und gekommen zu dir aus der Welt des Wesens. Und denke du, wie wir sassen unter den Birken am Sommerabend. Und denke, wie unsre rechten Hände einander umschlangen in der Stunde meines Sterbens." Aber der Träumende schrie: „Das Gleiche 
sagst du Nacht für Nacht, und fängst du mich und ich hebe mich zu dir, da gehst du hin in die Schatten. So lass nun ab von mir, und sieh, ich mache mich los!" Und nochmals versuchte der Gekommene den Kampf und rief: „Hast du nicht selbst gesprochen: $\mathrm{Ja}$, es ist?" Jener jedoch lachte mit harter Stimme: „Wohl habe ich gesprochen, und auch gewartet habe ich. Aber der Verheissene kam nicht, und nun schaue ich es: ich war das Spiel in der Hand einer grausamen Stunde. Die hat mich geknechtet und geschändet und hat das Ja des Verrates auf meine Lippen gebracht. Aber ich schreie dir entgegen: Nein, es ist nicht. Und Nein und Nein, und nun will ich dich in Stücke reissen, du tolle Lüge!" Da wich der Jüngling und bog sich zum Entschwinden, aber noch $\mathrm{kam}$ ihm ein Letztes, und aus matter Ferne rief er dem Genossen zu: ,So will ich dir ein Zeichen bringen. Am hellen Tage will ich wiederkehren und dir ein Zeichen bringen." Und er sah das Haupt des Geliebten müde, aber mit einem aufblinkenden Staunen, wie der erste Vorschein der Hoffnung, über den Augen in die Kissen zurücksinken.

Und in der oberen Welt eilte er zum Tempel der Wahrheit und suchte den Alten und fragte ihn: „Rede und hilf mir, welches Zeichen kann ich meinem Freunde bringen, dass ich in der Wahrheit bin?" Sprach der Alte: "Auch darin will ich dir raten, mein Sohn, und Gott sei mit dir. Siehe, am Mittage jedes Sabbats predigt der Baalschem in dem ewigen Lehrhause, das in dem Himmel des heiligen Erkennens 
steht, von den Geheimnissen der Lehre. Und bei der dritten Sabbatmahlzeit, welche genannt wird das Mahl der heiligen Königin, predigt er von diesen Geheimnissen vor den Ohren der Menschen, nachdem sein Wort die Weihe der oberen Welt empfangen hat. So gehe du am Mittage des Sabbats und höre die Rede deines Meisters in den Himmeln, und sodann steige zu deinem Freunde nieder, wenn er des Nachmittags auf seinem Lager ausgestreckt ist und nicht mehr wachen Sinnes, sich doch auch keine Ruhe finden kann, und vermelde ihm die Rede. Und dies sei ihm zum Zeichen, auf dass er zum Mahl der Königin in das Haus des Baalschem komme und die Worte vernehme aus seinem Munde."

Und der Jüngling tat also und nahm die Rede des Meisters auf und stieg nieder und trat in den Wachtraum seines Freundes nnd goss die Worte über ihn aus wie einen Balsara. Sodann beugte er sich über ihn und küsste ihn, Mund auf Mund, mit dem Kusse des Himmels. Dann entflog er.

Jener aber erhob sich alsbald und ihm war, als habe er das Unerfahrbare erfahren. Und ex ging hinaus, da standen die Birken in der Mittagsonne. Lange sass er unter den Birken wie ein Wissender, und in dem jungen, weit ausgespannten Sinne strahlte die Erfüllung von Ferne zu Ferne. Als aber die Sonne sich neigte, ging er zum Hause des Baalschem,

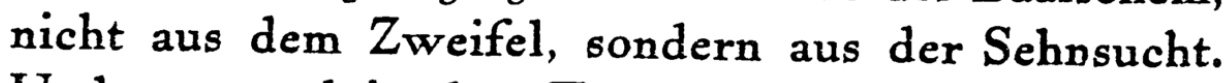
Und er stand in der Tür und hörte wie aus dem Munde der Gotteskraft die Worte aus dem Munde des Baalschem. Da neigte er sich zu den Füssen des 
Sprechenden und sagte: „Rabbi, segne mich, dieweil ich sterben will. Denn was soll ich noch hier?" Aber der Meister sprach: „Nicht also. $Z \mathfrak{u}$ den Birken tritt hinaus, die wieder im Sommerabend stehen, und rede $z u$ ihnen in deiner Freude: Ja, es ist. Und wohl segne ich dich, aber nicht $z$ lim Tode, sondern hier schon zu schreiten von Tor $z \mathrm{~s}$ Tor, von Heer zu Heer, und so für und für." 


\section{DAS DREIMALIGE LACHEN}

INMAL AN EINEM FREITAGABEND, als der Baalschem mit einigen seiner Schüler $z \mathfrak{u}$ Tische sass, begab es sich, da er eben den Segen über den Wein gesprochen hatte, dass sein ernstes Gesicht mit einem Male wie von innen heraus mit einem hellen freudigen Schein erstrahlte, und er begann $z u$ lachen und lachte gar sehr in einer innigen Weise. Die Schüler blickten im Zimmer umher und schauten sich untereinander an, aber da war kein Ding, das des Lachens Ursache hätte sein können. Nach einer kurzen Frist lachte der Baalschem zum andern Mal und ganz auf die selbe Art, wie mit der unvermuteten Fröhlichkeit und Helle eines Kindes. Und dann ging eine kleine Weile hin, und sein Lachen erklang zum dritten Male.

Die Schüler sassen schweigsam um den Tisch. In ihren Augen war dieser Vorfall ein seltsames und unbegreifliches Ding, denn sie kannten den Meister wohl und wussten, dass seine Seele sich nicht leichtfertig solcher Bewegung hingab. So ahnten sie einen tiefen unbekannten Grund dieser Freudigkeit und hätten ihn gern gekannt, doch keiner fand den Mut, dass er den Meister darum angegangen hätte. $\mathrm{Da}$ richteten sie alle ihre Augen auf den Rabbi Wolf in ihrer Mitte, dass der vom Meister erfrage, aus welcher Ursache dieses Lachen erklungen sei. Denn so war der Brauch, dass der Rabbi Wolf am Sabbatausgang, wenn der Baalschem 
in seiner Stube sass und Rast hielt, zu ihm trat, um von ihm $z u$ vernehmen, was im Laufe des Sabbats sich mochte zugetragen haben.

So geschah es auch diesmal, dass dieser Schüler zum Meister kam und ihn fragte: „Lass uns wissen, was der Sinn des Lachens war, das gestern abend über dich kam."

Da sprach der Baalschem: „Nun wohl, so möget ihr wissen, woher mir die Freude zuflog. Haltet euch bereit, mit mir zu kommen, und ihr sollt hören."

Darauf hiess er den Knecht die Pferde einspannen, denn so hielt es der Baalschem, dass er jedesmal nach Ausgang des Sabbats für eine Weile die Stadt liess, eine Fahrt ins freie Land zu tun. Er bestieg mit seinen Schülern das Gefährt, und sie kehrten nicht wie sonst nach einigen Stunden in ihre Heimat zurück, sondern fuhren die ganze Nacht weiter schweigend durch die Dunkelheit. Am Morgen langten sie in einem Ort an, und der Baalschem liess bei dem Hause des Vorstehers den Wagen halten. Bald war seine Ankunft der ganzen Judenheit bekannt geworden, und alle kamen und umringten das Haus, um ihn zu ehren. Er aber achtete niemandes, sondern befahl dem Vorsteher, ihm Sabbatai, den Buchbinder, rufen zu lassen. $\mathrm{Da}$ erwiderte Jener ein wenig unzufrieden: „Meister, was wollt Ihr von diesem, der ein kleiner unbeachteter Mann in unserer Gemeinde ist? Wohl weiss jeder von uns, er ist ein redlicher Jude, aber nie habe ich ihn um der ge. ringsten Wissenschaft willen rühmen hören. Was 
kánn Euch der frommen?" „Gleichwohl“, sprach der Meister, ,ist es mein Wille, dass du ihn mir rufest." Man schickte um ihn, und er kam, ein bescheidener grauhaariger Alter. Der Baalschem sah ihn und sprach: , Auch deine Ehefrau mögekommen", und auch sie war alsbald zur Stelle.

"Nun", heischte der Meister, ,magst du mir erzählen, was ihr in der letzten Sabbatnacht getan habt. Aber sage die schlichte Wirklichkeit, habe keine Scham und verbirg uns nichts."

„Herr," erwiderte jener, ,,nichts will ich vor dir verhehlen, und habe ich gesündigt, so siehst du mich bereit, aus deinen Händen die Busse zu nehmen, als käme sie von Gott.

Siehe, alle Tage, die mir der Himmel gegeben hat, kam mir mein Erwerb aus meiner Arbeit. Einst war sie gesegnet, und ich war tätig und vermochte mir beizeiten ein kleines Gut zur Seite zu legen. Von Anfang an aber war es mein Brauch, dass am Mittag des fünften Tages in der Woche mein Weib hinging, um mit aller Sorglichkeit jene Dinge einzukaufen, die nötig sind, den Sabbat zu feiern, unser Bedürfen an Mehl, Fleisch, Fischen und Lichtern. Und wenn am Vortag des Sabbats die zehnte Stunde sich erfüllt hatte, so liess ich meine Arbeit und ging zum Bethaus, um dort bis nach dem Abendgebet zu verweilen. So habe ich von Jugend an getan.

Jetzt aber, da ich zu altern anhebe, hat sich das Glücksrad über mir gedreht, mein Besitz ist mir aus den Händen geschwunden, und meine Kraft, 
mir aus meiner Arbeit Früchte zu schaffen, ist gar gering. Nun lebe ich ein bitteres Sorgenleben, und oft ist es mir nicht gegeben, alles Bedürfen des Sabbats am fünften Tage einzuschaffen, wie es unser Hausbrauch zu guter Zeit war. Mein Trost ist, - was auch über mich kommen mag, eines brauche ich nicht $z u$ lassen: um die zehnte Stunde des Sabbatvortages ins Bethaus $z u$ gehen und so das Meine zu tun.

Nun vernimm, Meister, es war die zehnte Stunde am Vortag dieses Sabbats, und in meiner Hand lag auch nicht ein Heller, die Bedürfnisse des Sabbats $z u$ erstehen, und mein armes Weib hatte kein Stäubchen Mehl mehr in der Truhe. Nun aber hatte ich alle Tage meines Lebens nie eines Menschen bedurft, so wollte ich auch diesen Tag ohne Almosen bestehen und nicht bittend eine Schwelle überschreiten. Und es war in meinem Herzen beschlossen, dass es besser sei, am Sabbat $z u$ fasten, denn eine Gabe zu begehren von Fleisch und Blut. Aber ich fürchtete, dass es meiner Frau allzusehr das Herz bedrücken würde, am Sabbat auch nicht eine Kerze auf dem Tische brennen $z u$ sehen, und dass sie eine oder etwa ein Sabbatbrot oder ein wenig Fisch annehmen möchte, wenn ihrs eine Nachbarin in Güte anböte. Darum redete ich zu ihr und verlangte ihr es ab, dass sie verspräche, von keinem Menschen eine Hilfe zu nehmen, sei es auch, dass wer sie darum bedrängte; denn verstehe, Meister, die Juden, unter denen wir leben, sind gut von Gemüt und möchten es schwerlich besehen, 
dass uns der Tisch am Sabbat leer stünde. Und meine Frau sagte mirs zu. Ehe ich zum Bethaus ging, sprach ich $z$ u ihr: „Heute werde ich säumen und mich im Gebet verweilen, bis der Tag sich neigt. Denn wenn ich mit den andern vom Bethaus heimginge und sie sähen in meinem Hause kein Licht, so würden sie mich um die Ursache fragen, und ich wüsste nicht, was ihnen antworten. Wenn ich aber dann komme, mein Weib, so wollen wir in Liebe empfangen, was der Himmel uns bescheiden wird." So sagte ich meiner alten Ehefrau zum Troste.

Sie aber blieb und kehrte und säuberte das Haus in allen Ecken und Winkeln, und da der Herd kalt war und sie keine Speise vorzubereiten hatte, blieb ihr viel $Z$ eit, die sie nicht anders hinzubringen wusste, als dass sie einen alten Schrein öffnete und die vergillbten, verblichenen Kleider aus unserer Jugend herausnahm, um sie zu bürsten und reinlich wieder einzubreiten. $\mathrm{Da}$ fand sie unter all dem alten vertragenen Zeug einen Ärmel, den wir vor Jahren einmal vermisst hatten und der seither nimmer aufzufinden gewesen war. Auf dem Kleidungsstücke aber sassen etliche Knöpfe, wie Blümlein geformt, aus Gold- und Silberdraht, wie man dergleichen lieben Zierat auf altem Zeug wohl antrifft. Die schnitt mein Weib gar eilig ab und trug sie dem Goldschmied hin, und der gab ihr so viel Münze, dass sie erstehen konnte, was an Speisen für den Sabbat not tat, auch zwei gute, starke Lichter und sogar noch, wessen wir für den nächsten Tag bedurften. 
Am Abend, als alles Volk gegangen war, schritt ich langsam die Gässchen lang unserem Hause zu und sah schon von weitem, dass ein Licht brannte, und der Kerzenschimmer liess sich gar festlich und traulich an. Ich aber mochte dessen nicht in mir achten und dachte: Siehe, meine alte Frau hat getan nach Weiberart und konnte sich nicht enthalten, etwas anzunehmen. Ich trat ein und fand den Tisch wohl gedeckt und bereitet mit Sabbatbrot und Fischen, und auch den Wein fand ich vor, den Segen darüber zu sprechen. Aber ich verwehrte mir, mich zu erzürnen, weil ich den Sabbat nicht zerreissen wollte. So hielt ich mich zurück und sprach den Segen und ass vom Fisch. Darnach sagte ich, aber ich tat es mit sanfter Rede, weil mich ihrer armen bekümmerten Seele erbarmte, zu meiner Frau: „Nun erweist es sich, dass dein Herz nicht bereit und stark ist, das Harte zu empfangen." Sie aber liess mich nicht zu Ende reden, sondern sprach mit heller Stimme: „Mein Mann, entsinnst du dich noch des alten Zeugs mit den Silberknöpfen, das uns seit Jahren mangelt? Als ich heute die grosse Truhe ausfegte, habe ich es vorgefunden. Die Knöpfe gab ich dem Goldschmied, und für das Geld habe ich den Sabbat bestellt."

Meister, als ich das hörte, da gingen mir die Augen von Tränen über, so gross war die Freude, die mir aus dem Herzen kam. Und ich warf mich nieder vor dem Herrn und dankte ihm, dass er meines Sabbats gedacht hatte. Ich sah mein Weib und sah ihr gutes Gesicht von meinem Glïck wieder- 
strahlen. Da wurde mir warm, und ich vergass der vielen kümmmerlichen Tage und fasste meine Frau und führte sie im Tanze rund in der Stube herum. Dann ass ich die Sabbatsuppe, und mir war immer leichter und dankbarer zumute; da tanzte ich in Freuden und Lachen ein zweites Mal, und als ich die Zukost verzehrt hatte, tat ichs zum dritten. Sieh, Meister, so gross war mein Glück, dass diese Segensgabe am Sabbat mir von Gott allein und nicht von den Menschen gekommen war. So konnte ich mein Herz nicht verschliessen in dieser gewaltigen Freude. Herr, wenn es aber, wiewohl es mir im Sinne lag, mich damit vor Gott zu neigen, unwürdige Torheit war vor dem Höchsten, dass ich mit meinem Weibe getanzt habe, so gebet mir eine gnädige Busse, und es soll an mir nicht fehlen, dass ich sie verrichte."

Hier schwieg Sabbatai, der Buchbinder. Und der Baalschem sprach zu seinen Schülern: „Wisset! alle Heerscharen des Himmels haben mit ihm gejubelt und mit ihm sich im Reigen gedreht, und eine goldene Freude strahlte im Paradiese um der Freude dieser beiden alten Herzen willen. ... Und ich, der all dies sah, lachte darob mit ihm zu den drei Malen." 


\section{DIE VOGELSPRACHE}

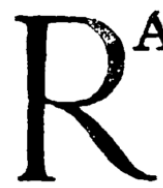

ABBI ARJE, DER PREDIGER VON POlana, trug in seiner Seele brennendes $\mathrm{Be}$ meinde der Irdischen so selten ist, dass nur einer, ein Einziger je in der Frist eines Menschenalters, ihr Erbe und Hüter ist. Zur Zeit, da Rabbi Arje auf Erden ging und um ihren Besitz rang und sich härmte, war es der Baalschem, der sie inne hatte, als Beute, die der Flug seiner Seele ihm gebracht, eines Tages, als sie in unermessliche Höhen sich erhoben und geweitet hatte.

Der Sinn der Weisheit aber war, dass der, so sie trug, Gehör hatte für die Sprache aller Kreaturen unter der Sonne. Es ging ihm ein, was die Tiere auf der Erde und in den Lüften zueinander redeten und sich vertrauten von den Geheimnissen ihres Daseins; ja selbst was Baum und Kraut aussprachen, war ihm kund. Und wenn er sein $\mathrm{Ohr}$ an den schwarzen Erdboden oder an den nackten Felsen presste, kam ihm das Raunen der Geschöpfe $z \mathfrak{u}$, die das Licht scheuen und in Spalten und Höhlen hausen.

Nun war Rabbi Arje in sich wohl klar, welche Vermessenheit in seinem Wunsche lag. Doch vermeinte er, indem er sich selbst zum Richter über seine Seele setzte, er dürfe ihn dennoch hegen, des hohen Willens halber, aus dem ihm dieses Begehren geboren war. Er, der ein Redner war und eindringlich und furchtbar im Worte werden 
konnte, er glaubte, wenn er die Sprache aller Kreaturen verstünde und auf seine Zunge leiten könnte, würde seine Rede mächtiger denn je die Seelen aller ihm zuführen, er würde predigen aus dem Geiste der Erde und der Himmel und so regieren die Herzen seiner Gemeinde, wie ein Kaiser seine Reiche. Und sein Inneres dürstete nach jener feinen, ungreifbaren Macht, die ihm herrlicher und begehrenswerter vorkam, denn irgend ein Ding der Welt.

So fasste er den Mut, zum Baalschem zu ziehen, ihm seine Begierde zu offenbaren und mit seinemVerlangen den Willen des Heiligen zu umspannen, auf dass der ihm gewogen werde und er aus dem seligen Munde die Weisung empfange, die zu jener wunderbaren Stufe führt, auf der das Menschenohr allen Stimmen unter dem Himmel verstehend sich auftut. Und er meinte, da das Endziel dessen, was er heischte, ein so hohes war, würde der Meister die Gewährung ihm nimmer versagen.

Wunsch und Hoffen beschwingten seine Füsse. So ging er des Weges, ohne Mensch und Ding zu achten, ganz eingesponnen in seinen Wundertraum der Seelenmacht. Und so trat er in die Stube des Meisters. Das Gemach war von Menschen erfüllt, die umher stehend oder sitzend lauschten, denn der Baalschem redete gerade.

Als Rabbi Arje die Tür hinter sich zugezogen hatte, neigte er tief und schweigend das Haupt gegen die Erde nieder, und als er es erhob, tauchte sein Blick, vom nie rastenden Begehren seines Geistes 
hartglänzend und unstet geworden, just in die milden blauleuchtenden Augen des Meisters, die wie zwei sanfte, friedenstrahlende Sterne über dem Raume waren. Der Baalschem stand sprechend ihm gegenüber an die Wand gelehnt. Der Rabbi fühlte an seinem Blick, dass er ihn wohl gesehen und erkannt hatte, aber der Heilige tat es durch kein Wort oder Zeichen kund, und so blieb der Gruss unerwidert, da alle, die sonst anwesend waren, aus Ehrfurcht vor dem Erhabenen nicht sprachen und sich nicht bewegten. Der Gast blieb neben der Tür stehen und wartete. Er bemerkte, dass der Meister in einem Gleichnis redete, doch war er nicht imstande, der Rede mit seinen Sinnen zu folgen, denn es kränkte ihn tief im Herzen, dass der Baalschem sich nicht unterbrach, ihn mit Worten willkommen $z u$ heissen oder ihm doch mit der Hand einen flüchtigen Gruss zuzuwinken. Doch zügelte er seine ungeduldigen Gedanken und nahm sich vor, sich stille zu verhalten, bis der Meister geendet haben würde, denn sicherlich wollte er ihm alsdann Willkomm und Frieden entbieten. Der Baalschem aber hatte gesprochen, und nun liess er den und jenen aus der Hörer Mitte zur Rede kommen, denn noch erzählend hatte er aus den Mienen gelesen, was ein jeder unter ihnen empfand, Widerspruch, Frage und Zustimmung. Während Rede und Gegenrede gehört wurden, achteten nicht Wirt noch Gäste auf den Angekommenen, und so stand der Rabbi fort und fort tottraurig und verwundet an der Tür. Die Scham, sich so missachtet $z$ u sehen, stieg ihm 
heiss und trocken in der Kehle auf und dörrte ihm schier den Atem. Und dennoch wusste er sich allzeit vom Heiligen geliebt und in Freundschaft gehalten. Es war ihm, als müsste er sich leise hinwegschleichen, um irgendwo sich auszuweinen; als könnte er sein Lebtag nimmer froh werden. Aber während seine Hand sich an die Klinke schleichen wollte, sie sachte niederzudrücken, gedachte er des Begehrens, das ihn hergebracht hatte, aufflammend beherrschte ihn sein ewiger Wunsch, und er meinte, keine Demütigung sei so elend, keine Schmach so brennend, als dass er sie um dieses Zieles willen nicht ertrüge. So harrte er aus.

Indessen wandten sich viele der Gäste zum Gehen. Der Wirt geleitete sie zur Tür, den Frieden spendend. Da, als sein Gewand den Rabbi streifte, wandte er sein Haupt fast unmerklich ihm zu und gab ihm den Gruss, gleichsam über die Schulter hinweg, ohne Freude und Bewegung, mit gleichmütiger Stimme, wie einem Niegesehenen, um den sich der Sinn nicht bekümmert. Dem Prediger war nun der Mut gar krank und siech geworden. Er empfand, als hätte man ihn des Bodens beraubt, darauf seine Füsse standen, und er sänke ganz allmählich tiefer und tiefer in eine kalte wirbelnde Finsternis. Doch wurde seine Sehnsucht wiederum wach und belebte ihn aufs neue, und er raffte all seine Stärke und all seine Geduld zusammen und wappnete sich so gegen die Unbill, die dieser Tag ihm brachte. Und er sagte sich: Mag es ein grausamer Zufall sein, der mich so beschämt, oder eine 
Prüfung, die der Meister als gut erfand zu meiner Läuterung, ich bleibe und harre der gütigen Stunde. So brachte er den Tag bis zum späten Nachmittag in dem Hause des Baalschem zu unter den Freunden und Schülern und empfing von seinem Herrn geringe Ehre und Beachtung.

Gegen Abend liess der Meister Wagen und Pferde zur Ausfahrt rüsten, denn er gedachte noch des selbigen Tages eine Reise nach Kaminka und Jampol anzutreten. Und schon befiel den Rabbi Arje kalt und bitter eine allerletzte Verzweiflung, da er den Herrn sich so seinem Wunsche entziehen sah, als der Meister mit einer freundlichen Bewegung seiner Hand ihn zu sich rief und ihm gebot, sich einigen anderen Männern seiner Begleitung auf dieser Reise zu gesellen. Da erbebte des Predigers Angesicht vor tiefer Freude, denn er wusste, der Heilige wählte mit Bedacht zu Genossen auf seinen Fahrten jene unter seinen Jüngern, denen er sich oder seinen Willen oder sein Erkennen in irgend einer Weise mitzuteilen gedachte. Nunmehr eilte das Schiff seiner Hoffnung aufs neue mit weissen, glänzenden Segeln vogelgleich auf das Meer seines stolzen Wunsches hinaus. Denn er fühlte, dass der Meister sein Begehren erkannt und die Gewährung auf dem Wege ihm zugedacht hatte.

Schweigsam und voller Bangen fuhren die Genossen in das schon dämmernde Land hinaus. Und wie nach dem Sonnenniedergang alle Gerüche der Pflanzen und der Dunst der Erde herber und stärker sich lösten und die Luft würzten, stieg die 
Erwartung aus den Seelen auf, denn auf diesen Reisen, die der Meister mit den Schülern unternahm, pflegten ernste und wunderbare Dinge sich $z \mathrm{u}$ erfüllen. Weisse Nebel, sonderbar gestaltet, wirbelten und zogen sich aus den Ackergründen auf den Weg heraus, warfen sich den Pferden entgegen, stiegen knapp neben dem Wagen aus der Erde auf, die Schauer der Insassen vermehrend. Und dann kam das Dunkel, und die Pferde griffen eiliger aus, alles verschwamm in der Finsternis.

Rabbi Arje. war nach dem ersten jubelnden Entzücken seines Geistes in eine seltsame müde Erstarrung verfallen. Während der scharfen Fahrt tat ihm die Nachtkühle weh, und sein Herz war ermattet von den wechselnden Gefühlen des Tages. Er hielt die brennenden Augen krampfhaft offen, denn, wie er meinte, jeden Augenblick konnte der Meister seinen Namen rufen, um mit ihm von dem zu reden, was er begehrte. Doch der Baalschem verblieb in wortloser Versunkenheit. Um Mitternacht gebot er dem Wagen Halt. Es war eine Herberge in einem Städtchen am Wege, vor der sie hielten. Der Meister stieg sogleich die Treppe empor zum Obergemach, wo der Wirt ihm eine Ruhestätte bereitete. Die Jünger verblieben insgesamt in der grossen Stube zu ebener Erde. Eine Magd richtete eilig mit einigen Polstern und Decken notdürftige Lager auf den Wandbänken her. Alle warfen sich ermattet nieder und schliefen ein.

Rabbi Arje legte sich mit den anderen hin, aber 
sowie sein Körper das Lager berührte, war alle die lähmende Müdigkeit, die ihn auf der Fahrt gepeinigt hatte, dahin. Seine Gedanken flogen in einem wirbelnden Tanze auf, und sein ewiger Wunsch kreiste in ihrer Mitte. Er fühlte den Sturm in seiner Seele wie einen äusseren Lärm. Mit Anstrengung lauschte er auf jeden Laut im Hause. Würde der Meister jetzt, jetzt, da alle schliefen, in der geheimnisreichsten Stunde der Nacht, ihn auf seine Kammer rufen, um ihm die Offenbarung $z u$ bescheren? Wie er lag und lauschte, befiel ihn ein halber Schlummer, aus dem alsbald ein trügerischer Ton ihn auffahren liess. Dann lag er glühend in dem Fieber seines Geistes und harrte dem Morgen entgegen.

Während die Schatten der Nacht aus dem tiefen Schwarz sich in ein fahles Grau verfärbten, vernahm er über sich ein Geräusch in den Dielen und erkannte die Schritte des Meisters. Dann wurde sachte eine Tür aufgetan, und eine Stille wie zuvor folgte. Der Prediger lag eine Weile und lauschte, dann bezwang ihn die Ungeduld, er schlich sich an den Schlafenden vorbei hinaus und eilte die Treppe hinauf, da er nun gewiss war, dass der Baalschem, der stets in einer geringen Frist des Schlafes die Quellen seines Lebens erneute, sein Lager verlassen hatte. Und Rabbi Arje vermeinte, diese nachtgeborene Stunde des kommenden Tages sei seiner Bitte günstig.

Auf den letzten Stufen der Treppe traf ihn ein so starkes, so blendendes Licht, dass er getroffen 
zurücktaumelte und eine Zeit mit geschlossenen Augen sich an dem Geländer festhielt. Als er mühsam die Augen aufzuhalten imstande war, gewahrte er den Heiligen in der Öffnung seiner Kammertür, und das Angesicht des Baalschem war der Kern jenes feurigen Glanzes, der ihn vorher zurückgeworfen hatte. Das Haupt des Meisters war wie von einer bleichglühenden flüssigen Materie; aus den Augen schienen blaue Silberbäche hervorzubrechen. Der Anblick war in Furcht und Schönheit von solcher Art, dass den Prediger eine zitternde Schwäche in allen Gliedern befiel und er sich auf der letzten Stufe niederwarf, das Antlitz auf den Boden bergend. Er fühlte, dass der Erhabene jetzt Eines mit dem höchsten Strom der Glorie war und nur die schimmernde Hülle, von der fernen Seele bestrahlt, vor seinen Augen zwischen den zwei Welten weilte. Als er es wagte, den Blick wieder zu erheben, glich das Antlitz des Herrn einem erbleichenden Gestirn, das der Tageshelle der Wirklichkeit weicht. Nach einer Weile rief ihn der Baalschem mit Namen. Er erhob sich von den Knien und eilte gesenkten Gesichtes zu dem Meister, warf sich dort aufs neue zur Erde und brach in Tränen aus. „Freund, was begehrst du von mir um diese frühe scheue Stunde?" fragte der Heilige. In dem Beben seines ehrfürchtigen Herzens fand der Prediger kein Wort zur Erwiderung. „Sei ohne Zagen, steh auf!" ermutigte ihn der Meister, doch als der Rabbi zu reden versuchte, brach nur ein rauhes Stammeln über seine Lippen. Da erhob 
er sich verstört und beschämt, verliess den Herrn, ging leise zu den Genossen hinunter, die tief im Morgenschlaf befangen sein Kommen überhörten, und suchte aufs neue sein Lager auf. Er erhob sich mit ihnen zum Frühmahl, sass verschlossen inmitten ihrer Gespräche und verriet mit keiner Silbe das Erlebnis der Nacht. Der Baalschem aber war wie immer, geruhig und mitten im Leben.

Als es zur Abfahrt ging, rief er den Prediger herbei und sagte $z u$ ihm: „Freund, du sollst den Platz an meiner Seite einnehmen, wir wollen beide selbander sein."

So fuhren sie in den lauten, geschäftigen Tag hinein. Als das Städtchen hinter ihnen lag, die Felder sich dehnten und fern ein Wald vor dem Blau des Himmels dunkelte, sah der Baalschem seinem Nachbarn mit einem eigentümlichen Lächeln ein wenig vorgebeugt unter die Augen und begann so zu reden: „Der Grund deiner Ankunft und deines Weilens in meinem Hause, Lieber, ist mir bewusst. Du hofftest, dass ich dich in meine Erkenntnis einführe, damit sich dein Ohr wie meines der Sprache aller Kreaturen öffne. Siehe, ich weiss, dies allein hat dich zu mir geführt." Rabbi Arje ergriff die Hand des Meisters und legte sein brennendes Angesicht darauf, und kein Ton der Antwort kam über seine Lippen. Der Baalschem aber sah hinaus auf die zartgrünen Saatfelder, und das Lächeln blieb auf seinen Mienen. Nach einer Frist redete er wieder: ,Setze dich näher zu mir und neige dein Ohr zu meinem Munde. Ich will dich nun meine Weisheit 
wohl lehren. Sei nur ohne Sorge, dass die Andern uns vernehmen möchten, meine Rede geht allein in dein Ohr ein, und der Lärm von Huf und Rad verschlingt meine Worte für die Genossen. Ehe ich dich in den Urgrund des Geheimnisses einführe, tut es not, dass ich ein Ding, das du weisst, vor dein Auge hebe. Aber wisse, dass dieses, was ich dir nun sagen will, nur die Vorbereitung für die letzte der Offenbarungen ist. Du weisst von dem gewaltigen Wagen, der in der höchsten Sphäre der oberen Welt steht. An seinen vier Enden ist je das Haupt einer Kreatur, eines Menschen, eines Stieres, eines Löwen und eines Adlers. Diese vier Geschöpfe bergen in sich Ursprung und Quell alles dessen, was in den lebenden Wesen unserer Welt sich ereignet und sich erfüllt, Atem gewinnt und als Wort geboren wird. Siehe, von dem Menschenantlitz kommt uns der Geist und die Seele der Sprache $z u$, die wir zu Menschen Geschaffenen hier unten tauschen. Aus dem Haupte des Stieres kommt den Tieren, die uns dienstbar und hilfreich wurden, die Kraft und der Sinn ihrer Laute; von dem des Löwen die Bedeutung der Schreie, die das unbändige und wilde Getier in denWäldern und Wüsten in die Dämmerung sendet, sich zu rufen und zu locken; der Kopf des Adlers aber erzeugt in seinem Gehirne die Laute der Vogelwelt, mit denen sie die Lüfte unter dem Himmel füllt.

Und das wisse, Freund, wer seine Seele so hoch zu spannen vermag, dass sie in jene Sphäre der oberen Welt eindringt, in der der Wagen steht, und wer dann aus ihren Augen so klar und tief schaut, dass 
er das Geheimnis des Grundwesens der vier Kreaturen des Wagens erkennt, die das Sinnbild der Geschöpfe unserer Welt sind, der, Freund, hat den Sinn offen für alle Laute auf Erden. Er scheidet das falsche Wort von dem wahren und den trügerischen Ton vom herzgeborenen. Er hört die Stimmen unter der Erde sich in den Nächten unterreden, wenn dem Menschengeschlecht die Stille vollkommen und jeder Laut abgestorben dünkt. Und die Stimmen der Tiere auf der Erde und der Vögel in den Lüften tragen ihm jene Heimlichkeiten der Natur und des Lebens herbei, für die die Sinne der Menschen sonst taub und unemptindlich sind. Siehe, und so schweigt die Welt ihm nie, sie drängt sich an ihn heran mit allen Wundern, nichts ist ihm starr und versagend, denn er hat die Wurzel, aus der alles kommt, im oberen Wagen geschaut und erkannt. Aber verstehe wohl: was ich dir nun sagen werde, ist der Kern der Offenbarung selbst. Darum beuge dein $\mathrm{Ohr}$ tief $\mathrm{zu}$ meinem Munde und höre mit ganzer Seele mir zu. Verschliess dich in diesem Augenblick vor allem, was ausser dir und meinen Worten weilt!" Und nun flüsterte der Meister dem Prediger erhabene und nie vernommene Dinge zu, dass die Mysterien des Wagens und seiner Gestaltenihmin ihrerletzten Tiefe erschlossen wurden. Und der Meister fuhr fort zu reden, und es war dem Prediger, als ob Tor um Tor vor ihm aufspringe, alle Schatten und Dunkelheiten wichen, alles Trübe und Unreine sich kläre und sein Herz dem grossen Herzen der Welt nahe sei. 
Und wie er so an den Meister gedrängt, das eine Ohr nahe dem Munde des Heiligen, sass und im Lauschen aufging, fuhr der Wagen in einen Wald ein. Der Weg war knapp und eng für das stattliche Gefährt, und dem Prediger streiften die Nadel$z$ weige das eine Ohr. So wurde er ein kleines aufmerksam auf den Ort und bemerkte, dass allerlei Vögel gar anmutig ihren Frühgesang aufführten. Und bald unterschied er wunderiich genug einzelne Worte und Partien, und das ganze war eine grosse Unterredung, und alles hatte einen munteren, lieblichen Sinn. Da wurde es dem Prediger fröhlich und stolz ums Herz, und er hörte emsig weiter zu und unterschied alsbald auch Stimmen anderer Tiere und den Inhalt ihrer Reden mit recht innigem Behagen an seiner wunderbaren Fähigkeit.

Über dem einen aber liess er das andere mit nichten, sondern horchte mit dem zweiten Ohre nicht minder eifrig den Worten des Meisters, und so mit geteiltem Geiste nahm er beides hin.

Der Wald ging zu Ende, und ganz nah sah man die Stadt liegen, die das Ziel des Baalschem war. Der Meister hatte seine Unterweisung geendet und blickte den Prediger stillschweigend und forschend an. „Hast du gut inne, was du von mir vernommen hast?" fragte er nach einer Weile. Und Rabbi Arje sah ihn jetzt mit sicheren, frohen Augen strahlend an und sagte; „Ja, Meister, alles hab ich wohl verstanden!"

$\mathrm{Da}$ fuhr ihm der Heilige mit der flachen Hand leicht über die Stirn. 
Siehe, nun hatte der Rabbi alles, alles vergessen, was der Baalschem an Offenbarung in seinen Geist gelegt hatte. Er sass da, trostlos leer und wie ausgebrannt, und hörte die Vögel in den Ackerfurchen schreien und verstand und empfand dabei so wenig als je vor diesem Tage - eines Getieres simpler, sinnloser Lautl

Der Baalschem aber lächelte und sprach: „O wehe dir, Rabbi Arje, der du eine unstete, gierige, naschhafte Seele hast! Konntest du sie mir nicht ganz überlassen in dem Augenblick, da ich die Gnade aller Gnaden in sie legen wollte? $O$ wehe dir, Freund, der du in Vielheit und Hast sie bereichern wolltest! Gottes Wunder sind derer, die sich in Einem sammeln und bescheiden können!"

$\mathrm{Da}$ sank der Prediger in sich zusammen und schluchzte schwer und bitterlich. 


\section{DAS RUFEN}

ABBI DAVID PIRKES, DER SCHWEIgende, der Schüler des Baalschem, wollte 1 den Messias rufen. Er wollte aus seinem Willen einen Sturmwind machen, der sollte an der oberen Pforte rütteln, sollte einziehen und rufen und fassen und auf die Erde reissen. Und er versammelte seine Kraft und holte sie aus allen Dingen, denen sie gegeben war, und band seinLeben los von allenWesen und Mächten. Und als seines Leibes Gegenwart und schwerer Sinn seine Weihetaten störten, kasteite er sich und brachte sich dahin, wo man der Speisen und des Schlafes entraten kann, und lebte in Einheit und Gelöstheit der Seele viele Tage und Nächte. Aber bald gewahrte er seine Schranken und sah, dass er allein war. Er sollte für die Zeit sprechen, aber er konnte es nicht. Er sollte ihre Reife künden, aber er fühlte sie nicht. Er war nicht mit ihr vermählt. Fern von ihm breiteten sich die Lager der Menschen.

Da fand Rabbi David, was ihm zu tun gebührte. In jedem Jahre am Versöhnungstag wurde er berufen, das grosse Gebet vor der Gemeinde zu sprechen. Jetzt verstand er den Sinn davon. Er wusste, er würde auf den Flügeln seines Wortes das Beten aller tragen, das Gebet der Gemeinde und das Gebet ganz Israels, denn ist nicht das Bethaus des Baalschem der Mittelpunkt der geistigen Erde? Und er beschloss, seinWort zu schleudern auf das Volk wie ein gewaltiges Netz, dass alle Inbrunst von ihren engen Eigenzielen weg. gezogen und dem Messias zugeführt werde. Binden 
wollte er die Seelen Israels zu einer ringenden Schar, zu einem fordernden Fluge. Ja, er wollte für die Zeit sprechen. Alle Worte sollten in sein Wort fliessen und in ihm emporströmen. Ja, er wollte die Reife der Zeit künden. Das Vielfache sollte zur Einheit zusammenwachsen, die keinen Mangel mehr kennt. Vermählen wollte er sich mit der Zeit und sein Blut mischen mit ihrem Blute, seine Seele mischen mit ihrer Seele, und das Vermählte in die Nachtwerfen um des Morgens willen.

DerVersöhnungstag war da, und die Gemeinde versammelte sich zum Frühgebete. Wie Tote standen sie in den Kleidern der Toten und bereiteten sich, in das Auge der Ewigkeit zu schauen. Nur der Meister fehlte. Der Baalschem war sonst der erste im Bethause, wie ein Torhüter Gottes. Heute säumte er, und die Schar der Seinen harrte sein voller Bangigkeit, denn sie wussten, wie alles, was er tat, seinen Sinn nahm aus dem heimlichen Geschehen der Welt. Als der Morgen sich schon in den breiten Tag ergossen hatte, trat der Baalschem endlich leise und fast zögernd ein und ging den Versammelten vorbei und sah keinen an und ging an seinen Ort und setzte sich und legte den Kopf auf das Betpult. Und jene standen und schauten $z u$ ihm und wagten nicht, mit dem Beten zu beginnen. Er aber hob den Kopf nach einer Weile, und seine Augen blinzelten wie eines, der sich müht, in die Sonne zu blicken, und dann senkte er ihn und hob ihn wieder, und dies währte eine Zeit. Danach regte er sich wie ein Erwachender, der einen umklammernden Traum von den Gliedern abtun will, und winkte, man solle 
sich zum Frühgebete stellen. Aberals dieses gesprochen war und die Gemeinde sich geweihtenHerzens zu dem grossen Gebete rüstete, welches das Mussaf genannt wird, sah der Meister sich im Kreise um und sah sie stehen, eine grosse Schar, stumm, im Gewande des Todes, hingegeben zum Sterben und zum Leben. Und leise, Wort von Wort gezogen, wie aus der Tiefe des Sterbens, sprach er zu denen, die umihn standen: ,Wer wird Mussaf vorbeten?" Und so kaum hörbar die Rede war, im gleichen Augenblick war ein Staunen entzündet in der Gemeinde und wogte still durch den stillen Raum. Denn alle wussten, dies war Rabbi Davids Amt, und er war eingesetzt vom Meister seit Jahr und Jahr und war Gottes Diener im lauten und tragenden Sprechen des hohen Mussaf am Tage der Versöhnung, aus all den zitternden Herzen und von all den flüsternden Lippen emporzutragen die Wünsche und die Bitten, von der Scheu der Herzen und Lippen gelöst. Aber keinerwagte, dem Heiligen zu antworten, und schweigend wogte das Staunen. Er jedoch fragte wieder und wieder, bis einer leise und mit Zagen sprach: „Rabbi David ist doch der Beter!“ Da richtete sich der Baalschem auf und wendete sich zur Lade, vor der RabbiDavid unirdisch bleich und wie abgestorben stand, und redete $z u$ ihm in gewaltigem Hohn, Wort von Wort gezogen, wie aus der Tiefe der Hölle: „Du, David, willstMussafvorbeten? Weisstnichts undwillst Mussaf vorbeten am Jomhakippurim?" Da standen sie alle bestürzt und verstanden nicht, was sich ereignete, und jeder fragte seine Seele, wie es möglich sei, dass derMeister dergestalt einenMenschen schmähe, 
und gar einen $Z$ addik, und gar am Tage derVersöhnung. Allein die Furcht war gross, und niemand sprach ein Wort. Rabbi David aber stand noch starr und aufgereckt vor der Lade, und ihm war, als trüge ihn ein Wirbelsturm durch die Nacht; und Fäuste hoben sich aus dem Wirbel und schlugen ihn, und dünne, spitzige Finger zerrten das Gewand von ihm, und stählerne Knöchel klopften ihm an Aug und Ohr und Brust und Arm und Knie und lähmten ihm Sinne und Glieder, und eisige Krallen rissen seine Seele hervor und warfen sie in die Nacht. So stand er wie in leerem Raume und wurde keiner Zeit gewahr und war verloren. Urplötzlich aber wich der Wirbel von ihm, und er sah sich vor der Lade stehen und hörte ein Wort des Baalschem zu sich herübertönen. Und der Baalschem redete mit leichter Stimme: ,Ist keiner da, vorzubeten, nun, so geh schon du, Rabbi David!" Da stürzten Rabbi David die Tränen hervor, und er weinte und weinte und begann aus dem Weinen zu beten und betete in grossem Weinen, und sein brechendes Herz sandte ihm Tränen und immer neue Tränen. Und die Tränen nahmen in ihrem Strome seine Bereitschaft mit und seinen grossen Willen und trugen mit sich davon die Kawwana seiner Seele, die Frucht der Tage und der Nächte, die Spannung des Unendlichen. Und nichts fühlte und wusste er mehr als das Leid seines Herzens, und aus seinem Herzeleid redete er zu Gott und betete und weinte. Und an seinem Leid entbrannte das Leid der Gemeinde und schlug empor wie Bergesfeuer. Wer eine Decke gebreitet hatte über dieWinkel seines Lebens, der zog sie nun weg und wies Gott seine 
Wunden wie einem Arzte. Wer eine Mauer errichtet hatte zwischen sich und den Menschen, der riss sie nieder und litt den Schmerz der anderen in seinem Schmerze mit. Und wem die Brust schwer war, weil er in seinen engen Kreisen das Wort nicht finden konnte, das hindringt zum Kern der Geschicke, der fand es nun und atmete in Freiheit.

Aber als das Fest sich geneigt hatte und die letzten Feiertöne der Neîla in den Abend verbraust waren, trat Rabbi David vor den Baalschem hin. Und als er vor ihm stand, ohne ihn anblicken zu können, und das gütige, ruhevolle Angesicht unfern des seinen nicht sah, nur fühlte, vermochte er sich nicht länger zu halten, sondern sank vor die Füsse des Herrn und lag eine Weile stumm und ringend da. Endlich hob er den Blick und sprach in schwerer Mühe: ,Rabbi, welche Schuld hast du an mir erschaut?" Und hinter ihm hatte sich die Gemeinde geschart, und alle harrten der Worte des Meisters; mit Augen, die das Gebet geläutert und befriedet hatte, sahen sie auf seinen Mund, und von all den Herzen, die aus dem Quell der Gottesglut gestillt waren, schlug ihm die eine Frage entgegen. Und der Baalschem sprach: „Keine Schuld finde ich an dir, Rabbi." Und legte ihm die Hände auf die Schultern, und neigte sich zu ihm wie ein Vater, der seinen Sohn im Schweigen segnet, und sprach zum andern Mal: „Keine Schuld finde ich an dir.“ Und als des andern trauervoller, wartender Blick zu ihm aufflog, sprach er weiter: „O Rabbi David, du hast dich bereitet und geheiligt und hast im Feuer der Kasteiung gebadet deinen Leib und hast deine Seele 244 
gespannt wie eine Bogensehne der Kawwana, um den Messias zu rufen." Und er hielt inne, und jener beugte die Stirn, und er sprach weiter: „O Rabbi David, du wolltest dein Wort wie ein Netz schleudern auf das Volk Israel und aller Willen dir dienstbar machen, um den Messias zu rufen." Und tiefer beugte jener die Stirn, und der Baalschem sprach weiter: ,O Rabbi David, vermeinst du, deine Gewalt könnte fassen das Unfassbare? Und dränge sie auch vor bis zum innersten Himmel und umfinge mit zwingenden Armen den Thron des Messias, vermeinst du, du hieltest ihn, wie meine Hand deine Schulter greift? Über die Sonnen, über die Erden wandelt Messias in tausend und tausend Gestalten, und die Sonnen und die Erden reifen ihm entgegen. In seiner obern Form gesammelt, zerstreut in unsägliche Weite, hütet er allerorten das Wachsen derSeele, hebt er aus allen Tiefen diegefallenen Funken. Täglich stirbt er die stillen Tode, täglich keimt er in stillen Geburten, täglich steigt er empor und nieder. Wenn einst die Seele schlank und vollendet mitreinen Sohlen den reinen Boden tritt, dann wird seine Stunde in seinem Herzen aufpochen, dann wird er sich aus allen Gestalten ziehen und wird sitzen aufdem Throne, Herr der Himmelsflammen, die gesprossen sind aus den erlösten Funken, und wird niedersteigen und kommen und leben und wird der Seele sein Reich schenken." Und weiter sprach der Baalschem: „Du aber, Rabbi David, was hast du getan? Du wolltest deine Seele mit der Seele Israels in die Nacht werfen um des Morgens willen. Aber kennst du den Herrn der Nacht, den Herrn des anderen Reiches? Wisse, immer ist Einer, der 
die Zeit befragt, und Einer, der für die Zeit antwortet. Einer, der geben will, und Einer, der nicht annehmen kann. Dieser ist er, der Herr der Nacht, der dazu eingesetzt ist, das Fehle der Zeit zu künden und zu vollziehen. Und als er sah, dass du dich bereitetest und heiligtest, da glomm eine grosse Freude in ihm auf, und er gedachte in deinem Gebete das GebetIsraels einzufangen und sich ein Spiel und ein Kleinod daraus zu machen. Und auch er spannte seine Seele wie eine Bogensehne der Kawwana, und stellte sich auf dem Wege auf, wo dein Gebet aufsteigen sollte, und mühte sich, es zu fangen. Und ich stritt mit ihm an diesem Morgen und wollte ihn verjagen, aber ich konnte es nicht. Da schlug ich deine Seele mit einem Wirbel der Schande, dass sie ihren Willen verliess und in Tränen aufging. Und dein Gebet stieg auf mitten in den Gebeten Israels und stieg frei empor zu Gott." Da beugte sich noch tiefer und völlig zu Boden die Stirn des Rabbi David. Aber der Baalschem hob ihn empor und zog ihn zu sich heran und sprach: ,Als dasWeinen über deine Seele kam, da ist an deinem Leide das Leid Israels entbrannt. Und jeder stand im Läuterfeuer seines Herzeleids vor Gott, und jeder wurde rein im Strome seiner Tränen. Wie viele gefallene Funken hast du da emporgehoben! Fürwahr, Rabbi, als du weintest, da war der Messias in dir."

JOMHAKIPPURIM = Versöhnungstag, NEÏLA $=$ Schlussgebet des Versöhnungstages. 


\section{DER HIRT}

\section{TMMER, WENN DAS LICHT SEINEN BOTEN}

sendet, sendet auch die Nacht ihren Boten. Das Licht hat nur sein Auge, aber die Nacht hat tausend Arme. Der Bote des Lichts hat nur seine Tat, aber der Bote der Nacht hat tausend Geberden.

Damals hiess er Jakob Frank. Aller Kunst des Truges kundig, fälschte er das Heiligste, durchzog mit zwölf Erwählten die Städte Polens und liess sich als den Messias und Gottessohn verehren. Der farbige Bann der Lüge ging von ihm aus, sein weicher glänzender Blick berauschte das Land, und jedes schwankende Herz fiel ihm zu.

An einem Morgen fühlte der Baalschem eine Hand auf seiner Schulter, und als er sich wandte, sah er den Engel des Kampfes mit bleicher Stirn und zürnenden Brauen. „Was begehrst du, o Herr?" fragte er mit unsicherem Munde. Aber jener sah ihn von Grund $z u$ Grund an, wie der Himmel einen Brunnen ansieht, und sprach nur: „Du weisst es" und ging. Und der Baalschem fühlte, dass die Hand von seiner Schulter gewichen war, aber an ihrer Statt war die Last eines langen Lebens gekommen und wollte nicht weichen.

Dennoch rüstete er sich. Und da er sah, dass der Kraft, die in ihm wohnte, nicht genug war zum Werke, beschloss er, alle Strahlen heimzurufen, die er je an irdische Wesen gespendet hatte. Und er beschwor weithin die Strahlen und warf einen 
Ruf über die Erde und sprach: ,,Kehret heim, meine Kinder, denn ich bedarf euer zum Kampfe." Und flogen alsbald herbei die Strahlenkinder und umlagerten ihn in urweitem Kreise und schwiegen. Und Israel der Sohn des Elieser, der Baalschem, blickte weit hinaus, wo Sphäre der Seinen sich leuchtend um Sphäre schloss, wie die sinkende Sonne am Tagesrande ihr Bild anschaut, ausgegossen im Abendrot über alle Fernen. Sodann sprach er mit leisen und langsamen Lippen: „Meine Kinder, meiner Kraft Gestirne und wandernde Flammen. Ich habe euch einst entsendet und hingeschenkt, Trost $z \mathfrak{u}$ bringen oder $T$ at oder Freude oder Lösung. Aber nun rufe ich euch heim, dass ihr wieder mein seiet und mir helfet in dem grossen Streite wider den Boten der Nacht. Und seht, ich hätte euch nicht gezogen von den Stätten der lebendigen Welt, darin ihr wachset und Leben wecket, wenn es nicht um das Heil ginge und um die Geburt der Zukunft. Nun aber berufe ich euch." $\mathrm{Da}$ war wieder das Schweigen und lag über dem Lande, als sei jeder Laut aufgesogen von dem schweigenden Licht der Strahlenkinder. Endlich sprach eines: „Vater und unser Meister. Vergib $\mathrm{du}$, und auch ihr alle vergebet, dass ich leichtes Ding vor euch rede. Aber es ist dies, dass ich dich bitten will, lieber Herr, du mögest mich wieder an meine Stätte lassen. Denn als du mich aus dir gabst, hast du mich in das Herz eines Jünglings entsandt, der sehr traurig war. Er sah von seinem Fenster auf einen wildbewachsenen 
Hügel, der war einmal grün und einmal gelb und rot und einmal weiss, nach dem Wege des Jahres. Und der Jüngling stand da und sah darauf hin, wie man so auf die Dinge hinsieht. Aber seit ich in sein Herz gekommen bin, sieht er von seinem Fenster auf den Hügel des Lebens, und Grün und Rot und Weiss sind die Lichter eines zauberhaften süssen Spieles. Willst du es ihm nehmen?" Da schwieg der Baalschem und winkte dem Fünklein Gewährung zu. Aber alsogleich hoben andere Stimmen an und erzählten von den Menschen, die sie aus $Z_{\text {weifel }}$ und Leere, aus Taumel und Bitterkeit, aus Blindheit und tiefer Not befreit hatten und die, wenn sie von ihnen gingen, wieder hinsinken müssten in die harte verschlingende Finsternis. Und bald tönte es von tausend Mündern durch die Luft: „Willst du sie alle verderben, die du gelöst hast? Und welches Heil könnte es je sühnen, wenn alle diese jetzt heillos würden?" So tönte tausendfältig die Frage hin.

Lange sass der Baalschem und lauschte der erschütterten Luft, die auch nach dem letzten Ton nicht wieder ruhig werden wollte, sondern zitterte und sang. Dann lächelte er seltsamen Angesichtes und sprach: „Wohl denn, meine Kinder, und ich segne euch zum andern Male. Und nun - kehret heim!" Und er erhob sich und breitete seine Hände über die leuchtenden Scharen, und es war wie ein Gruss der letzten Stunde.

Und als er allein war und weit am Himmelsrand das letzte Strahlengold zurück in die Welt ver- 
fliessen sah, sprach er zu seiner Seele: „So suche dir nun eine Gefährtin, liebe Seele, die in ihre Tat gehüllt und geschlossen ist wie der ruhende Vogel in seine Schwingen und die also in der Glorie ihrer Gnaden steht, dass alle Strahlen ihrer Kraft nur den Glanz ihres Kleides dichter und dichter weben. Suche dir die Schwester, liebe Seele, und lege auf ihre Schultern die Botschaft und das Geheiss, und deinen Arm lege um ihren Nacken, und lenke sie wider den Mann, der tausend Geberden, dass sie ihn vertilge." Und er schwang sich empor in die obere Welt und trat in den Prophetenhimmel. Da fand er Achija von Schilo, den Alten, der einst als der Gesandte des göttlichen Zornes wider die Könige Judas über die heilige Erde geschritten war. Der grüsste den Baalschem und sprach: "Gesegnet sei, der da kommt: Israel, mein Sohn. Ich höre eines Wunsches Rauschen um deine Schritte, eines mächtigen Wunsches $\mathrm{Ge}$ brause. Wie in der Zeit, da ich zu dir dem Knaben in den Nächten niederstieg und dich das Geheimnis des Eifers lehrte, und hell auf lodertest du mir entgegen und hieltest mich in den Armen deiner Feuerbrände, ehe ich noch bei dir war, so bist du noch heute des Feuers voll und glühst über und über. Wahrlich wie der Seraphim einer, der Feurigen, die ewig die eigene Flamme trinken und doch alle Welten aus ihr ernähren." Aber der Baalschem gab ihm die Gegenrede: „Nicht also, lieber Meister, sondern hingegeben habe ich der Glut aus dem Kerne viel und viel, und bin nur noch der Schatten 
meiner Flamme, bewegt wie sie aber dunkel. Und dies ist mein Wunsch, den du entlauscht hast meinem Schritte, und wohl ein mächtiger: zu finden die Seele, die in einsamem Feuer atmet wie die Seraphim. Denn ich will ihr Feuer werfen auf den Boten der Nacht, dass es ihn aufschlürfe und zu nichte mache." Da sprach Achija: „Des ist mir wehe, mein Sohn, dass ich dir die Kunde nicht schenken kann. Denn mein Amt ist, die erwählten Seelen das Geheimnis des Eifers zu lehren. Aber die solcher Lehre bedürftig und ihr geöffnet ist, und sei es die höchste Seele, es ist nicht die, die du suchst. Denn nicht dringt das Geheimnis zu denen, die selbst das Geheimnis sind. Doch lass uns Elija fragen, den Boten des Bundes. Auf seinen Fahrten über die Erden mag er wohl erschaut haben, die du suchst." Und sie traten zu Elija hin, der eben mit flüchtiger Sohle durch die Halle des Prophetenhimmels ging, die Glieder noch gespannt vom Fluge, im Herzen schon neuen Weges gewärtig. Als sie an ihn traten, neigte er sich $z u$ ihnen, und es war, als ob ein Wandelstern in seiner Bahn innehielte, um einen Menschen anzuschauen. Und ehe noch die Frage sich von ihnen gelöst hatte, redete der Seher zum Baalschem: „Den du suchst, ist Mosche der Hirt. Und wisse, er weidet die Schafe in den Bergen, die genannt werden die Poloninen." Und kaum hatte das Wort ihn verlassen, neigte sich Elija wieder seinen Erden $z u$ und bereitete sich zur neuen Fahrt. 
Die milden Matten neigten sich wie Wellen, von dem Atem des tiefen und stillen Sommers regiert. Die Luft war voll eines Wissens, das nicht reden mag. Der Baalschem ging, und nichts rührte an seine Seele, denn sein Wille war über ihr und hielt sie jeglichem Ding verschlossen, die in einem langen Leben sich an ein jegliches Ding dahingegeben hatte in strömendem Mitdasein. Er achtete der Tiere nicht, die aus dem Walde traten mit traulichem Geäuge, da sie seinen Schritt vernahmen, und antwortete dem $Z_{\text {weige nicht, der seinen Arm }}$ liebkoste. Ganz in sich gezogen ging er durch den Stolz der Gelände hin. Seine Füsse verspürten den Weg nicht und trugen ihn wie in einem steten Anbeginn. So kam er an die grosse Bergwiese, die hinter einem breiten Graben anhebend in jähem Schwung sich bis zum Gipfel des Berges aufreckte. Auf der mächtigen Fläche waren Mosches Schafe wie ein leichtes weisses Wölkchenvolk verstreut. Als der Baalschem die Weide erblickte, fuhr er sich schwer über die Augen, wie wer wider die Heimsuchung eines Bildes streitet, und trat alsdann hinter ein Gebüsch, um unbemerkt nach dem Hirten auszuschauen, denn er fühlte noch kein Wort in sich.

$\mathrm{Da}$ sah er einen Jüngling, der stand am Rande des Grabens, die Schultern von den lichten Haaren gedeckt und das Auge wie eines Kindes Auge in seiner Bläue gross geöffnet, starker Gestalt, in grobem Gewande. Und der Jüngling tat den Mund auf und redete, und wiewohl keiner vor ihm war und in aller Weite keiner, hielt er $Z_{\text {wiesprach mit }}$ 
einem Wesen und gab viele inbrünstige Worte aus. Und also redete er: „Lieber Herr, so unterweise mich, was ich für dich tun mag! Hättest du doch Schafe, die ich hüten könnte, ich wollte ihrer warten zu Tage und zur Nacht, ohne Lohnes zu begehren. Sage, was ich tun soll!" Nun schwieg er, und da geriet der Wassergraben in seinen Blick. Da machte er sich auf und hub an, mit eingestemmten Armen, die Füsse dicht aneinander, über den Graben zu springen. Der war breit, Schlammes und allerlei Gezüchtes voll, und das Springen kostete dem Knaben den lichten Schweiss. Doch liess er nicht ab und hielt sich keines Augenblickes Dauer an einem Ufer, sondern sprang hinüber und herüber, sprechend: „Dir zur Liebe, süsser Herr, und dir zum Gefallen!“ Zuweilen nur unterbrach er sein Tun, um nach den Schafen auszusehen, die sich indessen allzusehr verstiegen hatten, und gab dem Vieh liebreiche Wörtlein und viel freundlicher Sorge. Dann aber lief er wieder zum Graben.

Lange schaute der Baalschem darauf, und war ihm, als sei dieser Dienst grösser als aller, den er je aus geweihter und gesammelter Seele Gott zugebracht hatte. Endlich kam er aus seinem Versteck, trat zu Mosche und sprach: „Ich habe ein Wort zu dir." Antwortete der Hirt: „Es ist mir nicht verstattet, denn mein $\mathrm{Tag}$ ist derer, die ihn gedungen haben." Der Meister sagte: „Sehe ich dich doch springen ohne Mass der Zeit." Der Hirt gab zurück: „Tu's um Gottes willen, und für ihn darf ich die Weile versäumen." Aber der Baal- 
schem legte ihm die gute Hand auf den Arm: „Freund, auch ich bin dir um Gottes willen gekommen." Da war jener erfasst, und sie sassen Seite an Seite unter einem Baum, und der Heilige redete von göttlichem $D$ ing in klarem und mächtigem Bekennen, dass der neben ihm aus einer bebenden Seele den Worten lauschte und sie in das Beben seiner Seele aufnahm und darin trug. Und der Baalschem sprach von den Trümmern des Gottestempels zu Jerusalem und von dem Herzen, das unter den Trümmern schlägt und wartet. Und von den Getrennten sprach er: von dem einsamen Gott, dem die Lichtglorie entsunken ist, vom Dunkel gekrönt schaut er in den wirbelnden Abgrund der Dinge und wartet; durch den Abgrund aber wandelt die Schechina, wie eine zarte verstossene Jungfrau im Sonnengewande, und bangt, und leuchtet, und alle Wesen trinken ihr Licht und ihre Bangigkeit. Und die Wesen hellen sich und glühen auf von der Gottesspende und brennen empor wie eine Flamme, die sich dem Himmel opfert. Und schneller wird das Schlagen des begrabenen Herzens, und sehnsüchtiger der Schritt der Herrlichkeit, und tiefer der Blick des Einsamen. Und schon ist es, als wollten alle Seelen heimkehren und Gottes Verbannung lösen und das Geheimnis der Ewigkeit erfüllen. Aber die Nacht ist wachsam: aus ihrer Höhle spähen tausend Augen in das Werden hinaus, und tausend Arme schlängeln sich in das Werden hinein. Und da es an der Zeit ist, sendet die Nacht ihren Boten. In weicher, 
lockender Finsternis zieht er über die Erde. Wen sein Wort berührt hat, von dem fällt die Lichthülle $a b$, und wer seinen Blick empfangen hat, in dem erlischt die opfernde Flamme.

Als der Baalschem von dem Boten redete, sprang der Hirt auf beide Füsse und schrie: „Herr, wo ist dieser Mann, von dem du sagst? Denn es soll nicht sein, dass er länger lebe, als bis zum Augenblick, da ich ihn finden werde!" Doch der Meister hiess ihn stille sein und begann ihn im Kampfe zu unterweisen.

Der Dämon des Widersachers aber schwang in den Lüften und wurde des Bundes der Seelen gewahr, wie die reife, erleuchtete die sturmstarke, wehende umfasste und lenkte. Und da er mit der Macht des Fluches in das Innere der geschehenden Welt zu schauen vermochte, verstand er, was das Zwiegespräch des Alten mit dem Jungen auf dieser Wiese am Walde ihm und der Ewigkeit meinte. Er streckte sich über die Welt und sog sich mächtig an all dem Bösen, das in jenen Tagen gedieh. Darauf erstritt er sich den Weg in das obere Reich und begehrte in gellendem Wort sein Recht auf die Zeiten. Da kam aus der namenlosen Mitte der Einsamkeit eine Stimme, die war so voll der Trauer und übervoll, wie eine Schale, über die sich die Flut des Meeres hingiesst; und die Trauer trieb und wogte um die Stimme wie die Flut des Meeres. Und der Dämon fiel nieder und erschrak, denn das Wissen war über ihn gekommen. Die Stimme aber sprach: „Fülle pocht wider Fülle, und 
der Kreis schlingt sich in den andern. In welchen Zeiten willst du walten? Der Augenblick ist dein, und immer der Augenblick, bis dich einst die Seele gewaltigt und du dich in mein Licht stürzest, weil du es nicht länger erträgst, der Herr des Augenblicks zu sein. Und siehe, du weisst es." Und die Stimme schwand, aber die Flut der Trauer trieb und wogte, und der Dämon lag vor ihr in den Fesseln des Wissens. Alsbald jedoch schüttelte er sie ab und fuhr nieder, und zitternd griff er in die Wolken und ballte sie mit wütigen Fäusten. Er riss den Sturm empor und entliess die Blitze und $z$ wang den Donner wieder und wieder zum Werke. Er entsandte die klamme Angst aus seinem Gefolge, und sie ergriff die Herzen mit Würgerhänden. Feuer fiel in die Stadt, und die Glocken stöhnten auf.

Da fuhr Mosche, der Hirt, als er Schall und Getöse vernahm, über den heiligen Worten auf und gedachte seiner Tiere, die in der Unbill des Himmels schutzlos über den Berg verstreut geblieben waren. Er sprang empor und eilte mit langen, eiligen Schritten hinan, die Verirrten mit kindlichen Schmeichelworten zu locken, und hörte nimmer auf den Heiligen und sein Warnen.

Der Baalschem wurde still, und die Trauer kam auf seine Stirn, und er beugte sich vor der Vernichtung. Und langsam, Haupt und Blick zur Erde gezogen, stieg er nieder. Aber als er im Tale stand, fühlte er einen Arm um seinen Nacken. Und da er sich wandte, sah er den Engel des Kampfes mit strahlender Stirn und liebreichen Brauen. Und 
der Engel legte auch den andern Arm um seinen Nacken und küsste ihr. Und Israel ben Elieser erkannte, dass dieser der Engel des Todes ist, der da heisst der Wiederbringer. Und sein Erkennen tröstete ihn. 


\section{IN HALT}

EINFÜHRUNG

\section{DAS LEBEN DER CHASSIDIM}

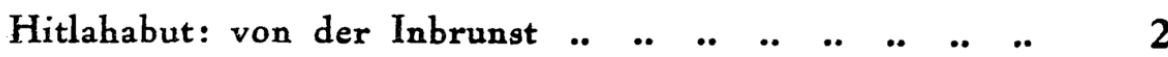

Aboda: von dem Dienste ..

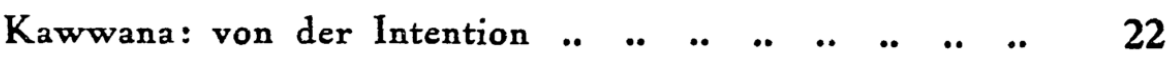

Schiflut: von der Demut ..

DER ERSTE KREIS

$\begin{array}{lllllllllllllll}\text { Der Werwolf } & . . & . . & . . & . & . & . . & . & . & . & . . & . . & . & & 48\end{array}$

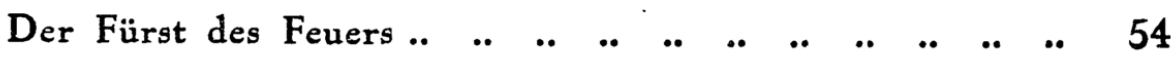

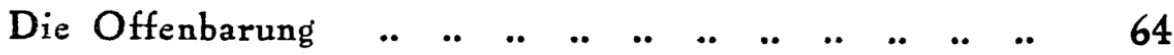

Die Heiligen und die Rache ..

Die Himmelwanderung ..

$\begin{array}{llllllllllllllll}\text { Jerusalem } & . . & . . & . & . . & . . & . . & . & . . & . & . . & . & . . & . . & . & 88\end{array}$

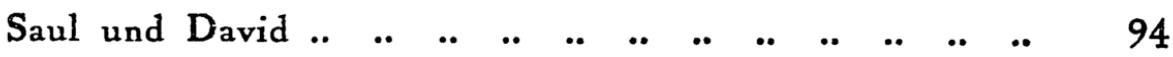

DER ZWEITE KREIS

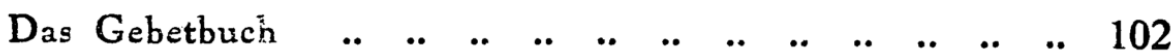

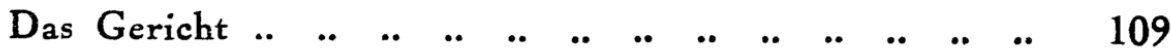

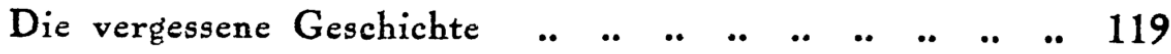

Die niedergestiegene Seele ..

Der Psalmensager ..

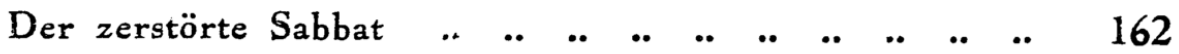

Der Widersacher ..

DER DRITTE KREIS

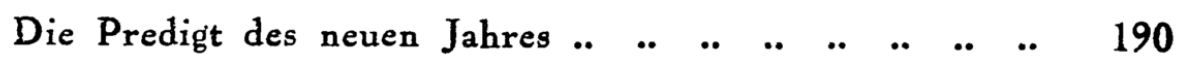

Die Wiederkehr

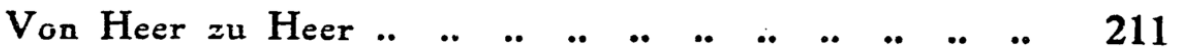

Das dreimalige Lachen ..

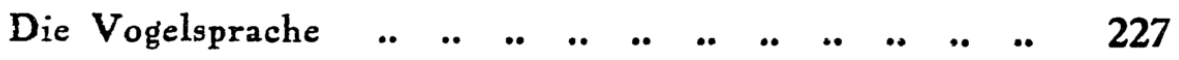

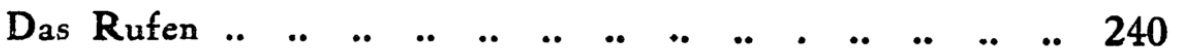

$\begin{array}{lllllllllllllll}\text { Der Hirt .. } & . . & . . & . & . . & . & . . & . . & . . & . . & . . & . . & . . & . . & 247\end{array}$ 
